Museu de Zoologia da Universidade de São Paulo

Henrique Miranda Rodrigues

Revisão taxonômica de Stagmatoptera Burmeister, 1838 (Mantodea, Mantidae, Stagmatopterinae)

São Paulo

2013 
Henrique Miranda Rodrigues

\title{
Revisão taxonômica de Stagmatoptera Burmeister, 1838 (Mantodea, Mantidae, Stagmatopterinae)
}

\begin{abstract}
Dissertação apresentada ao Programa de Pós-Graduação do Museu de Zoologia da Universidade de São Paulo para obtenção do título de Mestre em Sistemática, Taxonomia Animal e Biodiversidade.
\end{abstract}

Orientadora: Eliana Marques Cancello

São Paulo

2013 
Autorizo a reprodução e divulgação total ou parcial deste trabalho, por qualquer meio convencional ou eletrônico, para fins de estudo e pesquisa, desde que citada a fonte.

I authorize the reproduction and dissemination of this work in part or entirely, by any means, conventional or electronic, for study and research, provided the source is cited. 


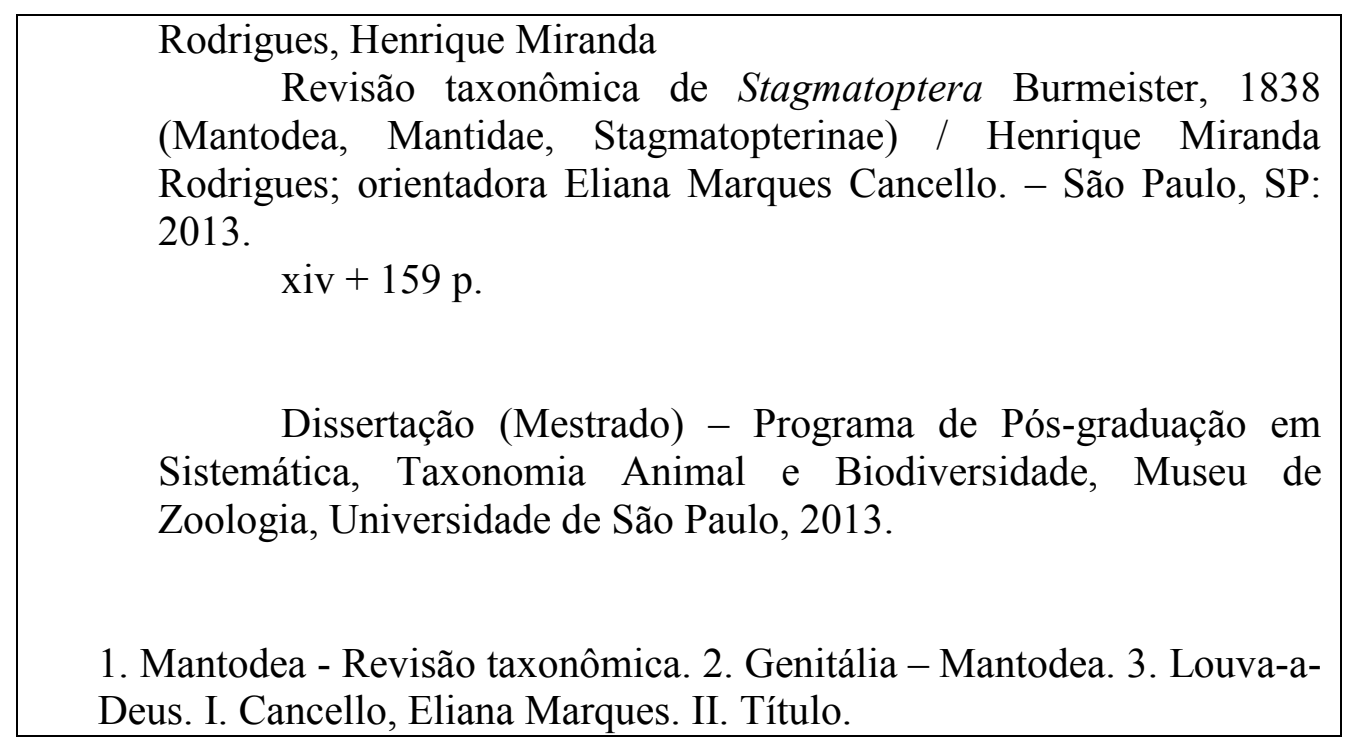

Banca examinadora

Prof. Dr. Instituição:

Julgamento: Assinatura:

Prof. Dr. Instituição:

Julgamento: Assinatura:

$\operatorname{Prof}^{\mathrm{a}} \mathrm{Dr}^{\mathrm{a}}$. Eliana Marques Cancello (Orientadora)

Julgamento: Assinatura: 


\section{Agradecimentos}

Agradeço à Prof ${ }^{\mathrm{a}}$ Eliana Marques Cancello pela orientação e apoio, não só durante a realização deste trabalho, mas mesmo antes dele, começando por ter aceitado orientar um aluno de graduação decidido em estudar um grupo com o qual não tinha tanta familiaridade.

Agradeço aos meus pais por seu apoio durante todos esses anos, por terem aceito e me apoiado em minhas decisões, sempre me dando conselhos quando pedi e quando precisei. Agradeço ao meu irmão pela ajuda e pelas conversas, que me ajudaram em momentos de dúvidas.

Agradeço às instituições que me emprestaram material e às instituições que me receberam e seus curadores: ao Dr. Augusto Henriques do INPA; ao Dr. Gervasio Carvalho do Museu de Ciências e Tecnologia da PUC-RS; ao Dr. Kjell Johanson do Naturhistoriska Riksmuseet de Estocolmo; ao Dr. Michael Ohl do Museum für Naturkunde der Humboldt de Berlim; à Dra. Susanne Randolf do Naturhistorischen Museum de Viena; ao Dr. Klaus Schönitzer e à Bärbel Stock do Zoologische Staatssammlung de Munique; ao Dr. Peter Schwendinger do Muséum de Histoire Naturelle de la Ville de Génève; ao Dr. Luca Picciau do Museo Regionale di Scienze Naturali di Torino; e ao Dr. Roger Roy, ao Dr. Philippe Grandcolas e à Dra. Roseli Pellens do Museum National d'Histoire Naturelle de Paris.

Agradeço à equipe da biblioteca do Museu de Zoologia pela ajuda com trabalhos antigos, muitas vezes tão difíceis de encontrar, e pelo seu empenho para que esse trabalho fosse possível.

Agradeço ainda aos amigos do Museu de Zoologia pela amizade, apoio e ajuda dados durante esses anos. Agradeço ao Sr Reinhard Ehrmann pelas sugestões e bibliografias, ambas dadas de modo tão generoso, e de importância fundamental; à Julio Rivera por seus conselhos; e à Carolina Medellín pelas fotos enviadas.

Agradeço à Capes pelo apoio financeiro que permitiu a realização deste trabalho. 


\section{Resumo}

Mantodea é uma ordem composta por insetos popularmente conhecidos como louva-adeus, incluindo aproximadamente 2300 espécies com distribuição principalmente pantropical. Trabalhos recentes trouxeram indícios de que a classificação atual não reflete a história evolutiva da ordem, sendo necessário realizar mais estudos para resolver esse problema.

O gênero Stagmatoptera foi criado por Burmeister em 1838 para abrigar as espécies de Mantodea conhecidas por ele que possuíam uma mancha no estigma da tégmina. Com as descrições de novas espécies e o trabalho de outros pesquisadores, a composição do gênero se alterou, e até o início deste trabalho ele incluía 15 espécies.

Stagmatoptera foi revisto, tendo como base material depositado em coleções científicas, visando determinar quais espécies eram válidas e se havia espécies não descritas. Também foi investigada a utilidade das genitálias masculina e feminina para estudos taxonômicos.

Após o estudo, o número de espécies dentro do gênero é reduzido para 14, com as seguintes alterações: restabelecimento da sinonímia entre Stagmatoptera supplicaria e $S$. flavipennis, sinonímia entre $S$. pia e $S$. nova, sinonímia entre S. femoralis e S. ignota, e a descrição de duas novas espécies. As genitálias se mostraram úteis na distinção entre as espécies, sendo uma fonte de caracteres morfológicos importantes para taxonomia, e possivelmente para estudos filogenéticos. 


\begin{abstract}
Mantodea is an order composed by insects popularly known as praying mantises, including about 2300 species with, mainly, a pantropical distribution. Recent works brought to light the possibility that the current classification does not reflect the evolutionary history of the order, thus being necessary more research to solve this problem.

The genus Stagmatoptera was created by Burmeister in 1838 to include the Mantodea species he knew, that had a spot on the tegmina. With the description of new species and the work of other scientists the genus composition changed, and at the beginning of this work Stagmatoptera included 15 species.

Stagmatoptera was revised using the material deposited in scientific collections, to determine which species were valid and if there were undescribed species. The utility of the male and female genitalia to taxonomic studies was also investigated.

After the study, the number of species in the genus is reduced to 14 with the following changes: reestablishment of the synonym between Stagmatoptera supplicaria and $S$. flavipennis, synonymization between $S$. pia and $S$. nova, synonymization between $S$. femoralis and S. ignota, and the description of two new species. The genitalia proved to be useful in the distinction among the species, being an important source of morphological characters to taxonomic studies and, possibly, phylogenetic studies.
\end{abstract}




\section{Lista}

Figura 1 - Cabeça de Stagmatoptera binotata macho, pag. 14

Figura 2 - Coxa anterior de Stagmatoptera binotata macho, pag.14

Figura 3 - Fêmur anterior de Stagmatoptera binotata macho, pag.14

Figura 4 - Tíbia anterior de Stagmatoptera binotata macho, pag.15

Figura 5 - Protorax de Stagmatoptera binotata macho, pag. 15

Figura 6 - Genitália masculina de Stagmatoptera binotata, pag.16

Figura 7 - Falômero esquerdo de Stagmatoptera binotata, pag.16

Figura 8 - Falômero direito de Stagmatoptera binotata em vista dorsal, pag.17

Figura 9 - Falômero direito de Stagmatoptera binotata em vista ventral, pag. 17

Figura 10 - Falômero direito de Stagmatoptera binotata em vista lateral direita, pag.17

Figura 11 - Ovipositor de Stagmatoptera binotata, pag. 18

Figura 12 - Detalhe da base do ovipositor de Stagmatoptera binotata, pag. 18

Figura 13 - Assoalho da câmara genital de Stagmatoptera binotata, pag.18

Figura 14 - Stagmatoptera abdominalis em ilustração de Stoll, 1787, pag. 22

Figura 15 - Foto do habitus dorsal de um casal de Stagmatoptera binotata, pag. 28

Figura 16 - Cabeça de Stagmatoptera binotata macho, pag. 29

Figura 17 - Protorax de Stagmatoptera binotata macho, pag. 29

Figura 18 - Coxa anterior de Stagmatoptera binotata macho, pag. 29

Figura 19 - Fêmur anterior de Stagmatoptera binotata macho, pag. 29

Figura 20 - Tíbia anterior de Stagmatoptera binotata macho, pag. 29

Figura 21 - Falômero esquerdo de Stagmatoptera binotata em vista dorsal, pag. 30

Figura 22 - Falômero esquerdo de Stagmatoptera binotata em vista ventral, pag. 30

Figura 23 - Detalhe da apófise falóide de Stagmatoptera binotata em vista dorsal, pag. 30

Figura 24 - Detalhe da apófise falóide de Stagmatoptera binotata em vista lateral, pag. 30

Figura 25 - Falômero direito de Stagmatoptera binotata em vista dorsal, pag. 31

Figura 26 - Falômero direito de Stagmatoptera binotata em vista ventral, pag. 31

Figura 27 - Falômero direito de Stagmatoptera binotata em vista lateral direita, pag. 31

Figura 28 - Cabeça de Stagmatoptera binotata fêmea, pag. 32

Figura 29 - Protorax de Stagmatoptera binotata fêmea, pag. 32

Figura 30 - Coxa anterior de Stagmatoptera binotata fêmea, pag. 32

Figura 31 - Fêmur anterior de Stagmatoptera binotata fêmea, pag. 32

Figura 32 - Tíbia anterior de Stagmatoptera binotata fêmea, pag. 32

Figura 33 - Ovipositor de Stagmatoptera binotata, pag. 33

Figura 34 - Detalhe da base do ovipositor de Stagmatoptera binotata, pag. 33

Figura 35 - Assoalho da câmara genital de Stagmatoptera binotata, pag.33

Figura 36 - Foto do habitus dorsal de um casal de Stagmatoptera biocellata, pag. 38

Figura 37 - Cabeça de Stagmatoptera biocellata macho, pag. 39

Figura 38 - Protorax de Stagmatoptera biocellata macho, pag. 39

Figura 39 - Coxa anterior de Stagmatoptera biocellata macho, pag. 39

Figura 40 - Fêmur anterior de Stagmatoptera biocellata macho, pag. 39

Figura 41 - Tíbia anterior de Stagmatoptera biocellata macho, pag. 39

Figura 42 - Falômero esquerdo de Stagmatoptera biocellata em vista dorsal, pag. 40

Figura 43 - Falômero esquerdo de Stagmatoptera biocellata em vista ventral, pag. 40

Figura 44 - Detalhe da apófise falóide de Stagmatoptera biocellata em vista dorsal, pag. 40

Figura 45 - Detalhe da apófise falóide de Stagmatoptera biocellata em vista lateral, pag. 40

Figura 46 - Falômero direito de Stagmatoptera biocellata em vista dorsal, pag. 41

Figura 47 - Falômero direito de Stagmatoptera biocellata em vista ventral, pag.41

Figura 48 - Falômero direito de Stagmatoptera biocellata em vista lateral direita, pag. 41 
Figura 49 - Cabeça de Stagmatoptera biocellata fêmea, pag. 42

Figura 50 - Protorax de Stagmatoptera biocellata fêmea, pag. 42

Figura 51 - Coxa anterior de Stagmatoptera biocellata fêmea, pag. 42

Figura 52 - Fêmur anterior de Stagmatoptera biocellata fêmea, pag. 42

Figura 53 - Tíbia anterior de Stagmatoptera biocellata fêmea, pag. 42

Figura 54 - Ovipositor de Stagmatoptera biocellata, pag. 43

Figura 55 - Detalhe da base do ovipositor de Stagmatoptera biocellata, pag. 43

Figura 56 - Assoalho da câmara genital de Stagmatoptera biocellata, pag. 43

Figura 57 - Foto do habitus dorsal de um casal de Stagmatoptera femoralis, pag. 48

Figura 58 - Cabeça de Stagmatoptera femoralis macho, pag. 49

Figura 59 - Protorax de Stagmatoptera femoralis macho, pag. 49

Figura 60 - Coxa anterior de Stagmatoptera femoralis macho, pag. 49

Figura 61 - Fêmur anterior de Stagmatoptera femoralis macho, pag. 49

Figura 62 - Tíbia anterior de Stagmatoptera femoralis macho, pag. 49

Figura 63 - Falômero esquerdo de Stagmatoptera femoralis em vista dorsal, pag. 50

Figura 64 - Falômero esquerdo de Stagmatoptera femoralis em vista ventral, pag. 50

Figura 65 - Detalhe da apófise falóide de Stagmatoptera femoralis em vista dorsal, pag. 50

Figura 66 - Detalhe da apófise falóide de Stagmatoptera femoralis em vista lateral, pag. 50

Figura 67 - Falômero direito de Stagmatoptera femoralis em vista dorsal, pag. 51

Figura 68 - Falômero direito de Stagmatoptera femoralis em vista ventral, pag. 51

Figura 69 - Falômero direito de Stagmatoptera femoralis em vista lateral direita, pag. 51

Figura 70 - Cabeça de Stagmatoptera femoralis fêmea, pag. 52

Figura 71 - Protorax de Stagmatoptera femoralis fêmea, pag. 52

Figura 72 - Coxa anterior de Stagmatoptera femoralis fêmea, pag. 52

Figura 73 - Fêmur anterior de Stagmatoptera femoralis fêmea, pag. 52

Figura 74 - Tíbia anterior de Stagmatoptera femoralis fêmea, pag. 52

Figura 75 - Ovipositor de Stagmatoptera femoralis, pag. 53

Figura 76 - Detalhe da base do ovipositor de Stagmatoptera femoralis, pag. 53

Figura 77 - Assoalho da câmara genital de Stagmatoptera femoralis, pag. 53

Figura 78 - Foto do habitus dorsal de um casal de Stagmatoptera hyaloptera, pag. 59

Figura 79 - Cabeça de Stagmatoptera hyaloptera macho, pag. 60

Figura 80 - Protorax de Stagmatoptera hyaloptera macho, pag. 60

Figura 81 - Coxa anterior de Stagmatoptera hyaloptera macho, pag. 60

Figura 82 - Fêmur anterior de Stagmatoptera hyaloptera macho, pag. 60

Figura 83 - Tíbia anterior de Stagmatoptera hyaloptera macho, pag. 60

Figura 84 - Falômero esquerdo de Stagmatoptera hyaloptera em vista dorsal, pag. 61

Figura 85 - Falômero esquerdo de Stagmatoptera hyaloptera em vista ventral, pag. 61

Figura 86 - Detalhe da apófise falóide de Stagmatoptera hyaloptera em vista dorsal, pag. 61

Figura 87 - Detalhe da apófise falóide de Stagmatoptera hyaloptera em vista lateral, pag. 61

Figura 88 - Falômero direito de Stagmatoptera hyaloptera em vista dorsal, pag. 62

Figura 89 - Falômero direito de Stagmatoptera hyaloptera em vista ventral, pag. 62

Figura 90 - Falômero direito de Stagmatoptera hyaloptera em vista lateral direita, pag. 62

Figura 91 - Cabeça de Stagmatoptera hyaloptera fêmea, pag. 63

Figura 92 - Protorax de Stagmatoptera hyaloptera fêmea, pag. 63

Figura 93 - Coxa anterior de Stagmatoptera hyaloptera fêmea, pag. 63

Figura 94 - Fêmur anterior de Stagmatoptera hyaloptera fêmea, pag. 63

Figura 95 - Tíbia anterior de Stagmatoptera hyaloptera fêmea, pag. 63

Figura 96 - Ovipositor de Stagmatoptera hyaloptera, pag. 64

Figura 97 - Detalhe da base do ovipositor de Stagmatoptera hyaloptera, pag. 64

Figura 98 - Assoalho da câmara genital de Stagmatoptera hyaloptera, pag. 64 
Figura 99 - Stagmatoptera indicator em ilustração de Stoll, 1787, pag. 66

Figura 100 - Foto do habitus dorsal de um casal de Stagmatoptera pia, pag.71

Figura 101 - Cabeça de Stagmatoptera pia macho, pag. 72

Figura 102 - Protorax de Stagmatoptera pia macho, pag. 72

Figura 103 - Coxa anterior de Stagmatoptera pia macho, pag. 72

Figura 104 - Fêmur anterior de Stagmatoptera pia macho, pag. 72

Figura 105 - Tíbia anterior de Stagmatoptera pia macho, pag. 72

Figura 106 - Falômero esquerdo de Stagmatoptera pia em vista dorsal, pag. 73

Figura 107 - Falômero esquerdo de Stagmatoptera pia em vista ventral, pag. 73

Figura 108 - Detalhe da apófise falóide de Stagmatoptera pia em vista dorsal, pag. 73

Figura 109 - Detalhe da apófise falóide de Stagmatoptera pia em vista lateral, pag. 73

Figura 110 - Falômero direito de Stagmatoptera pia em vista dorsal, pag. 74

Figura 111 - Falômero direito de Stagmatoptera pia em vista ventral, pag. 74

Figura 112 - Falômero direito de Stagmatoptera pia em vista lateral direita, pag. 74

Figura 113 - Cabeça de Stagmatoptera pia fêmea, pag. 75

Figura 114 - Protorax de Stagmatoptera pia fêmea, pag. 75

Figura 115 - Coxa anterior de Stagmatoptera pia fêmea, pag. 75

Figura 116 - Fêmur anterior de Stagmatoptera pia fêmea, pag. 75

Figura 117 - Tíbia anterior de Stagmatoptera pia fêmea, pag. 75

Figura 118 - Ovipositor de Stagmatoptera pia, pag. 76

Figura 119 - Detalhe da base do ovipositor de Stagmatoptera pia, pag. 76

Figura 120 - Assoalho da câmara genital de Stagmatoptera pia, pag. 76

Figura 121 - Foto do habitus dorsal de um casal de Stagmatoptera precaria, pag. 82

Figura 122 - Cabeça de Stagmatoptera precaria macho, pag. 83

Figura 123 - Protorax de Stagmatoptera precaria macho, pag. 83

Figura 124 - Coxa anterior de Stagmatoptera precaria macho, pag. 83

Figura 125 - Fêmur anterior de Stagmatoptera precaria macho, pag. 83

Figura 126 - Tíbia anterior de Stagmatoptera precaria macho, pag. 83

Figura 127 - Falômero esquerdo de Stagmatoptera precaria em vista dorsal, pag. 84

Figura 128 - Falômero esquerdo de Stagmatoptera precaria em vista ventral, pag. 84

Figura 129 - Detalhe da apófise falóide de Stagmatoptera precaria em vista dorsal, pag. 84

Figura 130 - Detalhe de apófise falóide de Stagmatoptera precaria em vista lateral, pag. 84

Figura 131 - Falômero direito de Stagmatoptera precaria em vista dorsal, pag. 85

Figura 132 - Falômero direito de Stagmatoptera precaria em vista ventral, pag. 85

Figura 133 - Falômero direito de Stagmatoptera precaria em vista lateral direita, pag. 85

Figura 134 - Cabeça de Stagmatoptera precaria fêmea, pag. 86

Figura 135 - Protorax de Stagmatoptera precaria fêmea, pag. 86

Figura 136 - Coxa anterior de Stagmatoptera precaria fêmea, pag. 86

Figura 137 - Fêmur anterior de Stagmatoptera precaria fêmea, pag. 86

Figura 138 - Tíbia anterior de Stagmatoptera precaria fêmea, pag. 86

Figura 139 - Ovipositor de Stagmatoptera precaria, pag. 87

Figura 140 - Detalhe da base do ovipositor de Stagmatoptera precaria, pag. 87

Figura 141 - Assoalho da câmara genital de Stagmatoptera precaria, pag. 87

Figura 142 - Foto do habitus dorsal do macho de Stagmatoptera pumila, pag. 90

Figura 143 - Cabeça de Stagmatoptera pumila macho, pag. 91

Figura 144 - Protorax de Stagmatoptera pumila macho, pag. 91

Figura 145 - Coxa anterior de Stagmatoptera pumila macho, pag. 91

Figura 146 - Fêmur anterior de Stagmatoptera pumila macho, pag. 91

Figura 147 - Tíbia anterior de Stagmatoptera pumila macho, pag. 91

Figura 148 - Foto do habitus dorsal de um casal de Stagmatoptera reimoseri, pag. 96 
Figura 149 - Cabeça de Stagmatoptera reimoseri macho, pag. 97

Figura 150 - Protorax de Stagmatoptera reimoseri macho, pag. 97

Figura 151 - Coxa anterior de Stagmatoptera reimoseri macho, pag.97

Figura 152 - Fêmur anterior de Stagmatoptera reimoseri macho, pag. 97

Figura 153 - Tíbia anterior de Stagmatoptera reimoseri macho, pag. 97

Figura 154 - Falômero esquerdo de Stagmatoptera reimoseri em vista dorsal, pag. 98

Figura 155 - Falômero esquerdo de Stagmatoptera reimoseri em vista ventral, pag. 98

Figura 156 - Detalhe da apófise falóide de Stagmatoptera reimoseri em vista dorsal, pag. 98

Figura 157 - Detalhe da apófise falóide de Stagmatoptera reimoseri em vista lateral, pag. 98

Figura 158 - Falômero direito de Stagmatoptera reimoseri em vista dorsal, pag. 99

Figura 159 - Falômero direito de Stagmatoptera reimoseri em vista ventral, pag. 99

Figura 160 - Falômero direito de Stagmatoptera reimoseri em vista lateral direita, pag. 99

Figura 161 - Cabeça de Stagmatoptera reimoseri fêmea, pag. 100

Figura 162 - Protorax de Stagmatoptera reimoseri fêmea, pag. 100

Figura 163 - Coxa anterior de Stagmatoptera reimoseri fêmea, pag. 100

Figura 164 - Fêmur anterior de Stagmatoptera reimoseri fêmea, pag. 100

Figura 165 - Tíbia anterior de Stagmatoptera reimoseri fêmea, pag. 100

Figura 166 - Ovipositor de Stagmatoptera reimoseri, pag. 101

Figura 167 - Detalhe da base do ovipositor de Stagmatoptera reimoseri, pag. 101

Figura 168 - Assoalho da câmara genital de Stagmatoptera reimoseri, pag. 101

Figura 169 - Foto do habitus dorsal de um casal de Stagmatoptera septentrionalis, pag. 106

Figura 170 - Cabeça de Stagmatoptera septentrionalis macho, pag. 107

Figura 171 - Protorax de Stagmatoptera septentrionalis macho, pag. 107

Figura 172 - Coxa anterior de Stagmatoptera septentrionalis macho, pag. 107

Figura 173 - Fêmur anterior de Stagmatoptera septentrionalis macho, pag. 107

Figura 174 - Tíbia anterior de Stagmatoptera septentrionalis macho, pag. 107

Figura 175 - Falômero esquerdo de Stagmatoptera septentrionalis em vista dorsal, pag. 108

Figura 176 - Falômero esquerdo de Stagmatoptera septentrionalis em vista ventral, pag. 108

Figura 177 - Detalhe da apófise falóide de Stagmatoptera septentrionalis em vista dorsal, pag. 108

Figura 178 - Detalhe da apófise falóide de Stagmatoptera septentrionalis em vista lateral, pag. 108

Figura 179 - Falômero direito de Stagmatoptera septentrionalis em vista dorsal, pag. 109

Figura 180 - Falômero direito de Stagmatoptera septentrionalis em vista ventral, pag. 109

Figura 181 - Falômero direito de Stagmatoptera septentrionalis em vista lateral direita, pag. 109

Figura 182 - Cabeça de Stagmatoptera septentrionalis fêmea, pag. 110

Figura 183 - Protorax de Stagmatoptera septentrionalis fêmea, pag. 110

Figura 184 - Coxa anterior de Stagmatoptera septentrionalis fêmea, pag. 110

Figura 185 - Fêmur anterior de Stagmatoptera septentrionalis fêmea, pag. 110

Figura 186 - Tíbia anterior de Stagmatoptera septentrionalis fêmea, pag. 110

Figura 187 - Ovipositor de Stagmatoptera septentrionalis, pag. 111

Figura 188 - Detalhe da base do ovipositor de Stagmatoptera septentrionalis, pag. 111

Figura 189 - Assoalho da câmara genital de Stagmatoptera septentrionalis, pag. 111

Figura 190 - Foto do habitus dorsal de um casal de Stagmatoptera sp. n.1, pag. 115

Figura 191 - Cabeça de Stagmatoptera sp. n.1 macho, pag. 116

Figura 192 - Protorax de Stagmatoptera sp. n.1 macho, pag. 116

Figura 193 - Coxa anterior de Stagmatoptera sp. n.1 macho, pag. 116

Figura 194 - Fêmur anterior de Stagmatoptera sp. n.1 macho, pag.116

Figura 195 - Tíbia anterior de Stagmatoptera sp. n.1 macho, pag. 116 
Figura 196 - Falômero esquerdo de Stagmatoptera sp. n.1 em vista dorsal, pag. 117

Figura 197 - Falômero esquerdo de Stagmatoptera sp. n.1 em vista ventral, pag. 117

Figura 198 - Detalhe da apófise falóide de Stagmatoptera sp. n.1 em vista dorsal, pag. 117

Figura 199 - Detalhe da apófise falóide de Stagmatoptera sp. n.1 em vista lateral, pag. 117

Figura 200 - Falômero direito de Stagmatoptera sp. n.1 em vista dorsal, pag. 118

Figura 201 - Falômero direito de Stagmatoptera sp. n.1 em vista ventral, pag. 118

Figura 202 - Falômero direito de Stagmatoptera sp. n.1 em vista lateral direita, pag. 118

Figura 203 - Cabeça de Stagmatoptera sp. n.1 fêmea, pag. 119

Figura 204 - Protorax de Stagmatoptera sp. n.1 fêmea, pag. 119

Figura 205 - Coxa anterior de Stagmatoptera sp. n.1 fêmea, pag. 119

Figura 206 - Fêmur anterior de Stagmatoptera sp. n.1 fêmea, pag.119

Figura 207 - Tíbia anterior de Stagmatoptera sp. n.1 fêmea, pag. 119

Figura 208 - Ovipositor de Stagmatoptera sp. n.1, pag. 120

Figura 209 - Detalhe da base do ovipositor de Stagmatoptera sp. n.1, pag. 120

Figura 210 - Assoalho da câmara genital de Stagmatoptera sp. n.1, pag. 120

Figura 211 - Foto do habitus dorsal do macho de Stagmatoptera sp. n.2, pag. 123

Figura 212 - Cabeça de Stagmatoptera sp. n.2 macho, pag. 124

Figura 213 - Protorax de Stagmatoptera sp. n.2 macho, pag. 124

Figura 214 - Coxa anterior de Stagmatoptera sp. n.2 macho, pag. 124

Figura 215 - Fêmur anterior de Stagmatoptera sp. n.2 macho, pag. 124

Figura 216 - Tíbia anterior de Stagmatoptera sp. n.2 macho, pag. 124

Figura 217 - Falômero esquerdo de Stagmatoptera sp. n. 2 em vista dorsal, pag. 125

Figura 218 - Falômero esquerdo de Stagmatoptera sp. n.2 em vista ventral, pag. 125

Figura 219 - Detalhe da apófise falóide de Stagmatoptera sp. n.2 em vista dorsal, pag. 125

Figura 220 - Detalhe de apófise falóide de Stagmatoptera sp. n.2 em vista lateral, pag. 125

Figura 221 - Falômero direito de Stagmatoptera sp. n. 2 em vista dorsal, pag. 126

Figura 222 - Falômero direito de Stagmatoptera sp. n. 2 em vista ventral, pag. 126

Figura 223 - Falômero direito de Stagmatoptera sp. n.2 em vista lateral direita, pag. 126

Figura 224 - Foto do habitus dorsal de um casal de Stagmatoptera supplicaria, pag. 132

Figura 225 - Cabeça de Stagmatoptera supplicaria macho, pag. 133

Figura 226 - Protorax de Stagmatoptera supplicaria macho, pag. 133

Figura 227 - Coxa anterior de Stagmatoptera supplicaria macho, pag. 133

Figura 228 - Fêmur anterior de Stagmatoptera supplicaria macho, pag. 133

Figura 229 - Tíbia anterior de Stagmatoptera supplicaria macho, pag. 133

Figura 230 - Falômero esquerdo de Stagmatoptera supplicaria em vista dorsal, pag. 134

Figura 231 - Falômero esquerdo de Stagmatoptera supplicaria em vista ventral, pag. 134

Figura 232 - Detalhe da apófise falóide de Stagmatoptera supplicaria em vista dorsal, pag. 134

Figura 233 - Detalhe da apófise falóide de Stagmatoptera supplicaria em vista lateral, pag. 134

Figura 234 - Falômero direito de Stagmatoptera supplicaria em vista dorsal, pag. 135

Figura 235 - Falômero direito de Stagmatoptera supplicaria em vista ventral, pag. 135

Figura 236 - Falômero direito de Stagmatoptera supplicaria em vista lateral direita, pag. 135

Figura 237 - Cabeça de Stagmatoptera supplicaria fêmea, pag. 136

Figura 238 - Protorax de Stagmatoptera supplicaria fêmea, pag. 136

Figura 239 - Coxa anterior de Stagmatoptera supplicaria fêmea, pag. 136

Figura 240 - Fêmur anterior de Stagmatoptera supplicaria fêmea, pag. 136

Figura 241 - Tíbia anteriror de Stagmatoptera supplicaria fêmea, pag. 136

Figura 242 - Ovipositor de Stagmatoptera supplicaria, pag. 137

Figura 243 - Detalhe da base do ovipositor de Stagmatoptera supplicaria, pag. 137 
Figura 244 - Assoalho da câmara genital de Stagmatoptera supplicaria, pag. 137

Figura 245 - Mapa de distribuição de Stagmatoptera binotata, Stagmatoptera sp. n.1 e Stagmatoptera sp. n.2, pag. 139

Figura 246 - Mapa de distribuição de Stagmatoptera biocellata e S. femoralis, pag. 140

Figura 247 - Mapa de distribuição de Stagmatoptera hyaloptera e S. pia, pag. 141

Figura 248 - Mapa de distribuição de Stagmatoptera precaria e S. reimoseri, pag. 142

Figura 249 - Mapa de distribuição de Stagmatoptera septentrionalis e S. supplicaria, pag. 143 


\section{Sumário}

1. Introdução

Histórico da Ordem 1

Relações Filogenéticas da Ordem 3

Histórico do gênero Stagmatoptera 5

Uso das genitálias na taxonomia da ordem $\quad 7$

$\begin{array}{lr}\text { Objetivo } & 8\end{array}$

2. Material e métodos 10

Ilustrações e mensurações 11

Dissecção das genitálias $\quad 12$

Nomenclatura adotada $\quad 13$

3. Resultados 19

Chave de identificação 20

Stagmatoptera abdominalis $\quad 21$

Stagmatoptera binotata 23

Stagmatoptera biocellata $\quad 34$

Stagmatoptera femoralis $\quad 44$

Stagmatoptera hyaloptera $\quad 54$

Stagmatoptera indicator $\quad 65$

Stagmatoptera pia 67

$\begin{array}{ll}\text { Stagmatoptera precaria } & 77\end{array}$

$\begin{array}{ll}\text { Stagmatoptera pumila } & 88\end{array}$

Stagmatoptera reimoseri 92

Stagmatoptera septentrionalis $\quad 102$

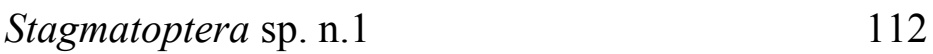

$\begin{array}{ll}\text { Stagmatoptera } \text { sp. n.2 } & 121\end{array}$ 
Mapas de distribuição

4. Discussão

Estudo das genitálias

5. Conclusão

150

6. Referências bibliográficas 


\section{Introdução}

Mantodea é a ordem de Insecta que compreende os insetos popularmente conhecidos no Brasil como louva-a-deus. A ordem é composta por aproximadamente 2.300 espécies (Ehrmann, 2002), distribuídas por todos os continentes, com exceção da Antártida. Apesar de serem encontrados em todos os continentes, são insetos predominantemente tropicais e subtropicais.

Todos os mantódeos são predadores, embora Beckman \& Hurd (2003) tenham registrado ninfas recém nascidas se alimentando de pólen, e tenham questionado qual a possível importância do pólen ingerido de maneira indireta através de presas polinizadoras.

A morfologia da maioria das espécies da ordem pode ser descrita resumidamente da seguinte maneira: cabeça triangular e móvel, dotada de um par de olhos compostos bem desenvolvidos, três ocelos, um par de antenas, mais desenvolvido nos machos, onde tem um papel na procura de fêmeas (Howell et al., 2007). Protorax alongado, dividido, na superfície dorsal, em prozona e metazona por um sulco. Meso- e metatorax semelhantes entre si, sendo este último dotado de um ouvido "cíclope" na superfície ventral, sensível para ondas mecânicas na faixa do ultrassom (Yager, 1999). Primeiro par de pernas modificado, com função raptorial, dotado de espinhos no fêmur e na tíbia que permitem a captura e retenção de presas. Pernas meso- e metatorácicas cursoriais, sem especializações. Primeiro par de asas modificado, com uma textura pergaminácea, servindo para proteção e segundo par de asas membranoso, utilizado para o voo. Abdômen sem modificações muito significativas, podendo ser cilíndrico ou achatado. Genitália masculina assimétrica, composta de dois falômeros, um esquerdo dividido em dorsal e ventral, e outro direito indiviso (Klass, 1997). A genitália masculina pode ser vista no louva-a-deus adulto em repouso, sobre a placa subgenital, no fim do abdômen. Genitália feminina simétrica, composta de três pares de valvas envolvidas pela placa subgenital, um vestíbulo e uma câmera genital (Klass, 1998a).

\section{Histórico da ordem}

As primeiras espécies da ordem Mantodea foram descritas por Linnaeus, em 1758 no seu trabalho "Systema Naturae", como espécies de gênero Gryllus subgênero Mantis. Foi Fabricius, em 1775, quem elevou o subgênero Mantis a gênero, iniciando o longo processo de separação entre louva-a-deus e os grilos mais os gafanhotos. Entre o fim do século XVIII e o começo do século XIX, vários pesquisadores descreveram espécies de mantódeos coletadas 
em diversas partes do mundo, porém essas novas espécies foram todas descritas como pertencentes a um mesmo gênero, isto é, Mantis.

Foram Audinet-Serville $(1831,1839)$ e Burmeister (1838) que iniciaram a divisão das diferentes espécies em grupos que eles julgaram ser mais próximos entre si com a criação de gêneros, subgêneros no trabalho de Burmeister, para agrupar as espécies já descritas, das quais tinham conhecimento, e as espécies novas que estavam descrevendo. Desde os trabalhos de Serville os mantódeos já eram considerados uma família, Mantides (Audinet-Serville, 1831) ou Mantodea (Burmeister, 1838), mas ainda eram agrupados, assim como Blattaria, Phasmatodea e Dermaptera, dentro da ordem Orthoptera.

Saussure (1869) publicou um trabalho intitulado "Essai d'un Système des Mantides" onde, como o título do trabalho indica, criou um esboço de divisão dos gêneros em subfamílias, tribos e subtribos, esboço esse que influenciou as classificações de outros autores. Neste trabalho Saussure divide os Mantodea conhecidos até então em três tribos e 12 subtribos, sendo a tribo "Mantii" a que abrigava a maior parte das espécies descritas. Em 1870, Saussure publicou outro trabalho, desta vez intitulado "Additions au Systhème des Mantides", onde ele faz algumas alterações na classificação, tendo como base um maior número de espécies estudadas.

Kirby, em 1904, publicou um catálogo das espécies de Orthoptera do mundo, onde incluiu e agrupou o conhecimento sobre as espécies de louva-a-deus, estabelecendo sinonímias, e mais importante, designando espécies tipos para vários gêneros.

Giglio-Tos publicou 21 trabalhos entre 1911 e 1921, descrevendo uma grande quantia de espécies de louva-a-deus, e tentando organizar todas essas novas espécies e as que já estavam descritas em um sistema de classificação mais complexo que o proposto por Saussure. Isso culminou em sua obra póstuma publicada em 1927, intitulada "Das Tierreich. Orthoptera-Mantinae". A ordem, que nesse trabalho ainda era considerada uma família dentro de Orthoptera, é dividida em 33 subfamílias e estas muitas vezes divididas em tribos. Neste trabalho também estão descritas quase todas as espécies conhecidas pelo autor, com chaves de identificação desde subfamílias até espécie.

Chopard (1949) foi o primeiro pesquisador a retirar os mantódeos da ordem Orthoptera, ao estabelecer Mantodea como uma subordem dentro da ordem Dictyoptera. Ele também elevou algumas subfamílias ao status de família, estabelecendo 13 famílias. 
Beier (1964) também propôs um sistema de classificação, para o que ele já considerava como ordem Mantodea, diferente do sistema proposto por Chopard (1949). No sistema de classificação proposto por Beier, a ordem seria dividida em oito famílias ao invés de 13, com algumas famílias propostas por Chopard rebaixadas a subfamílias, e apenas uma família nova. Na proposta de Beier apenas quatro famílias são divididas em subfamílias, em um total de 28 subfamílias. A proposta de Beier foi mais aceita que a de Chopard (op.cit.), tendo sido utilizada até a década de 1990.

Terra (1995) publicou uma revisão dos gêneros neotropicais de louva-a-deus, e entre outras mudanças, fez uma proposta de classificação, diferente da de Beier (1964), para os gêneros estudados por ele. Nesse trabalho ele propõe seis famílias de distribuição neotropical, Mantoididae, Chaeteessidae, Acanthopidae, Thespidae, Liturgusidae e Vatidae, ao contrário das quatro propostas por Beier, elevando quatro subfamílias à categoria de família.

Roy (1999), sem mencionar o trabalho de Terra, disse que o sistema de classificação proposto por Beier era artificial ao agrupar mais da metade das espécies descritas na família Mantidae, simplesmente por elas não serem distintas o suficiente para serem colocadas em outras famílias. Ele afirmou ser necessário reorganizar a classificação para torná-la natural.

Foi Ehrmann (2002) quem propôs um novo sistema de classificação para ordem, elevando o número de famílias de oito para 15 , ao elevar algumas subfamílias para famílias. Nessa nova proposta ele re-estabeleceu uma das famílias propostas por Chopard (1949), e concordou com o estabelecimento de três das quatro famílias propostas por Terra (1995), discordando apenas do status de Vatinae. Essa proposta feita por Ehrmann (op.cit.) é atualmente a aceita e utilizada, embora ela ainda apresente problemas.

\section{Relações filogenéticas da ordem}

A ordem Mantodea faz parte da superordem Dictyoptera juntamente com Isoptera e Blattaria, embora esses grupos possam parecer tão destoantes entre si. A monofilia dessa superordem é fortemente corroborada tanto por caracteres morfológicos, por exemplo, da genitália masculina, do ovipositor, do proventrículo, do tentório, da junção tibiotarsal (Klass, 1997; 1998a; 1998b; Klass \& Meier, 2006; Klass et al., 2009); quanto por caracteres moleculares (Maekawa et al., 1999; Ware et al., 2008). 
Entretanto, as relações internas deste grupo foram palco de muita divergência, com todas as possíveis combinações de relacionamento tendo sido propostas para explicar a história evolutiva das três ordens. A proposta mais aceita atualmente, tendo suporte morfológico e molecular, é a que considera Mantodea como grupo irmão de Blattaria mais Isoptera, sendo que este último é grupo irmão de um gênero de baratas (Cryptocercus) (Svenson \& Whiting, 2004; Klass \& Meier, 2006; Ware et al., 2008; Svenson \& Whiting, 2009), ou seja, Blattaria seria parafilético em relação à Isoptera. Krishna et al. (2013) publicaram um tratado dos cupins do mundo, onde consideram Isoptera como infraordem da ordem Blattaria.

Dentro da ordem Mantodea as relações entre os grupos também são confusas, e exceto pelos gêneros que sempre foram considerados mais basais dentro da ordem, Mantoida Newman, 1838, Chaeteessa Burmeister, 1838 e Metallyticus Westwood, 1835, nunca houve um consenso sobre as relações internas, e mesmo entre os três gêneros "basais", houve divergências entre qual seria o mais basal.

Klass (1997), com base em sua monografia sobre a terminália masculina dos Dictyoptera, propôs o seguinte arranjo para os grupos de Mantodea que ele estudou: Mantoida $+($ Chaeteessa $+($ Metallyticus + demais mantódeos $))$. Grimaldi (2003) propôs uma filogenia com base em dados morfológicos, onde incluiu espécies fósseis, e chegou a um resultado diferente do proposto por Klass: (Chaeteessa + (Mantoida + Metallyticus + (demais mantódeos))).

Svenson \& Whiting (2004), utilizando dados moleculares, publicaram a primeira filogenia da ordem Mantodea com mais de um representante por família. Neste trabalho, eles recuperaram Mantoida como sendo o gênero mais basal na filogenia, embora não tenham incluído representantes de Chaeteessa ou Metallyticus na análise. Outro resultado importante desse trabalho foi a constatação de que a classificação proposta por Ehrmann, em 2002, possivelmente ainda não era natural, uma vez que vários grupos propostos por ele eram parafiléticos na filogenia.

Yager \& Svenson (2008) incluíram Chaeteessa e Metallyticus, além de outros gêneros na sua análise, que utilizou dados moleculares e morfológicos, e recuperaram Mantoida como o mais basal na filogenia, e Metallyticus e Chaeteessa inseridos não na base da base da árvore como proposto por Klass (1997) e Klass \& Meier (2006), mas no meio do 
cladograma. Esse resultado não foi muito contraditório com o proposto por Klass (op.cit.), pois este só estudou outra espécie além das três já citadas. Contudo Yager \& Svenson (op.cit.) já alertaram para um possível problema com a amostra de DNA retirada do exemplar de Chaeteessa.

Svenson \& Whiting (2009) publicaram uma segunda filogenia baseada em dados moleculares, incluindo uma quantidade significativa de representantes de todas as famílias, amostrando quase $50 \%$ dos gêneros na análise. A filogenia proposta por eles nesse trabalho traz Mantoida como o grupo irmão de todos os demais Mantodea, e Chaeteessa como grupo irmão dos Mantodea menos Mantoida. Metallyticus ficou com um posicionamento incerto na filogenia, podendo ser o grupo irmão de todos os Mantodea viventes exceto Mantoida e Chaeteessa, ou então estar inserido mais internamente no cladograma. Outro resultado importante desse trabalho foi a constatação de que oito das 15 famílias, e 19 das 35 subfamílias com mais de um representante incluídos na análise foram recuperadas como sendo parafiléticas, demonstrando que a classificação proposta por Ehrmann seria artificial, porém, uma proposta de uma nova classificação não foi apresentada.

\section{Histórico do gênero Stagmatoptera}

O gênero Stagmatoptera pertence à Stagmatopterinae, dentro de Mantidae, sendo composto, até o início deste trabalho, por 15 espécies. O gênero foi criado em 1838 por Burmeister, como um subgênero do gênero Mantis, para agrupar 11 espécies que ele acreditava serem mais parecidas entre si: Mantis (Stagmatoptera) lineola, M. (S.) bioculata, M. (S.) bimaculata, M. (S.) musarum, M. (S.) latipennis, M. (S.) carolina, M. (S.) dimidiata, M. (S.) precaria, M. (S.) rogatoria, M. (S.) pavonina e M. (S.) unipunctata.

Saussure, em 1869, elevou o subgênero a gênero, e o alterou radicalmente, retirando todas as espécies que não eram americanas, transferiu Mantis carolina, M. dimidiata e $M$. latipennis para o recém-criado gênero Stagmomantis, incluiu M. flavoguttata Serville, 1839 e descreveu uma nova espécie para o gênero, Stagmatoptera biocellata. Também em 1869, Scudder descreveu Stagmatoptera binotata.

Em 1870, Saussure adicionou outras espécies ao gênero Stagmatoptera: $S$. obsecraria (Lichtenstein, 1802), S. birivia e S. sancta (Stoll, 1813), S. hyaloptera (Perty, 1832); e descreveu novas espécies para o gênero: S. pagana, S. praedicatoria e S. veneratoria. Em 1871, ele criou o gênero Parastagmatoptera, e transferiu S. unipunctata e S. flavoguttata 
para este novo gênero (Saussure, 1871b), além de ter transferido Mantis pavonina para Stagmatoptera (Saussure, 1871a).

Westwood (1889) fez uma sinopse das espécies de Mantodea, incluindo as espécies Stagmatoptera annulata e S. supplicaria (Burmeister, 1838), sinonimizou Mantis luna Serville, 1839 com S. hyaloptera e descreveu S. perpulchra. Saussure \& Zehntner (1894) descreveram Stagmatoptera femoralis, S. pia, S. septentrionalis e S. septentrionalis var. minor. Eles também criaram um novo gênero Pseudoxyops e transferiram S. perpulchra Westwood, 1889 para ele, além de terem transferido duas espécies de Madagascar, Hierodula freyi (Brancsik, 1892) e H. acutipennis (Westwood, 1889) para Stagmatoptera. Rehn (1904a, 1904b) publicou dois trabalhos sobre os louva-a-deus americanos onde descreveu duas espécies, Stagmatoptera insatiabilis e S. typhon, além de ter designado S. binotata como espécie tipo do gênero.

Kirby (1904) fez algumas mudanças em seu catálogo. Ele elevou Stagmatoptera septentrionalis var. minor a espécie, transferiu Mantis indicator Olivier, 1792, M. abdominalis Olivier, 1792 e M. costalis Burmeister, 1838 para Stagmatoptera; designou Stagmatoptera precaria como espécie tipo do gênero, embora a designação feita por Rehn (1904a) tenha precedência, sinonimizou M. hyalina Burmeister, 1838 e M. flavipennis Serville, 1839 com S. supplicaria; S. obsecraria, S. annulata, M. cubitata Goeze, 1778 e M. ocelata, Olivier, 1792 com S. precaria; S. sancta e M. bodogetica Lichtenstein, 1802 com S. indicator e S. birivia e M. urbana Lichtenstein, 1802 com S. abdominalis.

Giglio-Tos (1914) propôs uma chave de identificação que é basicamente a mesma publicada em sua obra póstuma de 1927. Ele afirmou que as espécies alocadas no gênero e de origem africanas não pertenceriam de fato ao gênero e as removeu. Neste trabalho ele também descreveu duas novas espécies para o gênero, Stagmatoptera incerta e S. ignota; descreveu uma variedade para $S$. femoralis que ele chamou de $S$. femoralis var. africana; desfez algumas mudanças propostas por Kirby (1904), sinonimizando S. minor com S. septentrionalis, separou S. flavipennis de S. supplicaria; sinonimizou Mantis octosetosa Goeze (1778) com S. precaria, S. praedicatoria com S. binotata. Giglio-Tos, em 1927, fez mais mudanças no gênero, transferindo Stagmatoptera pagana, S. insatiabilis e S. costalis para Stauromantis e Stagmatoptera typhon para Auromantis. 
Werner descreveu duas espécies para o gênero, a primeira em 1925: Stagmatoptera pumila, e a segunda em 1933: S. vischeri. Beier também descreveu duas espécies, uma em 1929: $S$. reimoseri e outra em 1930: $S$. nova.

Na década de 1990, Ehrmann publicou dois trabalhos envolvendo espécies do gênero, no primeiro de 1995, ele sinonimizou Stagmatoptera vischeri Werner, 1933 com Sphodromantis viridis occidentalis Werner, 1906. No segundo, de 1999, ele sinonimizou Stagmatoptera pavonina Burmeister, 1838 com S. hyaloptera (Perty, 1832) e sinonimizou $S$. femoralis var. africana com S. femoralis. Terra, também em 1995, sinonimizou S. incerta com S. septentrionalis.

No começo deste trabalho as espécies nominais do gênero Stagmatoptera eram:

- Stagmatoptera abdominalis (Olivier, 1792)

- Stagmatoptera binotata Scudder, 1869

- Stagmatoptera biocellata Saussure, 1869

- Stagmatoptera femoralis Saussure \& Zehntner, 1894

- Stagmatoptera flavipennis (Serville, 1839)

- Stagmatoptera hyaloptera (Perty, 1832)

- Stagmatoptera ignota Giglio-Tos, 1914

- Stagmatoptera indicator (Olivier, 1792)

- Stagmatoptera nova Beier, 1930

- Stagmatoptera pia Saussure \& Zehntner, 1894

- Stagmatoptera precaria (Linnaeus, 1758)

- Stagmatoptera reimoseri Beier, 1929

- Stagmatoptera pumila Werner, 1925

- Stagmatoptera septentrionalis Saussure \& Zehntner, 1894

- Stagmatoptera supplicaria (Burmeister, 1838)

\section{Uso das genitálias na taxonomia da ordem}

As genitálias, tanto masculinas quanto femininas, não foram utilizadas na taxonomia do grupo durante um longo tempo. Os primeiros trabalhos a descrever morfologicamente as genitálias de Mantodea foram publicados por Snodgrass (1935, 1937) e Leverault (1936), porém estes trabalhos eram pontuais, pois quando muito, descreviam apenas a genitália de 
uma espécie. Foi La Greca (1954) quem primeiro fez um estudo comparativo da genitália masculina de representantes de diferentes gêneros, e quem estabeleceu uma nomenclatura especifica para a ordem. Entretanto este trabalho não teve um impacto muito grande na taxonomia, pois muito poucas espécies foram descritas após sua publicação.

O próximo pesquisador a estudar a genitália masculina foi Cerdá em 1993, em um trabalho onde ele investigou a utilidade da genitália masculina para estudos taxonômicos, chegando à conclusão de que esta era uma fonte de informações interessante do ponto de vista da Taxonomia.

Klass (1997) publicou uma monografia sobre a genitália masculina de Mantodea, de Blattaria, estabelecendo homologias entre elas, e propondo uma nomenclatura única para Dictyoptera. Trabalhos publicados após o fim da década de 1990 utilizaram a genitália masculina como fonte de informações taxonômicas, mostrando sua importância nestes estudos.

Klass (1998) também publicou outro trabalho sobre a genitália feminina de Mantodea. Como em seu trabalho publicado no ano anterior, ele estabeleceu homologias entre a genitália feminina de Mantodea, Blattaria e Isoptera, além de propor uma nomenclatura única para as três. Mas, ao contrario do que ocorreu em relação ao estudo da genitália masculina, a genitália feminina continuou sendo ignorada em trabalhos de taxonomia, e seu valor taxonômico permaneceu desconhecido.

\section{Objetivo}

O presente trabalho teve por objetivo a revisão do gênero Stagmatoptera, procurando reconhecer quais espécies descritas são realmente válidas, e descobrir se havia espécies que ainda não tinham sido descritas.

O gênero Stagmatoptera faz parte da subfamília Stagmatopterinae, e, assim como em outras, sua monofilia foi questionada na filogenia proposta por Svenson \& Whiting (2009). Para resolver essa questão, e confirmar ou refutar a validade da subfamília, primeiro é necessário ter uma noção da real diversidade dos gêneros nela incluídos. O gênero Stagmatoptera foi escolhido por ser um dos mais diversos dentro da subfamília e por ser comum em coleções científicas. 
Este trabalho também tinha por objetivo descobrir se os caracteres da genitália feminina, negligenciada em estudos taxonômicos, poderiam ser utilizados na diferenciação entre as diversas espécies do gênero. 


\section{Material e métodos}

Durante a realização deste trabalho foram examinados 346 indivíduos, depositados nas seguintes instituições:

- Instituto Nacional de Pesquisas Amazônicas (INPA), Manaus

- Museu de Ciência e Tecnologia da PUC-RS (MCTP), Porto Alegre

- Muséum de Histoire Naturelle de la Ville de Génève (MHNG), Genebra, Suíça

- Muséum National d'Histoire Naturelle (MNHN), Paris, França

- Museo Regionale di Scienze Naturali di Torino (MRSN), Turim, Itália

- Museu de Zoologia da Universidade de São Paulo (MZSP), São Paulo

- Naturhistorischen Museum Wien (NHMW), Viena, Áustria

- Naturhistoriska Riksmuseet (NHRS), Estocolmo, Suécia

- Museum für Naturkunde (ZMB), Berlim, Alemanha

- Zoologische Staatssammlung (ZSM), Munique, Alemanha

Foram examinados os tipos das seguintes espécies: Stagmatoptera binotata Scudder, 1869 (síntipo do sinônimo junior S. praedicatoria, uma $\uparrow$ - MHNG); S. biocellata Saussure,

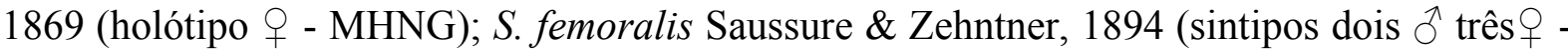
MHNG); S. hyaloptera (Perty, 1832) (lectótipo §ิ - ZSM); S. nova Beier, 1930 (holótipo đ̂ e parátipo $\widehat{~}$ - NHMW); S. pia Saussure \& Zehntner, 1894 (holótipo $q$ - MHNG); S. pumila Werner, 1925 (holótipo $\widehat{o}$ - NHRS); S. reimoseri Beier, 1929 (holótipo ô e parátipo $q$ NHMW) ; S. septentrionalis Saussure \& Zehntner, 1894 (síntipo de S. septentrionalis var. minor $\widehat{\sigma}$ - MHNG). O holótipo de Stagmatoptera ignota Giglio-Tos, 1914 foi examinado através de fotografias enviadas pelo curador responsável da coleção (MRSN).

A lista de material examinado foi organizada por ordem alfabética de país, estado e localidade, com informações sobre o número de exemplares, sexo e coleção de origem do material colocadas no fim. Ex: “Corema, vi.1957, Exp. Dept. Zoologia, $2 \widehat{\jmath}$ (MZSP).” 
A lista de sinonímias traz informações sobre o tipo de estudo taxonômico realizado em cada trabalho de acordo com o seguinte código:

- Descrição (descr.)

- Redescrição (redesc.)

- Sinonímia (sin.)

- Menção (men.)

\section{Ilustrações e mensurações}

Os desenhos foram feitos com o auxílio de uma câmara clara acoplada a um estereomicroscópio. Após os desenhos terem sido feitos, eles foram digitalizados, e finalizados no programa Adobe Ilustrator CS2.

As fotos de habitus dorsal foram tiradas com uma câmera fotográfica Sony $\alpha 33$, e finalizadas com um editor de imagens. As fotos das genitálias femininas e masculinas foram tiradas com o auxílio de câmara de vídeo Leica DFC295 acoplada a uma lupa Leica M205C. e do software Leica Application Suite v.3.6.0, e depois finalizadas com um editor de imagens. As fotos das genitálias masculinas foram todas dispostas de modo que o sentido anterior ficasse na parte de cima, enquanto que nas fotos das genitálias femininas, as fotos do ovipositor e das basiválvulas foram dispostas com o sentido anterior na parte de baixo da foto e as fotos do assoalho da câmara genital foram dispostas com o sentido anterior para cima.

Essa disposição das fotos das genitálias femininas foi escolhida, pois a genitália teve que ser aberta e separada para ser possível tirar as fotos. A genitália feminina é invertida, isto é, o ápice do abdômen, juntamente com os elementos da genitália, é direcionado anteriormente, formando um espaço que pode ser dividido em um vestíbulo e uma câmara genital, onde ocorre a deposição do espermatóforo e posteriormente a fecundação dos ovos. Para manter a mesma disposição nas fotos do ovipositor e das basiválvulas seria necessário dispor as estruturas de uma forma que, acredito, seria muito confusa.

As medidas e escalas das fotos de habitus dorsal e dos desenhos foram feitas com um paquímetro digital, devido ao tamanho dos indivíduos.

Os mapas de distribuição foram confeccionados com o programa Quantum GIS. Para a confecção dos mapas foi necessário utilizar as coordenadas geográficas, dado que raramente estava disponível nas etiquetas de localidade. Foi feito o levantamento dos locais de coleta 
dos indivíduos estudados, e quando as informações eram suficientes, as coordenadas foram levantadas com o auxílio do programa Google Earth. Os mapas utilizados no programa, assim como o traçado de rios e os marcadores de longitude e latitude foram baixados do site www.naturalearthdata.com, um banco de mapas de domínio público.

\section{Dissecção das genitálias}

Para estudar as genitálias foi adotado o seguinte procedimento, com uma leve diferença entre machos e fêmeas:

O individuo foi colocado em uma câmara úmida por cinco dias para hidratar e amolecer as membranas de suas articulações e facilitar o seu manuseio. Se após cinco dias o individuo não estivesse mole ele era posto novamente na câmara úmida por mais dois dias, repetindo esse procedimento até ser possível manuseá-lo.

Com o auxílio de um estereomicroscópio e uma tesoura para cirurgia oftalmológica, nos machos, foram feitas incisões nas pleuras dos seguimentos abdominais, do ápice até o sétimo segmento e seccionada a membrana abaixo dos paraproctos, para ser possível rebater a superfície dorsal do abdômen. Ainda com a tesoura, foram seccionadas as ligações laterais e ventral entre a genitália e a placa subgenital, assim como a ligação entre a genitália a massa visceral abdominal.

Nas fêmeas, foram feitas incisões nas pleuras dos seguimentos abdominais, do ápice até o quinto segmento e seccionada a membrana abaixo dos paraproctos, as ligações da placa subgenital com o esternito VI, assim como a ligação entre a genitália e a massa visceral abdominal.

Após serem removidas todas as ligações da genitália com o abdômen, ela foi retirada com uma pinça de ponta fina. Após a remoção, a genitália foi fervida em uma solução $10 \%$ de $\mathrm{KOH}$ por cinco minutos para dissolver os tecidos moles. Depois da fervura, com o auxílio de duas pinças de ponta fina, a maior parte dos tecidos moles foi retirada, deixando apenas as membranas e os escleritos.

Este procedimento foi escolhido por conservar o individuo inteiro, ao contrário do método mais usual, em que todo o ápice do abdômen é cortado e fervido, para só então retirar 
a genitália. Entretanto, houve casos em que não foi possível evitar a queda do ápice do abdômen.

As genitálias preparadas, e o ápice do abdômen em alguns casos, foram conservados em álcool 70\% durante o estudo, e posteriormente transferidas para eppendorfs com glicerina alcoólica.

\section{Nomenclatura adotada}

A nomenclatura da morfologia adotada neste trabalho é a tradicionalmente utilizada nos trabalhos de morfologia e de taxonomia da ordem. As principais características na cabeça são a fronte bem desenvolvida e destacada, chamada de "escudo frontal", e o vértice, com lobos justaoculares (Fig.1). O protorax é dividido em duas regiões, prozona e metazona, por um sulco dorsal (Fig.5).

O primeiro par de pernas modificado, permitindo a captura de presas, com as coxas alongadas (Fig.2), fêmur alongado e alargado, portando três fileiras de espinhos, uma na margem externa da superfície ventral, outra na margem interna, e finalmente a terceira fileira entre as duas primeiras, no meio da superfície ventral (Fig. 3). O fêmur pode apresentar manchas na superfície interna, manchas estas que estão relacionadas com comportamentos de defesa. A tíbia também é alongada e alargada, embora menos que o fêmur, com duas fileiras de espinhos, uma em cada margem da superfície ventral, além de um espinho maior que os demais e tradicionalmente chamado de garra tibial, localizado no ápice da tíbia (Fig.4).

Já a nomenclatura adotada para as genitálias segue aquela proposta por Klass (1997; 1998) tanto para as genitálias masculinas quanto para as genitálias femininas. Estruturas da genitália masculina que não foram nomeadas por Klass (1997) em sua monografia, foram nomeadas seguindo a terminologia proposta por La Greca (1954), que é o trabalho utilizado por Klass como referencia. As figuras 6 a 13 mostram as estruturas utilizadas neste trabalho indicadas e nomeadas, sendo referência para todas as demais fotos de genitália aqui apresentadas. 

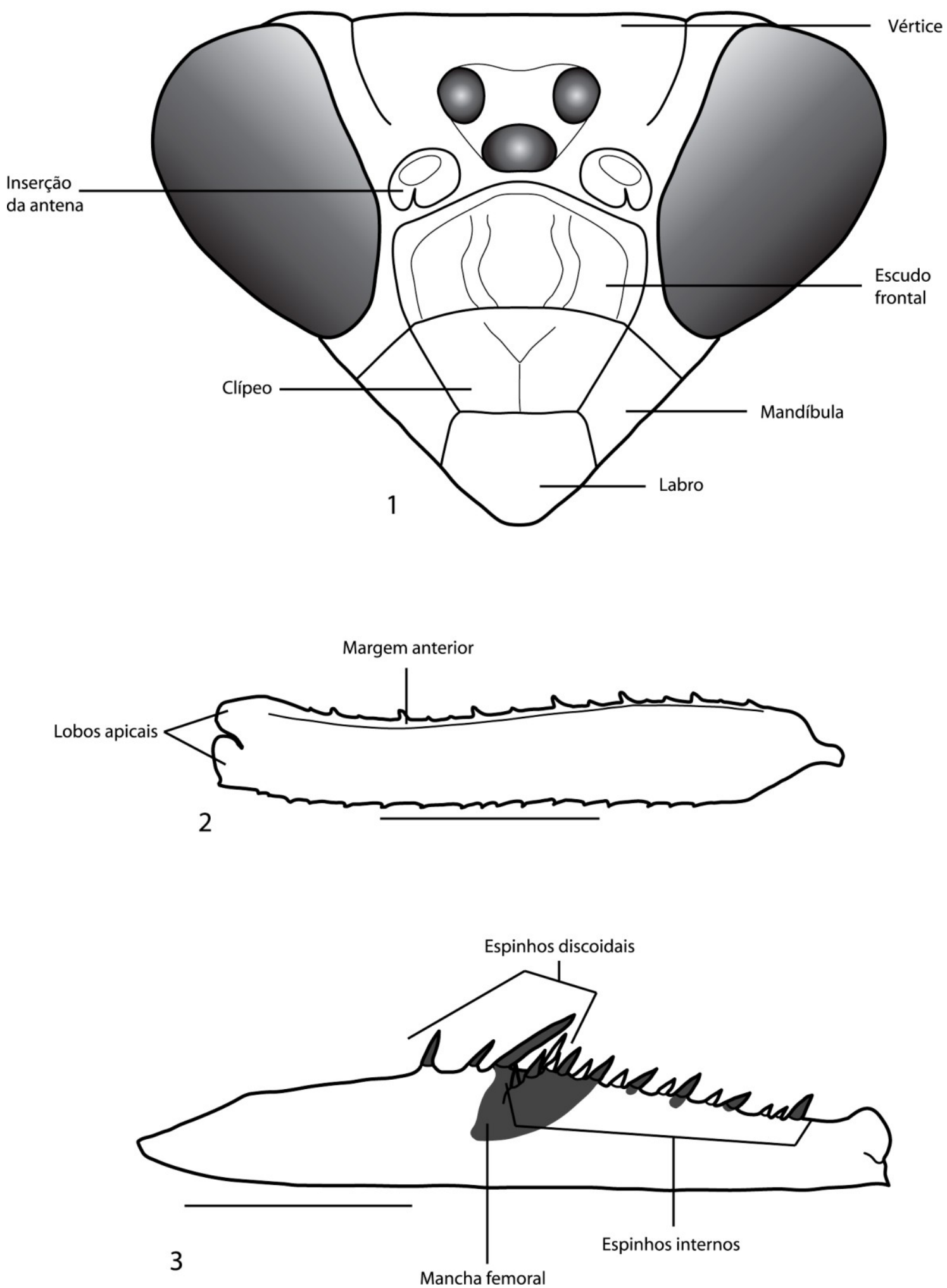

Figuras 1-3. Stagmatoptera binotata macho. 1, cabeça, vista frontal, com algumas características indicadas; 2 , coxa anterior, vista interna, com algumas características indicadas; 3, fêmur anterior, vista interna, com algumas características indicadas. Escalas $=5 \mathrm{~mm}$. 

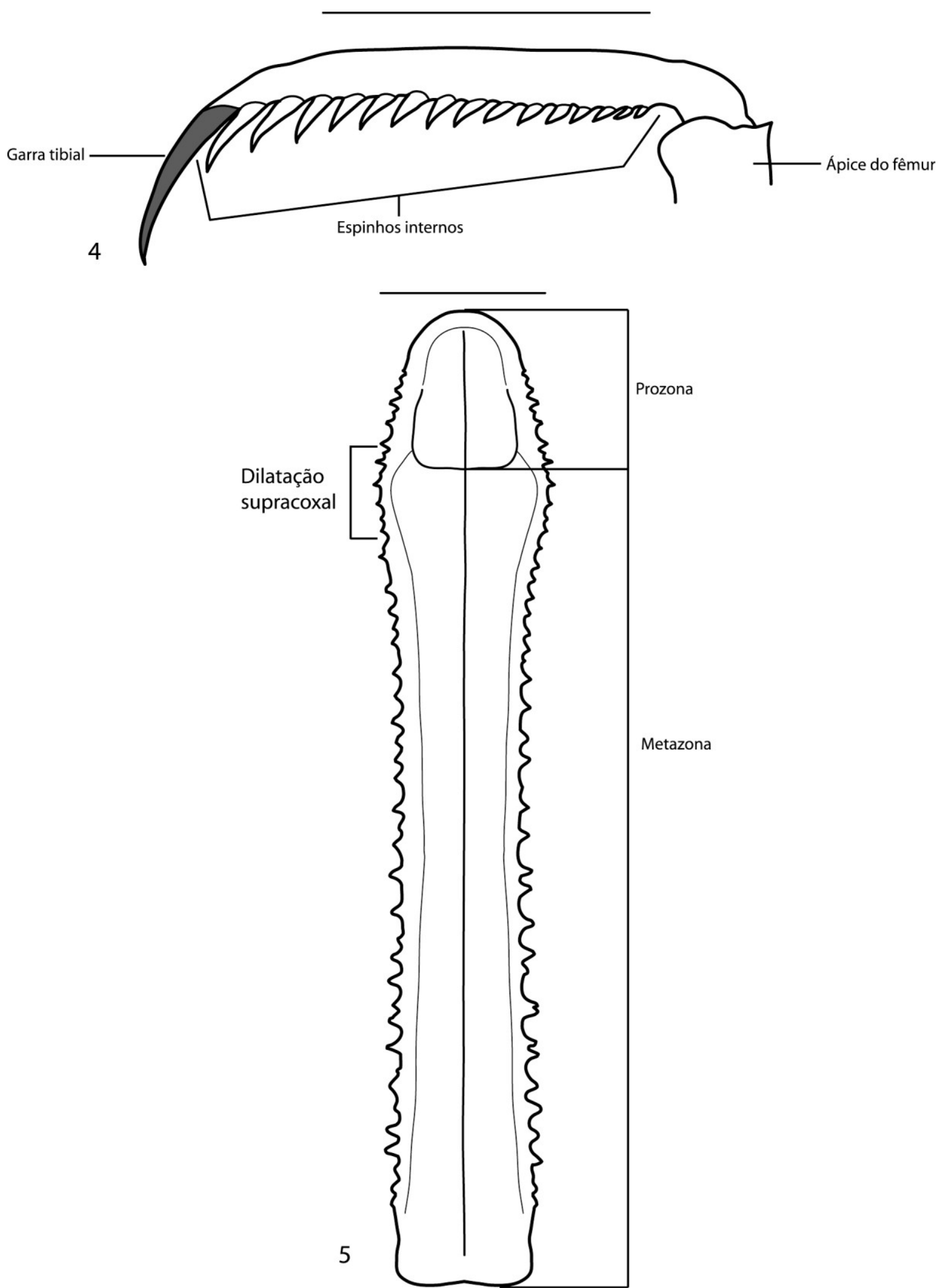

Figuras 4 e 5. Stagmatoptera binotata macho. 4, tíbia anterior, vista interna, com algumas características indicadas; 5 , protorax, vista dorsal, com algumas características indicadas. Escalas $=5 \mathrm{~mm}$. 

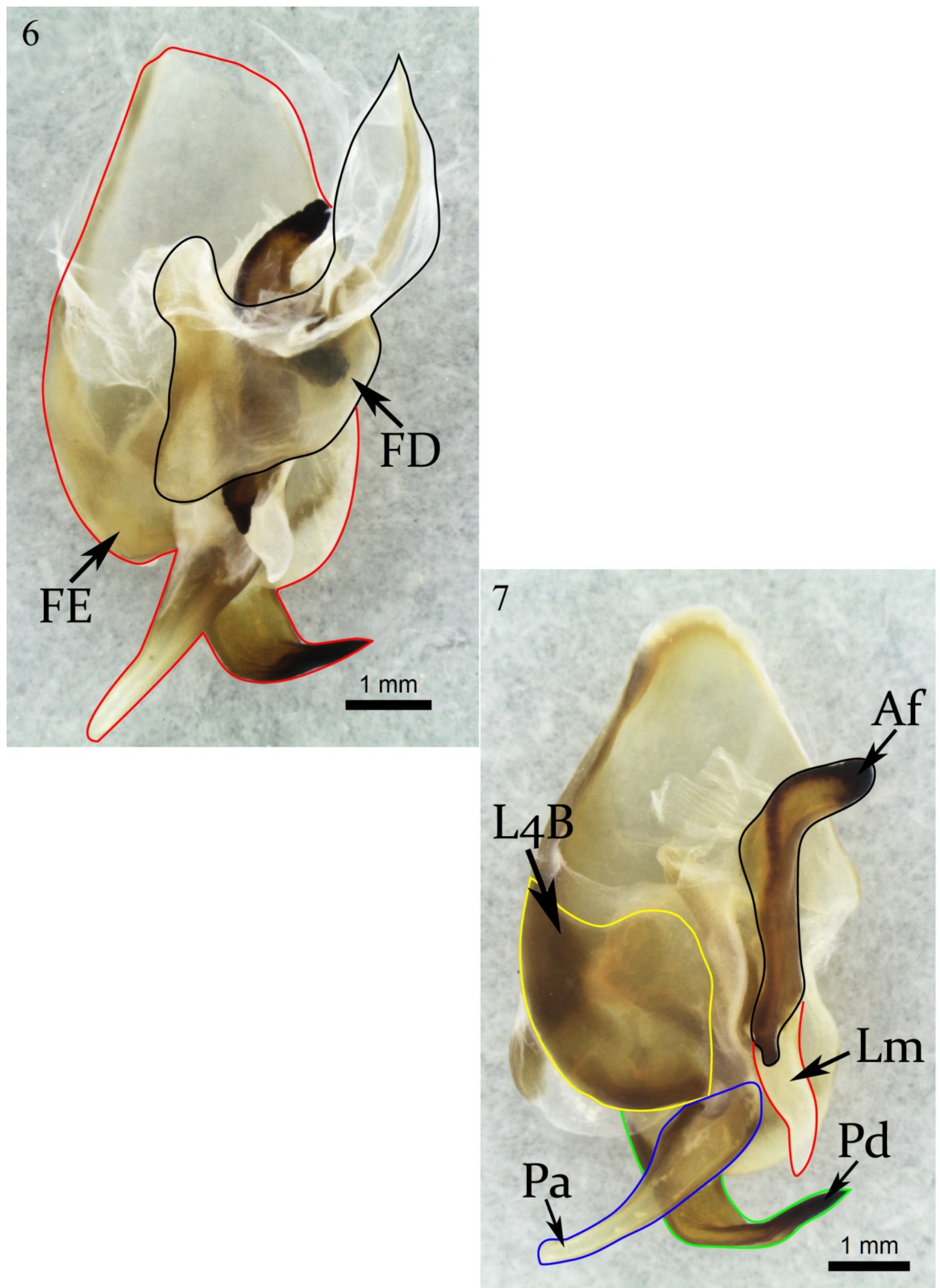

Figuras 6 e 7. Stagmatoptera binotata macho. 6, genitália masculina em vista dorsal, com os dois falômeros circundados; 7, falômero esquerdo em vista dorsal, com as principais estruturas circundadas. Af $=$ Apófise falóide; FD = Falômero direito; $\mathrm{FE}=$ Falômero esquerdo; $\mathrm{L} 4 \mathrm{~B}=$ esclerito dorsal do falômero esquerdo; $\mathrm{Lm}=$ Lobo membranoso; $\mathrm{Pa}=$ Processo apical; $\mathrm{Pd}=$ Processo distal. 


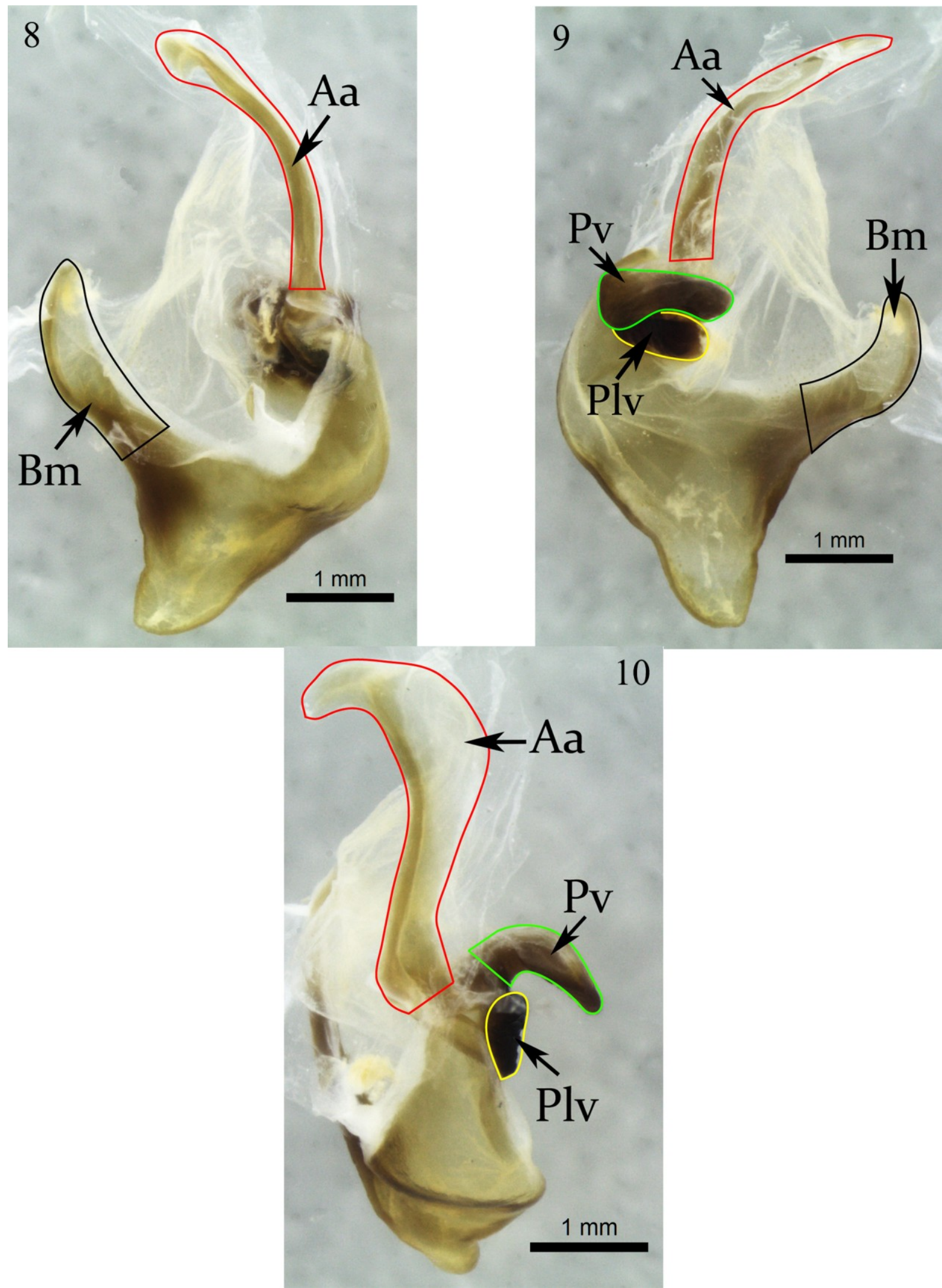

Figuras 8-10. Stagmatoptera binotata macho. 8, falômero direito em vista dorsal, com as principais estruturas circundadas; 9, falômero direito em vista ventral, com as principais estruturas circundadas; 10, falômero direito em vista lateral direita, com as principais estruturas circundadas. Aa = Apódema anterior; $\mathrm{Bm}=$ Braço médio; $\mathrm{Plv}=$ Placa ventral; $\mathrm{Pv}=$ Processo ventral. 


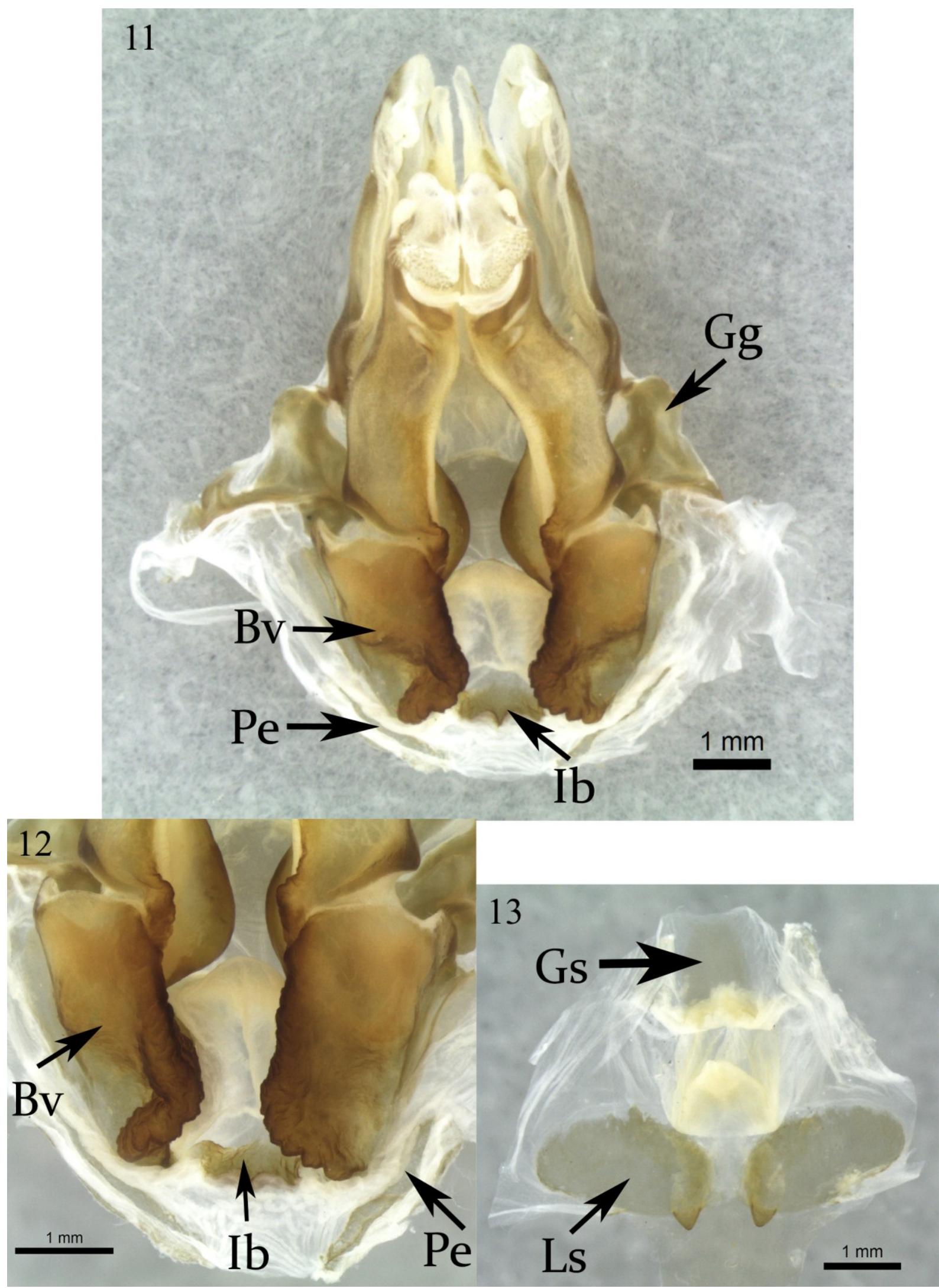

Figuras 11-13. Stagmatoptera binotata fêmea. 11, Ovipositor em vista ventral, com as principais estruturas estudadas indicadas por setas; 12 , detalhe da base do ovipositor, com as principais estruturas estudadas indicadas por setas; 13, assoalho da câmara genital em vista dorsal, com as principais estruturas estudadas indicadas por setas. $\mathrm{Bv}=$ Basiválvula; $\mathrm{Gg}=$ Gonângulo; $\mathrm{Gs}=$ esclerito na parede dorsal da papila genital; $\mathrm{Ib}=$ Interbasiválvula; Ls = Plataforma lateroesternal; $\mathrm{Pe}=$ Extensão posterolateral. 


\section{Resultados}

Stagmatoptera Burmeister, 1838

Mantis (Stagmatoptera) Burmeister, 1838, p.537 (descr.).

Stagmatoptera: Saussure, 1869, p.67 (redesc.); Saussure, 1870, p.231 (men.); Saussure, 1871a, p.64 (men.); Saussure, 1871b, p.80 (men.); Saussure, 1872, p.225 (men.); Stål, 1877, p.72 (men.); Wattenwyl, 1893, p.74 (men.); Saussure \& Zehntner, 1894, p.185 (men.); Rehn, 1904, p.571 (men.); Kirby, 1904, p.229 (men.); Rehn, 1911, p.11 (redesc.); Giglio-Tos, 1914, p.24 (redesc.); Giglio-Tos, 1919, p.75 (men.); Giglio-Tos, 1927, p.593 (redesc.); Beier, 1964, p.950 (men.); Jantsch, 1980, p.68 (men.); Terra, 1995, p.64 (redesc.); Ehrmann, 1999, p.10 (men.); Ehrmann, 2002, p.327 (redesc.); Agudelo et al., 2007, p.110 (men.).

Espécie tipo: Mantis (Stagmatoptera) rogatoria Burmeister, 1838 (non Stoll,1813) = Stagmatoptera binotata Scudder, 1869 (designação subsequente, Rehn, 1904, antecede a designação de Gryllus (Mantis) precarius Linnaeus, 1758 por Kirby, 1904).

Redescrição: Cabeça triangular, vértice reto mais alto que os olhos. Ocelos desenvolvidos, grandes e próximos entre si nos machos, menores e mais afastados nas fêmeas. Olhos globosos, levemente alongados. Antenas longas, ultrapassando o protorax nos machos, e curtas atingindo a metazona nas fêmeas. Antenômeros das fêmeas filiformes. Clípeo com uma carena central percorrendo sua extensão, se bifurcando próximo da margem superior. Escudo frontal subpentagonal, mais largo do que alto, com as margens laterais e a margem superior intumescidas.

Protorax alongado. Prozona com margens achatadas e levemente expandidas lateralmente, convergentes. Metazona mais longa que a prozona, com uma quilha central que pode ser bem desenvolvida. Coxas anteriores com margem anterior crenulada, lobos apicais internos convergentes. Fêmures anteriores alongados, com quatro espinhos externos, quatro espinhos discoidais e 11 a 17 espinhos internos, sendo o número mais frequente 15. Mancha femoral interna ausente ou presente. Tíbias anteriores dotadas de 9 a 14 espinhos externos, e 12 a 18 espinhos internos.

Tégminas dos machos verdes opacas na área costal. Área anal hialina. Asas dos machos com área costal hialina e as áreas discoidal e anal totalmente hialinas ou com 
molduras amarelas nas veias transversais. Tégminas das fêmeas verdes opacas com manchas hialinas na margem posterior. Asas das fêmeas com área costal hialina e as áreas discoidal e anal com molduras amarelas nas veias transversais, ou amarelas com uma faixa hialina na borda.

Abdômen dos machos cilíndrico e das fêmeas levemente achatado. Placa supra-anal triangular, mais larga que longa, cercos cilíndricos, com aproximadamente 20 segmentos. Gonângulo com um formato aproximadamente triangular.

\section{Chave de Identificação}

1 - Tégminas com uma mancha ou faixa escura no estigma -2

1' - Tégminas sem manchas ou faixas (Fig. 99) - Stagmatoptera indicator.

2 - Tégminas com duas faixas castanhas, sendo a mais basal maior e ramificada (Fig. 14) Stagmatoptera abdominalis.

2' - Tégminas com uma mancha diferente da descrita -3

3 - Mancha femoral interna se estendendo ao menos até o $8^{\circ}$ espinho - 4

$3^{\prime}$ - Mancha femoral interna, se presente, estendendo-se no máximo até o $6^{\circ}$ espinho -8

4 - Mancha do estigma grande, alcançando a margem posterior da tégmina (Fig. 190) Stagmatoptera sp. n.1.

4' - Mancha do estigma pequena a média, sem alcançar a margem posterior da tégmina - 5

5 - Mancha do estigma com duas faixas marrom laterais separadas (Fig. 148) -

Stagmatoptera reimoseri.

5' - Mancha do estigma sem duas faixas marrom separadas -6

6 - Mancha do estigma totalmente envolvida pela faixa verde opaca da área discoidal (Fig. 211) - Stagmatoptera sp. n. 2.

6' - Mancha do estigma parcialmente envolvida pela faixa verde opaca da área discoidal - 7

7- Protorax delgado, mancha femoral interna se estendendo até o $8^{\circ}$ espinho - Stagmatoptera femoralis.

$7^{\prime}$ - Protorax grosso, mancha femoral interna se estendendo até o $10^{\circ}$ espinho -

Stagmatoptera biocellata.

8 - Tégminas e asas não ultrapassam o abdômen - Stagmatoptera pumila.

8 ' - Tégminas e asas ao menos tão longas quanto o abdômen -9

9 - Metazona fortemente crenulada (Fig. 17 e 29) - Stagmatoptera binotata.

9' - Metazona finamente denticulada nas fêmeas, lisa nos machos - 10

10 - Pequena mancha na base dos espinhos 5, 6 e/ou 7, a partir do ápice na face interna das tíbias anteriores -11

$10^{\prime}$ - Sem mancha na face interna das tíbias anteriores -13 
11 - Mancha do estigma nos machos com uma região branca, nas fêmeas circular com um único tom de marrom (Fig. 100) - Stagmatoptera pia.

11' - Mancha do estigma nos machos sem uma região branca, nas fêmeas oval com uma mancha marrom escura e outra marrom claro -12

12 - Mancha do estigma nos machos com região hialina sem veias transversais, mancha das fêmeas pequena (Fig. 169). Asas das fêmeas hialinas com molduras amarelas - Stagmatoptera septentrionalis.

12' - Mancha do estigma nos machos com região hialina com veias transversais, mancha das fêmeas grande. Asas das fêmeas amarelas, com toda a margem hialina com molduras amarelas (Fig. 224) - Stagmatoptera supplicaria.

13 - Mancha do estigma circular e média, semelhante a um olho (Fig. 78) - Stagmatoptera hyaloptera.

13' - Mancha do estigma circular e pequena, sem assemelhar-se a um olho (Fig. 121) Stagmatoptera precaria.

Stagmatoptera abdominalis (Olivier, 1792)

Figura 14.

Mantis abdominalis Olivier, 1792, p.640 (descr.); Audinet-Serville, 1831, p.54 (men.).

Stagmatoptera abdominalis, Kirby, 1904, p.301 (men.); Rehn, 1911, p.13 (men.); Giglio-Tos, 1914, p.35 (redesc.); Giglio-Tos, 1927, p.599 (redesc.); Terra, 1995, p.64 (men.); Ehrmann, 2002, p.328 (men.); Agudelo et al., 2007, p.125 (men.); Ehrmann \& Koçak, 2009, p.11 (men.).

= Mantis urbana Lichtenstein, 1802, p.27 (descr.); Kirby, 1904, p.301 (sin.).

= Mantis birivia Stoll, 1813, p.28, t.9, f.31 (descr.)

$=$ Mantis (Cardioptera) birivia, Burmeister, 1838, p.541 (redesc.).

= Stagmatoptera birivia, Saussure, 1870, p.232 (men.); Kirby, 1904, p.301 (sin.).

$=$ Cardioptera birivia, Westwood, 1889, p.15 (men.).

Durante a realização do trabalho não possível encontrar nenhum exemplar pertencente a esta espécie, por este motivo são dadas duas descrições e uma ilustração já publicadas na literatura.

Tradução da descrição feita por Stoll, 1787: 
"Ele tem a cabeça o tronco e o corpo muito grande e largo, o tronco é denteado nas laterais, com uma quilha no meio; pernas raptoriais dotadas de espinhos pontiagudos na face inferior, com os quais estes insetos agarram e capturam sua presa, enquanto eles jogam sua garra longa e serreada, mais longa e maior que o normal nas outras espécies, de onde fica evidente que eles podem prender grandes insetos, dos quais eles se alimentam; o tarso possui cinco segmentos. Os élitros são frequentemente verdes e pergamináceos, entretanto a margem posterior é um pouco transparente e marcada de marrom. As asas também tem a margem anterior pergaminácea, marrom nas pontas, mas o resto é membranoso, transparente e reticulado."

Tradução da descrição feita por Giglio-Tos, 1927:

"Verde. Pronoto com a dilatação oval, as bordas denteadas. Élitros grandes, arredondados na ponta, área costal opaca, ao menos tão larga quanto a metade da área discoidal, esta sub-hialina na região da margem posterior, cruzada por duas faixas marrom obliquas, onde a primeira se divide em 2 ramos sobre a área costal, e a posterior é pouco marcada. Asas sub-hialinas, área costal verde opaca. Coxas anteriores com vários espinhos. Fêmures anteriores com a mancha interna preta estreita."

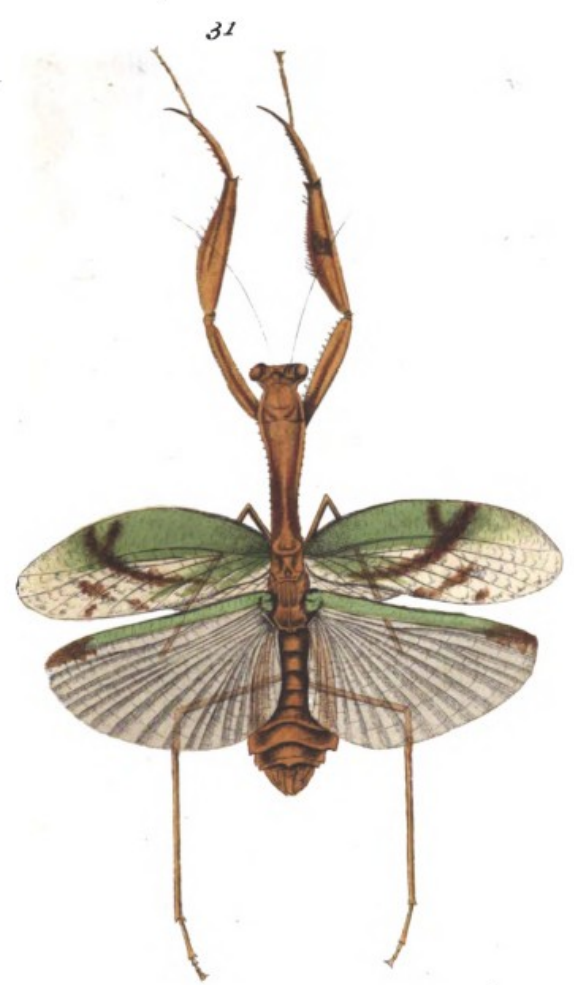

Figura 14. Ilustração de Stagmatoptera abdominalis publicada por Stoll em seu trabalho de 1787. 
Stagmatoptera binotata Scudder, 1869, p.341 (descr.); Saussure, 1871, p. 94 (men.); Westwood, 1889, p.16 (men.); Kirby, 1904, p.300 (men.); Rehn, 1911, p.12 (men.); Giglio-Tos, 1914, p. 29 (redesc.); Werner, 1925d, p.166 (men.); Giglio-Tos, 1927, p.596 (redesc.); Beier, 1930, p.31 (men.); Jantsch \& Corseuil, 1988, p.233 (men.); Terra, 1995, p.64 (men.); Ehrmann, 2002, p.328 (men.); Agudelo et al., 2007, p.125 (men.); Ehrmann \& Koçak, 2009, p.11 (men.).

Tipo: um macho e uma fêmea, Rio Napo ou Rio Marañon.

= Mantis (S.) rogatoria Burmeister, 1838 non M. rogatoria Stoll, 1813, p. 540 (descr.); de Haan, 1842, p.74 (men.).

= Stagmatoptera rogatoria, Saussure, 1870, p. 231 (men.); Rehn, 1904, p.571 (men.); Kirby, 1904, p.300 (sin. c/ S. praedicatoria).

= Stagmatoptera praedicatoria Saussure, 1870, p.232 (descr.); Saussure, 1871, p.92, t.1, f.10 (men.); Stål, 1877, p.72 (men.); Westwood, 1889, p.16, t.4, f.6 (men.); Rehn, 1904, p.571 (sin. c/ S. rogatoria); Kirby, 1904, p.300 (men.); Rehn, 1911, p.12 (men.); Giglio-Tos, 1914, p. 29 (sin. c/ S. binotata).

Tipo: Brasil (examinados)

Redescrição: Macho - Figuras 15A, 16-27.

Antenômeros filiformes. Escudo frontal com duas elevações centrais (Fig. 16).

Protorax alongado, delgado, com margens dotadas de crenulação bem desenvolvida. Metazona com uma quilha central bem desenvolvida (Fig. 17). Coxas anteriores com margem anterior crenulada dotada de 6 a 13 espinhos grandes e 2 a 10 espinhos menores (Fig.18). Fêmures anteriores alongados e finos, com os três primeiros espinhos discoidais a partir da base, pretos em sua face interna; 11 a 16 espinhos internos, sendo o número mais frequente 15 , o primeiro espinho interno a partir da base e os grandes espinhos internos são pretos na face interna, podendo apresentar uma pequena mancha de mesma coloração na inserção dos espinhos 8, 10 e 12. Mancha femoral interna estendendo-se da canaleta da garra tibial até o $6^{\circ}$ espinho interno a partir da base, com formato triangular e uma coloração preta brilhante (Fig. 19). Tíbias anteriores dotadas de 9 a 12 espinhos externos, sendo mais frequente entre 10 e 11 
espinhos, e 12 a 17 espinhos internos, sendo mais frequente 15 espinhos; a garra tibial é preta na face interna (Fig. 20). Tarsos com manchas pretas apicais na face interna dos tarsômeros I a IV.

Área discoidal das tégminas verde opaca em uma faixa anterior, passando gradualmente até hialina ou passando bruscamente. Estigma circular de tamanho mediano, alcançando a metade da área discoidal, com o seguinte padrão: uma mancha branca de formato crescente, envolvida por uma mancha marrom e no centro, entre as duas, uma pequena mancha semi-hialina. Asas com as áreas discoidal e anal totalmente hialinas ou com molduras amarelas nas veias transversais somente em suas metades anteriores (Fig. 15A).

Genitália: Falômero esquerdo mais longo que largo, esclerito L4B aproximadamente tão largo quanto longo. Processo apical longo, levemente dilatado no lado esquerdo de sua base; inclinado em relação à base, formando um ângulo de aproximadamente $45^{\circ}$; ápice expandido, bilobado, voltado ventralmente (Fig. 21). Processo distal largo e longo, achatado, curvado bruscamente $90^{\circ}$ para a direita, ápice bem esclerosado e levemente afilado (Fig.22). Apófise falóide longa e paralela em relação à genitália (Fig. 23); margem direita lisa e sinuosa (Fig. 24); ápice posterior simples e indiviso, levemente rugoso e moderadamente esclerosado; ápice anterior curvado $90^{\circ}$ para a direita, margem esquerda com esclerosamento progressivamente mais intenso até a extremidade (Fig. 23). Lobo membranoso longo, reto (Fig. 23). Membrana adjacente à apófise falóide glabra (Fig. 23).

Falômero direito com ápice posterior arredondado; braço médio curto, com o ápice levemente expandido, formando uma elevação suave (Fig. 25); placa ventral longa, moderadamente esclerosada (Fig. 26 e 27); processo ventral longo, moderadamente esclerosado, ápice arredondado (Fig. 26); apódema anterior longo, passando suavemente a um ápice arredondado (Fig. 27).

Fêmea - Figuras 15B, 28-35.

Escudo frontal com duas elevações centrais (Fig. 28).

Protorax alongado, delgado, com margens dotadas de crenulação bem desenvolvida. Metazona com uma quilha central bem desenvolvida (Fig. 29). Coxas anteriores com margem anterior crenulada dotada de 6 a 15 espinhos grandes e 4 a 13 espinhos menores (Fig. 30). Fêmures anteriores alongados e finos, com os três primeiros espinhos discoidais a partir da 
base pretos em sua face interna; 14 a 16 espinhos internos, sendo o número mais frequente 15 , o primeiro espinho interno a partir da base e os grandes espinhos internos são pretos na face interna, podendo apresentar uma pequena mancha de mesma coloração na inserção dos espinhos 8, 10 e 12. Mancha femoral interna estendendo-se da canaleta da garra tibial até o $6^{\circ}$ espinho interno a partir da base, com formato triangular e uma coloração preta brilhante (Fig. 31). Tíbias anteriores dotadas de 9 a 12 espinhos externos, sendo mais frequente entre 10 e 11 espinhos, e 14 a 16 espinhos internos, sendo mais frequente 15 espinhos; a garra tibial é preta na face interna (Fig. 32). Tarsos com manchas pretas apicais na face interna dos tarsômeros I a IV.

Estigma circular de tamanho mediano, alcançando a metade da área discoidal, com o seguinte padrão: uma mancha branca de formato crescente, envolvida por uma mancha marrom e no centro entre as duas uma pequena mancha semi-hialina. Asas com área costal hialina e as áreas discoidal e anal com molduras amarelas nas veias transversais (Fig. 15B).

Genitália: Base das gonapófises VIII projetando-se internamente (Fig. 33). Basiválvula com formato aproximadamente retangular, com as margens anteriores internos curvando-se externamente (Fig. 33); toda a superfície interna esculpida (Fig. 34). Interbasiválvula fracamente esclerosada (Fig. 34). Extensões posterolaterias longas, fracamente esclerosadas com margens lisas (Fig. 34). Esclerito na parede dorsal da papila genital quase membranoso, liso (Fig. 35). Plataforma lateroesternal oval, processos posteriores curtos com formato de triângulo equilátero (Fig. 35).

Localidade tipo: Rio Napo ou Rio Marañon, Peru

Outras localidades: Brasil (Amapá, Amazonas, Pará, Rio Grande do Sul [?], Rondônia), Guiana Francesa, Peru.

Diagnose: Protorax com crenulação bem desenvolvida em ambos os sexos, mancha femoral interna triangular de coloração preta brilhante. 
Tabela 1. Medidas e razões de machos e fêmeas de Stagmatoptera binotata.

\begin{tabular}{|c|c|c|}
\hline & Macho $(\mathrm{N}=19)$ & Fêmea $(\mathrm{N}=17)$ \\
\hline Comprimento & 70,1 a $81 \mathrm{~mm}$ & 78,4 a $96,1 \mathrm{~mm}$ \\
\hline Largura da cabeça & 6,5 a $7,3 \mathrm{~mm}$ & 8,1 a $9,6 \mathrm{~mm}$ \\
\hline Comprimento da Prozona & 4,4 a $5,3 \mathrm{~mm}$ & 6,1 a $7,8 \mathrm{~mm}$ \\
\hline Comprimento da Metazona & 22,2 a $26,5 \mathrm{~mm}$ & 28,4 a $35,8 \mathrm{~mm}$ \\
\hline Largura da Dilatação & 4,5 a $5,5 \mathrm{~mm}$ & 6,7 a $8,3 \mathrm{~mm}$ \\
\hline Comprimento da Tégmina & 48,8 a $58,1 \mathrm{~mm}$ & 43,7 a $53 \mathrm{~mm}$ \\
\hline Comprimento da Asa & 46,8 a $52,1 \mathrm{~mm}$ & 40,7 a $48 \mathrm{~mm}$ \\
\hline Comprimento da Coxa Anterior & 12,2 a $15,7 \mathrm{~mm}$ & 17,8 a $22,3 \mathrm{~mm}$ \\
\hline Comprimento do Fêmur Anterior & 14,7 a $18,1 \mathrm{~mm}$ & 21,1 a $26,3 \mathrm{~mm}$ \\
\hline Largura do Fêmur Anterior & 2,2 a $2,7 \mathrm{~mm}$ & 3,2 a $4,4 \mathrm{~mm}$ \\
\hline Comprimento da Tíbia Anterior & 6,6 a $8,1 \mathrm{~mm}$ & 9,2 a $11,9 \mathrm{~mm}$ \\
\hline Razão Cabeça/Dilatação & 1,29 a 1,57 & 1,12 a 1,26 \\
\hline Razão Metazona/Prozona & 4,52 a 5,1 & 4,14 a 4,78 \\
\hline Razão Prozona/Dilatação & 0,93 a 1,16 & 0,84 a 1 \\
\hline Razão Metazona/Dilatação & 4,44 a 5,3 & 3,95 a 4,44 \\
\hline Razão Metazona/Coxa Anterior & 1,64 a 1,82 & 1,47 a 1,66 \\
\hline $\begin{array}{c}\text { Razão Comprimento/Largura } \\
\text { Fêmur Anterior }\end{array}$ & 6,22 a 7,17 & 5,89 a 7,12 \\
\hline Razão Fêmur/Tíbia & 1,94 a 2,36 & 2,11 a 2,38 \\
\hline
\end{tabular}

Material examinado: Brasil; 19 , $(\mathrm{MNHN})$. Síntipo de $S$. praedicatoria, Alto Amazon., M. Brunner d. W. , 19 (MHNG). Síntipo de S. praedicatoria, Rio Purus, 1904, J.A.

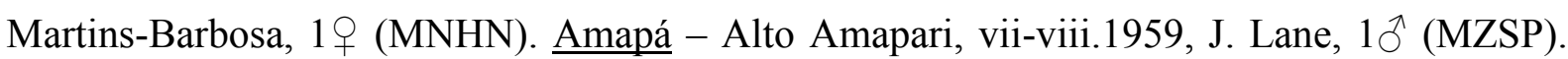
Serra do Navio, xi.1964, E. Dente col. , 1 ( (MZSP). Amazonas - Benjamin Constant, v.1961, Dirings col., $1{ }^{\Uparrow} 1 q$ (MZSP). B. Constant, 19.viii.1984, J. Kuhn, 1ð, 1224 (MCTP). B. Constant, 1983, J. Kuhn, 1ð̊, 0726 (MCTP). Benj. Const. 13.viii.1980, J. Maia leg., 1, 0534 (MCTP). Benj. Const., 17.i.1983 [?], J. Kuhn, 19, 0725 (MCTP). Benj. Const., 07.ix.1979, A. Maia leg., 1ð̂, 0099 (MCTP). Paxiúba, Rio Abacaxis, Borba, 04²8’48”S 58³4’24”W, 0204.vi.2008, J.A. Rafael e equipe, $1 \delta^{\Uparrow}$ (INPA). Paraná de Urariá, Fortaleza, 24.ii.1972, EPA [Expedição Permanente da Amazônia], 10ત (MZSP). Humaitá, ix.1980, Andrade col., 1 q (MZSP). Estirão da Preta, Rio Liberdade, Ipixuna, 07²1'46,7”S 7152'07,1"W, 1115.v.2011, J.A. Rafael, D. Takiya, A. Somavilla \& A. Agudelo, 19 (INPA). Est. Mn., CEPLAC, Itacoatiara, 06.v.1976, Eduardo col., 1ðぇ (INPA). Resev Unini, Rio Unini,

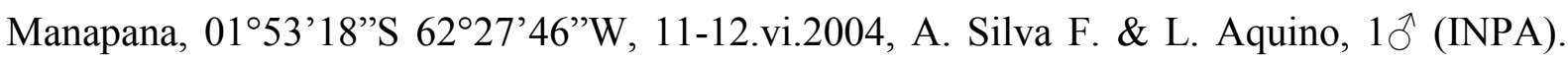


Manaus, [AM], síntipo de S. praedicatoria, M. Brunner d. W., $1 ð$ (MHNG). C1 ASA Manaus, 12.iii.1986, P.E. Gonçalves col., 1 ㅇ (INPA). Campus INPA, Manaus, 22.iii.1988, Celia col., 1 을 (INPA). Campus INPA, Manaus, 08.iv.1988, da Silva, B.M. col., 1 우 (INPA). Vale do Sol II, Aleixo, Manaus, 29.iii.1986, Vera Lucia L. Lima col., 1 ㅇ (INPA). Reserva Adolpho Ducke, Manaus, $02^{\circ} 55^{\prime} 51^{\prime}$ 'S 5958'59”W, floresta úmida, 06-10.iii.2007, L.M. Fusari leg., $1 q$ (INPA). São Lázaro, Manaus, 08.v.1988, Leite, S.S. col., 19 (INPA). Um Est Amo 1 km60, Res Camp, 05.iv.1976, Germano G. Neto, 1 ㅇ (INPA). Pará - PA, Schulz, $1 \delta^{\lambda}$ (MHNG). Tipo de S. rogatória, PA, $1 q$ (ZMB). PA, $2 q$ (ZMB). Belém, 16.ii.1983, A.L. Henriques, 1 ㅇ (INPA). Capitão Poço, 26.ii.1978, P. Tadeu, 1ð (MZSP). Liverpool, Foz do Taipuru, 12.xi.1969, EPA [Expedição Permanente da Amazônia], 10̊ (MZSP). Santo Antonio de Tauá, PA, 5-15.x.1979, Michel Boulard rec., $1 \overbrace{}^{\Uparrow}(\mathrm{MNHN})$. Rio Grande do Sul - Nova Petrópolis, 24.iii.1979,V. Lima leg., 1q, 0439 (MCTP). Porto Alegre, 03.iv.1980, E. Acauan leg., 1ठ઼, 0091 (MCTP). Rondônia - Porto Velho, 28.ix.1979, J. Campbell, 1ठ (INPA).

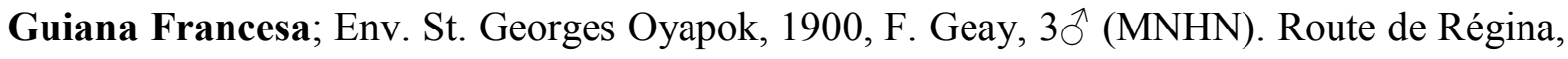
1984, Piège lumineux, S. Boucher, $1 \widehat{\jmath}$ (MNHN). Peru; Estiron, Rio Ampiyacu, Loreto, 1522.v.1966, B. Malkin col., 1 ㅇ (MZSP). Jenaro Herrera, 455’S 7340’W, Loreto, ix.1987, Piège lumineux, G. Couturier col., $1 \overbrace{}^{\Uparrow}(\mathrm{MNHN})$. Estiron, Rio Ampiyacu, Loreto, xii.1982, S. Poulain rec., $2 \widehat{\jmath}$ (MNHN). Estiron, Chemin de Paucar, Rio Ampiyacu, Loreto, xii.1983, Forêt primaire non inondable, C. Amedegnato \& S. Poulain rec., $2 \widehat{\bigcirc}(\mathrm{MNHN})$. 

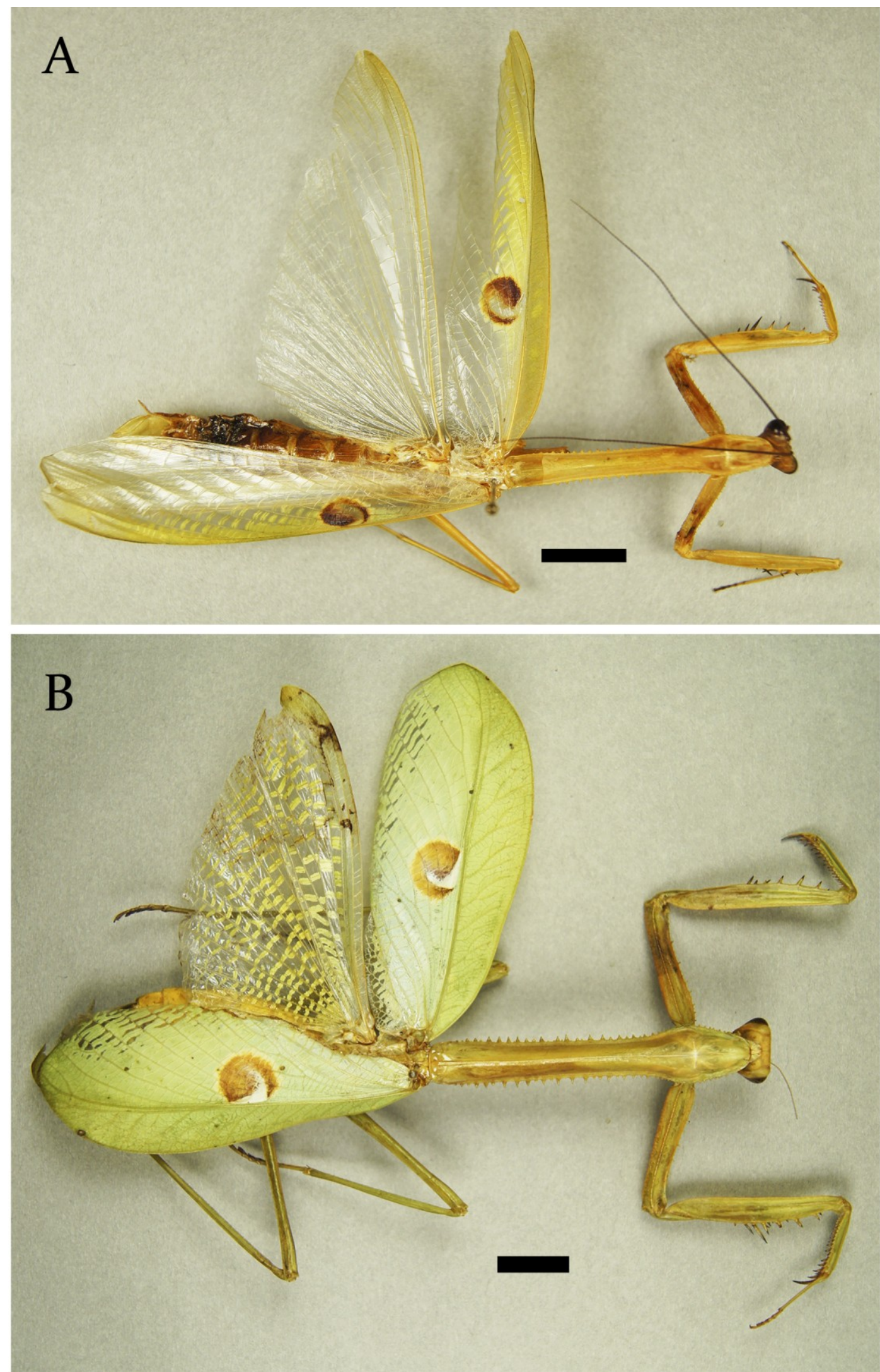

Figura 15. Stagmatoptera binotata, habitus dorsal. A, macho; B, fêmea. Escalas $=1 \mathrm{~cm}$. 


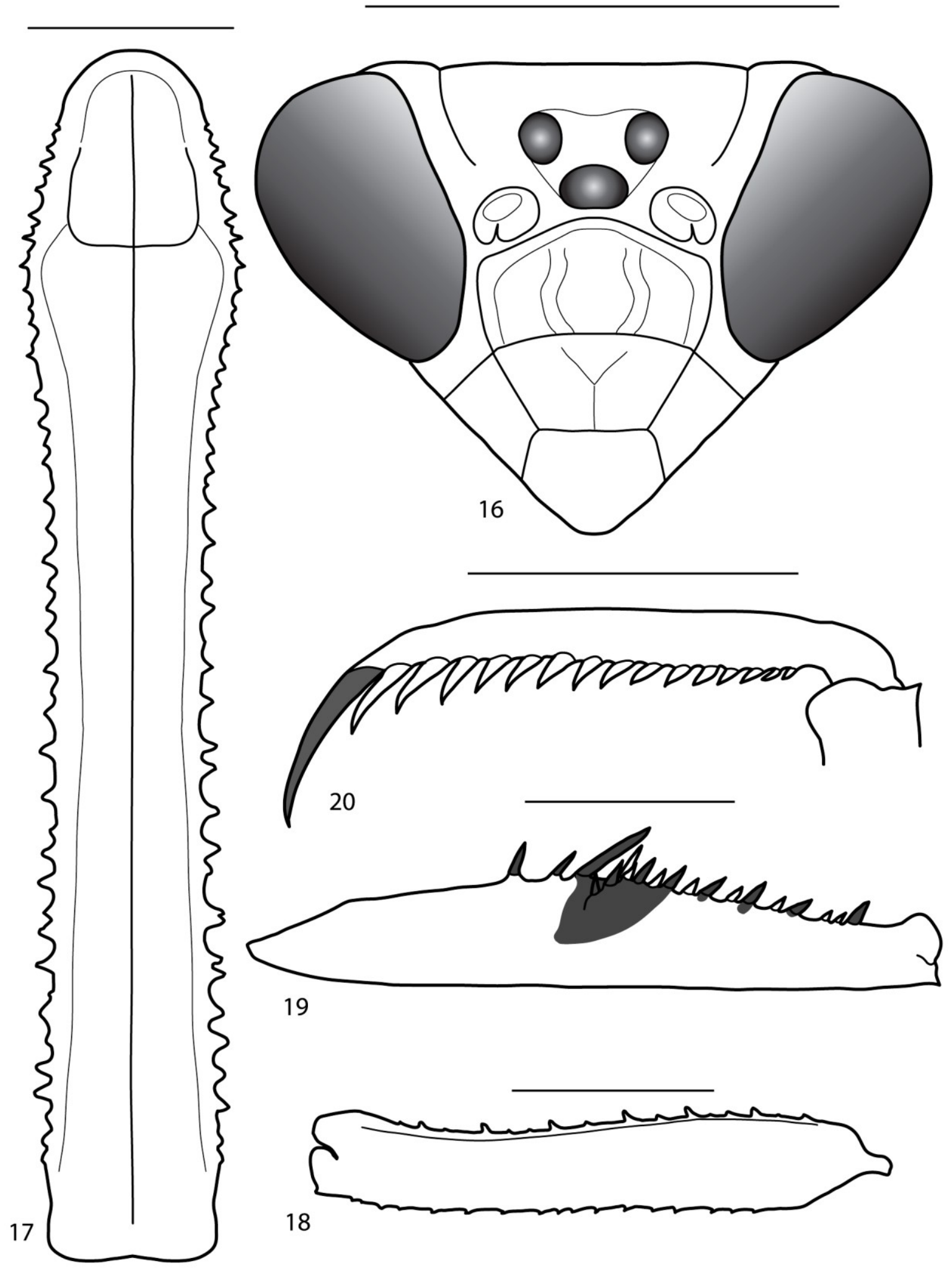

Figuras 16-20. Stagmatoptera binotata macho. 16, cabeça, vista frontal; 17, protorax, vista dorsal; 18, coxa anterior, vista interna; 19, fêmur anterior, vista interna; 20, tíbia anterior, vista interna. Escalas $=5 \mathrm{~mm}$. 

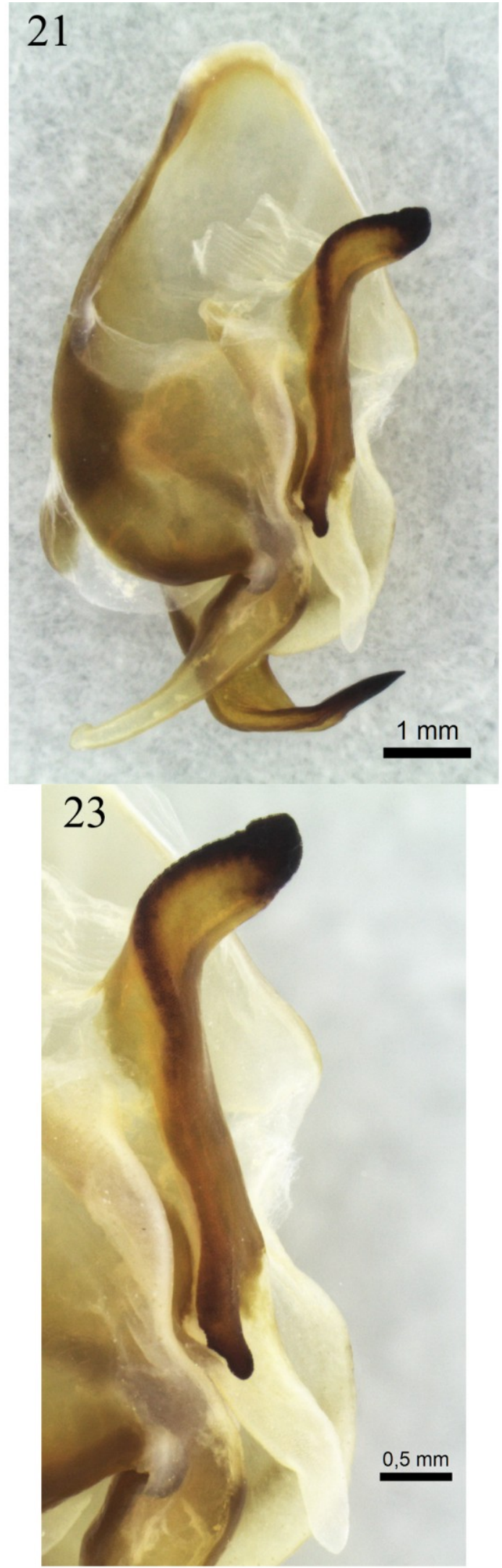

Figuras 21-24. Stagmatoptera binotata macho. 21, falômero esquerdo, vista dorsal; 22, falômero esquerdo, vista ventral; 23, apófise falóide e lobo membranoso, vista dorsal; 24, apófise falóide, vista lateral direita.
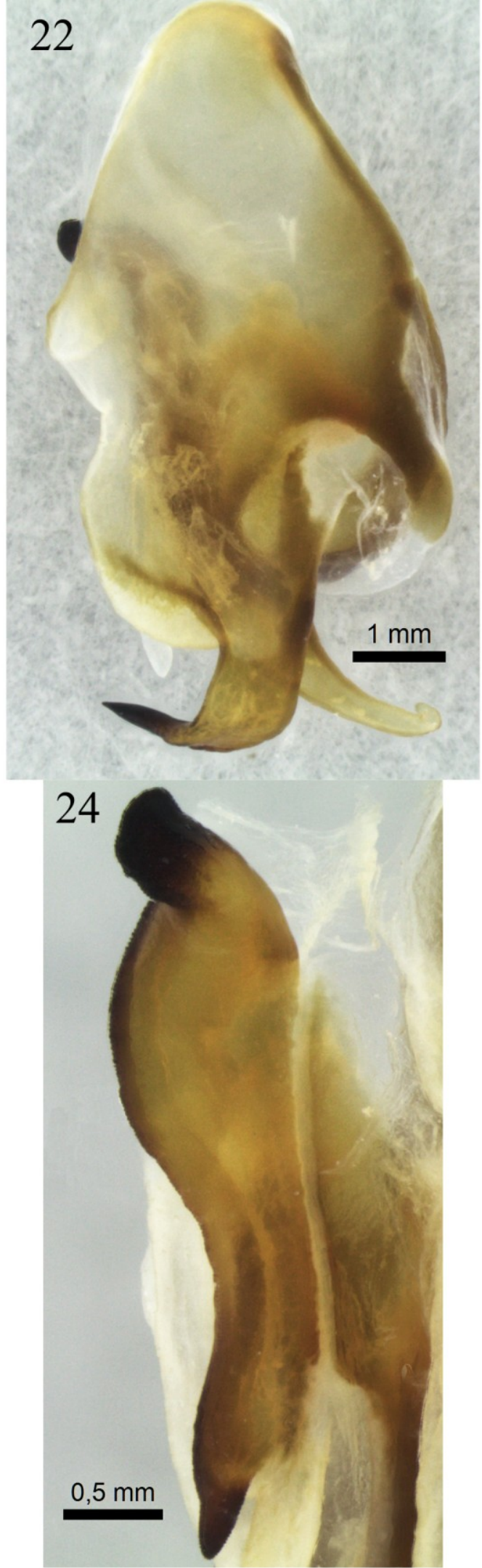


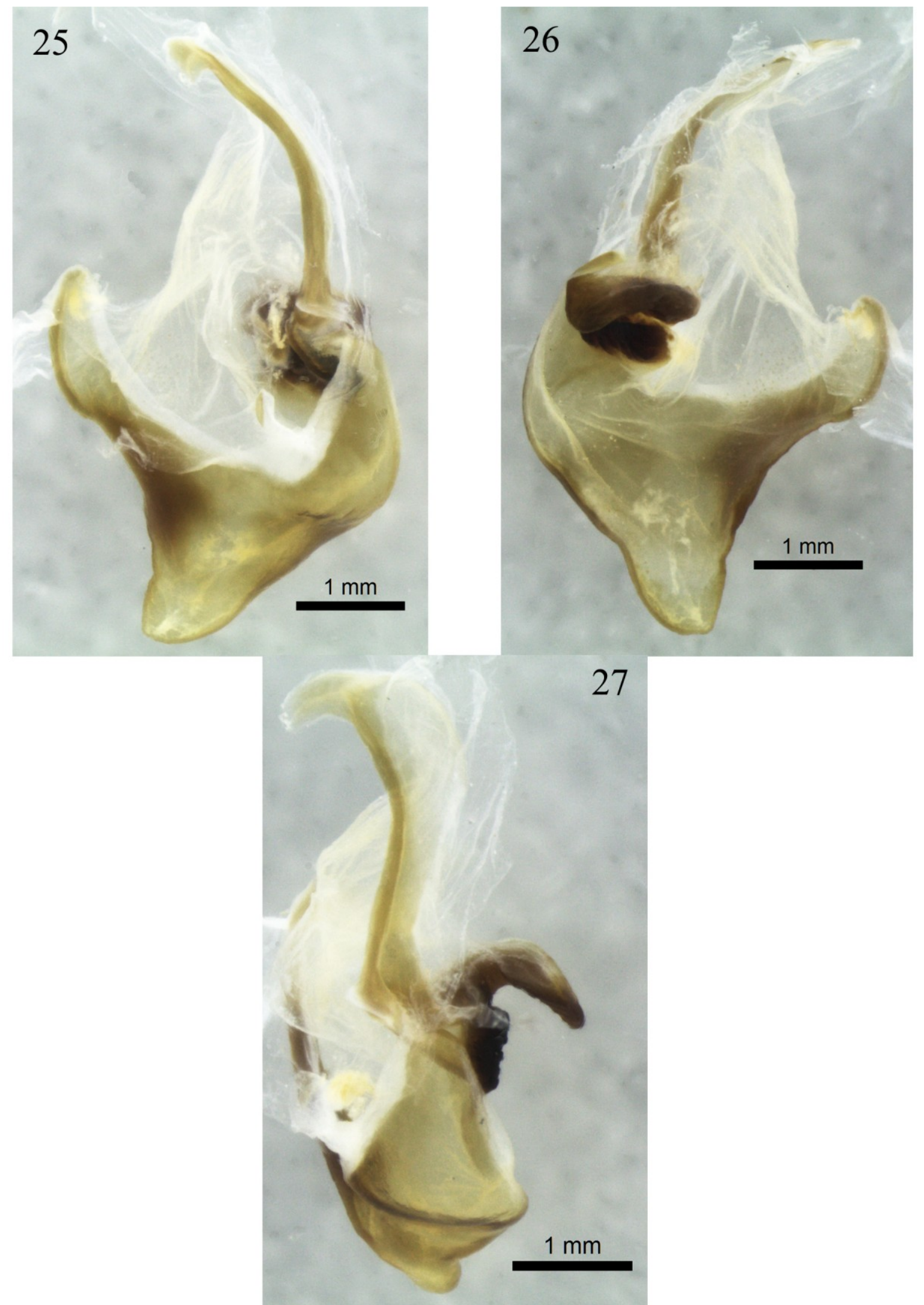

Figuras 25-27. Stagmatoptera binotata macho. 25, falômero direito, vista dorsal; 26, falômero direito, vista ventral; 27 , falômero direito, vista lateral direita. 


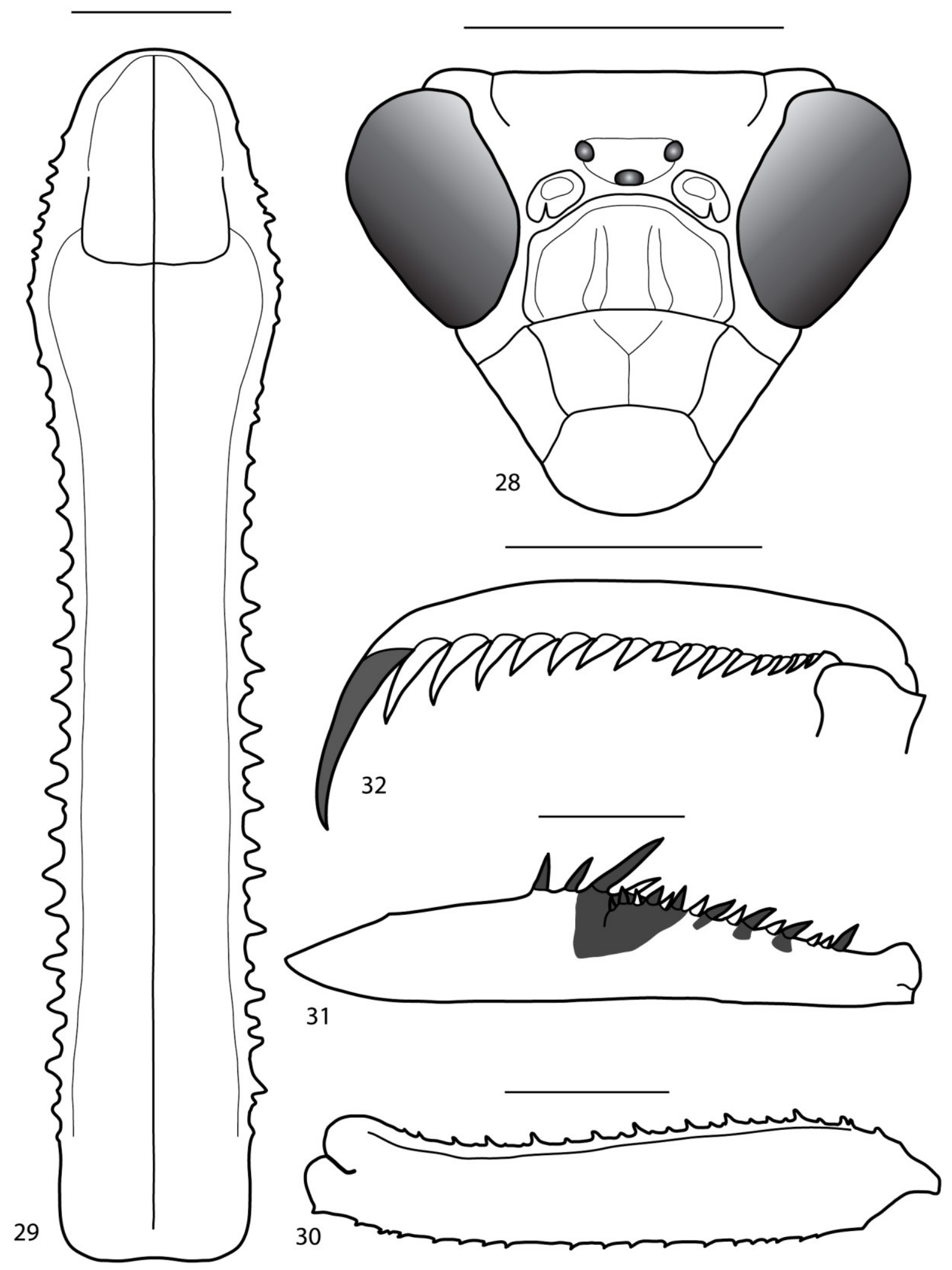

Figuras 28-32. Stagmatoptera binotata fêmea. 28, cabeça, vista frontal; 29, protorax, vista dorsal; 30, coxa anterior, vista interna; 31 , fêmur anterior, vista interna; 32 , tíbia anterior, vista interna. Escalas $=5 \mathrm{~mm}$. 


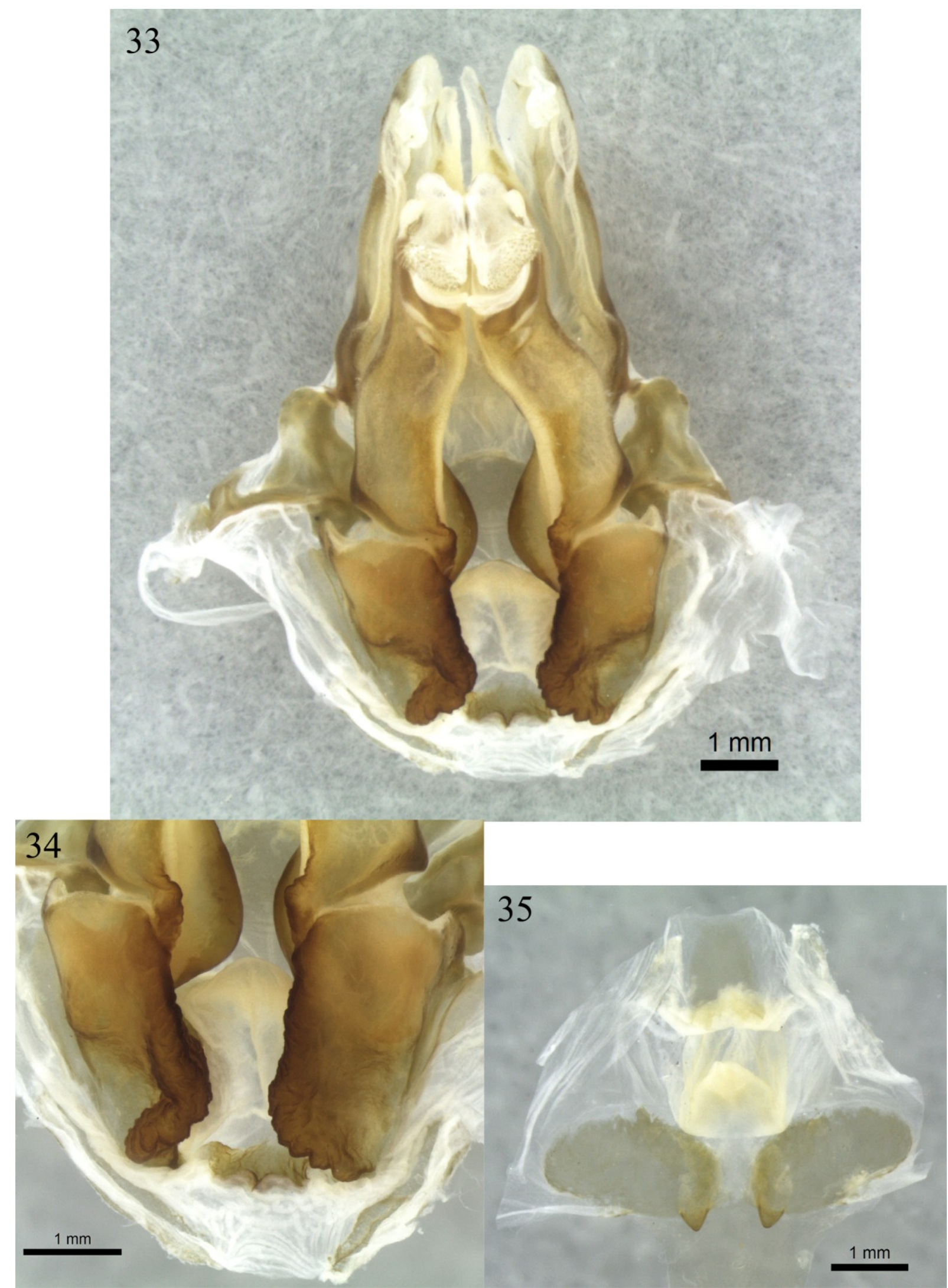

Figuras 33-35. Stagmatoptera binotata fêmea. 33, ovipositor, vista ventral; 34, detalhe das gonocoxas; 35, assoalho da câmara genital, vista dorsal. 
Stagmatoptera biocellata Saussure, 1869, p.67 (descr.); Saussure, 1870, p.231 (men.); Saussure, 1871b, p.96, t.1, f.13 (redesc.); Saussure, 1872, p.257 (men.); Westwood, 1889, p.16 (men.); Kirby, 1904, p.299 (men.); Rehn, 1911, p.12 (men.); Giglio-Tos, 1914, p.32 (redesc.); Giglio-Tos, 1927, p.598 (redesc.); Terra, 1995, p.64 (men.); Ehrmann, 2002, p.328 (men.); Agudelo et al., 2007, p.125 (men.); Ehrmann \& Koçak, 2009, p.11 (men.).

Tipo: uma fêmea, Brasil (examinada)

Redescrição: Macho - Figuras 36A, 37-48.

Antenômeros filiformes. Escudo frontal com duas elevações centrais (Fig. 37).

Protorax curto, largo, com margens dotadas de crenulação suave na prozona, lisas na metazona. Metazona com uma quilha central pouco desenvolvida (Fig. 38). Coxas anteriores com margem anterior crenulada dotada de 7 a 12 espinhos grandes e 1 a 8 espinhos menores (Fig. 39). Fêmures anteriores alongados e largos, com os três primeiros espinhos discoidais a partir da base, escuros em sua face interna; 15 a 17 espinhos internos, sendo o número mais frequente 15, o primeiro espinho interno a partir da base e os grandes espinhos internos são escuros na face interna. Mancha femoral interna estendendo-se da canaleta da garra tibial até o $10^{\circ}$ espinho interno a partir da base, com formato retangular e uma coloração preta fosca (Fig. 40). Tíbias anteriores dotadas de 10 a 13 espinhos externos, sendo mais frequente 12 espinhos, e 15 a 17 espinhos internos, sendo mais frequente 16 espinhos; a garra tibial é preta na face interna, uma mancha preta na metade da face interna (Fig. 41). Tarsos com manchas pretas apicais nas faces interna e externa dos tarsômeros I a IV.

Área discoidal das tégminas verde opaca em uma faixa anterior, passando gradualmente até hialina. Estigma circular de tamanho mediano, porém sem alcançar a metade da área discoidal, com o seguinte padrão: uma mancha branca anterior, uma mancha marrom posterior e no centro, entre as duas, uma pequena mancha semi-hialina. Asas com as áreas discoidal e anal totalmente hialinas ou com molduras amarelas nas veias transversais somente em suas metades anteriores (Fig. 36A).

Genitália: Falômero esquerdo, sem considerar o processo apical, tão longo quanto largo, esclerito L4B mais longo que largo. Processo apical curto; inclinado em relação à base, 
formando um ângulo de aproximadamente $45^{\circ}$ e depois curvando para a esquerda; ápice simples, voltado ventralmente (Fig. 42). Processo distal largo e curto, achatado, curvado bruscamente $90^{\circ}$ para a direita, comprimido em dois pontos, um após a curvatura, e outro na base do ápice; este bem esclerosado e afilado (Fig. 43). Apófise falóide longa e inclinada em relação à genitália (Fig. 44); margem direita rugosa e sinuosa (Fig. 45); ápice posterior intumescido com uma projeção na margem direita, rugoso e esclerosado; ápice anterior reto, margens bem esclerosadas, e intumescidas, formando uma canaleta (Fig. 44). Lobo membranoso curto, curvado para a direita (Fig. 44). Membrana adjacente à apófise falóide pilosa (Fig. 44).

Falômero direito com ápice posterior arredondado; braço médio curto, com uma expansão suave na metade, formando uma elevação (Fig. 46); placa ventral curta, fortemente esclerosada (Fig. 47 e 48); processo ventral curto, fortemente esclerosado, ápice assimétrico, arredondado em um lado e anguloso no outro (Fig. 47); apódema anterior longo, passando bruscamente a um ápice arredondado (Fig. 47).

Fêmea - Figuras 36B, 49-56.

Escudo frontal com duas elevações centrais (Fig. 49).

Protorax curto, largo, com margens dotadas de crenulação suave. Metazona com uma quilha central pouco desenvolvida (Fig. 50). Coxas anteriores com margem anterior crenulada dotada de 7 a 10 espinhos grandes e 2 a 9 espinhos menores (Fig. 51). Fêmures anteriores alongados e largos, com os três primeiros espinhos discoidais a partir da base escuros em sua face interna; 15 a 16 espinhos internos, sendo o número mais frequente 15, o primeiro espinho interno a partir da base e os grandes espinhos internos são escuros na face interna. Mancha femoral interna estendendo-se da canaleta da garra tibial até o $10^{\circ}$ espinho interno a partir da base, com formato retangular e uma coloração preta fosca (Fig. 52). Tíbias anteriores dotadas de 11 a 14 espinhos externos, sendo mais frequente 12 espinhos, e 14 a 17 espinhos internos, sendo mais frequente 16 espinhos; a garra tibial verde na face interna, uma mancha preta na metade da face interna (Fig. 53). Tarsos com manchas pretas apicais nas faces interna e externa dos tarsômeros I a IV.

Estigma circular de tamanho mediano, porém sem alcançar a metade da área discoidal, com o seguinte padrão: uma mancha branca anterior e uma mancha marrom 
posterior. Asas com área costal hialina e as áreas discoidal e anal com molduras amarelas nas veias transversais (Fig. 36B).

Genitália: Base das gonapófises VIII sem se projetar internamente (Fig. 54). Basiválvula com formato aproximadamente triangular (Fig. 54), a superfície interna esculpida (Fig. 55). Interbasiválvula fortemente esclerosada e esculpida (Fig. 55). Extensões posterolaterias curtas, fracamente esclerosadas com margens irregulares (Fig. 55). Esclerito na parede dorsal da papila genital fracamente esclerosado, liso (Fig.56). Plataforma lateroesternal aproximadamente triangular, processos posteriores curtos, cônicos (Fig. 56).

Localidade tipo: Brasil

Outras localidades: Colômbia, Venezuela.

Diagnose: Protorax largo e curto, mancha femoral interna se estendendo até o $10^{\circ}$ espinho.

Tabela 2. Medidas e razões de machos e fêmeas de Stagmatoptera biocellata.

\begin{tabular}{|c|c|c|}
\hline & Macho $(\mathrm{N}=12)$ & Fêmea $(\mathrm{N}=7)$ \\
\hline Comprimento & 61,3 a $72 \mathrm{~mm}$ & 72,9 a $91,5 \mathrm{~mm}$ \\
\hline Largura da cabeça & 7 a $8,2 \mathrm{~mm}$ & 9,6 a $10,7 \mathrm{~mm}$ \\
\hline Comprimento da Prozona & 4,6 a $5,6 \mathrm{~mm}$ & 6,6 a $7,6 \mathrm{~mm}$ \\
\hline Comprimento da Metazona & 16,5 a $19,6 \mathrm{~mm}$ & 22,1 a $26,5 \mathrm{~mm}$ \\
\hline Largura da Dilatação & 5 a $6,3 \mathrm{~mm}$ & 8,4 a $9,9 \mathrm{~mm}$ \\
\hline Comprimento da Tégmina & 45,1 a $54,3 \mathrm{~mm}$ & 44,6 a $51,6 \mathrm{~mm}$ \\
\hline Comprimento da Asa & 41,4 a $50,2 \mathrm{~mm}$ & 38,7 a $46,3 \mathrm{~mm}$ \\
\hline Comprimento da Coxa Anterior & 11,4 a $14,8 \mathrm{~mm}$ & 17,2 a $21,2 \mathrm{~mm}$ \\
\hline Comprimento do Fêmur Anterior & 14,2 a $17,8 \mathrm{~mm}$ & 21,4 a $24,4 \mathrm{~mm}$ \\
\hline Largura do Fêmur Anterior & 3,3 a $4,1 \mathrm{~mm}$ & 5,3 a $6,3 \mathrm{~mm}$ \\
\hline Comprimento da Tíbia Anterior & 7,3 a $9,9 \mathrm{~mm}$ & 11,1 a $13,8 \mathrm{~mm}$ \\
\hline Razão Cabeça/Dilatação & 1,28 a 1,44 & 1,06 a 1,18 \\
\hline Razão Metazona/Prozona & 3,33 a 4 & 3,19 a 3,49 \\
\hline Razão Prozona/Dilatação & 0,8 a 0,98 & 0,76 a 0,86 \\
\hline Razão Metazona/Dilatação & 3,11 a 3,37 & 2,55 a 2,82 \\
\hline Razão Metazona/Coxa Anterior & 1,3 a 1,49 & 1,23 a 1,31 \\
\hline Razão Comprimento/Largura & 4,17 a 4,7 & 3,87 a 4,33 \\
\hline Fêmur Anterior & 1,8 a 2,02 & 1,77 a 2,02 \\
\hline Razão Fêmur/Tíbia & & \\
\hline
\end{tabular}


Material examinado: América Meridional; Holótipo, Anc. Cozz., 19 (MHNG). Colômbia; Llanos del Meta, 250m, iii.1958, A. Balachowsky, $2 \widehat{\jmath}$ (MNHN). Venezuela; San Casimiro, Hazienda El Nigrito, [Aragua], Klaebisch S.G., $1 \delta^{\Uparrow}$ (ZMB). sem localidade, 1899, F. Geay, 19 (MNHN). San Fernando de Apure, Apure, viii.1923, Mayeul Grisol, 3§1ㅇ (MNHN). Maracay, coll. P. Vogl, $3 \jmath^{\Uparrow}$ (ZSM). Maracay, v.1934, coll. P. Vogl, $1{ }^{\Uparrow} 1 q$ (ZSM). Maracay, vii.1934, coll. P. Vogl, $1 \overbrace{}^{\Uparrow}$ (ZSM). Maracay, i-ii.1935, coll. P. Vogl, 1 q (ZSM). Maracay, v.1936, coll. P. Vogl, $1{ }^{\Uparrow} 1 q(\mathrm{ZSM})$. 

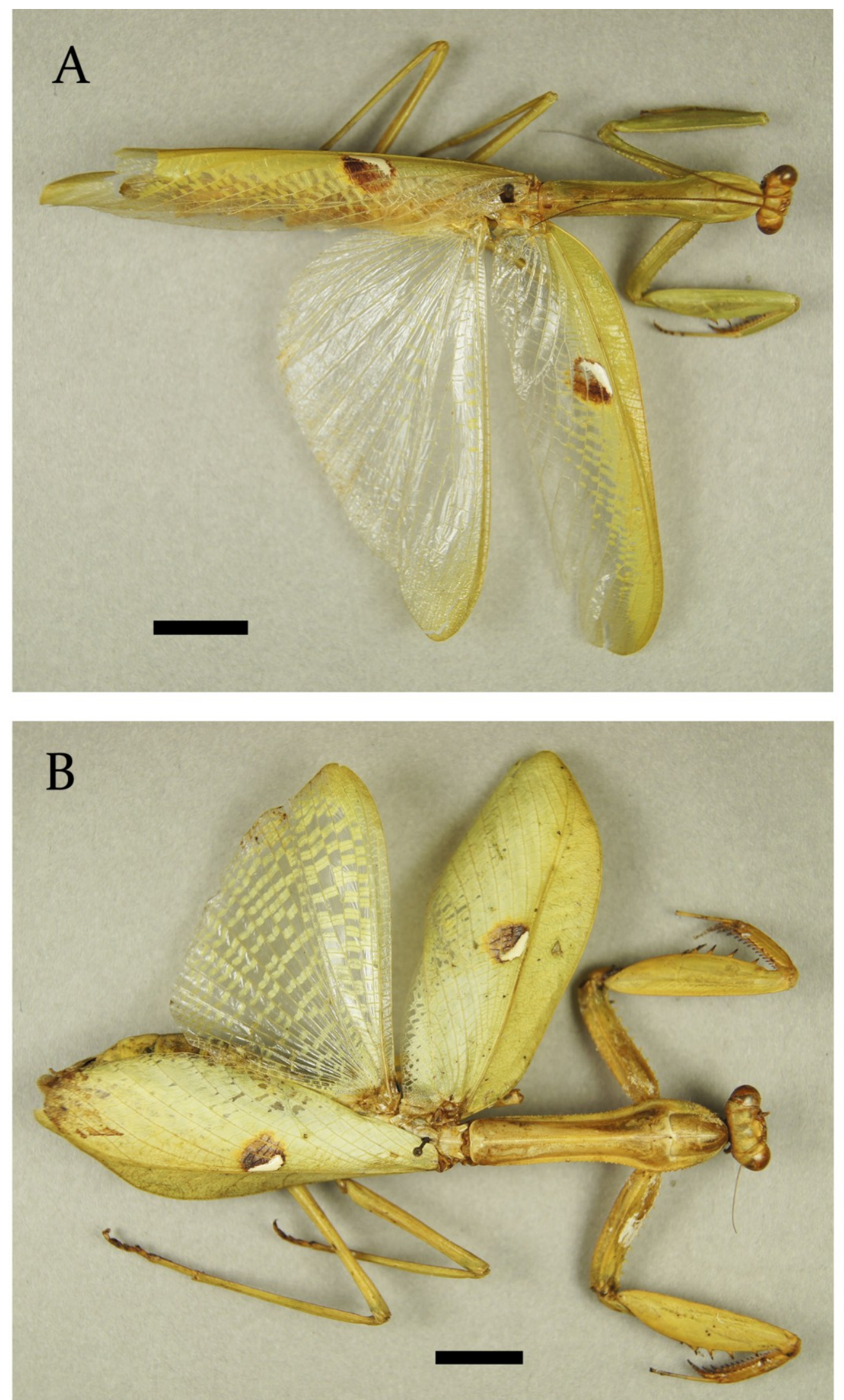

Figura 36. Stagmatoptera biocellata, habitus dorsal: A, macho; B, fêmea. Escalas $=1 \mathrm{~cm}$. 


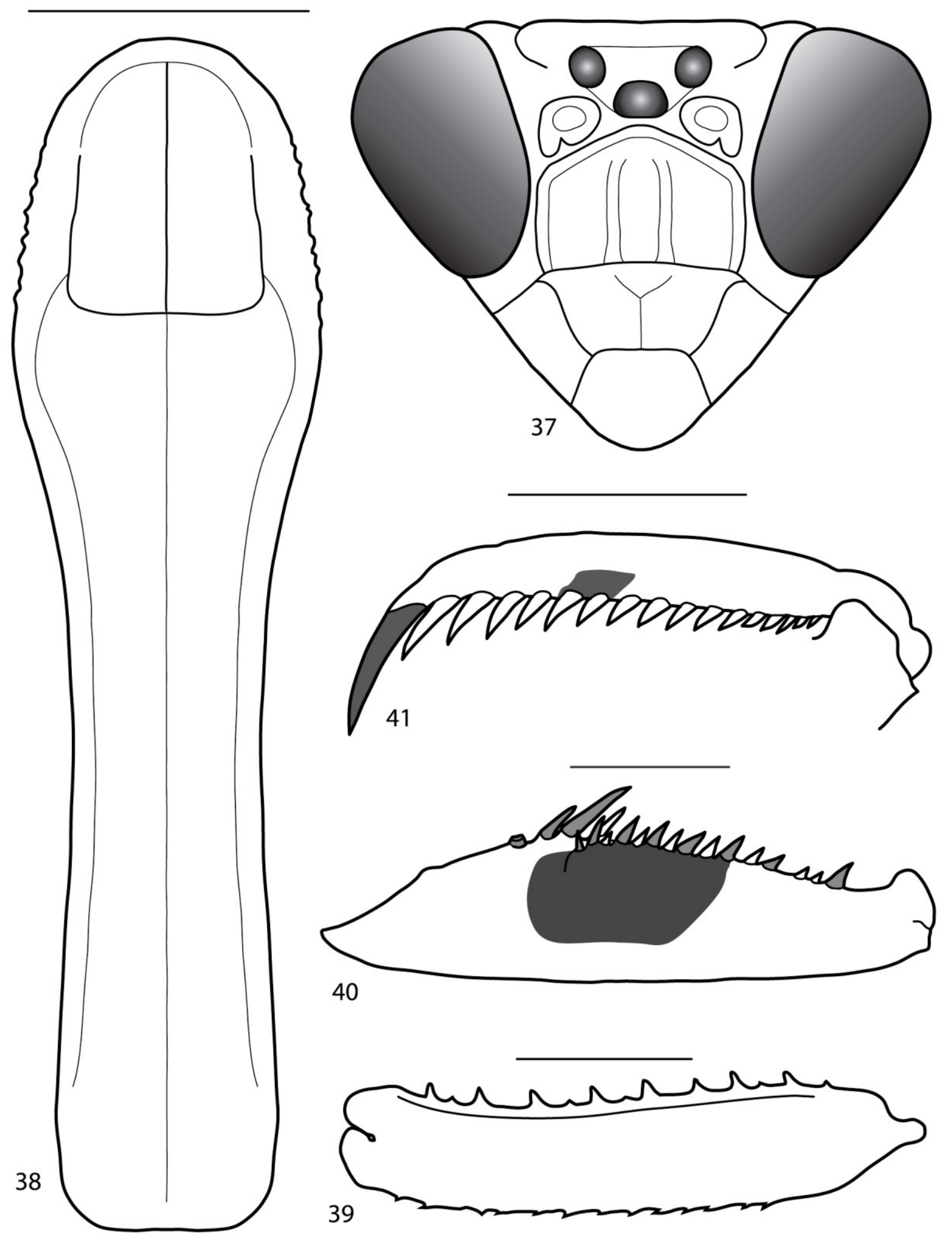

Figuras 37-41. Stagmatoptera biocellata macho. 37, cabeça, vista frontal; 38, protorax, vista dorsal; 39, coxa anterior, vista interna; 40, fêmur anterior, vista interna; 41, tíbia anterior, vista interna. Escalas $=5 \mathrm{~mm}$. 


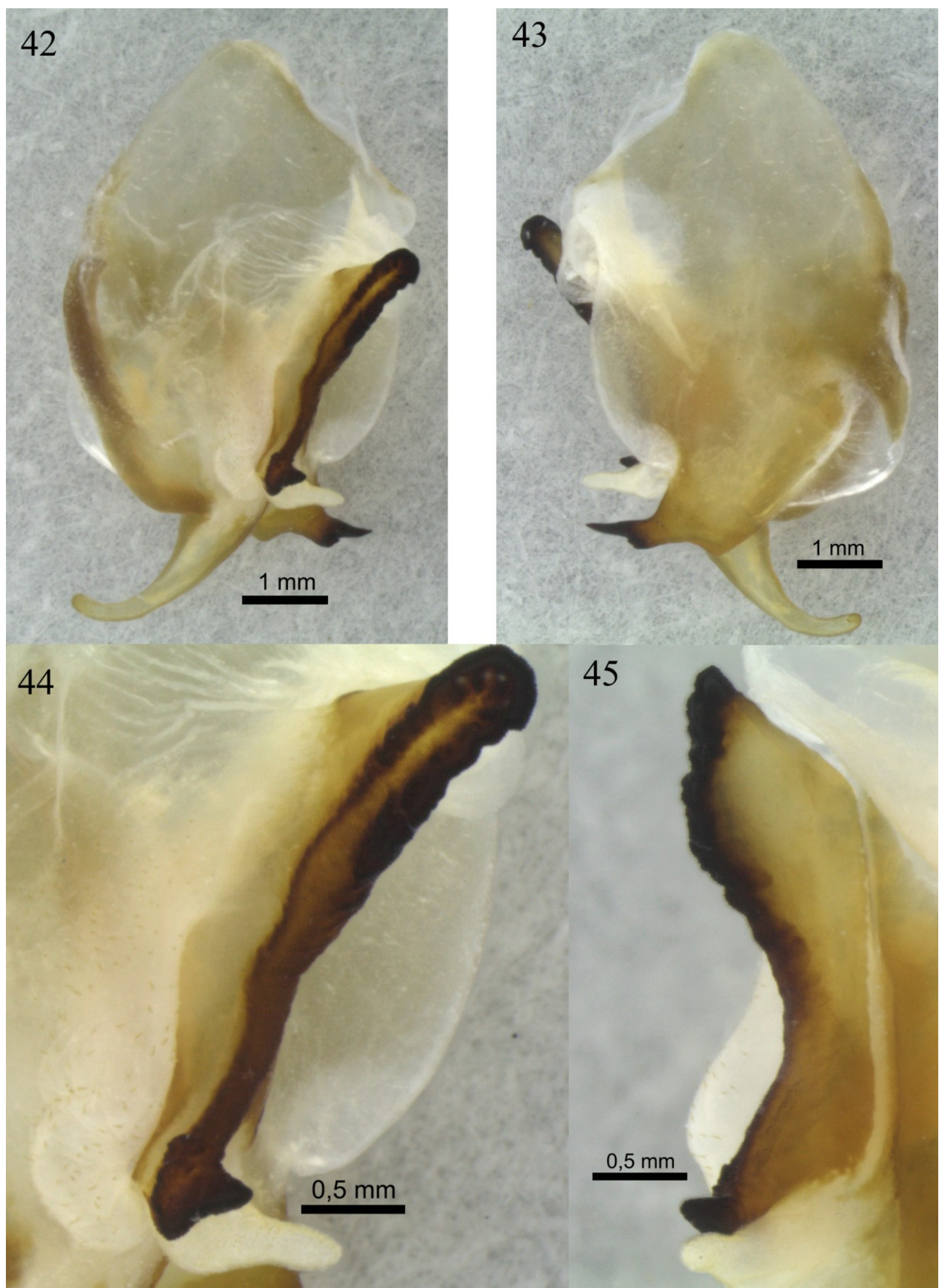

Figuras 42-45. Stagmatoptera biocellata macho. 42, falômero esquerdo, vista dorsal; 43, falômero esquerdo, vista ventral; 44, apófise falóide e lobo membranoso, vista dorsal; 45, apófise falóide, vista lateral direita. 

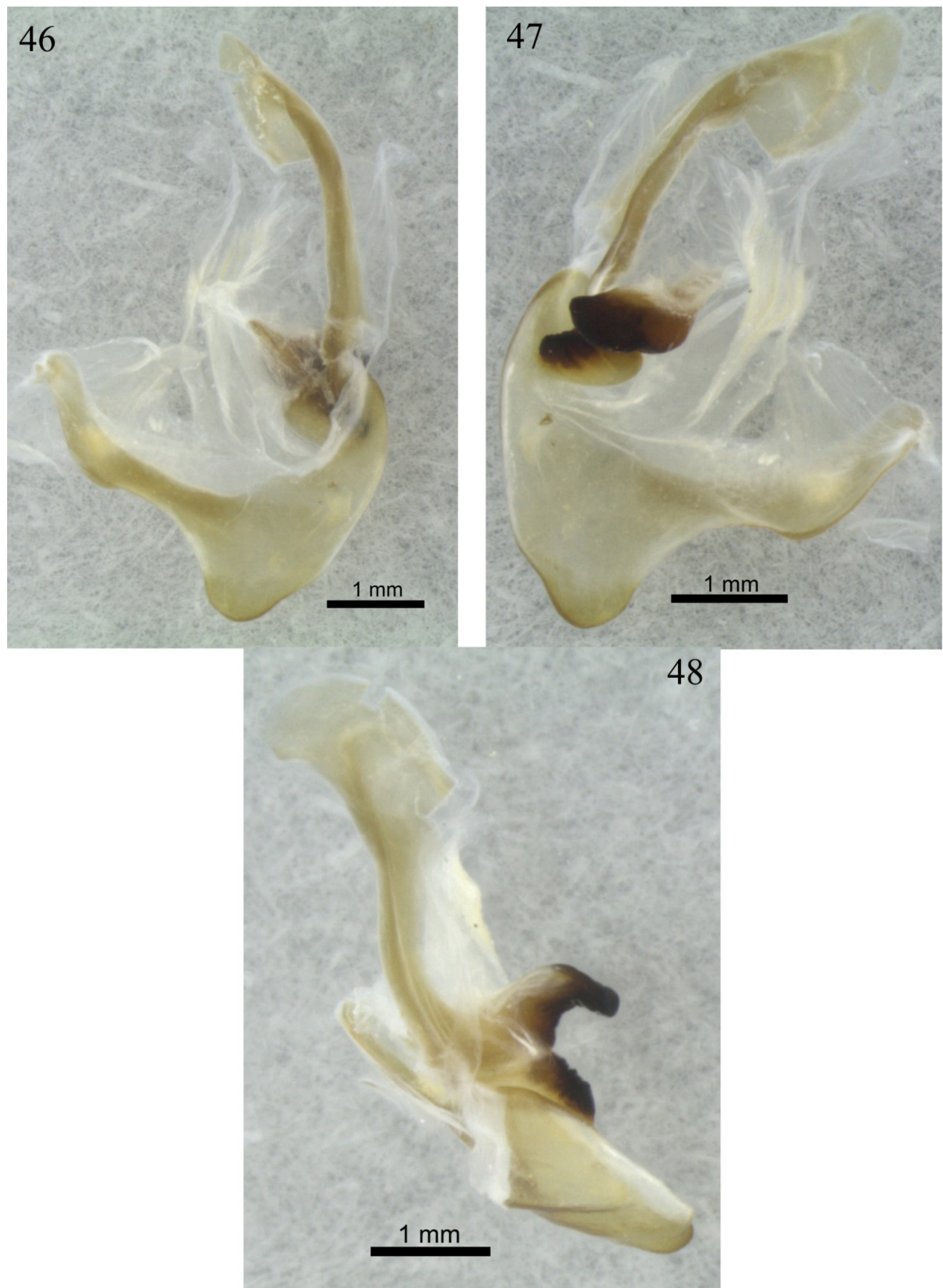

Figuras 46-48. Stagmatoptera biocellata macho. 46, falômero direito, vista dorsal; 47, falômero direito, vista ventral; 48 , falômero direito, vista lateral direita. 


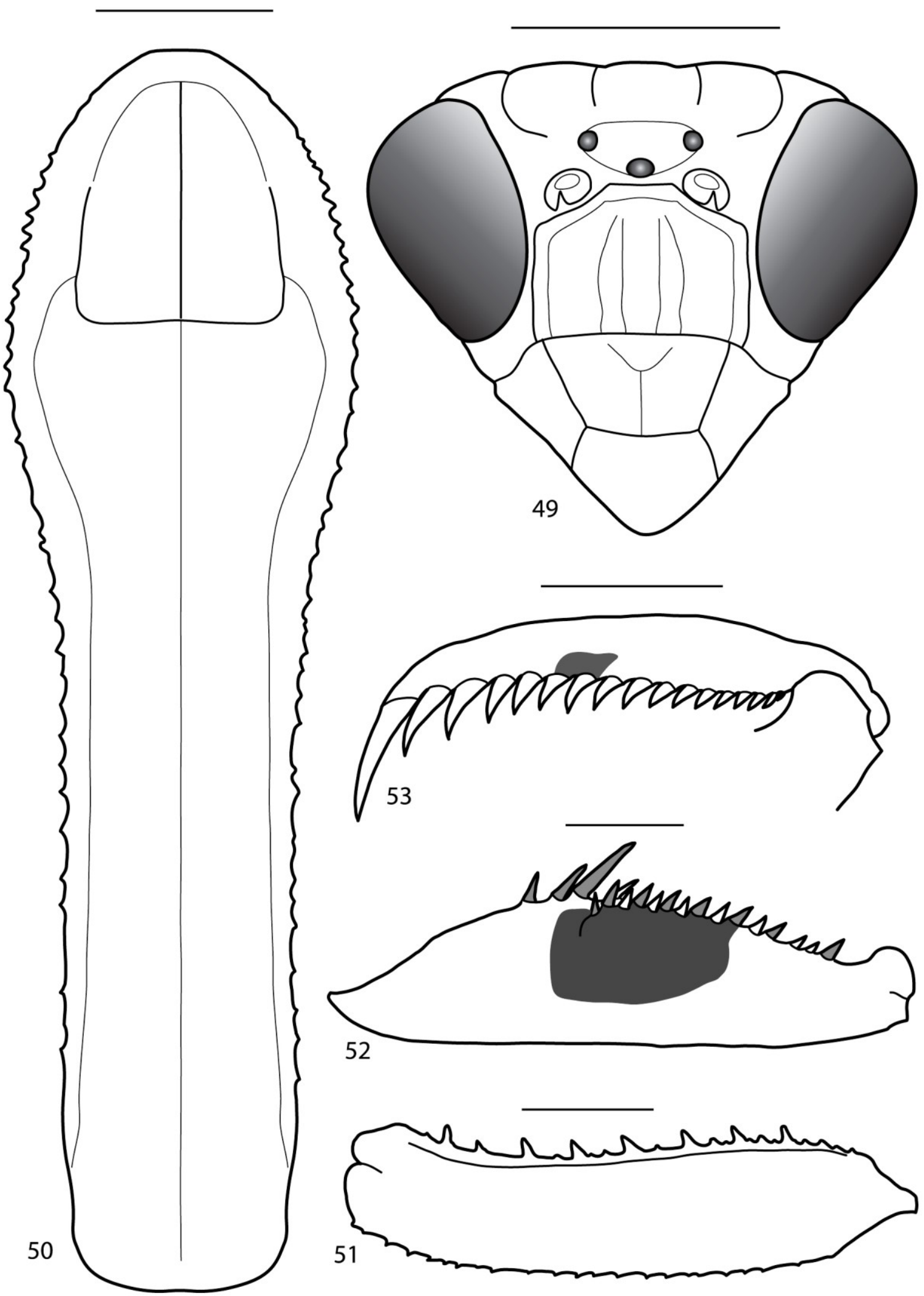

Figuras 49-53. Stagmatoptera biocellata fêmea. 49, cabeça, vista frontal; 50, protorax, vista dorsal; 51, coxa anterior, vista interna; 52, fêmur anterior, vista interna; 53, tíbia anterior, vista interna. Escalas $=5 \mathrm{~mm}$. 


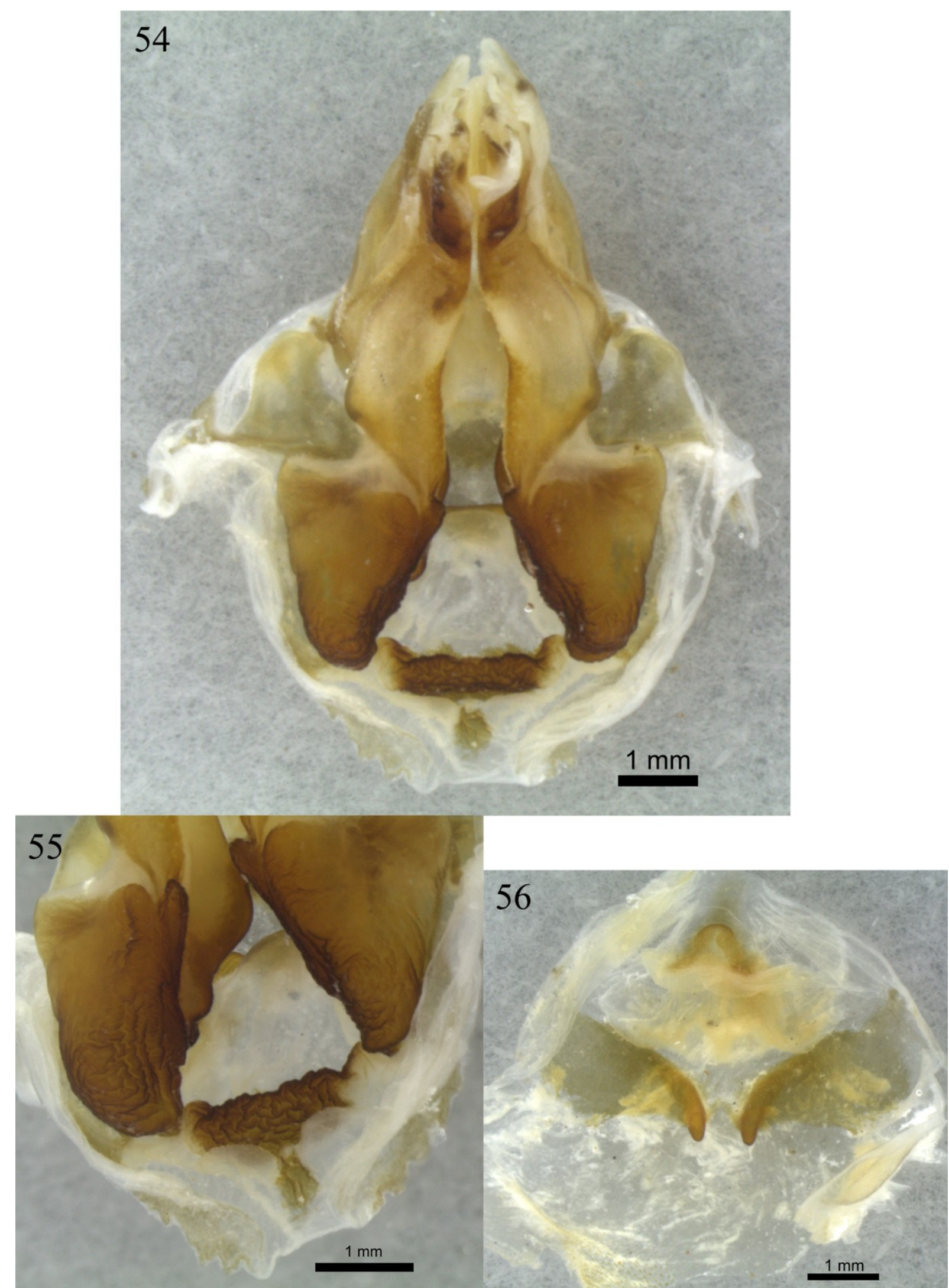

Figuras 54-56. Stagmatoptera biocellata fêmea. 54, ovipositor, vista ventral; 55, detalhe das gonocoxas; 56, assoalho da câmara genital, vista dorsal. 
Stagmatoptera femoralis Saussure \& Zehntner, 1894

Stagmatoptera femoralis Saussure \& Zehntner, 1894, p.187 (descr.); Kirby, 1904, p.301 (men.); Rehn, 1911, p.13 (men.); Giglio-Tos, 1914, p.30 (redesc.); Werner, 1925a, p.167; Giglio-Tos, 1927, p.597 (redesc.); Terra, 1995, p.64 (men.); Ehrmann, 1999, p.11 (redesc.); Ehrmann, 2002, p.328 (men.); Agudelo et al., 2007, p.125 (men.); Ehrmann \& Koçak, 2009, p.12 (men.).

Tipo: três fêmeas e três machos, Caiena, Guiana Francesa (examinados)

= Stagmatoptera femoralis var. africana Giglio-Tos, 1914, p.31 (descr.); Giglio-Tos, 1927, p.597 (redesc.); Ehrmann, 1999, p.11 (sin.).

Tipo: uma fêmea, Tanga, D. O. Africa.

= Stagmatoptera ignota syn. nov. Giglio-Tos, 1914, p.32 (descr.); Giglio-Tos, 1927, p.598 (redesc.); Terra, 1995, p.64 (men.); Ehrmann, 2002, p.329 (men.); Agudelo et al., 2007, p.125 (men.); Ehrmann \& Koçak, 2009, p.12 (men.).

Tipo: uma fêmea, sem localidade (examinada)

Redescrição: Macho - Figuras 57A, 58-69.

Antenômeros filiformes. Escudo frontal com duas elevações centrais (Fig. 58).

Protorax alongado, delgado, com margens dotadas de crenulação suave na prozona, lisas na metazona. Metazona com uma quilha central pouco desenvolvida (Fig.59). Coxas anteriores com margem anterior crenulada dotada de 7 a 11 espinhos grandes e 2 a 10 espinhos menores (Fig.60). Fêmures anteriores alongados e largos, com os três primeiros espinhos discoidais a partir da base, escuros em sua face interna; 13 a 16 espinhos internos, sendo o número mais frequente 15 , o primeiro espinho interno a partir da base e os grandes espinhos internos são escuros na face interna, podendo apresentar uma pequena mancha de mesma coloração na inserção dos espinhos 10 e 12. Mancha femoral interna estendendo-se da canaleta da garra tibial até o $8^{\circ}$ espinho interno a partir da base, com formato retangular e uma coloração preta fosca na base dos espinhos e suave no restante, ou totalmente suave (Fig. 61). Tíbias anteriores dotadas de 10 a 12 espinhos externos, sendo mais frequente 11 espinhos, e 15 a 16 espinhos internos; a garra tibial é preta na face interna, uma mancha preta suave na 
metade da face interna (Fig. 62). Tarsos com manchas pretas apicais na face interna dos tarsômeros I a IV e uma mancha basal interna no tarsômero I.

Área discoidal das tégminas verde opaca em uma faixa anterior, passando gradualmente para hialina. Estigma alongado e pequeno, com o seguinte padrão: uma mancha branca anterior, uma mancha marrom posterior. Asas com as áreas discoidal e anal totalmente hialinas ou com uma fileira de molduras amarelas nas veias transversais na área discoidal (Fig. $57 \mathrm{~A})$.

Genitália: Falômero esquerdo mais longo que largo, esclerito L4B tão longo quanto largo. Processo apical longo, levemente dilatado no lado esquerdo de sua base; inclinado em relação à base, formando um ângulo de aproximadamente $45^{\circ}$, e depois curvando para a esquerda; ápice simples, voltado ventralmente (Fig. 63). Processo distal estreito e curto, achatado, curvado bruscamente $90^{\circ}$ para a direita, ápice bem esclerosado e afilado (Fig. 64). Apófise falóide longa e paralela em relação à genitália (Fig. 65); margem direita lisa e levemente sinuosa (Fig. 66); ápice posterior intumescido sem projeções, rugoso e fortemente esclerosado; ápice anterior reto, margens bem esclerosadas, e intumescidas, porém sem formar uma canaleta (Fig. 65). Lobo membranoso curto, curvado para a direita (Fig. 65). Membrana adjacente à apófise falóide glabra (Fig. 65).

Falômero direito com ápice posterior arredondado; braço médio curto, com uma expansão na metade, formando uma elevação (Fig. 67); placa ventral longa, fracamente esclerosada (Fig. 68 e 69); processo ventral curto, fortemente esclerosado, ápice retangular (Fig. 68); apódema anterior longo, passando bruscamente a um ápice arredondado (Fig. 67 e 68).

Fêmea - Figuras 57B, 70-77.

Escudo frontal com duas elevações centrais (Fig. 70).

Protorax alongado, delgado, com margens dotadas de crenulação suave. Metazona com uma quilha central pouco desenvolvida (Fig. 71). Coxas anteriores com margem anterior crenulada dotada de 7 a 14 espinhos grandes e 4 a 8 espinhos menores (Fig. 72). Fêmures anteriores alongados e largos, com os três primeiros espinhos discoidais a partir da base escuros em sua face interna; 15 a 17 espinhos internos, sendo o número mais frequente 15 , o primeiro espinho interno a partir da base e os grandes espinhos internos são escuros na face 
interna, podendo apresentar uma pequena mancha de mesma coloração na inserção dos espinhos 10 e 12 . Mancha femoral interna estendendo-se da canaleta da garra tibial até o $8^{\circ}$ espinho interno a partir da base, com formato retangular e uma coloração preta suave (Fig. 73). Tíbias anteriores dotadas de 10 a 12 espinhos externos, sendo mais frequente 11 espinhos, e 14 a 17 espinhos internos, sendo mais frequente 16 espinhos; a garra tibial verde na face interna, uma mancha preta suave na metade da face interna pode ou não estar presente (Fig. 74). Tarsos com manchas pretas apicais na face interna dos tarsômeros I a IV e uma mancha basal interna no tarsômero I.

Estigma circular de tamanho mediano, porém sem alcançar a metade da área discoidal, com o seguinte padrão: uma mancha branca anterior e uma mancha marrom posterior. Asas com área costal hialina e as áreas discoidal e anal com molduras amarelas nas veias transversais (Fig. 57B).

Genitália: Base das gonapófises VIII sem se projetar internamente (Fig. 75). Basiválvula com formato aproximadamente triangular, o ápice anterior expandido (Fig. 75), a superfície interna esculpida (Fig. 76). Interbasiválvula fortemente esclerosada e esculpida (Fig. 76). Extensões posterolaterias curtas, fracamente esclerosadas com margens lisas (Fig. 76). Esclerito na parede dorsal da papila genital esclerosado, liso (Fig. 77). Plataforma lateroesternal aproximadamente retangular, processos posteriores longos, cônicos (Fig. 77).

Localidade tipo: Caiena, Guiana Francesa.

Outras localidades: Brasil, Colômbia, Paraguai [?], Suriname.

Diagnose: Mancha femoral interna se estendendo até o $8^{\circ}$ espinho, mancha estigmar dos machos alongada, não circular, das fêmeas circular, manchas apicais dos tarsos apenas na face interna. 
Tabela 3. Medidas e razões de machos e fêmeas de Stagmatoptera femoralis.

\begin{tabular}{|c|c|c|}
\hline & Macho $(\mathrm{N}=12)$ & Fêmea $(\mathrm{N}=15)$ \\
\hline Comprimento & 66,2 a $77,2 \mathrm{~mm}$ & 74 a $98,7 \mathrm{~mm}$ \\
\hline Largura da cabeça & 7,1 a $7,6 \mathrm{~mm}$ & 9 a $9,9 \mathrm{~mm}$ \\
\hline Comprimento da Prozona & 4,2 a $5 \mathrm{~mm}$ & 5,9 a $7,3 \mathrm{~mm}$ \\
\hline Comprimento da Metazona & 18,1 a $20,8 \mathrm{~mm}$ & 23,8 a $28,4 \mathrm{~mm}$ \\
\hline Largura da Dilatação & 4,6 a $5,4 \mathrm{~mm}$ & 7,2 a $8,5 \mathrm{~mm}$ \\
\hline Comprimento da Tégmina & 44,4 a $52,4 \mathrm{~mm}$ & 44 a $51,8 \mathrm{~mm}$ \\
\hline Comprimento da Asa & 44,6 a $46,7 \mathrm{~mm}$ & 38,9 a $45,1 \mathrm{~mm}$ \\
\hline Comprimento da Coxa Anterior & 12 a $14,6 \mathrm{~mm}$ & 17,1 a $20,9 \mathrm{~mm}$ \\
\hline Comprimento do Fêmur Anterior & 14,1 a $16,3 \mathrm{~mm}$ & 19,9 a $24 \mathrm{~mm}$ \\
\hline Largura do Fêmur Anterior & 3 a 3,5 mm & 4,5 a $5,4 \mathrm{~mm}$ \\
\hline Comprimento da Tíbia Anterior & 6,5 a $8,5 \mathrm{~mm}$ & 9,7 a $11,8 \mathrm{~mm}$ \\
\hline Razão Cabeça/Dilatação & 1,37 a 1,61 & 1,16 a 1,28 \\
\hline Razão Metazona/Prozona & 4 a 4,64 & 3,73 a 4,1 \\
\hline Razão Prozona/Dilatação & 0,87 a 1 & 0,81 a 0,93 \\
\hline Razão Metazona/Dilatação & 3,7 a 4,15 & 3,18 a 3,53 \\
\hline Razão Metazona/Coxa Anterior & $1,371,61$ & 1,29 a 1,47 \\
\hline Razão Comprimento/Largura & 4,11 a 5,23 & 4,09 a 5,22 \\
\hline Fêmur Anterior & 1,88 a 2,26 & 1,95 a 2,13 \\
\hline Razão Fêmur/Tíbia & \multicolumn{2}{|c}{} \\
\hline
\end{tabular}

Material examinado: Brasil; coll. Br. v. W., $1 q$ (NHMW). S. indicator, $2 q$ (ZMB). Colômbia; La Guadalupe, 1900, 19 (MNHN). Guiana Francesa; Cayenne, Sintipos de Stagmatoptera femoralis, M. Prudhomme, $2{ }^{\lambda} 3 \uparrow$ (MHNG). Herr, $2{ }^{\AA}$ (MHNG). S. indicator, $19(\mathrm{MNHN})$. S. indicator, Leprieur, $19(\mathrm{MNHN})$. Cayenne, M. H. de Saussure, $1 \overbrace{}^{\Uparrow}(\mathrm{MHNG})$. Cayenne, x.1954, Broche, $19(\mathrm{MNHN})$. Cayenne, 2.xi.1975, M. Condamin rec., $1{ }^{\Uparrow}(\mathrm{MNHN})$. Montjoly, 8.vi.1983, piège lumineux, Orstom, $1 \widehat{\jmath}(\mathrm{MNHN})$. Nouveau Chantier, ii.sem ano, 1 q $(\mathrm{MNHN})$. St Laurent du Maroni, ii.sem ano, $1 \widehat{\jmath}(\mathrm{MNHN})$. 1985, S. Boucher, $1 \widehat{\jmath}$ (MNHN). 1967, coll. Br. v. W., 19 (NHMW). Paraguai; S[?] Bernardino, coll. Br. v. W., 1 q (NHMW). Suriname; sem localidade, 1ð̋ (ZSM). Paramaribo, 28.xii.1939, Geijskes, 1 q (MZSP). Paramaribo, coll. Br. v. W., $2 \hat{\jmath}$ (NHMW). coll. Br. v. W., 1 q (NHMW). Paramaribo,

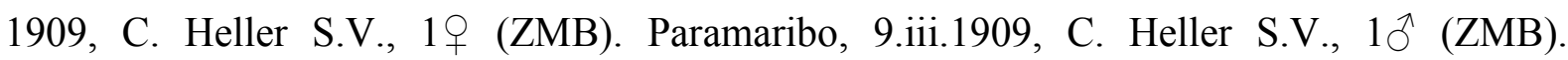
Paramaribo, vii.1908, Heller S.V., $2 \bigcirc^{\Uparrow}$ (ZMB). Sem localidade; Holótipo de Stagmatoptera ignota $1 q$ (MRSN). 2 q (MNHN). $1 q$ (ZSM). 

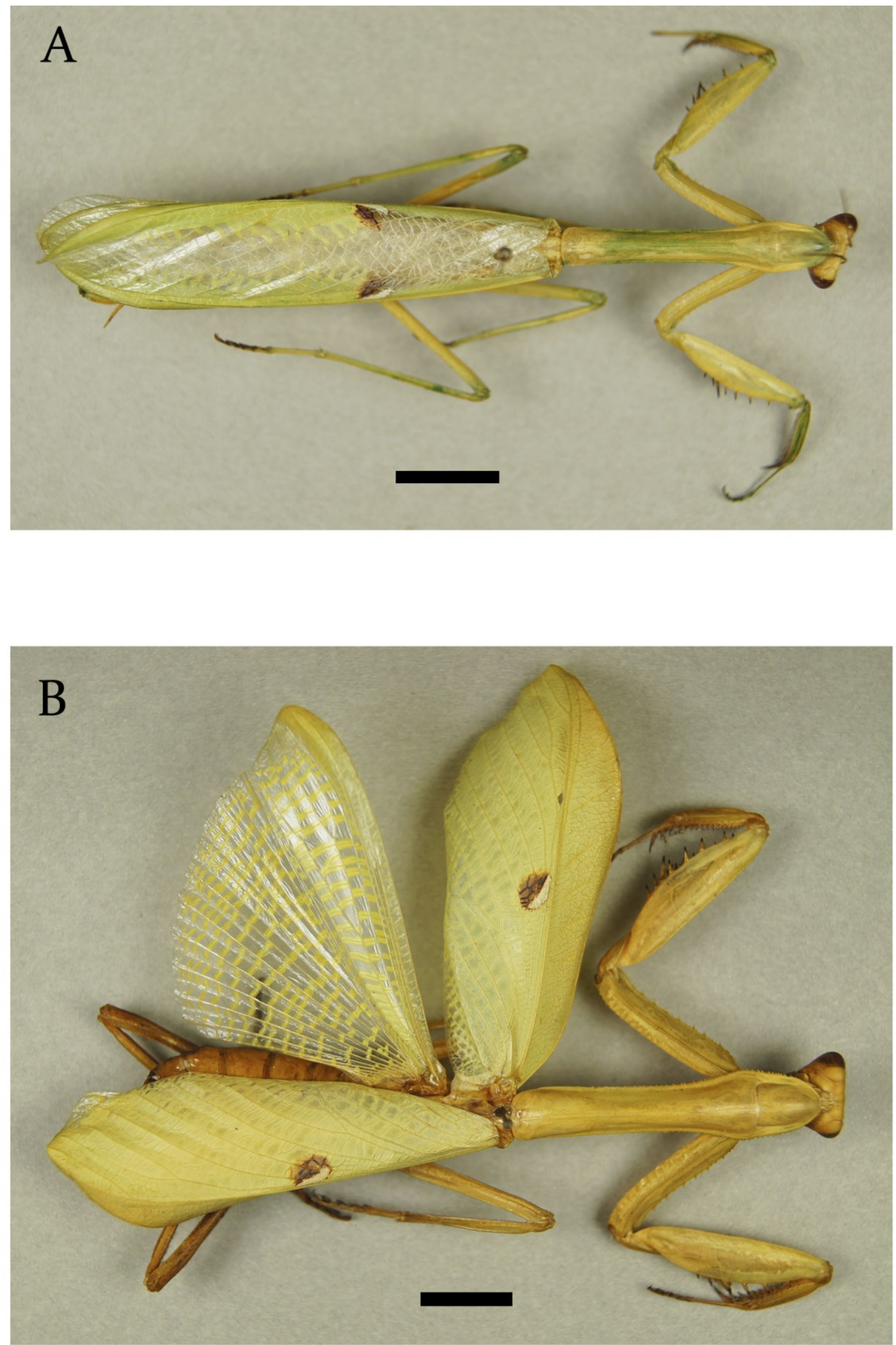

Figura 57. Stagmatoptera femoralis, habitus dorsal. A, macho; B, fêmea. Escalas $=1 \mathrm{~cm}$. 


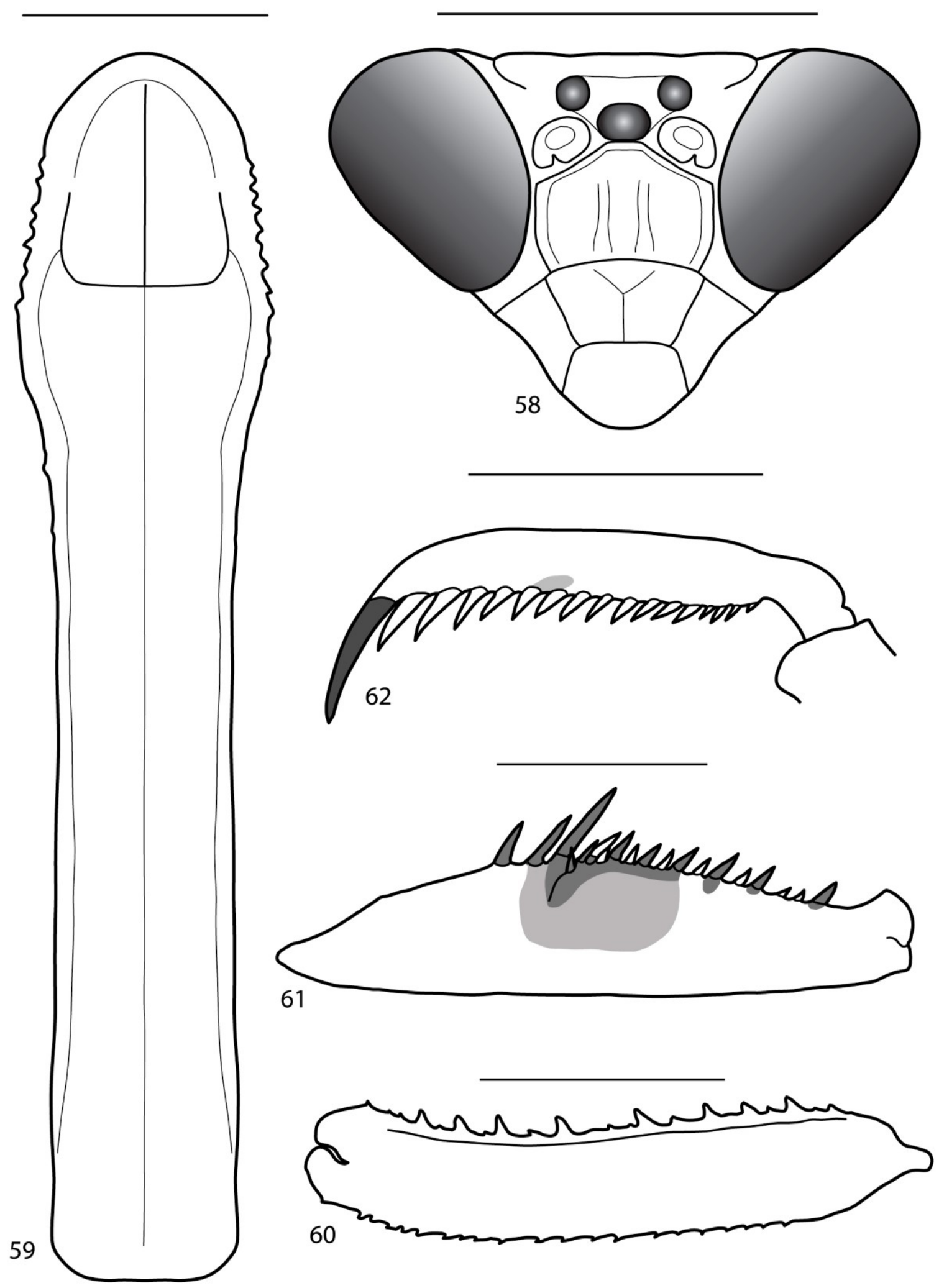

Figuras 58-62. Stagmatoptera femoralis macho. 58, cabeça, vista frontal; 59, protorax, vista dorsal; 60, coxa anterior, vista interna; 61, fêmur anterior, vista interna; 62, tíbia anterior, vista interna. Escalas $=5 \mathrm{~mm}$. 

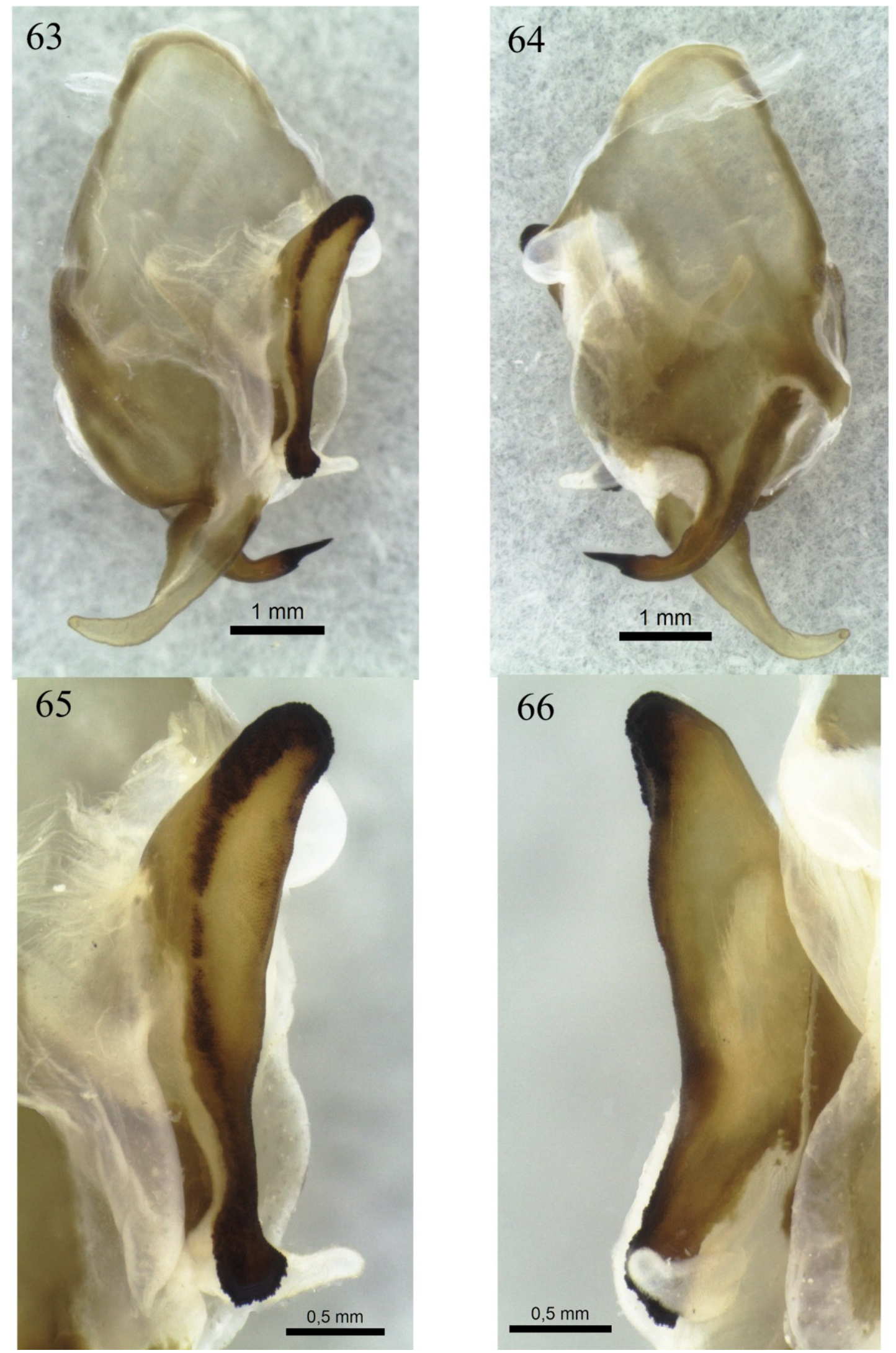

Figuras 63-66. Stagmatoptera femoralis macho. 63, falômero esquerdo, vista dorsal; 64, falômero esquerdo, vista ventral; 65, apófise falóide e lobo membranoso, vista dorsal; 66, apófise falóide, vista lateral direita. 


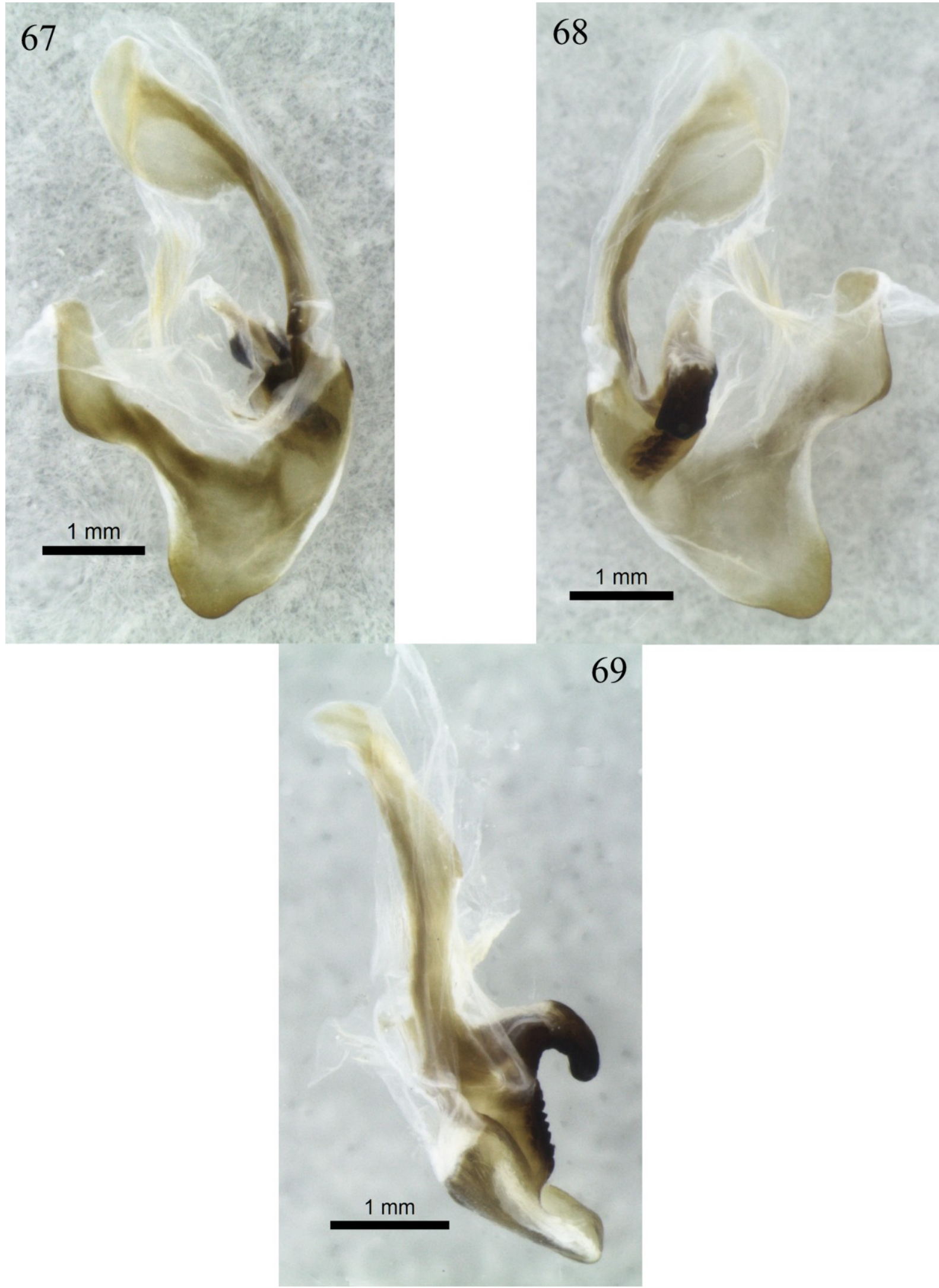

Figuras 67-69. Stagmatoptera femoralis macho. 67, falômero direito, vista dorsal; 68, falômero direito, vista ventral; 69, falômero direito, vista lateral direita. 


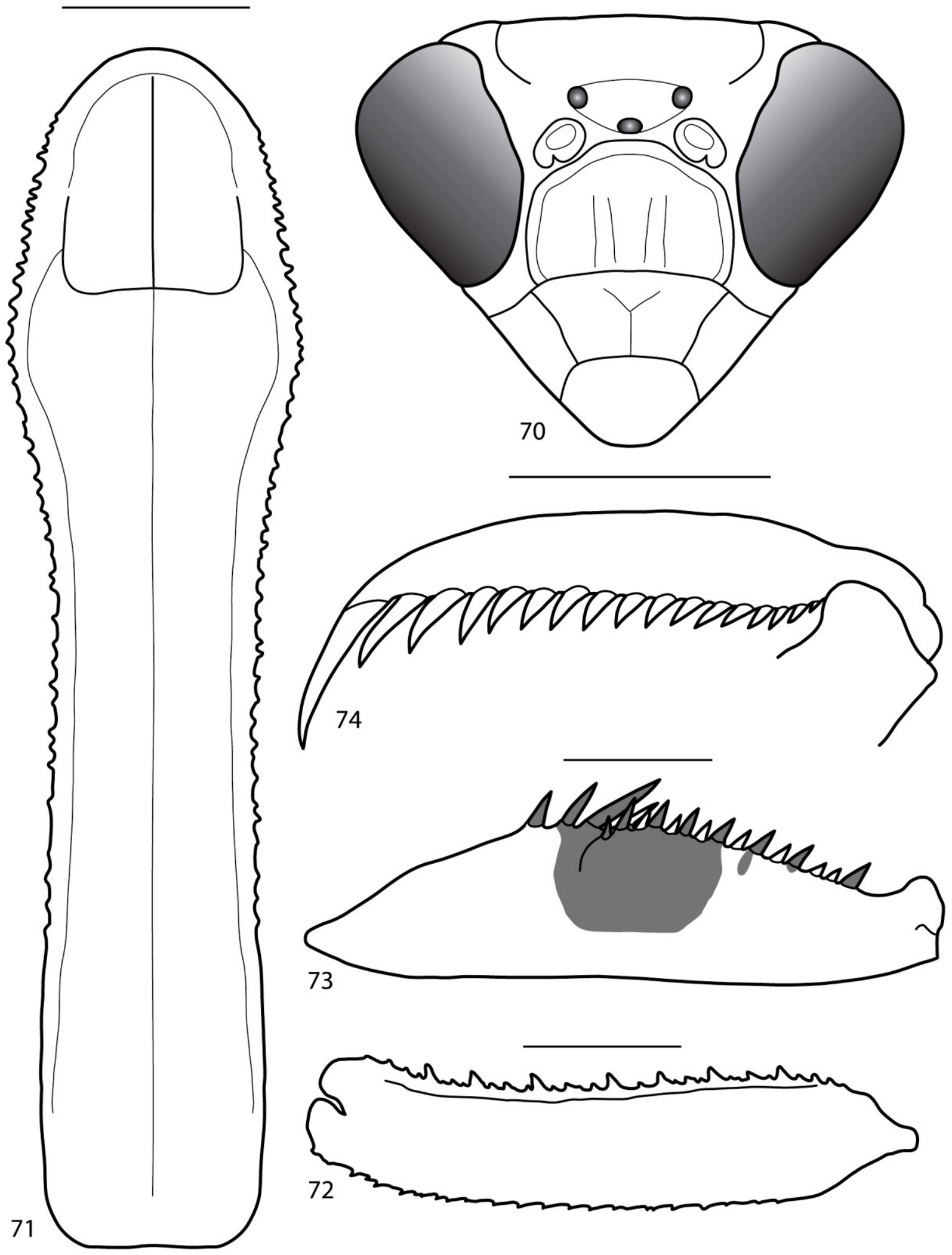

Figuras 70-74. Stagmatoptera femoralis fêmea. 70, cabeça, vista frontal; 71, protorax, vista dorsal; 72, coxa anterior, vista interna; 73, fêmur anterior, vista interna; 74, tíbia anterior, vista interna. Escalas $=5 \mathrm{~mm}$. 


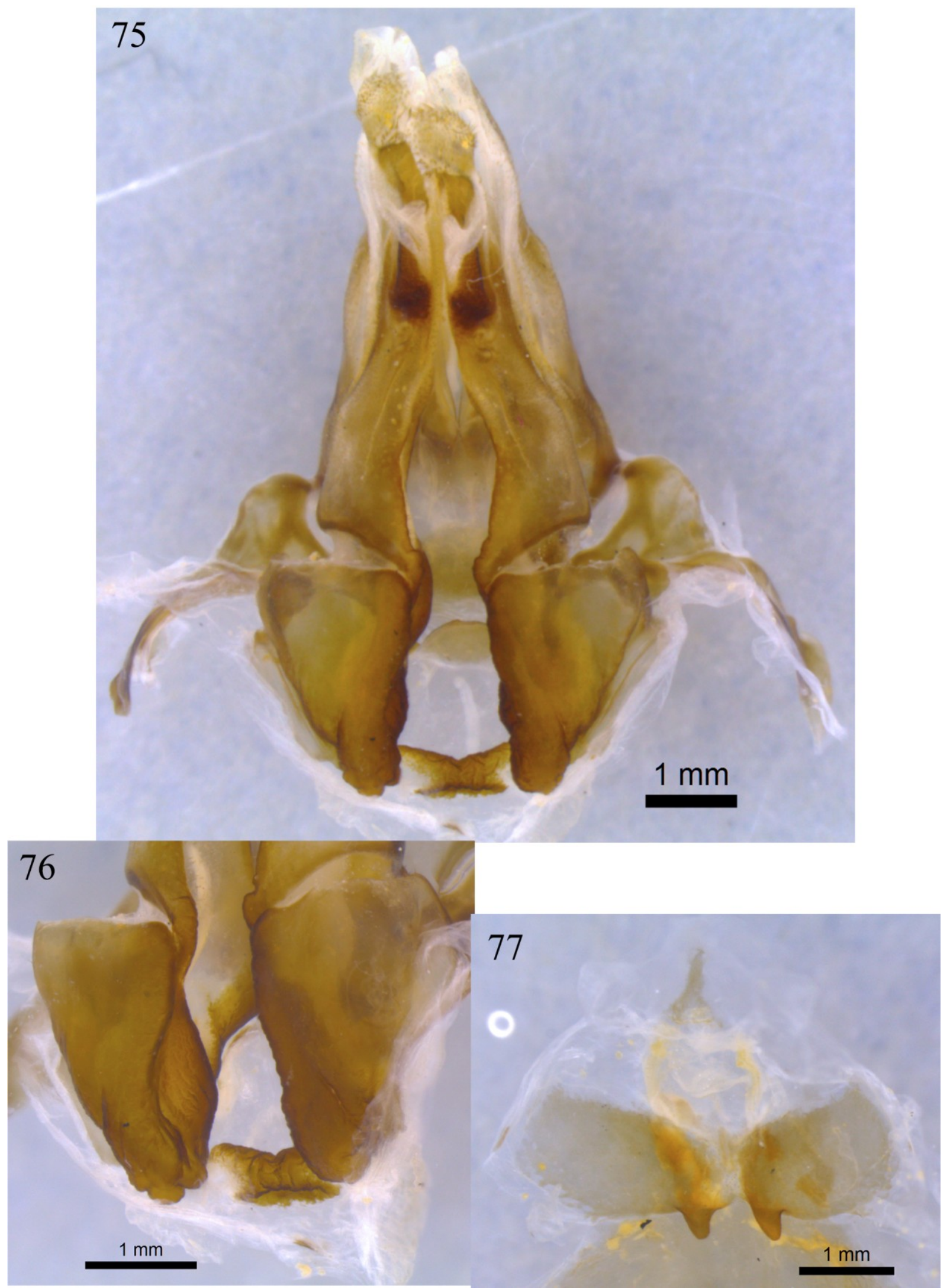

Figuras 75-77. Stagmatoptera femoralis fêmea. 75, ovipositor, vista ventral; 76, detalhe das gonocoxas; 77 , assoalho da câmara genital, vista dorsal. 
Mantis hyaloptera Perty, 1832, p.117, t.23, f.6 (descr.).

Tipo: Rio Amazonas.

Stagmatoptera hyaloptera, Saussure, 1869, p.67 (men.); Saussure, 1870, p.231 (men.); Saussure, 1871b, p.95, t.1, f.12 (redesc.); Saussure, 1872, p.257 (men.); Stål, 1877, p.72 (redesc.); Westwood, 1889, p.16 (men.); Giglio-Tos, 1897, p.15; Kirby, 1904, p.299 (men.); Rehn, 1911, p.12 (men.); Giglio-Tos, 1914, p.34 (redesc.); Giglio-Tos, 1927, p.599 (redesc.); Terra, 1995, p.64 (men.); Ehrmann, 1999, p.12 (redesc.); Ehrmann, 2002, p.328 (men.); Agudelo et al., 2007, p.125 (men.); Ehrmann \& Koçak, 2009, p.12 (men.).

$=$ Mantis pavonina Burmeister, 1838, p.540 (descr).

= Stagmatoptera pavonina, Saussure, 1871a, p.212 (redesc.); Ehrmann, 1999, p.12 (sin.).

= Chlidonoptera pavonina, Kirby, 1904, p. 292 (men.)

= Mantis luna Audinet-Serville, 1839, p.183 (descr.); Haan, 1842, p.74 (men.).

= Stagmatoptera luna, Kirby, 1904, p.300 (men.); Rehn, 1911, p.12 (men.); Giglio-Tos, 1914, p.34 (sin.).

Tipo: um macho, Cordoba.

= Stagmatoptera biocellata Saussure, 1869 de Werner, 1925a, p.167 - identificação errada (redesc).

Redescrição: Macho - Figuras 78A, 79-90.

Antenômeros filiformes. Escudo frontal com duas elevações centrais (Fig. 79).

Protorax alongado, delgado, com margens dotadas de crenulação suave na prozona, lisas na metazona. Metazona com uma quilha central pouco desenvolvida (Fig. 80). Coxas anteriores com margem anterior crenulada dotada de 7 a 11 espinhos grandes e 0 a 8 espinhos menores (Fig.81). Fêmures anteriores alongados e largos, com os três primeiros espinhos discoidais a partir da base, escuros em sua face interna; 14 a 17 espinhos internos, sendo o número mais frequente 15. Mancha femoral interna ausente ou, se presente, estendendo-se da 
canaleta da garra tibial até o $6^{\circ}$ espinho interno a partir da base, com formato retangular e uma coloração preta suave, ou uma coloração verde suave (Fig. 82). Tíbias anteriores dotadas de 9 a 13 espinhos externos, sendo mais frequente 11 espinhos, e 14 a 18 espinhos internos, sendo mais frequente 15 ou 16 espinhos; a garra tibial é verde na face interna (Fig. 83). Tarsos com manchas pretas apicais na face interna dos tarsômeros I a IV.

Área discoidal das tégminas verde opaca em uma estreita faixa anterior e ao redor do estigma, passando gradualmente para hialina. Estigma circular de tamanho mediano, alcançando a metade da área discoidal, com o seguinte padrão: uma mancha branca anterior circundada por uma mancha marrom, e uma pequena mancha semi-hialina no centro entre elas. Asas com a área discoidal hialina com molduras amarelas, e área anal totalmente hialina ou com molduras amarelas na metade anterior (Fig. 78A).

Genitália: Falômero esquerdo mais longo que largo, esclerito L4B tão longo quanto largo. Processo apical longo, levemente dilatado no lado esquerdo de sua base; inclinado em relação à base, formando um ângulo de aproximadamente $30^{\circ}$, e depois curvando para a esquerda; ápice simples, voltado ventralmente (Fig. 84). Processo distal largo e curto, achatado, curvado bruscamente $90^{\circ}$ para a direita, comprimido após a curvatura e na base do ápice; este bem esclerosado e afilado (Fig. 85). Apófise falóide longa e paralela em relação à genitália (Fig. 86); margem direita rugosa e levemente sinuosa (Fig. 87); ápice posterior intumescido com uma projeção desenvolvida na margem direita, rugoso e esclerosado; ápice anterior reto, margens bem esclerosadas, e intumescidas, formando uma canaleta (Fig. 86). Lobo membranoso curto, curvado para a direita (Fig. 86). Membrana adjacente à apófise falóide glabra (Fig. 86).

Falômero direito com ápice posterior arredondado; braço médio curto, com uma expansão na metade, formando uma elevação suave (Fig. 88); placa ventral curta, esclerosada (Fig. 89 e 90); processo ventral longo, fortemente esclerosado, ápice retangular (Fig. 89); apódema anterior longo, passando bruscamente a um ápice arredondado (Fig. 89 e 90).

Fêmea - Figuras 78B, 91-98.

Escudo frontal com duas elevações centrais (Fig. 91).

Protorax alongado, delgado, com margens dotadas de crenulação suave. Metazona com uma quilha central pouco desenvolvida (Fig. 92). Coxas anteriores com margem anterior 
crenulada dotada de 8 a 13 espinhos grandes e 1 a 10 espinhos menores (Fig. 93). Fêmures anteriores alongados e largos, com os três primeiros espinhos discoidais a partir da base escuros em sua face interna; 14 a 16 espinhos internos, sendo o número mais frequente 15 . Mancha femoral interna ausente ou, se presente, estendendo-se da canaleta da garra tibial até o $6^{\mathrm{o}}$ espinho interno a partir da base, com formato retangular e uma coloração preta suave, ou uma coloração verde suave (Fig. 94). Tíbias anteriores dotadas de 10 a 13 espinhos externos, sendo mais frequente 11 espinhos, e 14 a 16 espinhos internos, sendo mais frequente 15 espinhos; a garra tibial verde na face interna (Fig. 95). Tarsos com manchas pretas apicais na face interna dos tarsômeros I a IV.

Estigma circular de tamanho mediano, sem alcançar a metade da área discoidal, com o seguinte padrão: uma mancha branca anterior circundada por uma mancha marrom, e uma pequena mancha semi-hialina no centro entre elas. Asas com área costal hialina e as áreas discoidal e anal com molduras amarelas nas veias transversais (Fig. 78B).

Genitália: Base das gonapófises VIII se projetando internamente (Fig. 96). Basiválvula com formato aproximadamente triangular (Fig. 96), a superfície interna esculpida (Fig. 97). Interbasiválvula esclerosada e esculpida (Fig. 97). Extensões posterolaterias curtas, fracamente esclerosadas com margens irregulares (Fig. 97). Esclerito na parede dorsal da papila genital fracamente esclerosado, liso (Fig. 98). Plataforma lateroesternal aproximadamente retangular, processos posteriores longos, cônicos (Fig. 98).

Localidade tipo: Rio Amazonas

Outras localidades: Argentina, Bolívia, Brasil (Mato Grosso, Mato Grosso do Sul, Paraíba, Paraná, Pernambuco, Rio Grande do Sul, Rio Grande do Norte, São Paulo, Tocantins), Guiana Francesa, Paraguai.

Diagnose: Mancha estigmar circular, como na figura 78. 
Tabela 4. Medidas e razões de machos e fêmeas de Stagmatoptera hyaloptera.

\begin{tabular}{|c|c|c|}
\hline & Macho $(\mathrm{N}=31)$ & Fêmea $(\mathrm{N}=14)$ \\
\hline Comprimento & 49,8 a $64,7 \mathrm{~mm}$ & 56,4 a $79,3 \mathrm{~mm}$ \\
\hline Largura da cabeça & 6 a $7,3 \mathrm{~mm}$ & 7,3 a $9,4 \mathrm{~mm}$ \\
\hline Comprimento da Prozona & 3,4 a $4,6 \mathrm{~mm}$ & 4,7 a $6 \mathrm{~mm}$ \\
\hline Comprimento da Metazona & 12,9 a $17,8 \mathrm{~mm}$ & 15,9 a $22,7 \mathrm{~mm}$ \\
\hline Largura da Dilatação & 3,7 a $4,9 \mathrm{~mm}$ & 5,5 a $7,6 \mathrm{~mm}$ \\
\hline Comprimento da Tégmina & 35,2 a $46,3 \mathrm{~mm}$ & 34,2 a $45 \mathrm{~mm}$ \\
\hline Comprimento da Asa & 31,6 a $41 \mathrm{~mm}$ & 31,2 a $41,3 \mathrm{~mm}$ \\
\hline Comprimento da Coxa Anterior & 8,9 a $12 \mathrm{~mm}$ & 12,5 a $17,1 \mathrm{~mm}$ \\
\hline Comprimento do Fêmur Anterior & 10,7 a $14,6 \mathrm{~mm}$ & 15 a $20 \mathrm{~mm}$ \\
\hline Largura do Fêmur Anterior & 2,2 a $3 \mathrm{~mm}$ & 3,3 a $4,4 \mathrm{~mm}$ \\
\hline Comprimento da Tíbia Anterior & 5,7 a $7,8 \mathrm{~mm}$ & 7,7 a $10,3 \mathrm{~mm}$ \\
\hline Razão Cabeça/Dilatação & 1,34 a 1,67 & 1,17 a 1,38 \\
\hline Razão Metazona/Prozona & 3,32 a 4,28 & 3,23 a 3,78 \\
\hline Razão Prozona/Dilatação & 0,84 a 1,03 & 0,78 a 0,91 \\
\hline Razão Metazona/Dilatação & 3,19 a 3,79 & 2,66 a 3,1 \\
\hline Razão Metazona/Coxa Anterior & 1,33 a 1,57 & 1,21 a 1,38 \\
\hline Razão Comprimento/Largura & 4,52 a 5,48 & 4,33 a 4,77 \\
\hline Fêmur Anterior & 1,84 a 2,15 & 1,9 a 2,13 \\
\hline Razão Fêmur/Tíbia & \multicolumn{2}{|c}{} \\
\hline
\end{tabular}

Material examinado: Argentina; $1 \widehat{\delta}(\mathrm{ZSM})$. Chaco de Santa Fé, Las Garzas, bords du Rio Las Garzas, 25 Km O d'Ocampo, 1903, E.R. Wagner, 1ðð (MNHN). Chaco de Santiago del Estero, bords du Rio Salado, env. d'Icaño, 1904, E.R. Wagner, $1 q$ (MNHN). Chaco de Santiago del Estero, bords du Rio Salado, env. d'Icaño, 1910, E.R. Wagner, $1 \delta^{\lambda}$ (MNHN). Chaco de Santiago del Estero, bords du Rio Salado, la Palisa del Bracho, 20Km NNO d'Icaño, Laguna Mamaíta, 1904, E.R. Wagner, $1 q$ (MNHN). Chaco de Santiago del Estero, bords du Rio Salado, la Palisa del Bracho, 25Km NO d'Icaño, xii.1909, E.R. Wagner, $1 q(\mathrm{MNHN})$. Env. d'Icaño, bords du Rio Salado, Santiago del Estero, 1909, E.R. Wagner, $1 \delta^{\lambda}$ (MNHN). Jujui, iii.1958, Martinez \& Pereira col., 1ठ (MZSP). Eldorado, Misiones, 08.ii.1969, 1ठ (MHNG). Eldorado, Misiones, 09.ii.1969, achat Bâle 1971, 1ठ (MHNG). Eldorado, Misiones, 13.ii.1969, achat Bâle 1971, 1ðَ(MHNG). Mina Clavero, Córdoba, 01.iii.2005, Dr. Forest, 1ठ઼ (MNHN). Rosário, Santa Fé, Hubrist S.V., $1 \widehat{\jmath}$ (ZMB). San Ignacio, Huat-Parana, Misiones, i.sem ano, E.R. Wagner, $1 \delta^{\lambda}(\mathrm{MNHN})$. Tapia, Tucuman, iiiiv.1903, G.A. Baer, $1 \widehat{\jmath}(\mathrm{MNHN})$. Tucuman, 1 ํ $1 \delta^{\Uparrow}(\mathrm{ZSM}) .40 \mathrm{~km}$ O de Salavina, Santiago 
del Estero, 1909, E.R. Wagner, $1+$ (MNHN). Tucuman, i.1928, Schreiter. leg. F. Nosswitz, 1 을. ZSM). Vila Lutecia, env. de San Ignacio, Missiones, 1910, E.R. Wagner, $1 ð$ (MNHN). Bolívia; El Carmen, 26-28.ii.1958, Lauro col., 1 ( (MZSP). Sara, Steinbach S.V., 2 (ZMB) Brasil; Mato Grosso - MT, 1 ( Cruz, 1ð̋ (MZSP). Paraíba - Corema, vi.1957, Exp. Dept. Zoologia, 2ð (MZSP). Paraná Rolândia, Dirings, i.1954, 1ठ (MZSP). Pernambuco - Afrânio, 08³1'53”S 4102’59”W, 550m, 16.v.2007, J.A. Rafael \& F.F. Xavier Fo ${ }^{\mathrm{O}}$ (INPA). Rio Grande do Sul - Bom Jesus, 17.iii.1980, L. Jantsch leg., 1ð̂, 0531 (MCTP). Pelotas, 1980, Cavero, 1q, 0926 (MCTP). Porto Alegre, 12.ii.1982, C.C. Morate leg., 1ð̄, 0365 (MCTP). Porto Alegre, 05.v.1982, N. Andrade, 1ð̄, 0727 (MCTP). Santo Cristo, 26.ii.1981, A. Heck leg., 1, 0287 (MCTP). São Borja, 10.iv.1982, L. Ramos leg, 1q, 0323 (MCTP). São Sepé, 13.iii.1986, C.M. Souto, 1ठ, 1226 (MCTP). Sta. C. do Sul, 12.iii.1980, L. Jantsch leg., 1ðึ, 0471 (MCTP). Uruguaiana, 08.ii.1989, S.M. Piment, 1 \&, 1339 (MCTP). $\underline{\text { São Paulo }-A n d e s, ~ i i .1955, ~ M . ~ C a r r e r a, ~} 2 \widehat{ }$ (MZSP). Catanduva, i.1956, O.P. Silva, 1 ㅇ (MZSP). Ilha Seca, 18-26.ii.1940, Com. I. O.

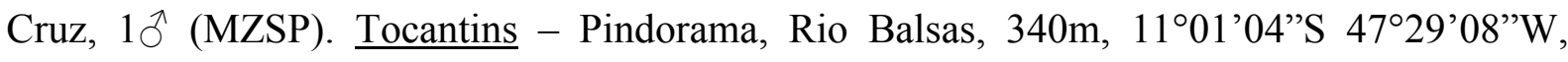
28.iii.2008, J.A. Rafael \& F.F. Xavier Fo $\mathrm{F}^{\mathrm{o}}$ 2 (INPA). Guiana Francesa; Herr, $1+1 \hat{\jmath}$ (MHNG). Paraguai; École agricole, Santa Rosa del Araguay, 200m, 2346'47"S 56³2'46"W, San Pedro, 24.i.2001, H.-P. Aberlenc \& P. Silvie leg., $1 \overbrace{}^{\Uparrow}$ (MNHN). Vila Rica, G. Schauer, $1 ð$ (ZMB). Vila Rica, iii.1934, M. Holtz, $1 \widehat{\varnothing}$ (ZMB). Sem localidade; Lectótipo de $S$.

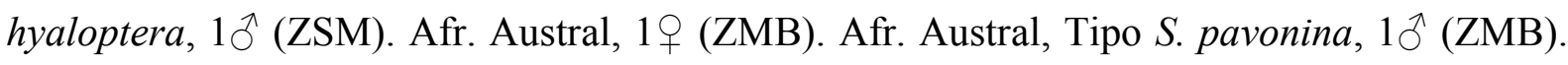
Gran Chaco, 1 , , (MNHN). 

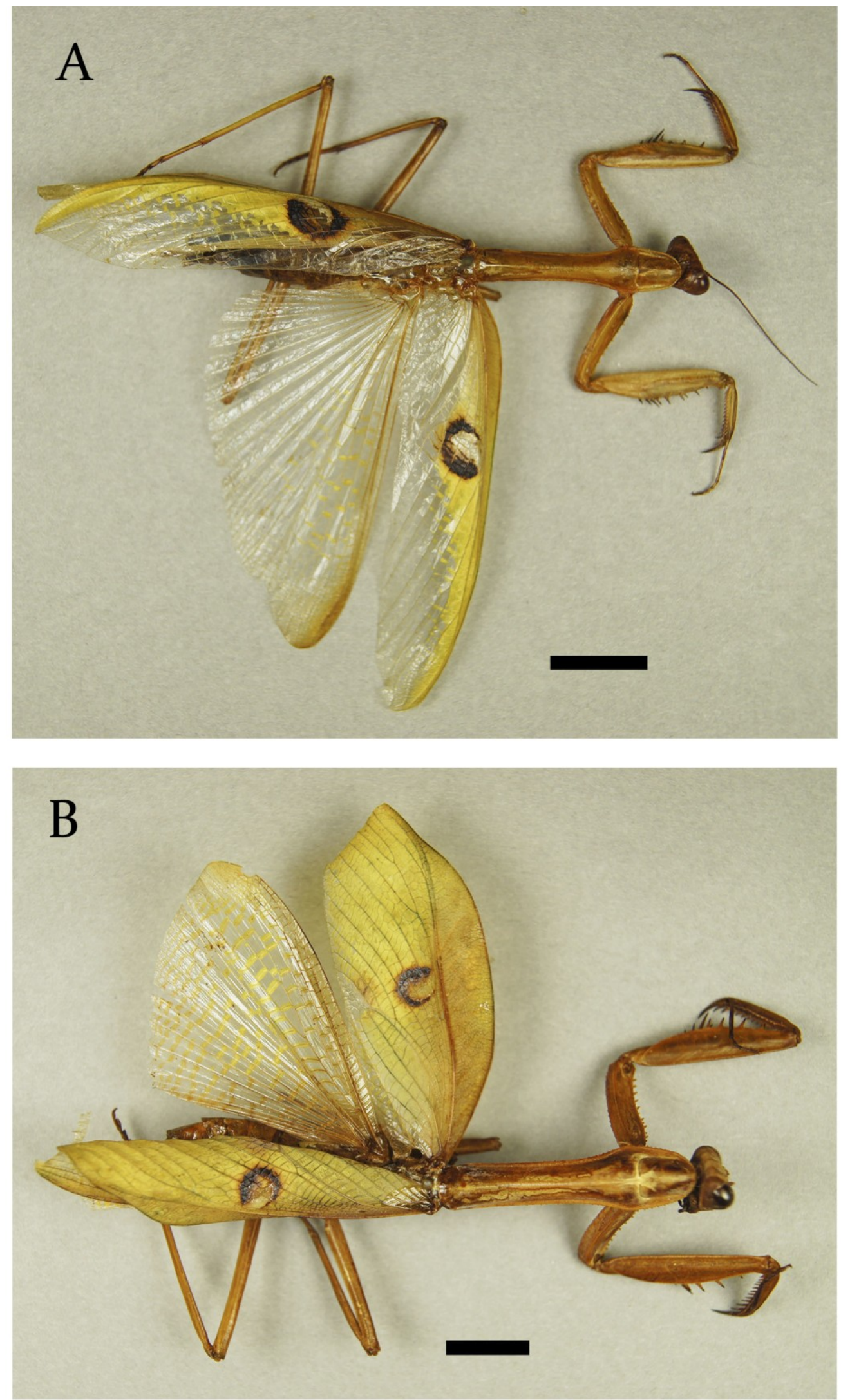

Figura 78. Stagmatoptera hyaloptera, habitus dorsal. A, macho; B, fêmea. Escalas $=1 \mathrm{~cm}$. 


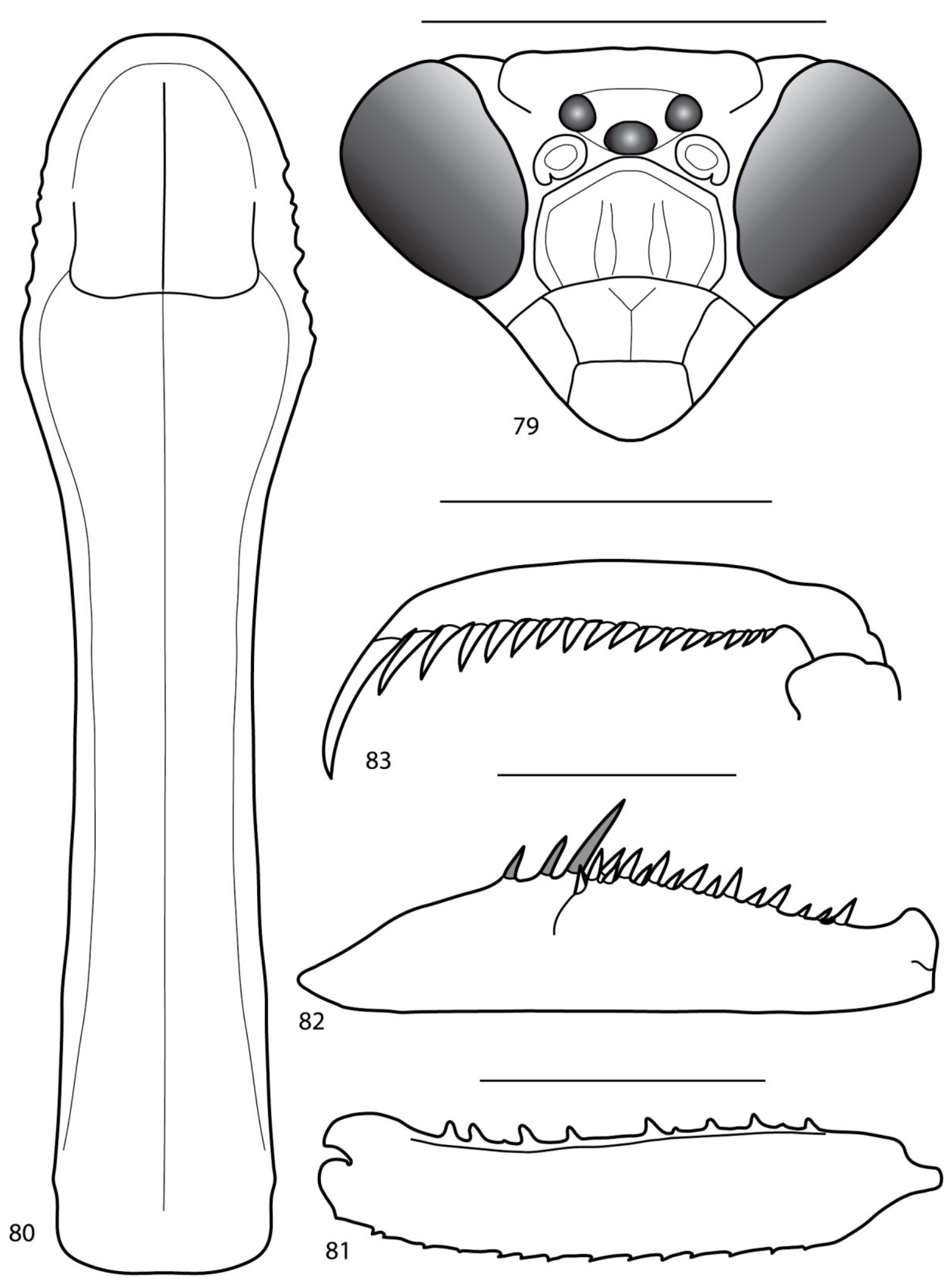

Figuras 79-83. Stagmatoptera hyaloptera macho. 79, cabeça, vista frontal; 80, protorax, vista dorsal; 81, coxa anterior, vista interna; 82, fêmur anterior, vista interna; 83, tíbia anterior, vista interna. Escalas $=5 \mathrm{~mm}$. 

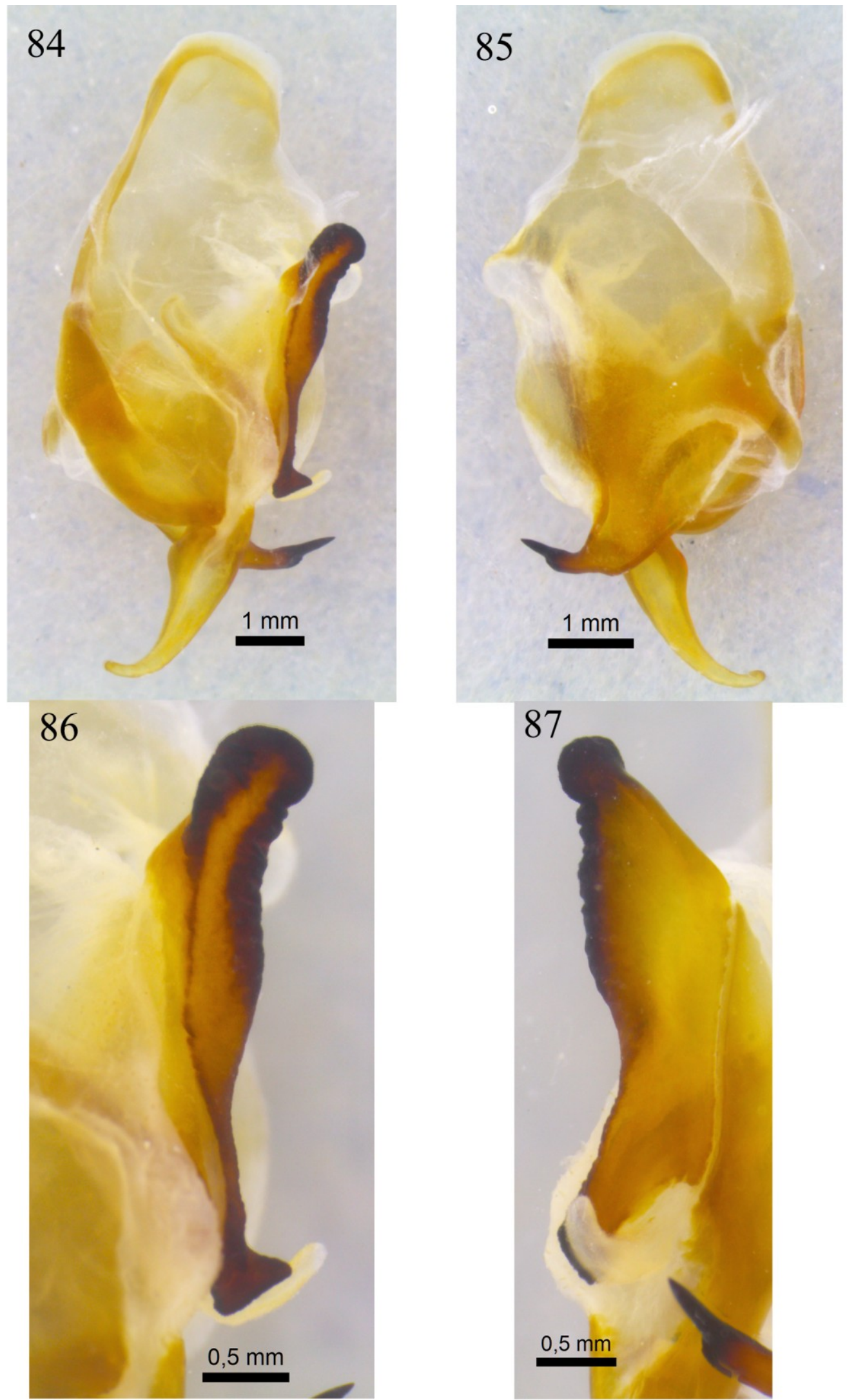

Figuras 84-87. Stagmatoptera hyaloptera macho. 84, falômero esquerdo, vista dorsal; 85, falômero esquerdo, vista ventral; 86, apófise falóide e lobo membranoso, vista dorsal; 87, apófise falóide, vista lateral direita. 


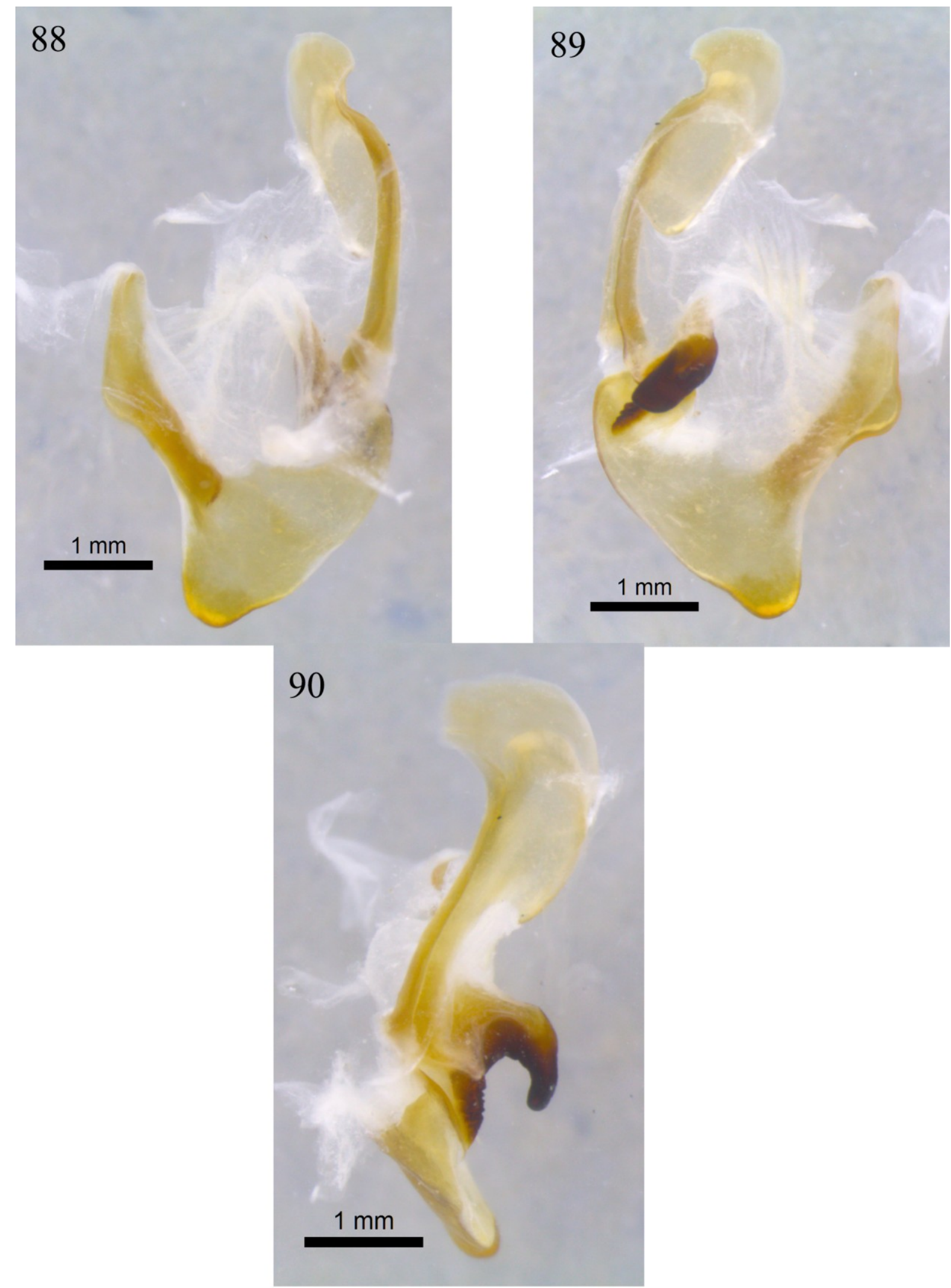

Figuras 88-90. Stagmatoptera hyaloptera macho. 88, falômero direito, vista dorsal; 89, falômero direito, vista ventral; 90, falômero direito, vista lateral direita. 


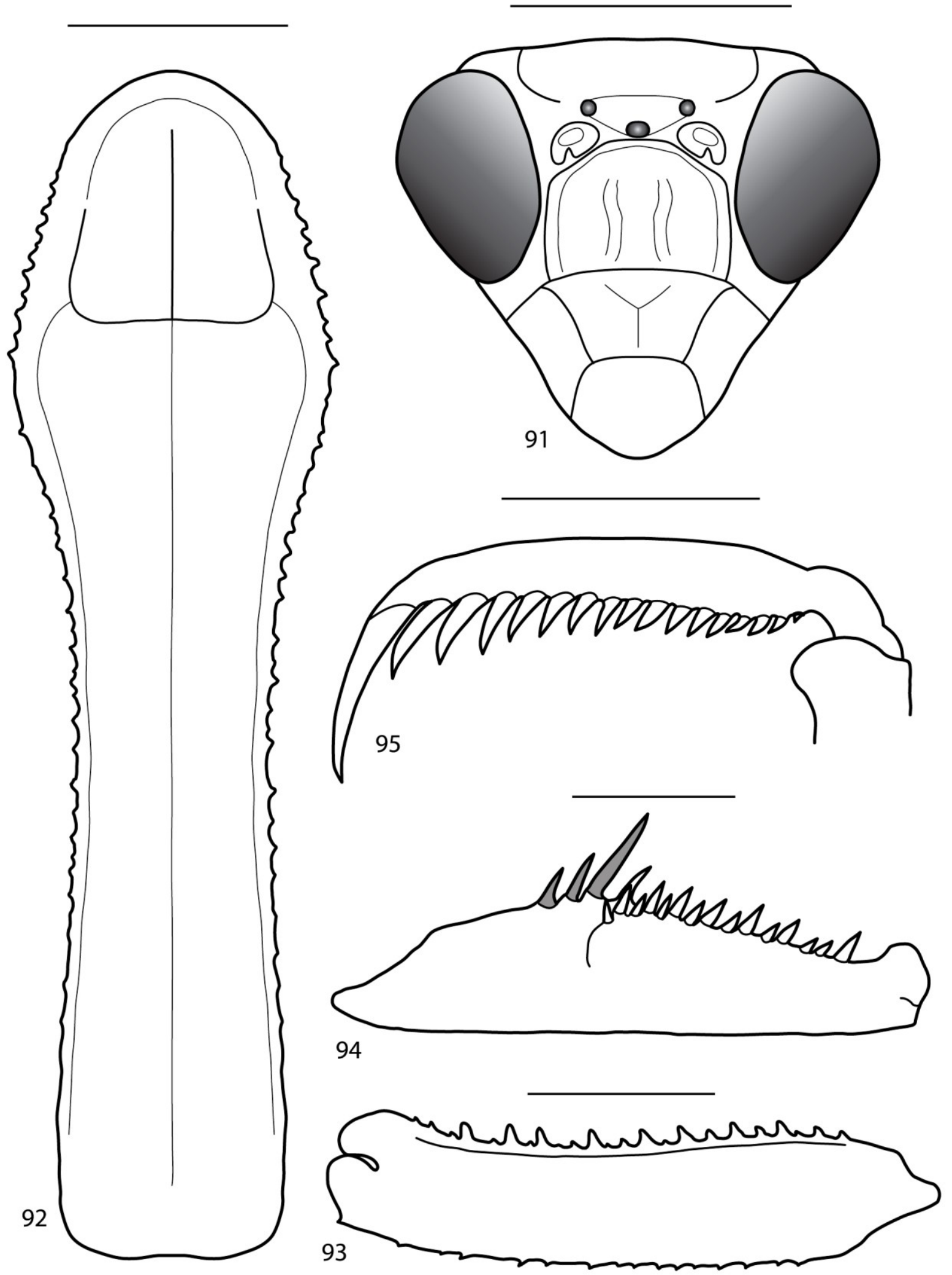

Figuras 91-95. Stagmatoptera hyaloptera fêmea. 91, cabeça, vista frontal; 92, protorax, vista dorsal; 93, coxa anterior, vista interna; 94, fêmur anterior, vista interna; 95, tíbia anterior, vista interna. Escalas $=5 \mathrm{~mm}$. 


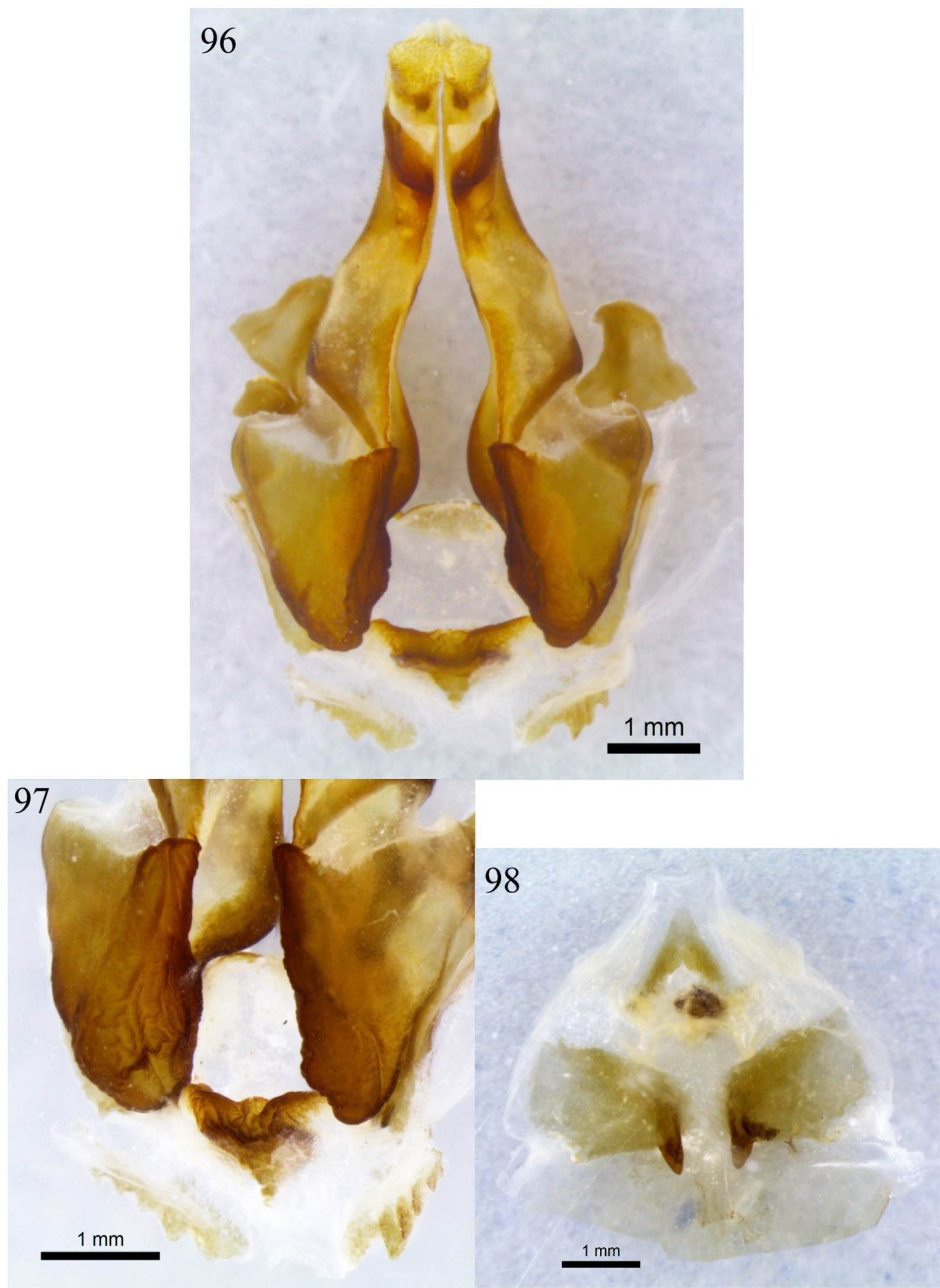

Figuras 96-98. Stagmatoptera hyaloptera fêmea. 96, ovipositor, vista ventral; 97, detalhe das gonocoxas; 98, assoalho da câmara genital, vista dorsal. 
Figura 99.

Mantis indicator Olivier, 1792, p.641 (descr.); Audinet-Serville, 1831, p.54 (men.).

Stagmatoptera indicator, Kirby, 1904, p.301 (men.); Rehn, 1911, p.13 (men.); Giglio-Tos, 1914, p.35 (redesc.); Giglio-Tos, 1927, p.600 (redesc.); Terra, 1995, p.64 (men.); Ehrmann, 2002, p.329 (men.); Agudelo et al., 2007, p.125 (men.); Ehrmann \& Koçak, 2009, p.12 (men.).

$=$ Mantis bodegetica Lichtenstein, 1802, p.26 (descr.); Kirby, 1904, p.301 (sin.).

$=$ Mantis sancta Stoll, 1813, p.52, t.17, f.63 (descr.)

$=$ Mantis (Acontistes) sancta, Burmeister, 1838, p.542 (descr.).

= Stagmatoptera sancta, Saussure, 1870, p.232 (men.); Westwood, 1889, p.15 (men.); Rehn, 1904, p.572 (men.); Kirby, 1904, p.301 (sin.).

$=$ Mantis hodegetica, Kirby, 1910, p.568 (men.); Giglio-Tos, 1914, p.35 (men.).

Durante a realização do trabalho não possível encontrar nenhum exemplar pertencente a esta espécie, por este motivo são dadas duas descrições e uma ilustração já publicadas na literatura.

Tradução da descrição feita por Stoll, 1787:

"Com as antenas filiformes cinza, os olhos brancos salientes, a cabeça reta e simples, o tronco com quilha e elevado no meio, as bordas deste munidas de pequenos espinhos, a cor do tronco, do abdômen e das pernas marrom amarelado. Pernas raptoriais dotadas de espinhos pontiagudos na face inferior, e na face interna dos fêmures elas possuem uma grande mancha marrom. Os élitros têm uma bela cor verde e são pergamináceos. As asas também são pergamináceas na borda externa, mas no resto amareladas com faixas de um verde sujo, ondulantes e transparentes."

Tradução da descrição feita por Giglio-Tos, 1927 : 
"Verde. Pronoto delgado, a dilatação oval. Élitros ovalados, a ponta angulosa, opacos ou quase membranosos, o estigma branco sem manchas pretas. Asas reticuladas de amarelo. A mancha interna dos fêmures anteriores quase imperceptível, se extendendo apenas até o $3^{\circ}$ grande espinho interno. Os espinhos discoidais e os grandes espinhos internos percorridos internamente por uma faixa preta. A garra das tíbias anteriores totalmente preta internamente, o espinhos que a precede preto na ponta."

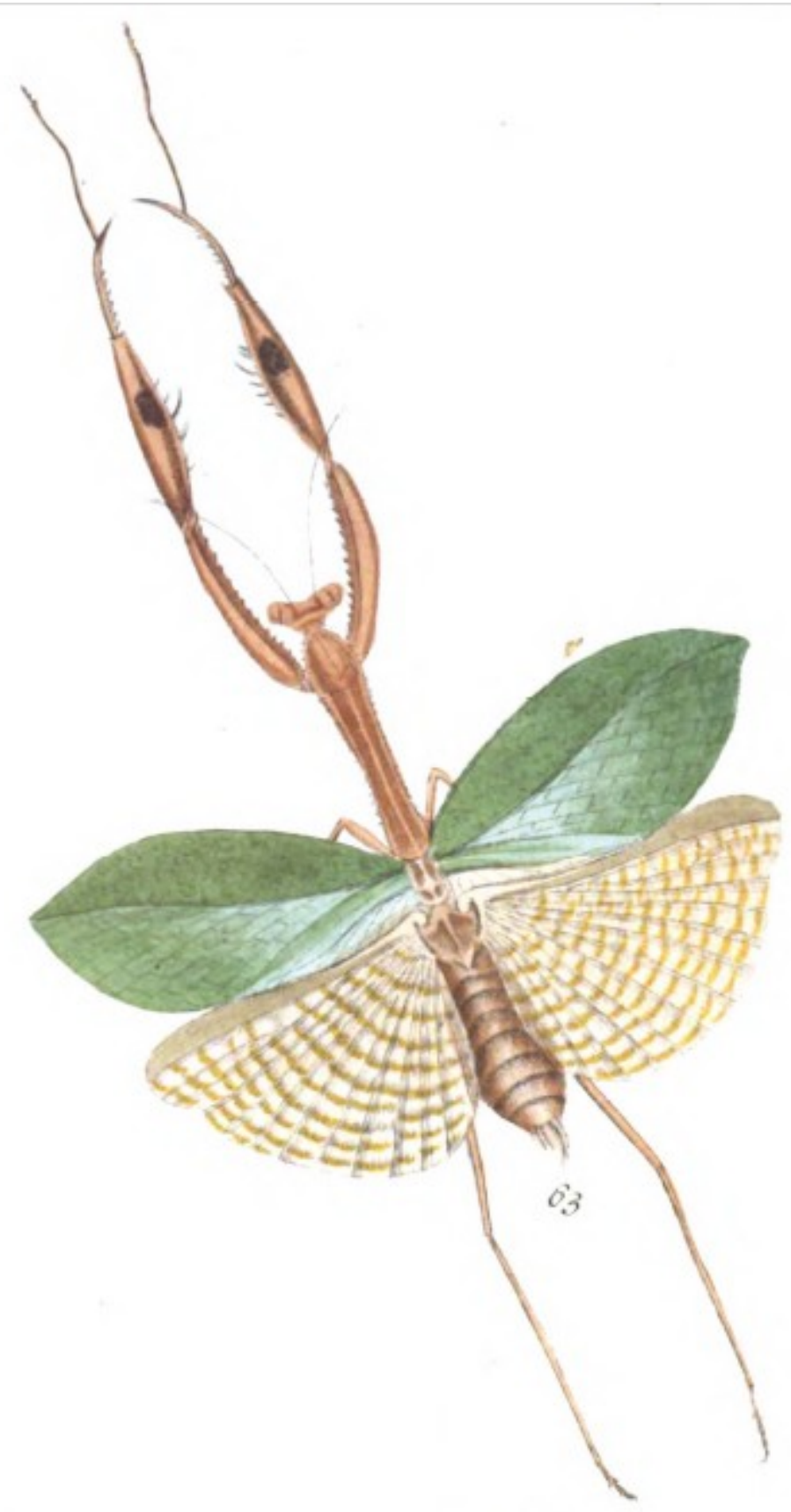

Figura 99. Ilustração de Stagmatoptera indicator publicada por Stoll em seu trabalho de 1787. 
Stagmatoptera pia Saussure \& Zehntner, 1894

Stagmatoptera pia Saussure \& Zehntner, 1894, p.187 (descr.); Kirby, 1904, p.300 (men.); Rehn, 1911, p.13 (men.); Giglio-Tos, 1914, p.28 (redesc.); Werner, 1925b, p.383 (redesc.); Giglio-Tos, 1927, p.596 (redesc.); Terra, 1995, p.64 (men.); Ehrmann, 2002, p.329 (men.); Agudelo et al., 2007, p.125 (men.); Ehrmann \& Koçak, 2009, p.12 (men.).

Tipo: uma fêmea, Brasil (examinada)

= Stagmatoptera nova syn. nov. Beier, 1930, p.32 (descr.); Terra, 1995, p.64 (men.); Ehrmann, 2002, p.329 (men.); Agudelo et al., 2007, p.125 (men.); Ehrmann \& Koçak, 2009, p.12 (men.).

Tipo: dois machos, Recife, Pernambuco, 27.iv-04.v. 1927, Zerny leg. (examinados)

Redescrição: Macho - Figuras 100A, 101-112.

Antenômeros filiformes. Escudo frontal com duas elevações centrais (Fig. 101).

Protorax alongado, delgado, com margens dotadas de crenulação suave na prozona, lisas na metazona. Metazona com uma quilha central pouco desenvolvida (Fig. 102). Coxas anteriores com margem anterior crenulada dotada de 6 a 11 espinhos grandes e 1 a 7 espinhos menores (Fig. 103). Fêmures anteriores alongados e largos, com os três primeiros espinhos discoidais a partir da base, escuros em sua face interna; 14 a 15 espinhos internos, sendo o número mais frequente 15 , o primeiro espinho interno a partir da base e os grandes espinhos internos são escuros na face interna, podendo apresentar uma pequena mancha de mesma coloração na inserção dos espinhos 8, 10 e 12. Mancha femoral interna ausente ou presente; se presente, estendendo-se da canaleta da garra tibial até o $6^{\circ}$ espinho interno a partir da base, com formato retangular e uma coloração preta suave (Fig. 104). Tíbias anteriores dotadas de 11 a 13 espinhos externos, e 14 a 16 espinhos internos; a garra tibial e o último espinho que a precede são escuros na face interna, ou somente a garra tibial escura, uma mancha preta na metade da face interna (Fig. 105). Tarsos com manchas pretas apicais na face interna dos tarsômeros I a IV.

Área discoidal das tégminas verde opaca em uma estreita faixa anterior após o estigma, passando bruscamente ou gradualmente para hialina. Estigma circular pequeno a alongado, sem alcançar a metade da área discoidal, com o seguinte padrão: uma mancha 
branca anterior e uma mancha marrom posterior. Asas com a área discoidal hialina com molduras amarelas ou hialina, e área anal totalmente hialina (Fig. 100A).

Genitália: Falômero esquerdo mais longo que largo, esclerito L4B mais longo que largo. Processo apical longo, levemente dilatado no lado esquerdo de sua base; inclinado em relação à base, formando um ângulo de aproximadamente $45^{\circ}$, e depois curvando para a esquerda; ápice simples, voltado ventralmente (Fig. 106). Processo distal estreito e curto, achatado, curvado bruscamente $90^{\circ}$ para a direita, ápice bem esclerosado e afilado (Fig. 107). Apófise falóide longa e paralela em relação à genitália (Fig. 108); margem direita lisa e sinuosa (Fig. 109); ápice posterior intumescido com uma projeção para a direita, rugoso e fortemente esclerosado; ápice anterior reto, margens bem esclerosadas, e intumescidas, porém sem formar uma canaleta (Fig. 108). Lobo membranoso curto, curvado para a direita (Fig. 108). Membrana adjacente à apófise falóide glabra (Fig. 108).

Falômero direito com ápice posterior arredondado; braço médio curto, com uma expansão na metade, formando uma elevação (Fig. 110); placa ventral curta, fracamente esclerosada (Fig. 111 e 112); processo ventral curto, esclerosado, ápice retangular (Fig. 111); apódema anterior longo, passando suavemente a um ápice arredondado (Fig. 112).

Fêmea - Figuras 100B, 113-120.

Escudo frontal com duas elevações centrais (Fig. 113).

Protorax alongado, delgado, com margens dotadas de crenulação suave. Metazona com uma quilha central pouco desenvolvida (Fig. 114). Coxas anteriores com margem anterior crenulada dotada de 7 a 11 espinhos grandes e 6 a 10 espinhos menores (Fig. 115). Fêmures anteriores alongados e largos, com os três primeiros espinhos discoidais a partir da base escuros em sua face interna; 15 espinhos internos, o primeiro espinho interno a partir da base e os grandes espinhos internos são escuros na face interna, podendo apresentar uma pequena mancha de mesma coloração na inserção dos espinhos 8, 10 e 12. Mancha femoral interna ausente ou presente; se presente, estendendo-se da canaleta da garra tibial até o $6^{\circ}$ espinho interno a partir da base, com formato retangular e uma coloração preta suave (Fig. 116). Tíbias anteriores dotadas de 11 a 12 espinhos externos, e 15 a 16 espinhos internos; a garra tibial e o último espinho que a precede escuros na face interna, ou somente a garra tibial escura, uma mancha preta suave na metade da face interna (Fig. 117). Tarsos com manchas pretas apicais na face interna dos tarsômeros I a IV. 
Estigma circular de tamanho mediano, sem alcançar a metade da área discoidal, com o seguinte padrão: uma mancha branca anterior e uma mancha marrom posterior. Asas com área costal hialina e as áreas discoidal e anal com molduras amarelas nas veias transversais (Fig. 100B).

Genitália: Base das gonapófises VIII se projetando internamente (Fig. 118). Basiválvula com formato aproximadamente triangular (Fig. 118), ápice intumescido, a superfície interna esculpida (Fig. 119). Interbasiválvula esclerosada e esculpida (Fig. 119). Extensões posterolaterias curtas, fracamente esclerosadas com margens lisas (Fig. 119). Esclerito na parede dorsal da papila genital fracamente esclerosado, liso (Fig. 120). Plataforma lateroesternal aproximadamente retangular, processos posteriores longos, cônicos (Fig. 120).

Localidade tipo: Brasil

Outras localidades: Brasil (Bahia, Espírito Santo, Pernambuco, Rio Grande do Norte)

Diagnose: Mancha no estigma dos machos circular a alongado, das fêmeas circular, em ambos os sexos com uma mancha branca anterior e uma mancha marrom posterior, uma mancha na metade da face interna da tíbia anterior. 
Tabela 5. Medidas e razões de machos e fêmeas de Stagmatoptera pia.

\begin{tabular}{|c|c|c|}
\hline & Macho $(\mathrm{N}=15)$ & Fêmea $(\mathrm{N}=3)$ \\
\hline Comprimento & 58 a $77,4 \mathrm{~mm}$ & 74,9 a $80,3 \mathrm{~mm}$ \\
\hline Largura da cabeça & 6,6 a $8,5 \mathrm{~mm}$ & 9,4 a $10 \mathrm{~mm}$ \\
\hline Comprimento da Prozona & 3,5 a $4,9 \mathrm{~mm}$ & 6,3 a $6,9 \mathrm{~mm}$ \\
\hline Comprimento da Metazona & 16,6 a $24,8 \mathrm{~mm}$ & 25,1 a $29,1 \mathrm{~mm}$ \\
\hline Largura da Dilatação & 3,9 a $5,6 \mathrm{~mm}$ & 7 a $7,8 \mathrm{~mm}$ \\
\hline Comprimento da Tégmina & 42,4 a $57,1 \mathrm{~mm}$ & 41,3 a $49,9 \mathrm{~mm}$ \\
\hline Comprimento da Asa & 40,5 a $51,6 \mathrm{~mm}$ & 37,8 a $44,7 \mathrm{~mm}$ \\
\hline Comprimento da Coxa Anterior & 11 a $16,5 \mathrm{~mm}$ & 17,3 a $19,8 \mathrm{~mm}$ \\
\hline Comprimento do Fêmur Anterior & 12,1 a $18,5 \mathrm{~mm}$ & 20,4 a $23,2 \mathrm{~mm}$ \\
\hline Largura do Fêmur Anterior & 2,5 a 3,4 mm & 4,3 a $4,8 \mathrm{~mm}$ \\
\hline Comprimento da Tíbia Anterior & 6 a $9,1 \mathrm{~mm}$ & 9,9 a $11,4 \mathrm{~mm}$ \\
\hline Razão Cabeça/Dilatação & 1,44 a 1,72 & 1,28 a 1,4 \\
\hline Razão Metazona/Prozona & 4,05 a 5,06 & 3,64 a 4,34 \\
\hline Razão Prozona/Dilatação & 0,85 a 1 & 0,86 a 0,99 \\
\hline Razão Metazona/Dilatação & 3,48 a 4,43 & 3,39 a 3,73 \\
\hline Razão Metazona/Coxa Anterior & 1,41 a 1,69 & 1,42 a 1,47 \\
\hline Razão Comprimento/Largura & 4,26 a 5,44 & 4,53 a 4,83 \\
\hline Fêmur Anterior & 1,88 a 2,11 & 2,03 a 2,07 \\
\hline Razão Fêmur/Tíbia & & \\
\hline
\end{tabular}

Material examinado: Brasil; Holótipo de S. pia, M.H. de Saussure, 19 (MHNG). Bahia - 1912, P. Serre, $1 \delta$ (MNHN). 1913, P. Serre, $2 \widehat{\jmath}(\mathrm{MNHN})$. H. de S., $1 \delta$ (MHNG). Campo Formoso, 24.vii.1990, Amedegnato \& Poulain rec., $1 \sigma^{\lambda}(\mathrm{MNHN}) .1$ Ondina, 25.vii.1951, $1 \overbrace{}^{\Uparrow}$ (MZSP). Salvador, 04.vii.1984, D.H. Smith, luz UV, 1ठ, 1928 (MCTP). Salvador, 15.iv.1985, D.H. Smith, luz UV, 1ठ̂, 1929 (MCTP). Salvador, 20.ix.1985, D.H. Smith, 1, 1932 (MCTP). Espírito Santo - Parque Soóretama, Cupido, ii-iii.1948, L. Trav., Freitas \& H. Trav., $1 \widehat{\jmath}$ (MZSP). Linhares, 25.iv.1990, J.S. Santos, 10 , 1922 (MCTP).

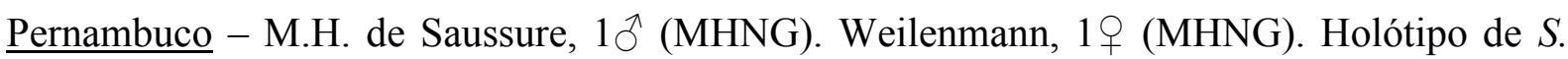
nova, Recife, 27.iv-04.v.1927, Zerny, 1ठ઼ (NHMW). Parátipo de S. nova, Recife, 27.iv04.v.1927, Zerny, 1ðð (NHMW). Rio Grande do Norte - Canto do Amaro, Mossoró, 1819.vi.1996, Varela col., $2 \widehat{\bigcirc}$ (MZSP). Canto do Amaro, Central de Resíduos, Mossoró, 0102.vii.1995, Equipe SEPERNA, 1ठ (MZSP). Faz. Sombras Grandes, Mossoró, 0102.vii.1995, Equipe SEPERNA, $1 \delta^{\Uparrow}$ (MZSP). Pq. Est. das Dunas Costeiras, Natal, 21.vii.1994, Equipe Zoologia 94.2, $1 q$ (MZSP). Sem localidade; $2 \hat{\jmath}(\mathrm{ZSM}) .1 q(\mathrm{ZSM})$. 

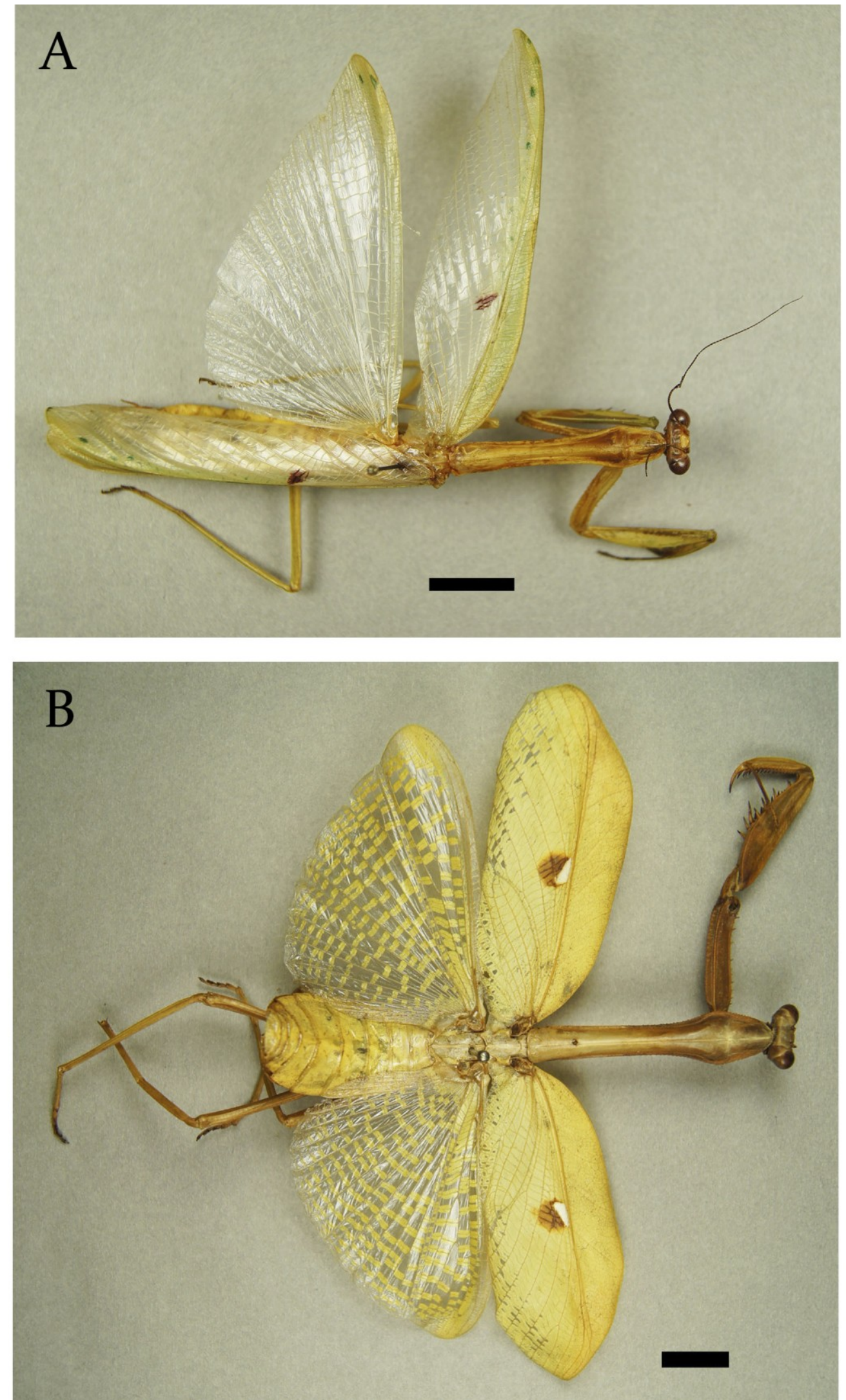

Figura 100. Stagmatoptera pia, habitus dorsal. A, macho; B, fêmea. Escalas $=1 \mathrm{~cm}$. 


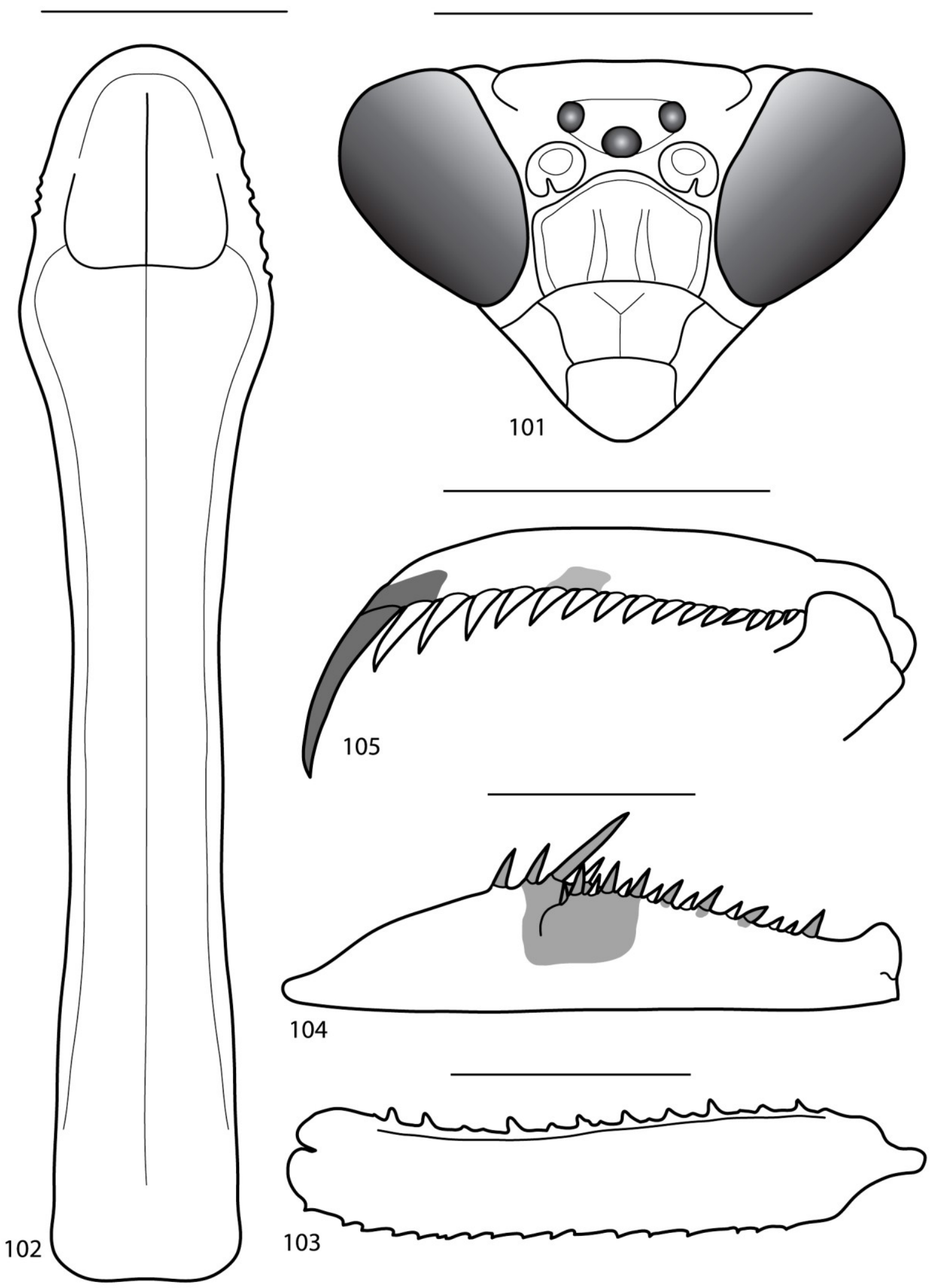

Figuras 101-105. Stagmatoptera pia macho. 101, cabeça, vista frontal; 102, protorax, vista dorsal; 103, coxa anterior, vista interna; 104, fêmur anterior, vista interna; 105, tíbia anterior, vista interna. Escalas $=5 \mathrm{~mm}$. 

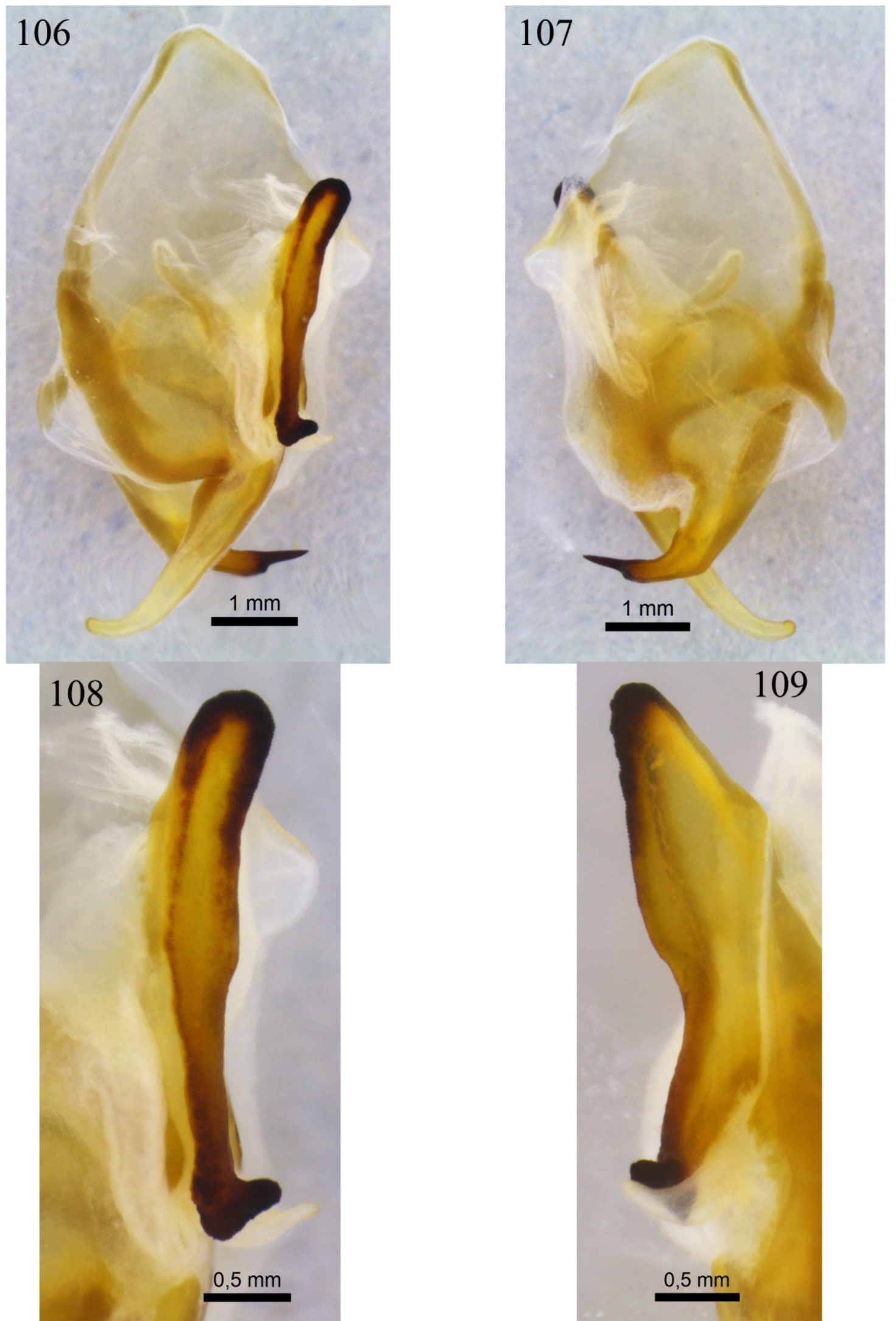

Figuras 106-109. Stagmatoptera pia macho. 106, falômero esquerdo, vista dorsal; 107, falômero esquerdo, vista ventral; 108, apófise falóide e lobo membranoso, vista dorsal; 109, apófise falóide, vista lateral direita. 

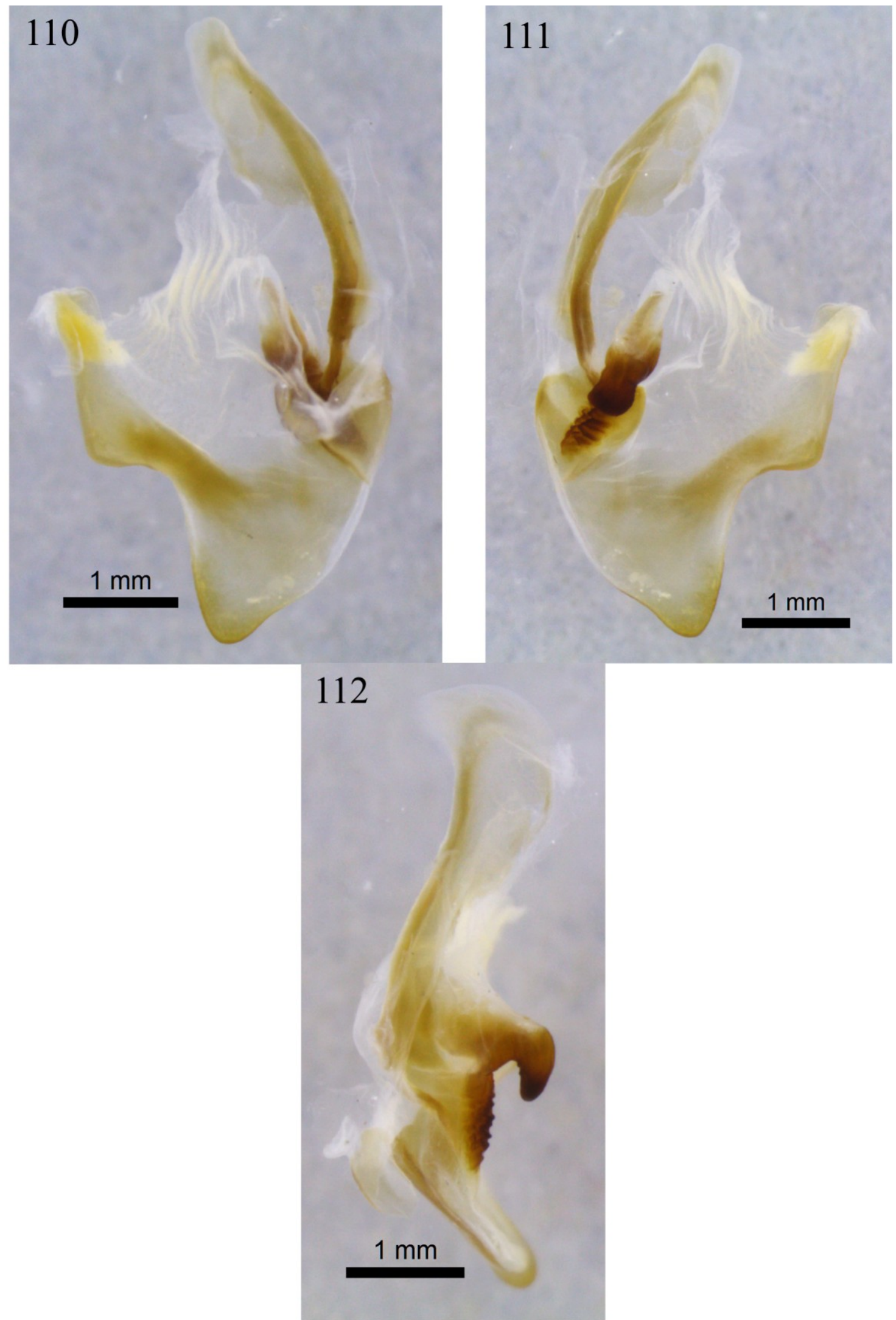

Figuras 110-112. Stagmatoptera pia macho. 110, falômero direito, vista dorsal; 111, falômero direito, vista ventral; 112, falômero direito, vista lateral direita. 


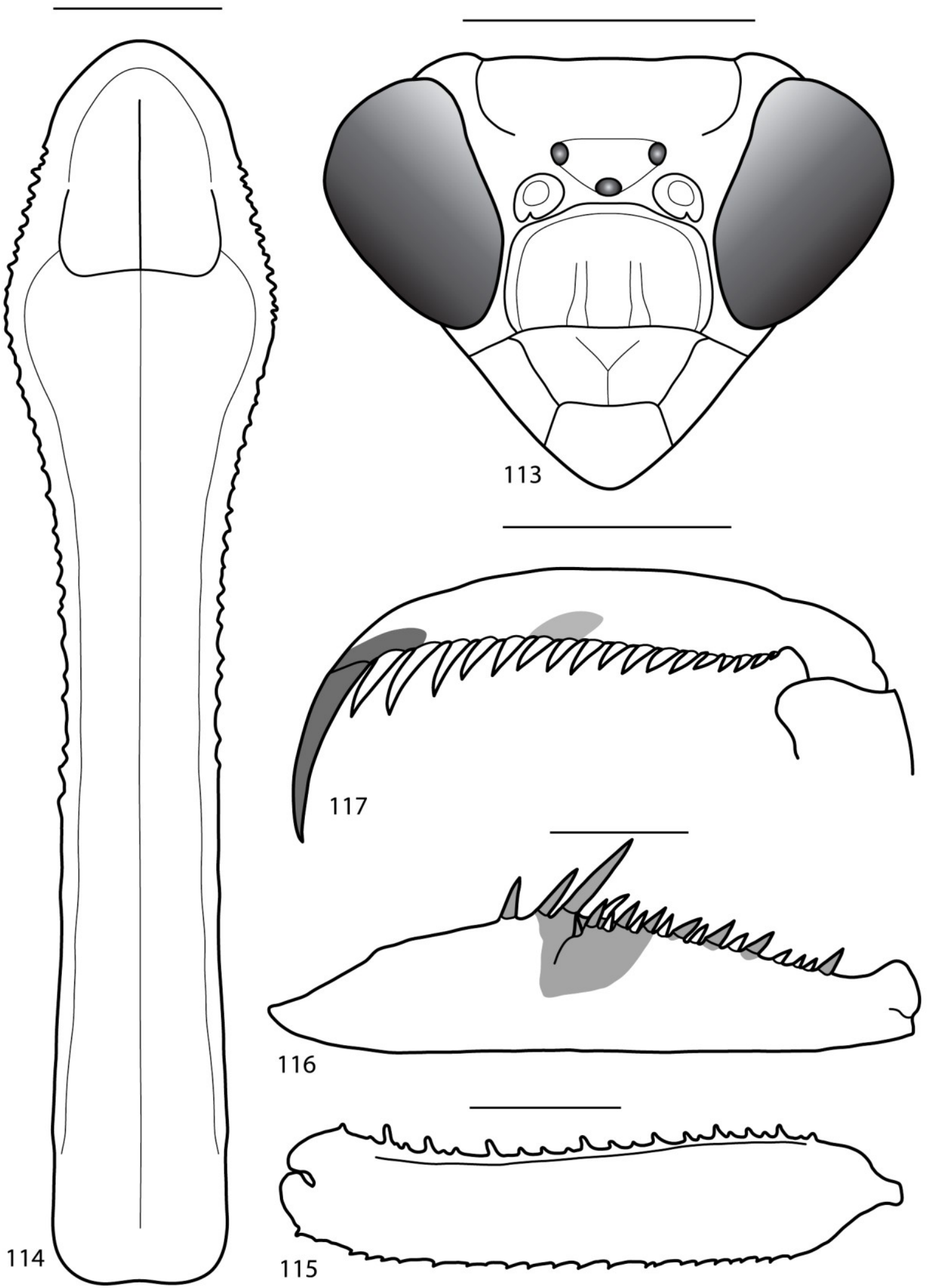

Figuras 113-117. Stagmatoptera pia fêmea. 113, cabeça, vista frontal; 114, protorax, vista dorsal; 115, coxa anterior, vista interna; 116, fêmur anterior, vista interna; 117, tíbia anterior, vista interna. Escalas $=5 \mathrm{~mm}$. 


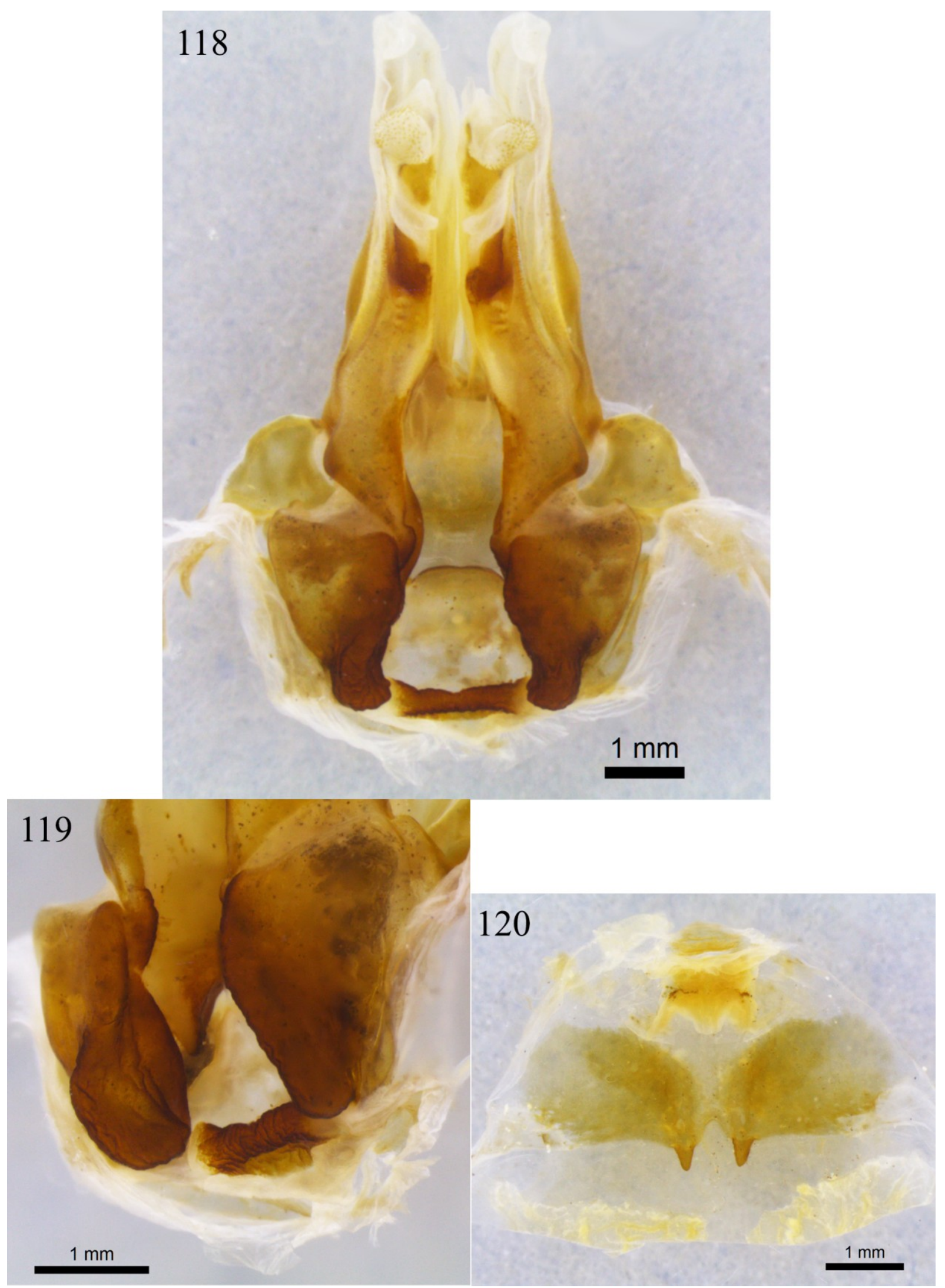

Figuras 118-120. Stagmatoptera pia fêmea. 118, ovipositor, vista ventral; 119, detalhe das gonocoxas; 120, assoalho da câmara genital, vista dorsal. 
Stagmatoptera precaria (Linnaeus, 1758)

Gryllus (Mantis) precarius Linnaeus, 1758, p.426 (descr.); Linnaeus, 1764, p.114 (redesc.); Linnaeus, 1767, p.691 (redesc.); Gmelin-Linné, 1790, p.2050 (redesc.).

Mantis precaria, Fabricius, 1775, p.277 (redesc.); Goeze, 1778, p.25 (redesc.); Fabricius, 1781, p.349 (redesc.); Fabricius, 1787, p.228 (redesc.); Olivier, 1792, p.628 (redesc.); Fabricius, 1793, p.20 (redesc.); Lichtenstein, 1802, p.26 (redesc.); Palisot, 1805, p.61, t.12, f.1 (redesc.); Thunberg, 1815, p.290 (redesc.); Audinet-Serville, 1831, p.53 (men.); Audinet-Serville, 1839, p.181 (redesc.); Charpentier, 1841, p.292 (redesc.); Charpentier, 1844, p.302 (men.).

Stagmatoptera precaria, Saussure, 1869, p.67 (men.); Saussure, 1870, p.232 (men.); Kirby, 1904, p.300 (men.); Brunner, 1906, p.144 (men.); Rehn, 1911, p.13 (men.); Giglio-Tos, 1914, p.32 (redesc.); Giglio-Tos, 1927, p.598 (redesc.); Terra, 1995, p.65 (men.); Ehrmann, 2002, p.329 (men.); Agudelo et al., 2007, p.125 (men.); Ehrmann \& Koçak, 2009, p.12 (men.).

= Mantis cubitata Goeze, 1778, p.34 (descr.); Kirby, 1904, p.300 (sin.).

= Mantis octosetosa Goeze, 1778, p.35 (descr.); Kirby, 1904, p.300 (sin.).

= Mantis ocellata Olivier, 1792, p.639 (descr.); Kirby, 1904, p.300 (sin.).

= Mantis obsecraria Lichtenstein, 1802, p.28 (descr.).

= Mantis annulata Stoll, 1813, p.55, t.18, f.66 (descr.);

= Mantis (Stagmatoptera) praecaria, Burmeister, 1838, p.539 (redesc.).

= Mantis praecaria, Burmeister, 1864, p.236 (redesc.); Werner, 1925a, p.167 (redesc.).

= Stagmatoptera obsecraria, Saussure, 1869, p.67 (men.); Saussure, 1870, p.232 (men.); Kirby, 1904, p.300 (sin.).

= Stagmatoptera annulata Saussure, 1871b, p.91, t.1, f.9 (redesc.); Saussure, 1872, p.256 (men.); Stål, 1877, p.72 (men.); Borre, 1883, p.66 (men.); Westwood, 1889, p.15 (men.); Saussure \& Zehntner, 1894, p.187 (redesc.); Kirby, 1904, p.300 (sin.).

= Stagmomantis precaria, Brunner, 1897, p.3, t.2, f.22; Giglio-Tos, 1927, p.598 (men.). 
Redescrição: Macho - Figuras 121A, 122-133.

Antenômeros filiformes. Escudo frontal com duas elevações centrais (Fig. 122).

Protorax alongado, delgado, com margens dotadas de crenulação suave na prozona, lisas na metazona. Metazona com uma quilha central pouco desenvolvida (Fig. 123). Coxas anteriores com margem anterior crenulada dotada de 6 a 11 espinhos grandes e 0 a 7 espinhos menores (Fig. 124). Fêmures anteriores alongados e largos, com os três primeiros espinhos discoidais a partir da base, pretos em sua face interna; 14 a 17 espinhos internos, sendo o número mais frequente 15 , o primeiro espinho interno a partir da base e os grandes espinhos internos são pretos na face interna, podendo apresentar uma pequena mancha de mesma coloração na inserção dos espinhos 8, 10 e 12. Mancha femoral interna estendendo-se da canaleta da garra tibial até o $6^{\circ}$ espinho interno a partir da base, com formato retangular e uma coloração preta suave, ou começando forte e enfraquecendo-se em direção ao ápice do fêmur (Fig. 125). Tíbias anteriores dotadas de 10 a 13 espinhos externos sendo mais frequente 11, e 14 a 16 espinhos internos, sendo mais frequente 15; a garra tibial e o último espinho que a precede são escuros na face interna (Fig. 126) ou somente a garra tibial escura. Tarsos com manchas pretas apicais na face interna dos tarsômeros I a IV.

Área discoidal das tégminas verde opaca em uma estreita faixa anterior, passando bruscamente ou gradualmente para hialina. Estigma circular e pequeno, com o seguinte padrão: uma mancha branca anterior e uma mancha marrom posterior. Asas com as áreas discoidal e anal hialinas, com molduras amarelas na metade anterior ou totalmente hialinas (Fig. 121A).

Genitália: Falômero esquerdo mais longo que largo, esclerito L4B tão longo quanto largo. Processo apical longo, levemente dilatado no lado esquerdo de sua base; inclinado em relação à base, formando um ângulo de aproximadamente $45^{\circ}$, ápice simples, voltado ventralmente (Fig. 127). Processo distal estreito e curto, achatado, curvado bruscamente $90^{\circ}$ para a direita, ápice bem esclerosado e afilado (Fig. 128). Apófise falóide longa e paralela em relação à genitália (Fig. 129); margem direita lisa e sinuosa (Fig. 130); ápice posterior intumescido com uma projeção para a direita, rugoso e fortemente esclerosado; ápice anterior reto, margens bem esclerosadas, e intumescidas, formando uma canaleta (Fig. 129). Lobo 
membranoso curto, curvado para a direita (Fig. 129). Membrana adjacente à apófise falóide glabra (Fig. 129).

Falômero direito com ápice posterior arredondado; braço médio curto, com uma expansão na metade, formando uma elevação alta e estreita (Fig. 131); placa ventral longa, esclerosada (Fig. 132 e 133); processo ventral curto, bem esclerosado, ápice retangular (Fig. 132); apódema anterior longo, passando suavemente a um ápice arredondado (Fig. 133).

Fêmea - Figuras 121B, 134-141.

Escudo frontal com duas elevações centrais (Fig. 134).

Protorax alongado, delgado, com margens dotadas de crenulação suave. Metazona com uma quilha central pouco desenvolvida (Fig. 135). Coxas anteriores com margem anterior crenulada dotada de 7 a 13 espinhos grandes e 3 a 11 espinhos menores (Fig. 136). Fêmures anteriores alongados e largos, com os três primeiros espinhos discoidais a partir da base pretos em sua face interna; 14 a 20 espinhos internos, sendo o mais frequentes 15 , o primeiro espinho interno a partir da base e os grandes espinhos internos são pretos na face interna, podendo apresentar uma pequena mancha de mesma coloração na inserção dos espinhos 8, 10 e 12. Mancha femoral interna estendendo-se da canaleta da garra tibial até o $6^{\circ}$ espinho interno a partir da base, com formato retangular e uma coloração preta suave, ou começando forte e enfraquecendo-se em direção ao ápice do fêmur (Fig. 137). Tíbias anteriores dotadas de 10 a 13 espinhos externos, sendo mais frequente 11, e 14 a 17 espinhos internos, sendo mais frequente 15; a garra tibial e o último espinho que a precede escuros na face interna (Fig. 138) ou somente a garra tibial escura. Tarsos com manchas pretas apicais na face interna dos tarsômeros I a IV.

Estigma circular e pequeno, com o seguinte padrão: uma mancha branca anterior e uma mancha marrom posterior. Asas com área costal hialina e as áreas discoidal e anal com molduras amarelas nas veias transversais (Fig. 121B).

Genitália: Base das gonapófises VIII se projetando internamente (Fig. 139). Basiválvula com formato aproximadamente triangular, ápice intumescido (Fig. 139), a superfície interna esculpida (Fig. 140). Interbasiválvula esclerosada e esculpida (Fig. 140). Extensões posterolaterias curtas, esclerosadas, com margens lisas (Fig. 140). Esclerito na 
parede dorsal da papila genital esclerosado, liso (Fig. 141). Plataforma lateroesternal aproximadamente retangular, processos posteriores longos, cônicos (Fig. 141).

\section{Localidade tipo: -}

Outras localidades: Brasil (Espírito Santo, Rio de Janeiro, Rio Grande do Sul, Santa Catarina, São Paulo)

Diagnose: Mancha no estigma circular e pequena, sem mancha na metade da face interna das tíbias anteriores

Tabela 6. Medidas e razões de machos e fêmeas de Stagmatoptera precaria.

\begin{tabular}{|c|c|c|}
\hline & Macho $(\mathrm{N}=30)$ & Fêmea $(\mathrm{N}=23)$ \\
\hline Comprimento & 64 a $81,9 \mathrm{~mm}$ & 68,9 a $91,3 \mathrm{~mm}$ \\
\hline Largura da cabeça & 7,2 a $8,1 \mathrm{~mm}$ & 8,6 a $10,8 \mathrm{~mm}$ \\
\hline Comprimento da Prozona & 4,3 a $5,3 \mathrm{~mm}$ & 5,7 a $7,5 \mathrm{~mm}$ \\
\hline Comprimento da Metazona & 17,6 a $22,5 \mathrm{~mm}$ & 23,3 a $32,3 \mathrm{~mm}$ \\
\hline Largura da Dilatação & 4,5 a $5,3 \mathrm{~mm}$ & 6,3 a $8,5 \mathrm{~mm}$ \\
\hline Comprimento da Tégmina & 45 a $57,8 \mathrm{~mm}$ & 43,2 a $51,1 \mathrm{~mm}$ \\
\hline Comprimento da Asa & 42,1 a $53,3 \mathrm{~mm}$ & 38,3 a $45,6 \mathrm{~mm}$ \\
\hline Comprimento da Coxa Anterior & 12,5 a $14,6 \mathrm{~mm}$ & 16,3 a $20,9 \mathrm{~mm}$ \\
\hline Comprimento do Fêmur Anterior & 14,8 a $17,6 \mathrm{~mm}$ & 19,2 a $25,1 \mathrm{~mm}$ \\
\hline Largura do Fêmur Anterior & 2,6 a 3,3 mm & 3,9 a $5,2 \mathrm{~mm}$ \\
\hline Comprimento da Tíbia Anterior & 7,2 a $8,6 \mathrm{~mm}$ & 9,4 a $11,8 \mathrm{~mm}$ \\
\hline Razão Cabeça/Dilatação & 1,44 a 1,67 & 1,18 a 1,37 \\
\hline Razão Metazona/Prozona & 3,74 a 4,77 & 3,55 a 4,36 \\
\hline Razão Prozona/Dilatação & 0,9 a 1,07 & 0,82 a 0,97 \\
\hline Razão Metazona/Dilatação & 3,59 a 4,67 & 3,13 a 3,92 \\
\hline Razão Metazona/Coxa Anterior & 1,38 a 1,66 & 1,31 a 1,55 \\
\hline Razão Comprimento/Largura & 4,88 a 6,27 & 4,31 a 5,23 \\
\hline Fêmur Anterior & 1,92 a 2,22 & 1,97 a 2,21 \\
\hline Razão Fêmur/Tíbia & &
\end{tabular}

Material examinado: Brasil; Yersin, 19 (MHNG). 1903, Mme. Cerqueira, $1 \delta^{\lambda}$ (MNHN). v.1969, R. Pujol, 2ð (MNHN). Minas, Abbé David Dedit, $1 q(\mathrm{MNHN})$. Rio Tapajós, 1883, Parton, $1 q(\mathrm{MNHN})$. Espírito Santo - Coll. R. Ebner, 1§ิ (NHMW). Linhares,

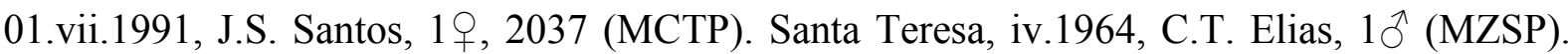




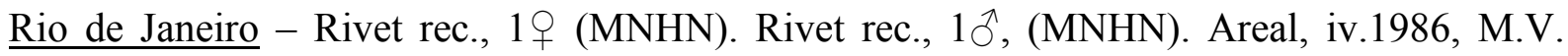
Ferraz, 1ð̄, (MZSP). Montagne des Orgues, environs de la Tijuca, 500-1000m, 1902, E.R. Wagner, 1 ( $\mathrm{MNHN}$ ). Montagne des Orgues, environs de la Tijuca, 500-1000m, 1902, E.R. Wagner, $1 \delta^{\Uparrow}(\mathrm{MNHN})$. Sepitiba, 27-30.iv.1957, M.A. D’Andretta, $1 \delta^{\Uparrow}$ (MZSP). Rio Grande do Sul - Imbé, ii.1986, L. Balinski, 1q, 1223 (MCTP). Osório, 1969, L. Famer leg., 10̂, 0522 (MCTP). Porto Alegre, 27.iii.1967, M. Drummond, 1§, 0060 (MCTP). Porto Alegre, 02.x.1975, Silvana Luciano, 1q, 0389 (MCTP). Porto Alegre, 15.ix.1989, R.A. Ramos, 1, 1438 (MCTP). Sta. C. do Sul, 17.ix.1980, L. Jantsch leg., 1ð̃, 0470 (MCTP). São Leopoldo, 10.iii.1965, Celio Valle col., 1ðึ (MZSP). Taquara, 22.iii.1983, R.T. Lupetti leg., 1 , 0363 (MCTP). Viamão, 07.viii.1973, Y.L.B. de Oliveira leg., 1, 0391 (MCTP). Santa Catarina H. Schulz., 2 q (ZSM). H. Schulz., $1 ð$ (ZSM). Col. Hansa [Corupá], 1901, Ehrhardt leg., $1 \overbrace{}^{\Uparrow}$ (MZSP). Nova Teutônia, 27.iii.1967, leg. F. Plaumann, 1 ( (MHNG). Nova Teutônia, 01.iv.1967, leg. F. Plaumann, $1 \widehat{\jmath}$ (MHNG). Nova Teutônia, 13.iv.1967, leg. F. Plaumann, $1 \widehat{\jmath}$ (MHNG). Rio Vermelho, xi.1950, Dirings col., 1 q (MZSP). [Colônia] Teresópolis, [Águas

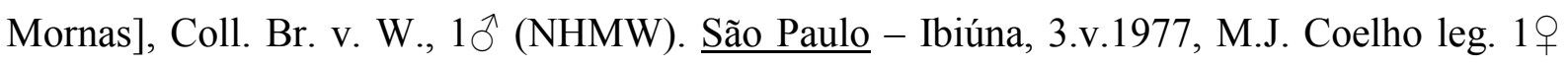
(MZSP). Ilhabela, 03-06.v.1962, Vanzolini col., 1ð̋ (MZSP). Piedade, 27.iii.2011, Rodrigues col., 19 (MZSP). Salesópolis, 850m, 13.iv.1966, Rabello col., 1ð̋ (MZSP). Bairro do Paúba,

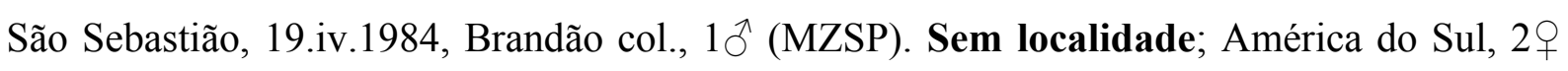
(ZMB). $1 q$ (MHNG). $1 q(\mathrm{NHMW}) .1 q(\mathrm{ZSM})$. Yersin, $1 q(\mathrm{MHNG})$. 

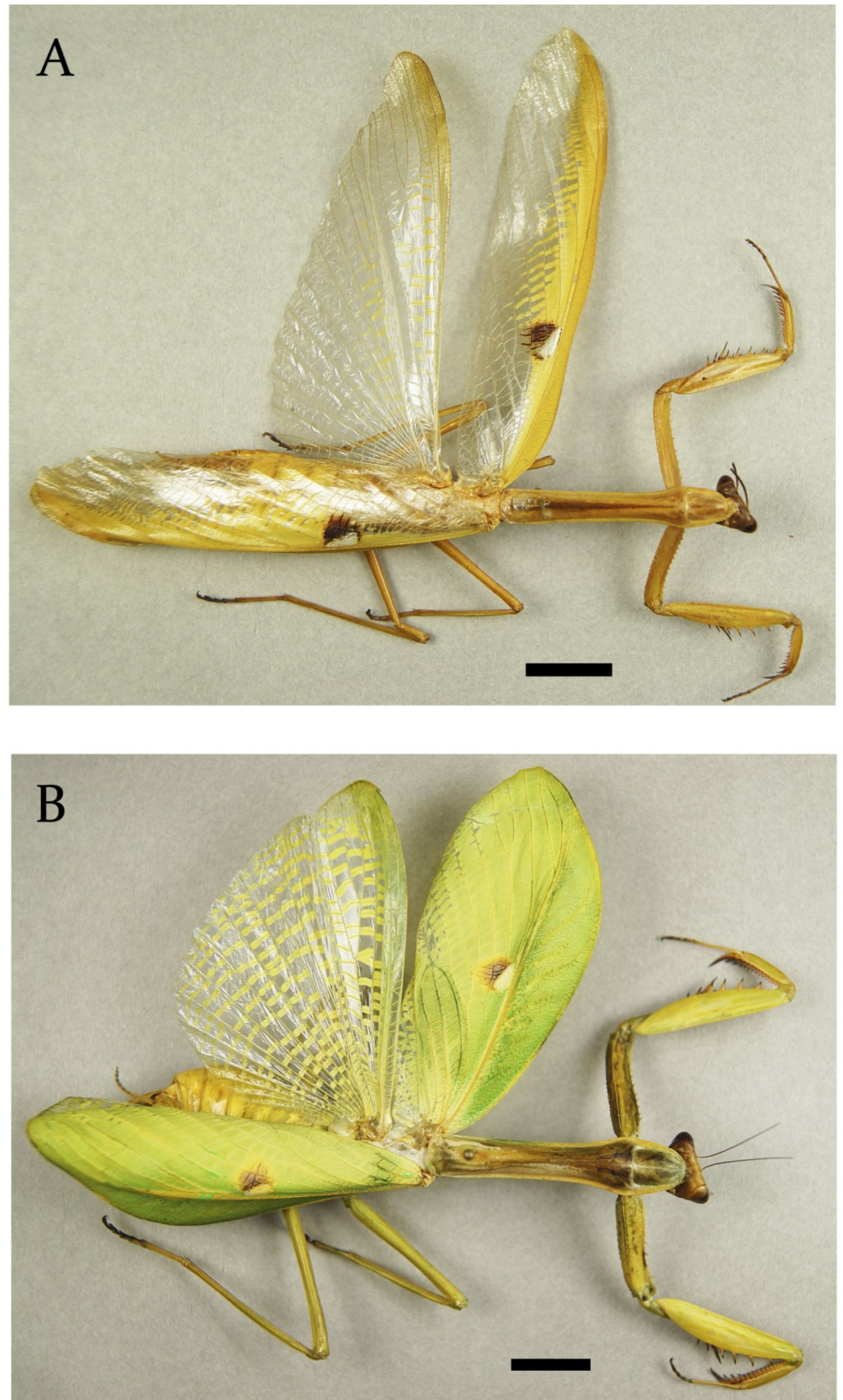

Figura 121. Stagmatoptera precaria, habitus dorsal. A, macho; B, fêmea. Escalas $=1 \mathrm{~cm}$. 


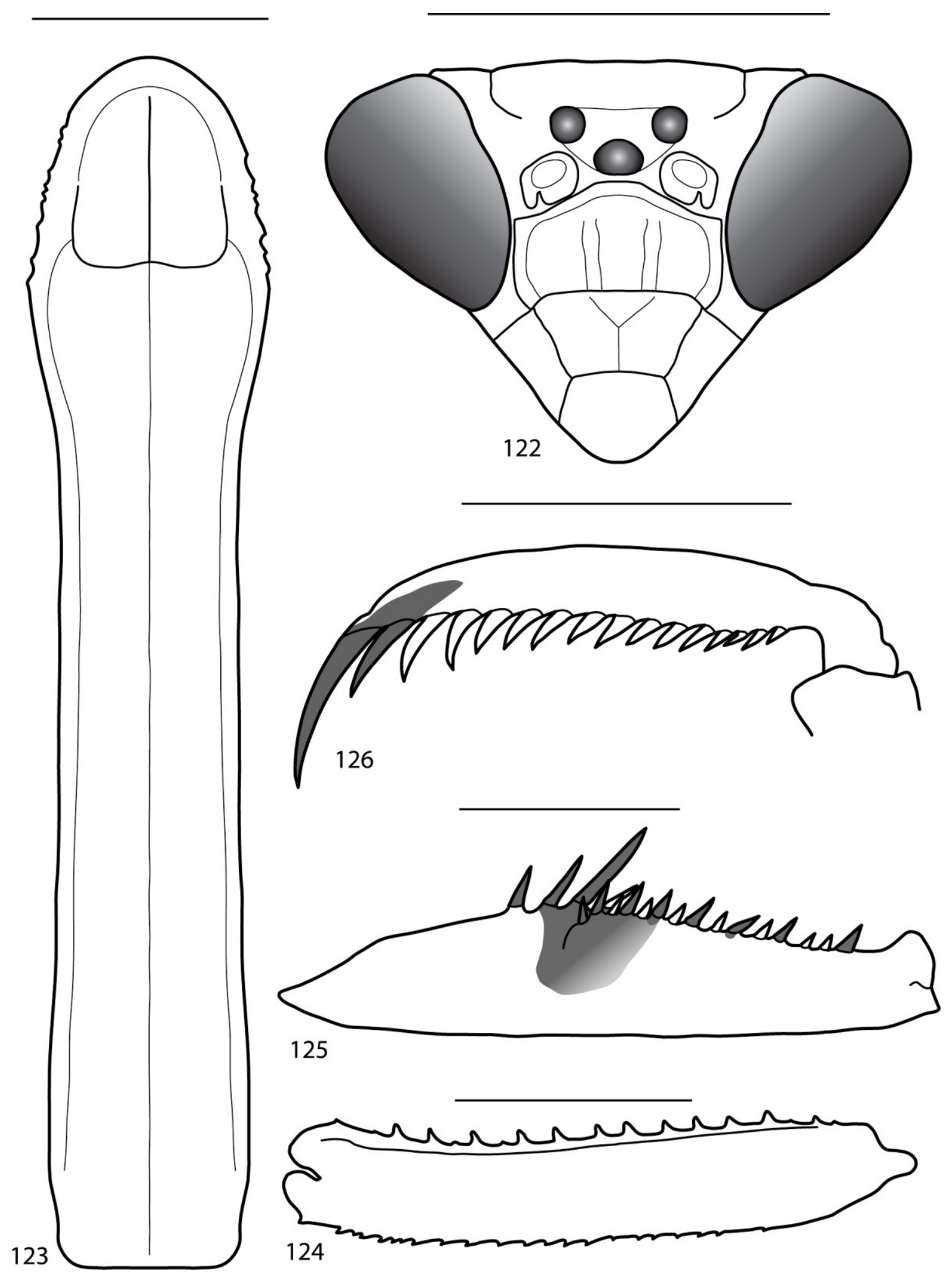

Figuras 122-126. Stagmatoptera precaria macho. 122, cabeça, vista frontal;12 3, protorax, vista dorsal; 124 , coxa anterior, vista interna; 125 , fêmur anterior, vista interna; 126, tíbia anterior, vista interna. Escalas $=5 \mathrm{~mm}$. 


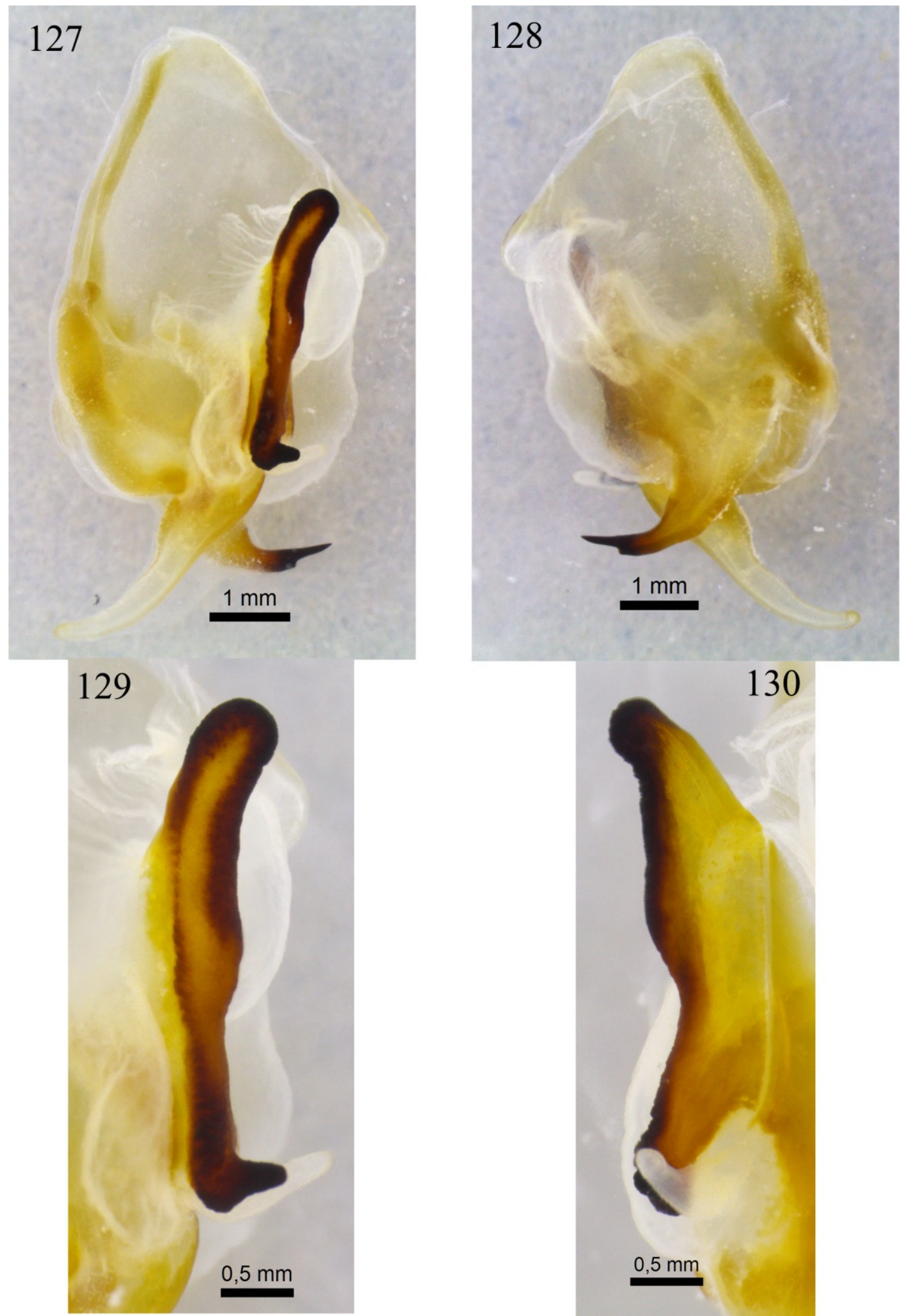

Figuras 127-130. Stagmatoptera precaria macho. 127, falômero esquerdo, vista dorsal; 128, falômero esquerdo, vista ventral; 129, apófise falóide e lobo membranoso, vista dorsal; 130, apófise falóide, vista lateral direita. 

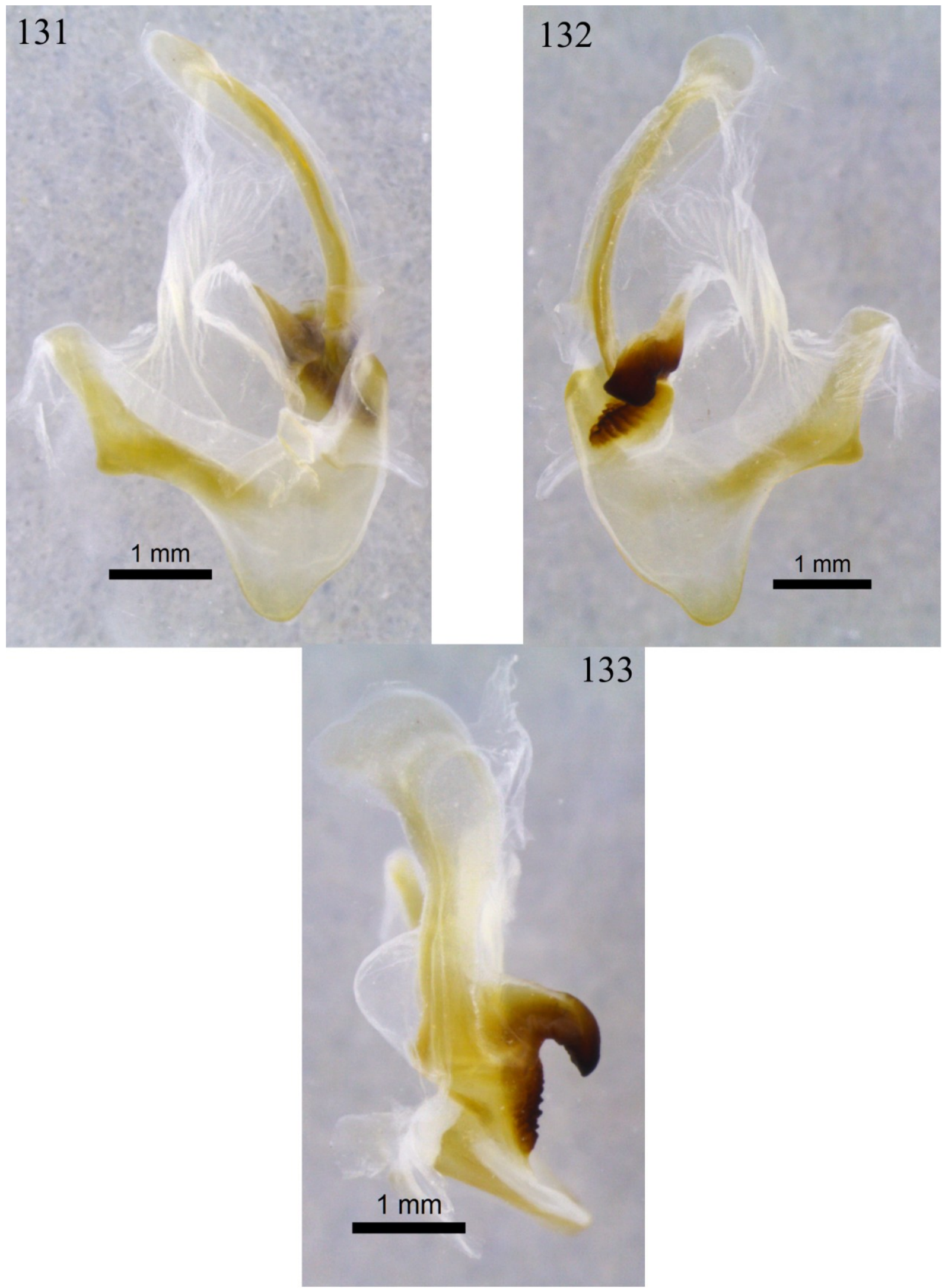

Figuras 131-133. Stagmatoptera precaria macho. 131, falômero direito, vista dorsal; 132, falômero direito, vista ventral; 133, falômero direito, vista lateral direita. 


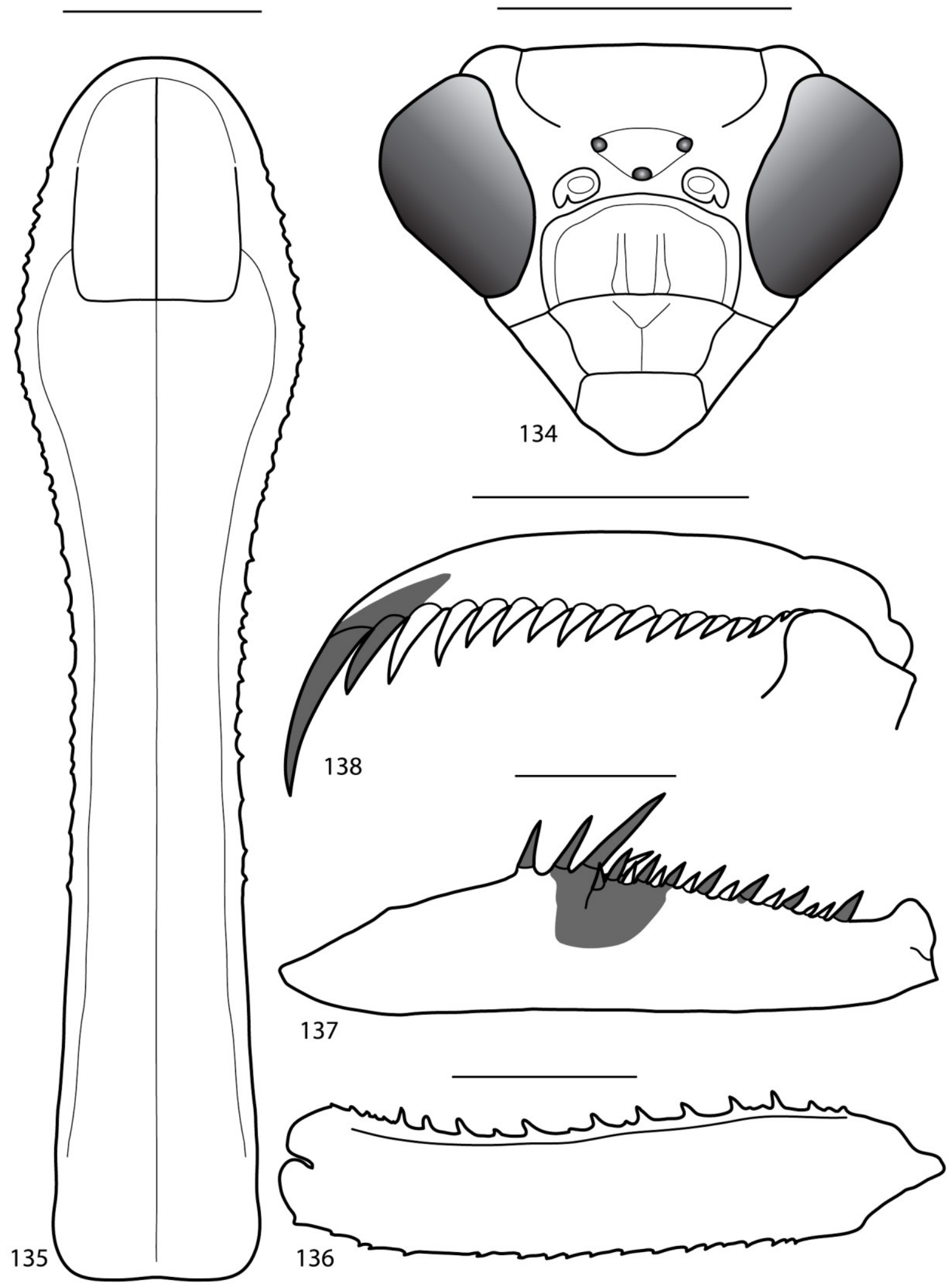

Figuras 134-138. Stagmatoptera precaria fêmea. 134, cabeça, vista frontal; 135, protorax, vista dorsal; 136, coxa anterior, vista interna; 137, fêmur anterior, vista interna; 138, tíbia anterior, vista interna. Escalas $=5 \mathrm{~mm}$. 


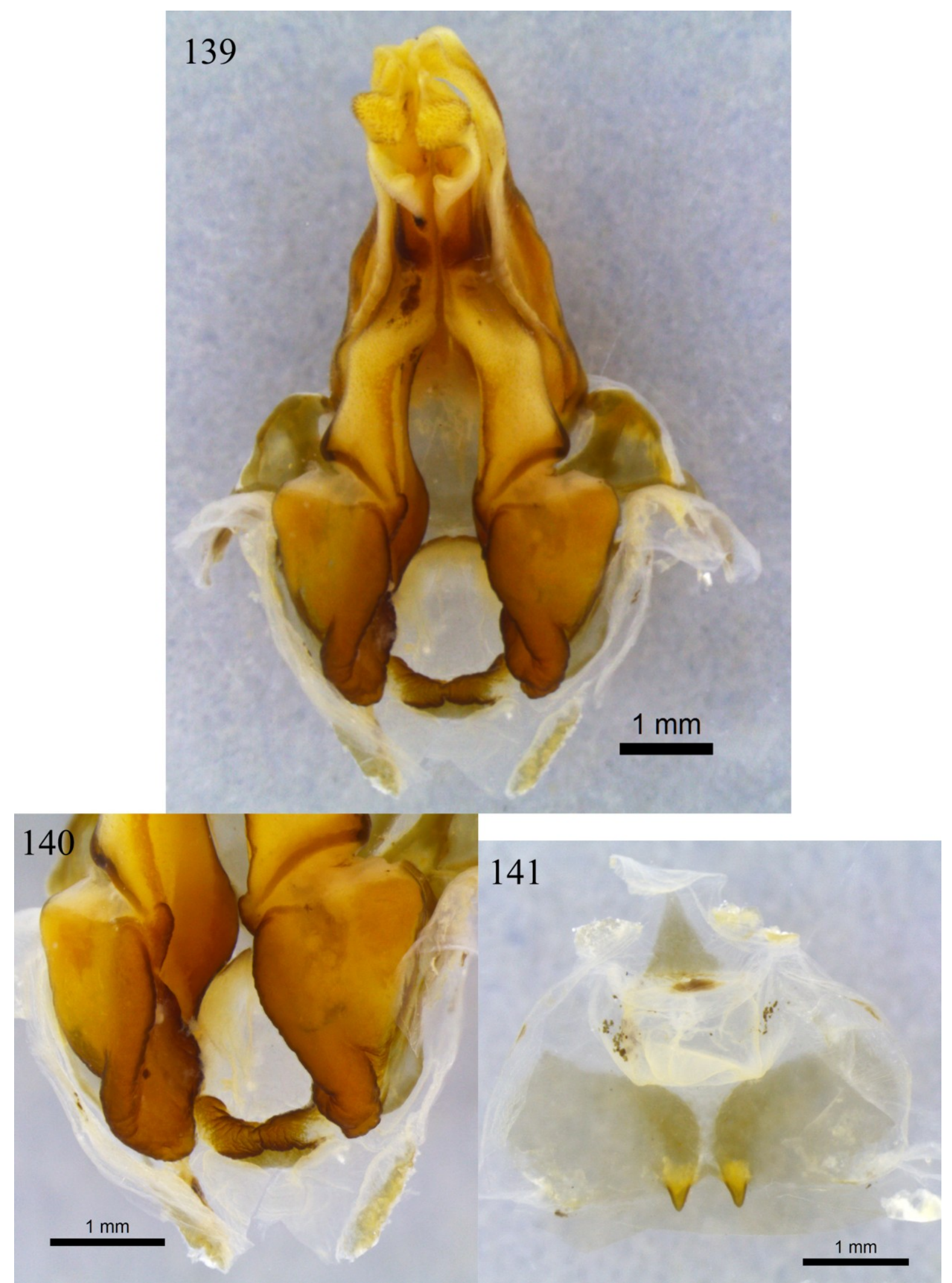

Figuras 139-141. Stagmatoptera precaria fêmea. 139, ovipositor, vista ventral; 140, detalhe das gonocoxas; 141, assoalho da câmara genital, vista dorsal. 
Stagmatoptera pumila Werner, 1925

Stagmatoptera pumila Werner, 1925, p.383 (descr.); Terra, 1995, p.65 (men.); Ehrmann, 2002, p.329 (men.); Agudelo et al., 2007, p.125 (men.); Ehrmann \& Koçak, 2009, p.12 (men.).

Tipo: um macho, sem localidade (examinado)

Redescrição: Macho - Figuras 142-147.

Antenômeros filiformes. Escudo frontal com duas elevações centrais (Fig. 143).

Protorax alongado, delgado, com margens dotadas de crenulação suave na prozona, lisas na metazona. Metazona com uma quilha central pouco desenvolvida (Fig. 144). Coxas anteriores com margem anterior crenulada dotada de 9 espinhos grandes e 4 a 10 espinhos menores (Fig. 145). Fêmur anterior alongado e fino, com os três primeiros espinhos discoidais a partir da base, pretos em sua face interna; 15 espinhos internos, os dois primeiros espinhos internos a partir da base e os grandes espinhos internos são pretos na face interna, apresentando uma pequena mancha de mesma coloração na inserção dos espinhos 6, 8, 10 e 12. Mancha femoral interna estendendo-se da canaleta da garra tibial até o $4^{\circ}$ espinho interno a partir da base, com formato retangular começando forte e enfraquecendo-se em direção ao ápice do fêmur (Fig. 146). Tíbia anterior dotada de 10 espinhos externos, e 14 espinhos internos; a garra tibial e o último espinho que a precede são escuros na face interna (Fig. 147).

Área discoidal das tégminas opaca em uma faixa anterior, passando gradualmente para hialina. Estigma circular de tamanho mediano, com o seguinte padrão: uma mancha branca anterior e uma mancha marrom posterior. Asas com a área discoidal com molduras amarelas e a área anal hialinas com molduras amarelas na metade anterior (Fig. 142).

\section{Localidade tipo: -}

\section{Outras localidades: -}

Diagnose: Tégminas mais curtas que as asas na posição de repouso, ambas mais curtas que o abdômen. 
Tabela 7. Medidas e razões do macho de Stagmatoptera pumila.

\begin{tabular}{|c|c|c|}
\hline & Macho & Fêmea \\
\hline Comprimento & $53,8 \mathrm{~mm}$ & - \\
\hline Largura da cabeça & $6,4 \mathrm{~mm}$ & - \\
\hline Comprimento da Prozona & $3,9 \mathrm{~mm}$ & - \\
\hline Comprimento da Metazona & $15,7 \mathrm{~mm}$ & - \\
\hline Largura da Dilatação & $3,9 \mathrm{~mm}$ & - \\
\hline Comprimento da Tégmina & $24,3 \mathrm{~mm}$ & - \\
\hline Comprimento da Asa & $24,2 \mathrm{~mm}$ & - \\
\hline Comprimento da Coxa Anterior & $10,7 \mathrm{~mm}$ & - \\
\hline Comprimento do Fêmur Anterior & $12,6 \mathrm{~mm}$ & - \\
\hline Largura do Fêmur Anterior & $2,4 \mathrm{~mm}$ & - \\
\hline Comprimento da Tíbia Anterior & $6,3 \mathrm{~mm}$ & - \\
\hline Razão Cabeça/Dilatação & 1,64 & - \\
\hline Razão Metazona/Prozona & 4,03 & - \\
\hline Razão Prozona/Dilatação & 1 & - \\
\hline Razão Metazona/Dilatação & 4,03 & - \\
\hline Razão Metazona/Coxa Anterior & 1,47 & - \\
\hline Razão Comprimento/Largura & 5,25 & - \\
\hline Fêmur Anterior & 2 & - \\
\hline Razão Fêmur/Tíbia & & \\
\hline
\end{tabular}

Material examinado: Sem localidade; Holótipo, $1 \delta$ (NHRS). 


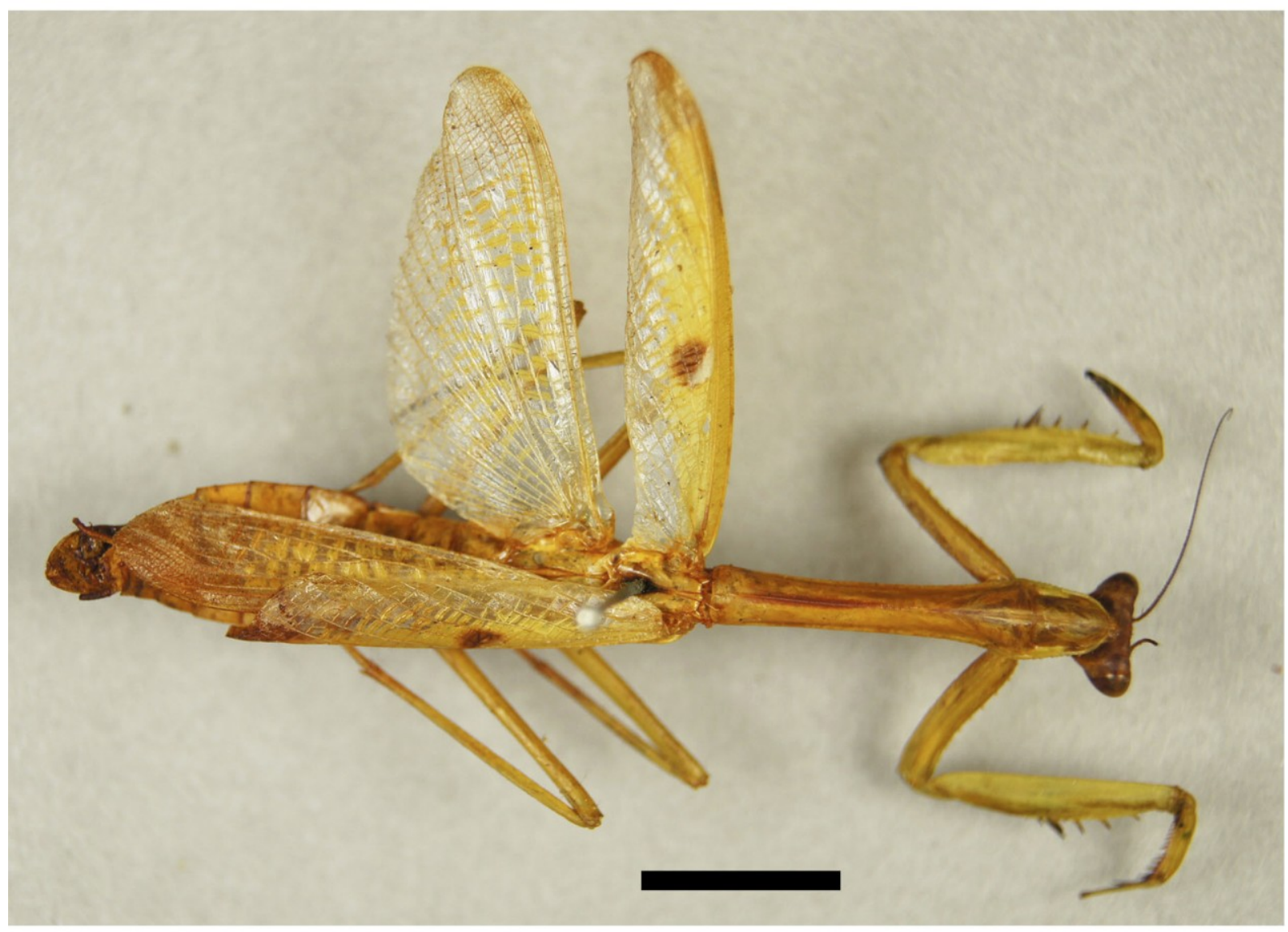

Figura 142. Stagmatoptera pumila, habitus dorsal, macho. Escalas $=1 \mathrm{~cm}$. 


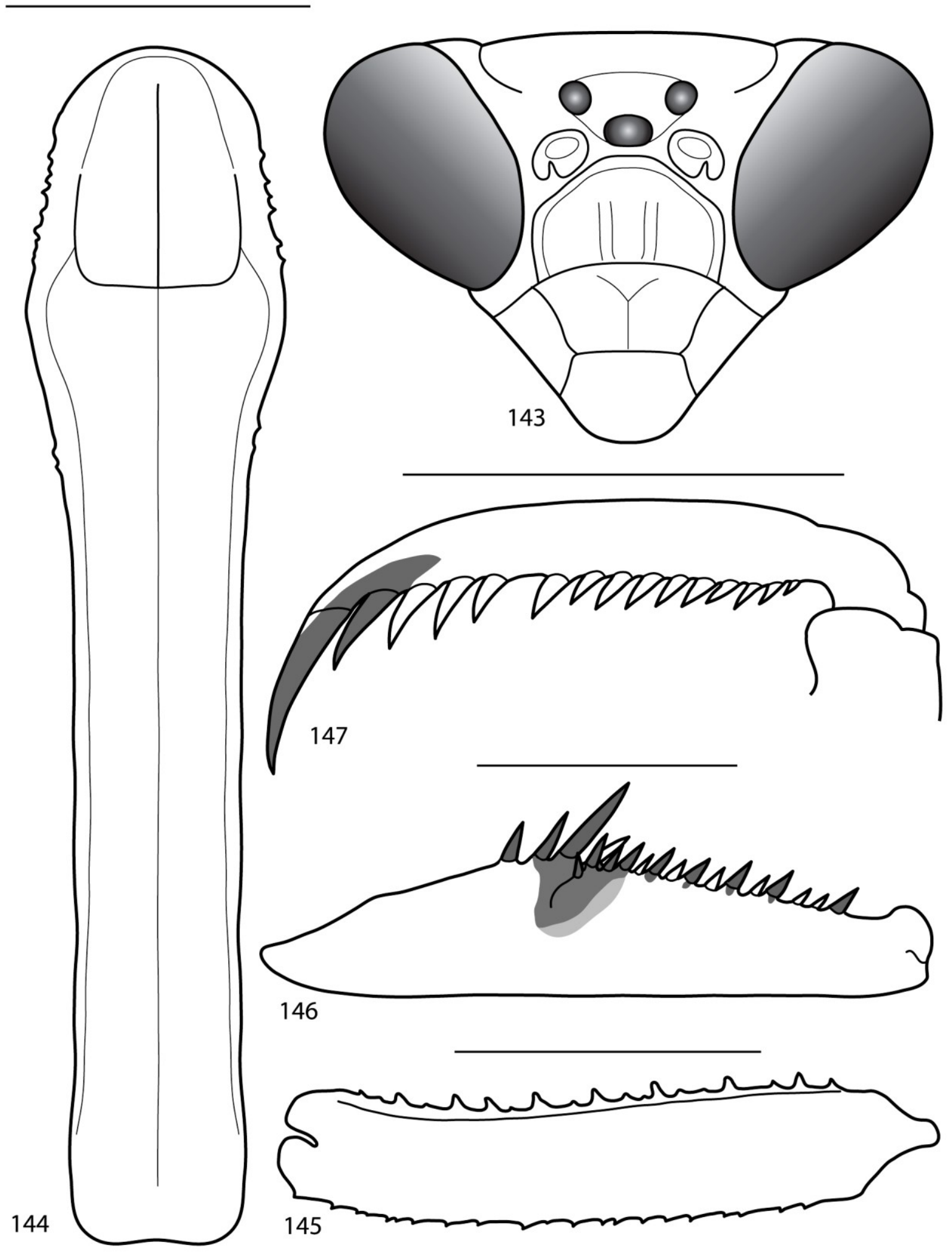

Figuras 143-147. Stagmatoptera pumila macho. 143, cabeça, vista frontal; 144, protorax, vista dorsal; 145, coxa anterior, vista interna; 146, fêmur anterior, vista interna; 147, tíbia anterior, vista interna. Escalas $=5 \mathrm{~mm}$. 
Stagmatoptera reimoseri Beier, 1929

Stagmatoptera hyaloptera, Perty, 1832 de Werner, 1925b, p.382 - identificação errada (descr.).

Stagmatoptera reimoseri Beier, 1929, p. 252 (descr.); Ehrmann, 2002, p.330 (men.); Agudelo et al., 2007, p.126 (men.); Ehrmann \& Koçak, 2009, p.12 (men.).

Tipos: um macho e uma fêmea, Santa Sofia, Paraguai, 1908, Reimoser leg. (examinados); uma fêmea, San Luis, Paraguai, 1908, Reimoser leg.; uma fêmea, São Paulo.

Redescrição: Macho - Figuras 148A, 149-160.

Antenômeros filiformes. Escudo frontal com quatro elevações (Fig. 149).

Protorax curto, largo, com margens dotadas de crenulação suave na prozona, lisas na metazona. Metazona com uma quilha central pouco desenvolvida (Fig. 150). Coxas anteriores com margem anterior crenulada dotada de 5 a 8 espinhos grandes e 0 a 5 espinhos menores (Fig. 151). Fêmures anteriores alongados e largos, com os três primeiros espinhos discoidais a partir da base, escuros em sua face interna; 14 a 15 espinhos internos, sendo o número mais frequente 15, o primeiro espinho interno a partir da base e os grandes espinhos internos são escuros na face interna, podendo apresentar uma pequena mancha de mesma coloração na inserção dos espinhos 10 e 12. Mancha femoral interna estendendo-se da canaleta da garra tibial até o $8^{\circ}$ espinho interno a partir da base, com formato retangular e uma coloração preta suave, podendo ser um pouco mais forte na base dos espinhos (Fig. 152). Tíbias anteriores dotadas de 9 a 11 espinhos externos sendo mais frequente 11, e 14 a 16 espinhos internos, sendo mais frequente 15; a garra tibial verde na face interna (Fig. 153). Tarsos com manchas pretas apicais na face interna dos tarsômeros I a IV.

Área discoidal das tégminas verde opaca em uma estreita faixa anterior, passando bruscamente ou gradualmente para hialina. Estigma de tamanho mediano, com o seguinte padrão: uma mancha branca anterior e duas manchas marrom laterais, aberta posteriormente. Asas totalmente hialinas (Fig. 148A).

Genitália: Falômero esquerdo mais longo que largo, esclerito L4B mais longo que largo. Processo apical longo, levemente dilatado no lado esquerdo de sua base; reto em relação à base, e depois curvando para a esquerda aproximadamente $45^{\circ}$; ápice simples, voltado ventralmente (Fig. 154). Processo distal largo e curto, achatado, curvado bruscamente 
$90^{\circ}$ para a direita, fortemente comprimido pouco antes do ápice, e comprimido novamente na base do ápice, que é bem esclerosado e afilado (Fig. 155). Apófise falóide longa e paralela em relação à genitália (Fig. 156); margem direita rugosa e sinuosa (Fig. 157); ápice posterior intumescido com duas projeções, uma voltada para a direita e outra posteriormente, rugoso e fortemente esclerosado; ápice anterior reto, margens fortemente esclerosadas, e intumescidas, formando uma canaleta (Fig. 156). Lobo membranoso curto, curvado para a direita e anteriormente (Fig. 156). Membrana adjacente à apófise falóide pilosa (Fig. 156).

Falômero direito com ápice posterior truncado; braço médio curto, com uma expansão antes da metade, formando uma elevação (Fig. 158); placa ventral curta, fortemente esclerosada (Fig. 159 e 160); processo ventral longo, esclerosado, ápice formando um ângulo (Fig. 159); apódema anterior longo, passando bruscamente a um ápice arredondado (Fig. 160).

Fêmea - Figuras 148B, 161-168.

Escudo frontal com quatro elevações (Fig. 161).

Protorax curto, largo, com margens dotadas de crenulação suave. Metazona com uma quilha central pouco desenvolvida (Fig. 162). Coxas anteriores com margem anterior crenulada dotada de 6 a 8 espinhos grandes e 1 a 12 espinhos menores (Fig. 163). Fêmures anteriores alongados e largos, com os três primeiros espinhos discoidais a partir da base escuros em sua face interna; 14 a 15 espinhos internos, sendo o mais frequentes 15 , o primeiro espinho interno a partir da base e os grandes espinhos internos são escuros na face interna, podendo apresentar uma pequena mancha de mesma coloração na inserção dos espinhos $10 \mathrm{e}$ 12. Mancha femoral interna estendendo-se da canaleta da garra tibial até o $8^{\circ}$ espinho interno a partir da base, com formato retangular e uma coloração preta suave (Fig. 164). Tíbias anteriores dotadas de 10 a 12 espinhos externos, sendo mais frequente 11, e 13 a 16 espinhos internos, sendo mais frequente 15; a garra tibial verde na face interna (Fig. 165). Tarsos com manchas pretas apicais na face interna dos tarsômeros I a IV.

Estigma de tamanho mediano, com o seguinte padrão: uma mancha branca anterior e duas manchas marrom laterais, podendo ser aberto posteriormente. Asas com área costal hialina e as áreas discoidal e anal com molduras amarelas nas veias transversais (Fig. 148B).

Genitália: Base das gonapófises VIII se projetando internamente (Fig. 166). Basiválvula com formato aproximadamente triangular (Fig. 166), a superfície interna 
esculpida (Fig. 167). Interbasiválvula esclerosada e esculpida (Fig. 167). Extensões posterolaterias curtas, fracamente esclerosadas com margens lisas (Fig. 167). Esclerito na parede dorsal da papila genital esclerosado, esculpido (Fig. 168). Plataforma lateroesternal aproximadamente retangular, processos posteriores curtos, cônicos (Fig. 168).

Localidade tipo: Santa Sofia, Paraguai

Outras localidades: Brasil (Mato Grosso, Minas Gerais, São Paulo, Tocantins)

Diagnose: Mancha no estigma em ambos os sexos com uma mancha branca anterior e duas manchas marrom, uma de cada lado da mancha branca, podendo ser aberta na parte posterior, protorax largo e curto. 
Tabela 8. Medidas e razões de machos e fêmeas de Stagmatoptera reimoseri.

\begin{tabular}{|c|c|c|}
\hline & Macho & Fêmea \\
\hline Comprimento & 60 a $64,3 \mathrm{~mm}$ & 58,3 a $76,6 \mathrm{~mm}$ \\
\hline Largura da cabeça & 7,7 a $8,3 \mathrm{~mm}$ & 8,8 a $10,7 \mathrm{~mm}$ \\
\hline Comprimento da Prozona & 4,6 a $5,2 \mathrm{~mm}$ & 5,5 a $6,7 \mathrm{~mm}$ \\
\hline Comprimento da Metazona & 14,7 a $16,4 \mathrm{~mm}$ & 16,1 a $21,4 \mathrm{~mm}$ \\
\hline Largura da Dilatação & 5,5 a $6,1 \mathrm{~mm}$ & 6,8 a $8,6 \mathrm{~mm}$ \\
\hline Comprimento da Tégmina & 49,6 a $52,1 \mathrm{~mm}$ & 41 a $48,4 \mathrm{~mm}$ \\
\hline Comprimento da Asa & 45,2 a $48,4 \mathrm{~mm}$ & 34,7 a $41,3 \mathrm{~mm}$ \\
\hline Comprimento da Coxa Anterior & 11,8 a $13,8 \mathrm{~mm}$ & 14,4 a $19,5 \mathrm{~mm}$ \\
\hline Comprimento do Fêmur Anterior & 14,8 a $15,8 \mathrm{~mm}$ & 17,2 a $21,7 \mathrm{~mm}$ \\
\hline Largura do Fêmur Anterior & 3,6 a $3,9 \mathrm{~mm}$ & 4,3 a $5,4 \mathrm{~mm}$ \\
\hline Comprimento da Tíbia Anterior & 7,9 a $9 \mathrm{~mm}$ & 8,8 a $11,8 \mathrm{~mm}$ \\
\hline Razão Cabeça/Dilatação & 1,31 a 1,4 & 1,17 a 1,34 \\
\hline Razão Metazona/Prozona & 2,94 a 3,35 & 2,76 a 3,33 \\
\hline Razão Prozona/Dilatação & 0,8 a 0,85 & 0,73 a 0,84 \\
\hline Razão Metazona/Dilatação & 2,49 a 2,72 & 2,26 a 2,49 \\
\hline Razão Metazona/Coxa Anterior & 1,17 a 1,25 & 1,02 a 1,2 \\
\hline Razão Comprimento/Largura & 3,82 a 4,39 & 3,82 a 4,29 \\
\hline Fêmur Anterior & 1,66 a 1,96 & 1,78 a 1,97 \\
\hline Razão Fêmur/Tíbia & & \\
\hline
\end{tabular}

Material examinado: Brasil; Mato Grosso - Mato Verde, 13.iii.1945, Raymundo P. Luz, 19, (MZSP). Minas Gerais - Lavras, 194?, C. Braga, 19 (MZSP). Sete Lagoas, iii.1963,

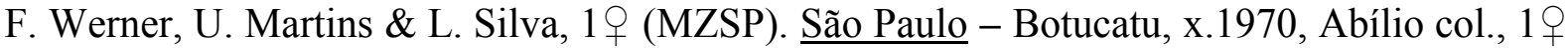
(MZSP). Botucatu, iv.1972, P. Assumpção \& A. Clarot, 1ठ (MZSP). Botucatu, 12.iii.1980, R. Carvalho, $1{ }^{\Uparrow}$ (MZSP). Faz. Itaquerê, Nova Europa, 23.iv.1968, K. Lenko col., $1 \hat{\jmath}$ (MZSP). Rio Claro, 25.ii.1943, Pd. F.S. Pereira col., $1 \widehat{\jmath}$ (MZSP). S. Paulo, 19 (NHMW). Tocantins Miranorte, iv.1965, L. Gomes col., $1 q$ (MZSP). Paraguai; Santa Sofia, Holótipo, Reimoser, $1 ठ \AA$ (NHMW). Santa Sofia, Parátipo, Reimoser, 1 ( NHMW). 


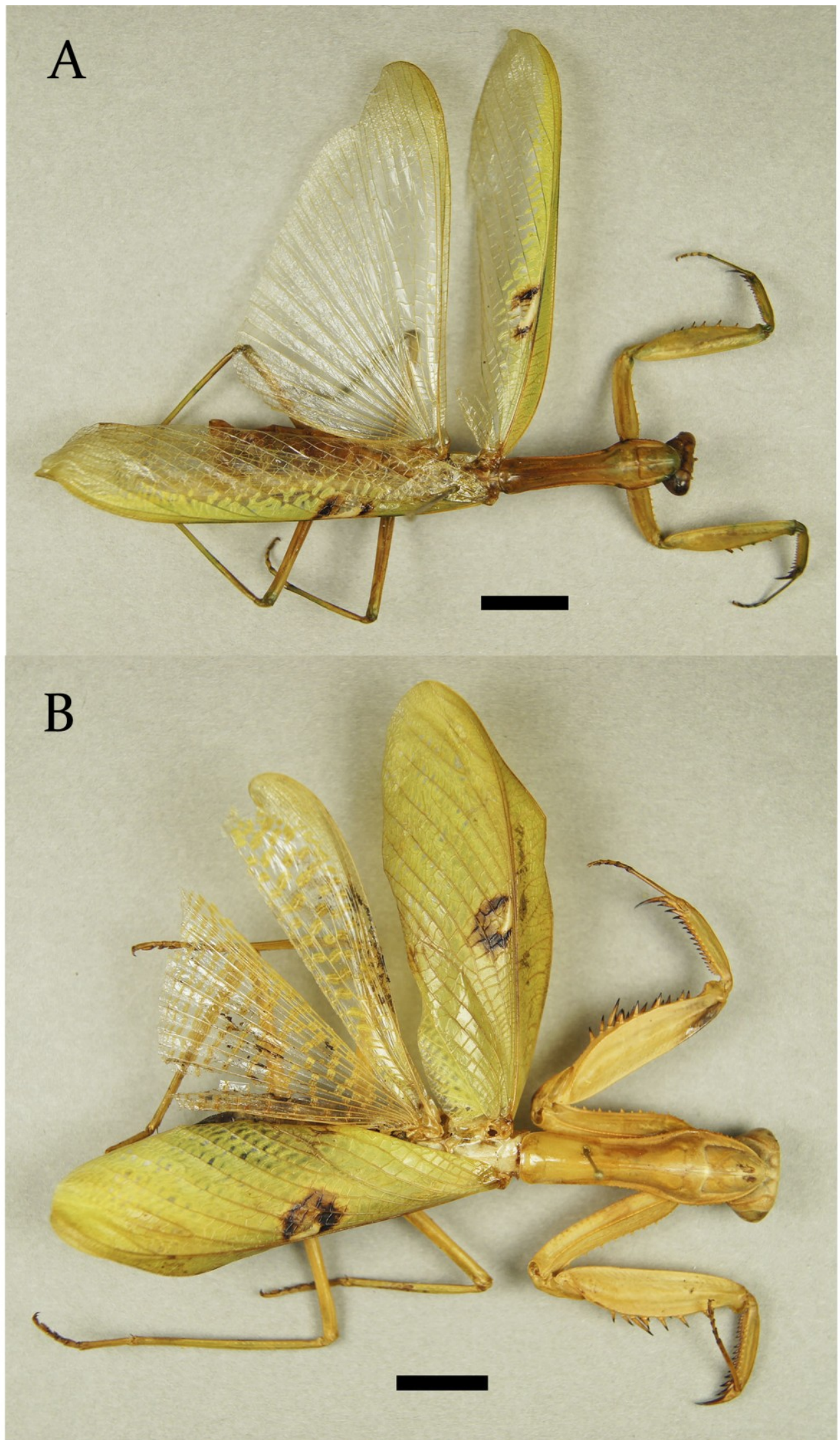

Figura 148. Stagmatoptera reimoseri, habitus dorsal. A, macho; B, fêmea. Escalas $=1 \mathrm{~cm}$. 


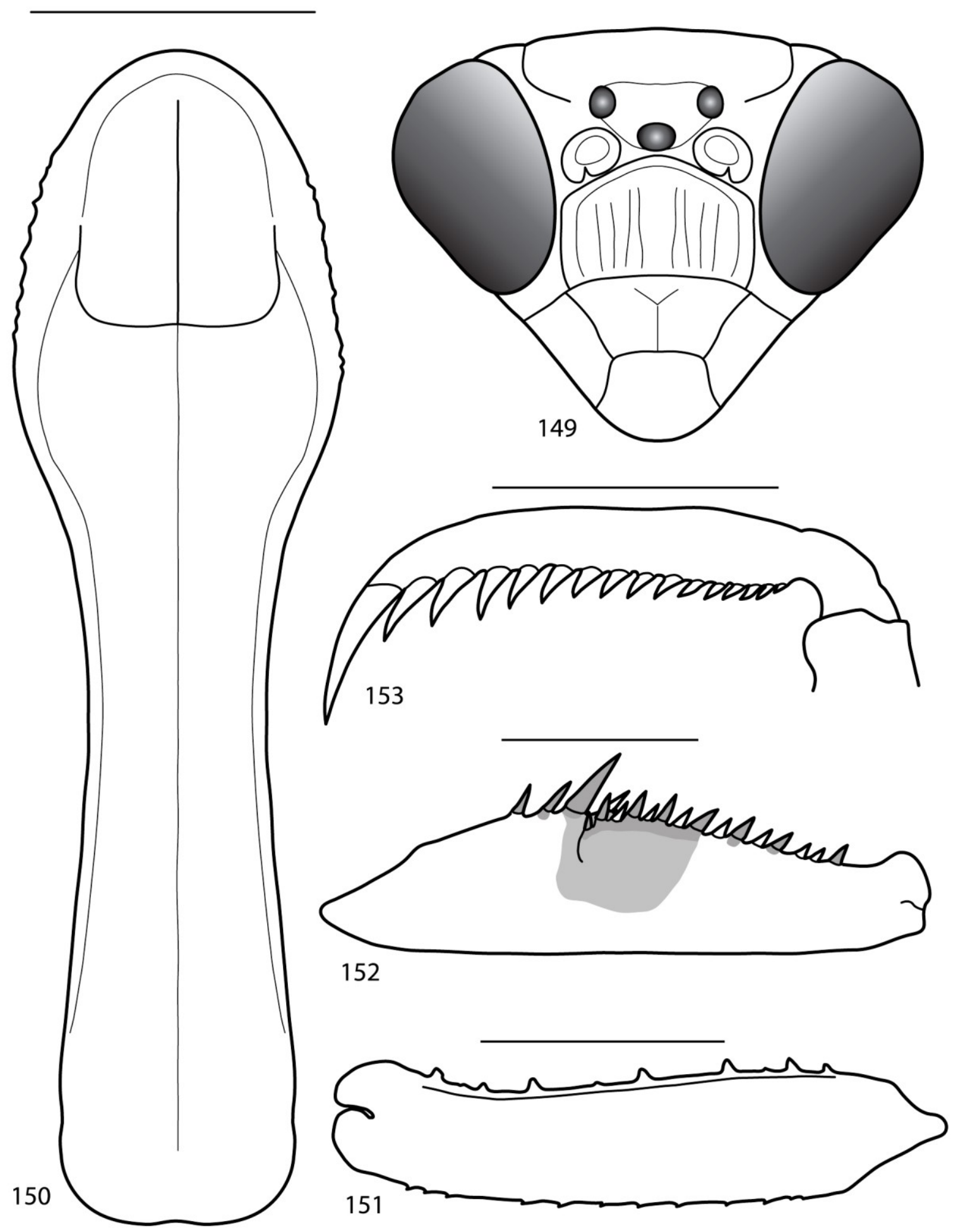

Figuras 149-153. Stagmatoptera reimoseri macho. 149, cabeça, vista frontal; 150, protorax, vista dorsal; 151, coxa anterior, vista interna; 152, fêmur anterior, vista interna; 153, tíbia anterior, vista interna. Escalas $=5 \mathrm{~mm}$. 

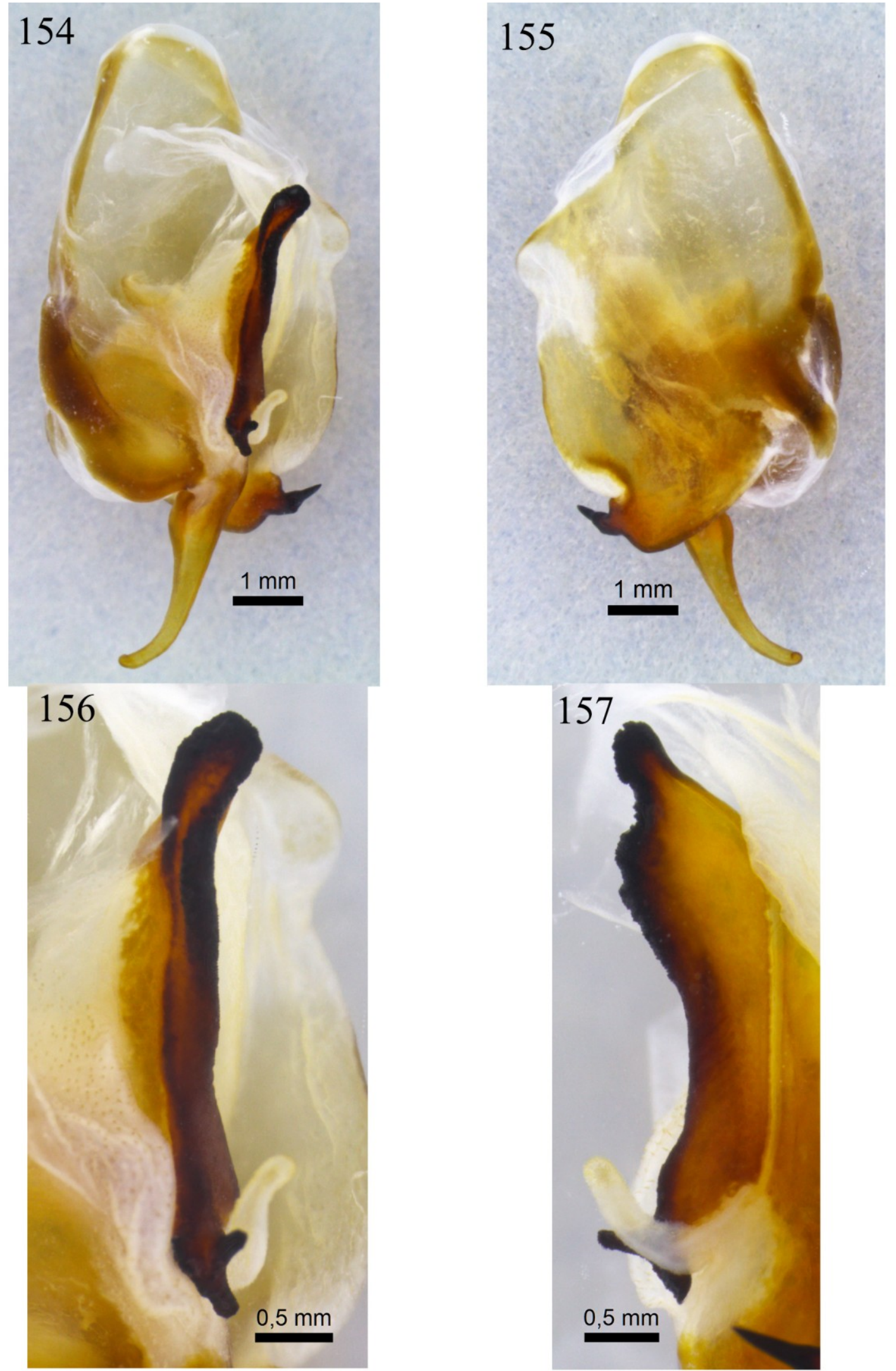

Figuras 154-157. Stagmatoptera reimoseri macho. 154, falômero esquerdo, vista dorsal; 155, falômero esquerdo, vista ventral; 156, apófise falóide e lobo membranoso, vista dorsal; 157, apófise falóide, vista lateral direita. 


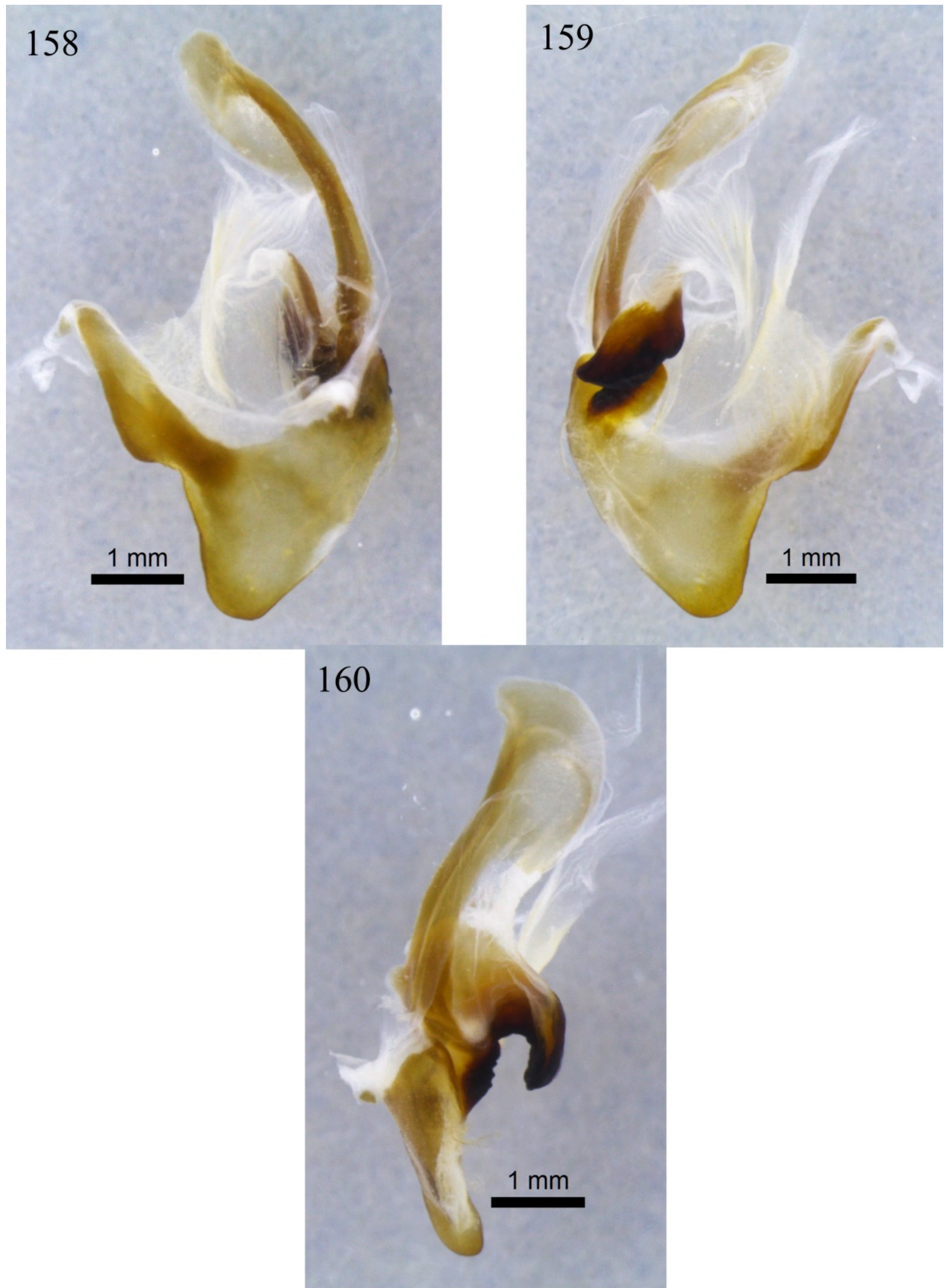

Figuras 158-160. Stagmatoptera reimoseri macho. 158, falômero direito, vista dorsal; 159, falômero direito, vista ventral; 160 , falômero direito, vista lateral direita. 


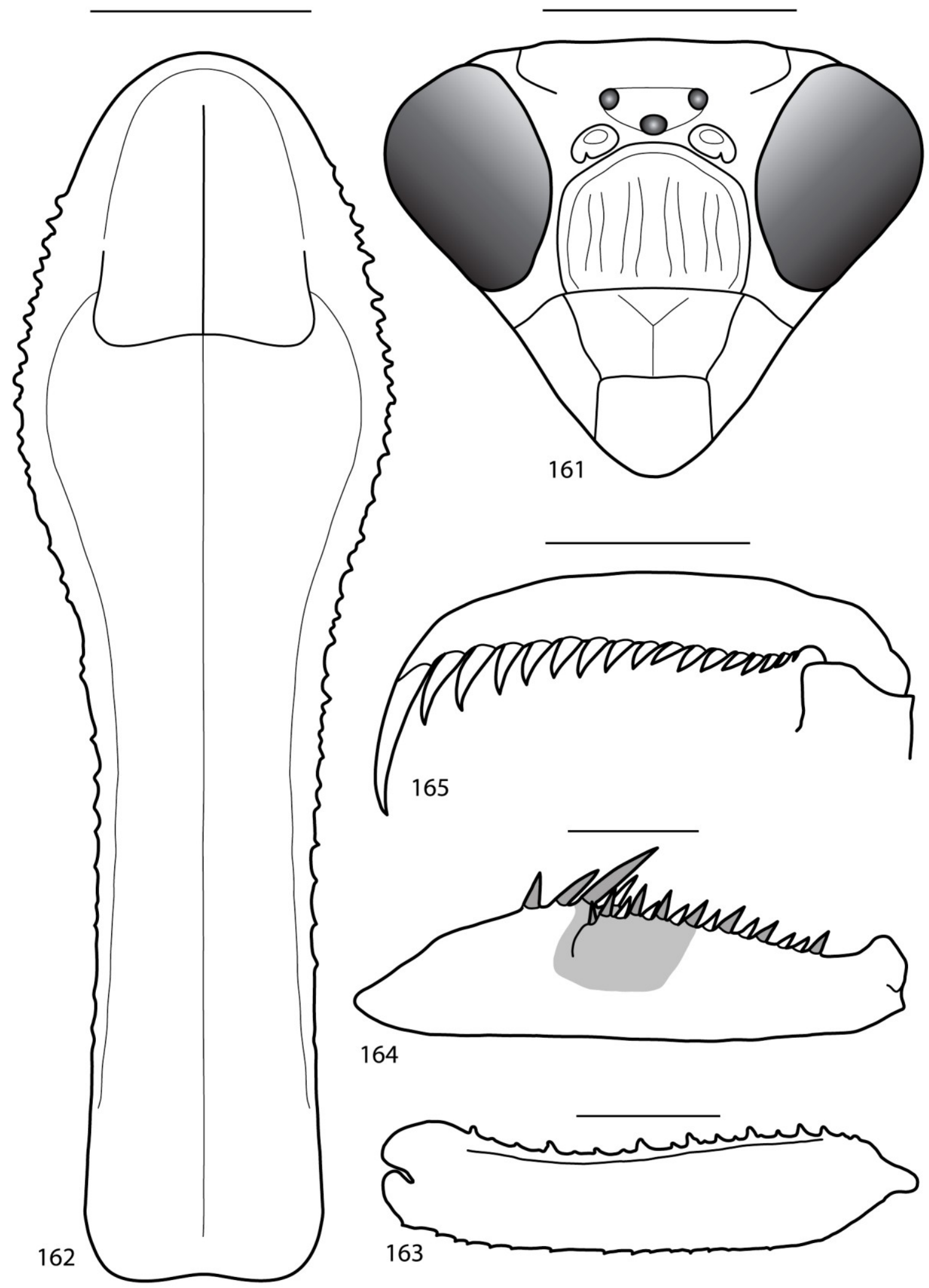

Figuras 161-165. Stagmatoptera reimoseri fêmea. 161, cabeça, vista frontal; 162, protorax, vista dorsal; 163, coxa anterior, vista interna; 164, fêmur anterior, vista interna; 165, tíbia anterior, vista interna. Escalas $=5 \mathrm{~mm}$. 


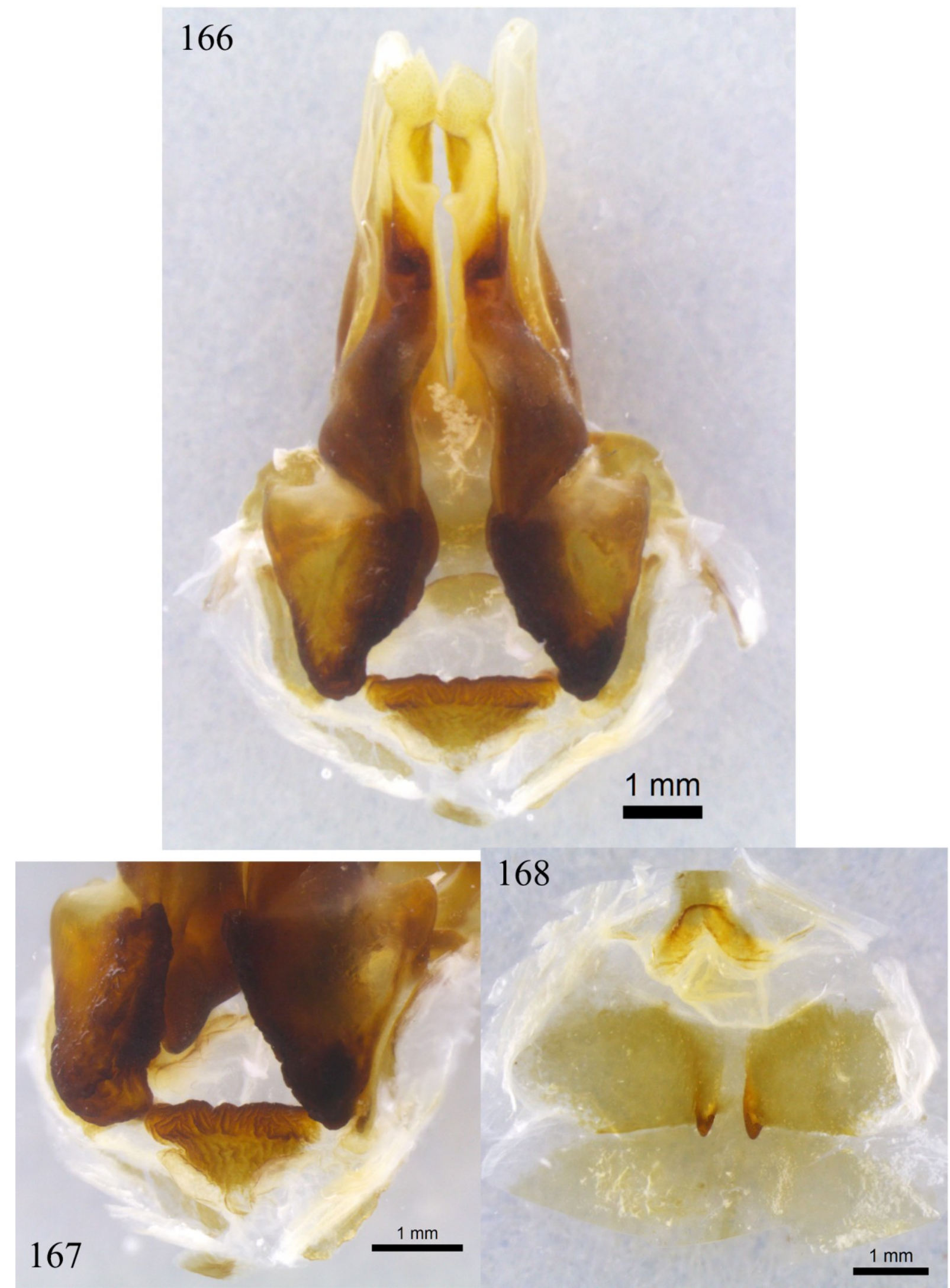

Figuras 166-168. Stagmatoptera reimoseri fêmea. 166, ovipositor, vista ventral; 167, detalhe das gonocoxas; 168, assoalho da câmara genital, vista dorsal. 
Stagmatoptera septentrionalis Saussure \& Zehntner, 1894

Stagmatoptera septentrionalis Saussure \& Zehntner, 1894, p.186, t.8, f.2 (desc.); Griffini, 1896, p.7; Kirby, 1904, p.300 (men.); Rehn, 1911, p.13 (men.); Giglio-Tos, 1914, p.28 (redesc.); Hebard, 1919, p.139 (men.); Hebard, 1921, p.160 (redesc.); Hebard, 1923, p.344 (men.); Giglio-Tos, 1927, p.596 (redesc.); Terra, 1995, p.65 (men.); Ehrmann, 2002, p.330 (men.); Agudelo et al., 2007, p.126 (men.); Ehrmann \& Koçak, 2009, p.12 (men.).

Tipo: uma fêmea, Bugaba, 800 a 1000 pés, Panamá.

= Stagmatoptera septentrionalis var. minor Saussure \& Zehntner, 1894, p.187 (descr.).

Tipo: uma fêmea, Colômbia; uma fêmea, Venezuela (examinada).

= Stagmatoptera minor, Kirby, 1904, p.300 (men.); Rehn, 1911, p.13 (men.); Giglio-Tos, 1914, p.28 (sin.).

= Stagmatoptera incerta Giglio-Tos, 1914, p.27 (desc.); Giglio-Tos, 1927, p.595 (redesc.); Terra, 1995, p.65 (sin.).

Tipo: um macho, Costa Rica; um macho, sem localidade.

Redescrição: Macho - Figuras 169A, 170-181.

Antenômeros serreados. Escudo frontal com duas elevações centrais (Fig. 170).

Protorax alongado, delgado, com margens dotadas de crenulação suave na prozona, lisas na metazona. Metazona com uma quilha central pouco desenvolvida (Fig. 171). Coxas anteriores com margem anterior crenulada dotada de 8 a 12 espinhos grandes e 2 a 8 espinhos menores (Fig. 172). Fêmures anteriores alongados e finos, com o terceiro espinho discoidal a partir da base, escuro em sua face interna; 15 a 17 espinhos internos, sendo o número mais frequente 15, o primeiro espinho interno a partir da base e os grandes espinhos internos são escuros na face interna, podendo apresentar uma pequena mancha de mesma coloração na inserção dos espinhos 8, 10, 12 e 15. Mancha femoral interna estendendo-se da canaleta da garra tibial até o $6^{\circ}$ espinho interno a partir da base, com formato retangular e uma coloração preta suave (Fig. 173). Tíbias anteriores dotadas de 10 a 12 espinhos externos sendo mais frequente 11, e 14 a 16 espinhos internos, sendo mais frequente 15; garra tibial e o último espinho que a precede pretos na face interna, uma mancha preta suave na metade da face 
interna (Fig. 174). Tarsos com manchas pretas apicais na face interna dos tarsômeros I a IV e uma mancha basal interna no tarsômero I.

Área discoidal das tégminas verde opaca em uma estreita faixa anterior após o estigma. Estigma pequeno, com o seguinte padrão: uma região hialina sem veias transversais anterior e uma mancha marrom posterior. Asas totalmente hialinas (Fig. 169A).

Genitália: Falômero esquerdo mais longo que largo, esclerito L4B tão longo quanto largo. Processo apical longo, levemente dilatado no lado esquerdo de sua base; inclinado em relação à base, formando um ângulo de aproximadamente $45^{\circ}$; ápice simples, voltado ventralmente (Fig. 175). Processo distal estreito e curto, achatado, curvado bruscamente para a direita e anteriormente, ápice bem esclerosado e afilado (Fig. 176). Apófise falóide longa e paralela em relação à genitália (Fig. 177); margem direita lisa e levemente sinuosa (Fig. 178); ápice posterior intumescido com duas pequenas projeções, voltadas posteriormente, rugoso e esclerosado; ápice anterior reto, margens esclerosadas, e intumescidas, sem formar uma canaleta (Fig. 177). Lobo membranoso curto, curvado para a direita (Fig. 177). Membrana adjacente à apófise falóide glabra (Fig. 177).

Falômero direito com ápice posterior arredondado; braço médio curto, com uma expansão antes da metade, formando uma suave elevação (Fig. 179); placa ventral curta, fortemente esclerosada (Fig. 180 e 181); processo ventral curto, esclerosado, ápice formando um ângulo (Fig. 180); apódema anterior longo, passando suavemente a um ápice arredondado (Fig. 181).

Fêmea - Figuras 169B, 182-189.

Escudo frontal com duas elevações centrais (Fig. 182).

Protorax alongado, delgado, com margens dotadas de crenulação suave. Metazona com uma quilha central pouco desenvolvida (Fig. 183). Coxas anteriores com margem anterior crenulada dotada de 7 a 10 espinhos grandes e 5 a 10 espinhos menores (Fig. 184). Fêmures anteriores alongados e finos, com o primeiro espinho discoidal a partir da base escuros em sua face interna; 15 a 16 espinhos internos, sendo o mais frequentes 15 , o primeiro espinho interno a partir da base e os grandes espinhos internos são escuros na face interna, podendo apresentar uma pequena mancha de mesma coloração na inserção dos espinhos 8,10 , 12 e 15. Mancha femoral interna estendendo-se da canaleta da garra tibial até o $6^{\circ}$ espinho 
interno a partir da base, com formato retangular e uma coloração preta suave (Fig. 185). Tíbias anteriores dotadas de 10 a 12 espinhos externos, e 15 a 17 espinhos internos; garra tibial e o último espinho que a precede pretos na face interna, uma mancha preta suave na metade da face interna (Fig. 186). Tarsos com manchas pretas apicais na face interna dos tarsômeros I a IV e uma mancha basal interna no tarsômero I.

Estigma oval e pequeno, com o seguinte padrão: uma mancha branca anterior, uma mancha preta proximal e uma mancha marrom posterior e lateral. Asas com área costal hialina e as áreas discoidal e anal com molduras amarelas nas veias transversais (Fig. 169B).

Genitália: Base das gonapófises VIII se projetando internamente (Fig. 187). Basiválvula com formato aproximadamente triangular, ápice anterior dilatado (Fig. 187), a superfície interna esculpida (Fig. 188). Interbasiválvula esclerosada e esculpida (Fig. 188). Extensões posterolaterias longas, fracamente esclerosadas com margens crenuladas (Fig. 188). Esclerito na parede dorsal da papila genital fracamente esclerosado, liso (Fig. 189). Plataforma lateroesternal aproximadamente retangular, processos posteriores longos, cônicos (Fig. 189).

Localidade tipo: Bugaba, Panamá.

Outras localidades: Colômbia, Costa Rica, Guiana Francesa, Trinidad \& Tobago, Venezuela.

Diagnose: Mancha no estigma dos machos com uma mancha marrom delimitando uma região hialina sem nervuras, das fêmeas com formato oval, pequena, composta de uma mancha branca anterior, uma preta proximal e outra marrom posterior e lateral. 
Tabela 9. Medidas e razões de machos e fêmeas de Stagmatoptera septentrionalis.

\begin{tabular}{|c|c|c|}
\hline & Macho $(\mathrm{N}=12)$ & Fêmea $(\mathrm{N}=7)$ \\
\hline Comprimento & 62,5 a $78,9 \mathrm{~mm}$ & 64 a $86,8 \mathrm{~mm}$ \\
\hline Largura da cabeça & 7 a $7,8 \mathrm{~mm}$ & 8,4 a $10 \mathrm{~mm}$ \\
\hline Comprimento da Prozona & 3,7 a $4,9 \mathrm{~mm}$ & 5,1 a $7 \mathrm{~mm}$ \\
\hline Comprimento da Metazona & 17,2 a $22,8 \mathrm{~mm}$ & 21,6 a $28 \mathrm{~mm}$ \\
\hline Largura da Dilatação & 4,2 a $5,3 \mathrm{~mm}$ & 6,3 a $8,2 \mathrm{~mm}$ \\
\hline Comprimento da Tégmina & 42,6 a $54,5 \mathrm{~mm}$ & 37,6 a $49 \mathrm{~mm}$ \\
\hline Comprimento da Asa & 44 a $48,5 \mathrm{~mm}$ & 37,1 a $40 \mathrm{~mm}$ \\
\hline Comprimento da Coxa Anterior & 11,7 a $14,5 \mathrm{~mm}$ & 15,6 a $19,2 \mathrm{~mm}$ \\
\hline Comprimento do Fêmur Anterior & 13,2 a $17,2 \mathrm{~mm}$ & 18 a $22,6 \mathrm{~mm}$ \\
\hline Largura do Fêmur Anterior & 2,5 a 3,2 mm & 3,9 a $5 \mathrm{~mm}$ \\
\hline Comprimento da Tíbia Anterior & 6,6 a $8,4 \mathrm{~mm}$ & 8,7 a $11 \mathrm{~mm}$ \\
\hline Razão Cabeça/Dilatação & 1,45 a 1,67 & 1,22 a 1,35 \\
\hline Razão Metazona/Prozona & 4,11 a 4,71 & 3,79 a 4,3 \\
\hline Razão Prozona/Dilatação & 0,88 a 1,02 & 0,78 a 0,94 \\
\hline Razão Metazona/Dilatação & 3,73 a 4,38 & 3,3 a 3,79 \\
\hline Razão Metazona/Coxa Anterior & 1,43 a 1,63 & 1,35 a 1,5 \\
\hline Razão Comprimento/Largura & 5,03 a 5,5 & 4,52 a 4,93 \\
\hline Fêmur Anterior & 1,87 a 2,19 & 1,94 a 2,15 \\
\hline Razão Fêmur/Tíbia & & \\
\hline
\end{tabular}

Material examinado: Colômbia; $1 q$ (ZMB). Harke, $1 q$ (ZMB). 1934, Eric de Belleville, $1 q(\mathrm{MNHN})$. Bogotá, Lindig, 10 (ZMB). Fusugusá, E. Pehlke S., $1 \overbrace{}^{\Uparrow}$ (NHMW). Rio Güejar (Macarena) 380m-420m, i.1951, Richter col., $1 \sigma^{\Uparrow}$ (NHMW). Guiana Francesa; $1 \widehat{\jmath}(\mathrm{MNHN})$. Panamá; 1889, 1 + (MNHN). Barro Colorado (Biol. Station), 05-08.viii.1965, B. Malkin \& S. Rand col., $2 \widehat{\varnothing}$ (MZSP). Trinidad \& Tobago; Arima Valley, Trinidad,

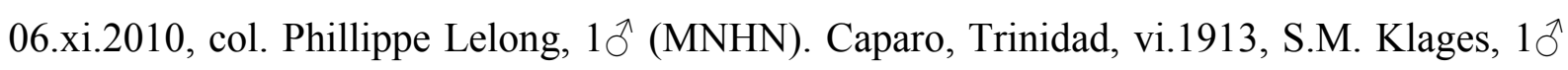
(MHNG). Venezuela; Síntipo de S. septentrionalis var. minor, 1 q (MHNG). Coll. Br. v. W., $1 q(\mathrm{NHMW})$. Caracas, 19 (ZMB). Caucagua, Miranda, 1923, Mayeul Grisol, 19 (MNHN).

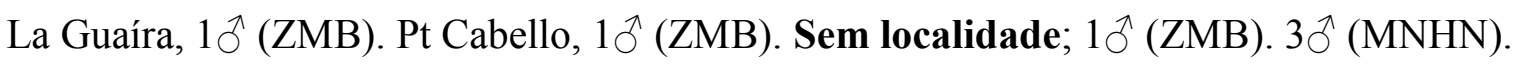



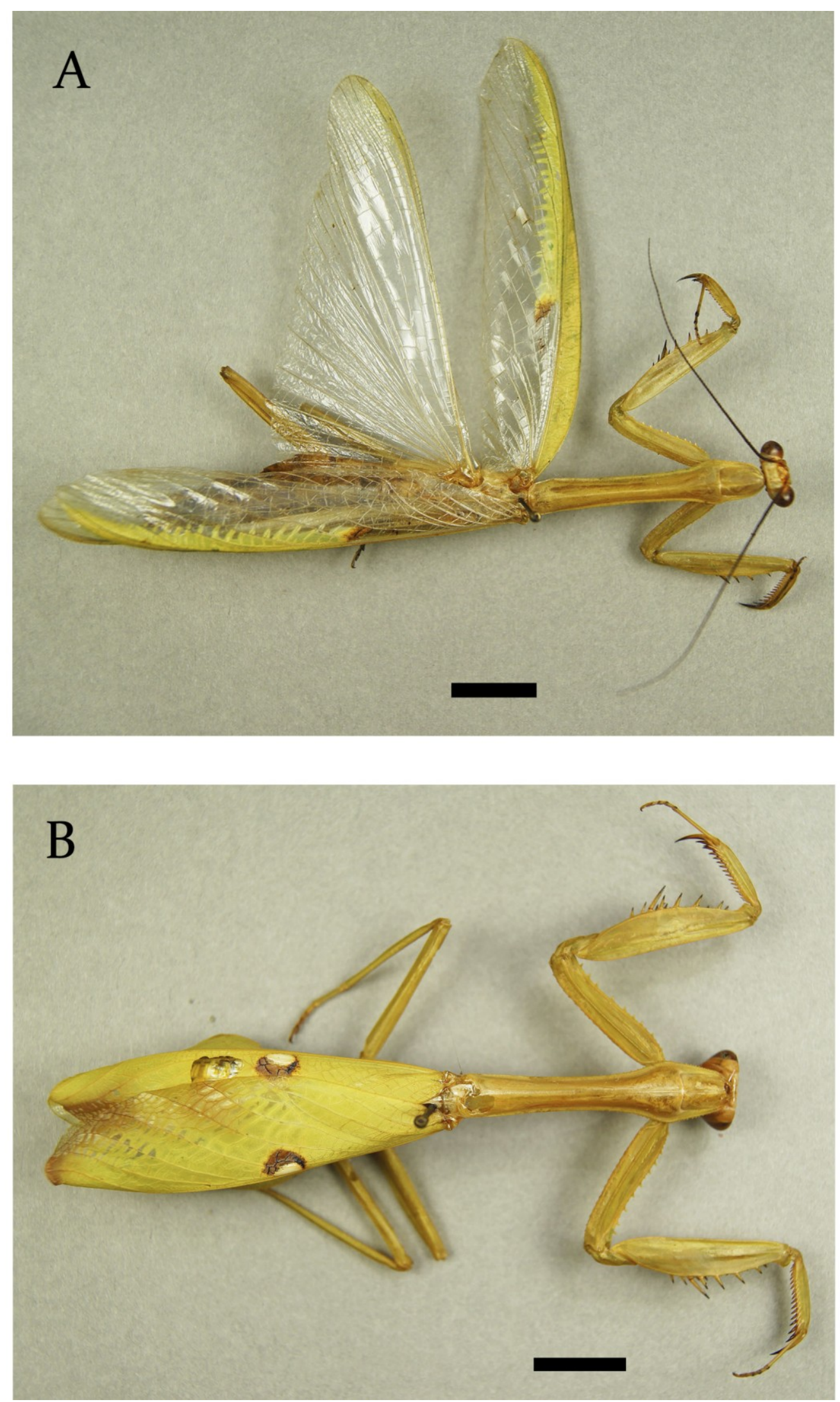

Figura 169. Stagmatoptera septentrionalis, habitus dorsal. A, macho; B, fêmea. Escalas $=1 \mathrm{~cm}$. 


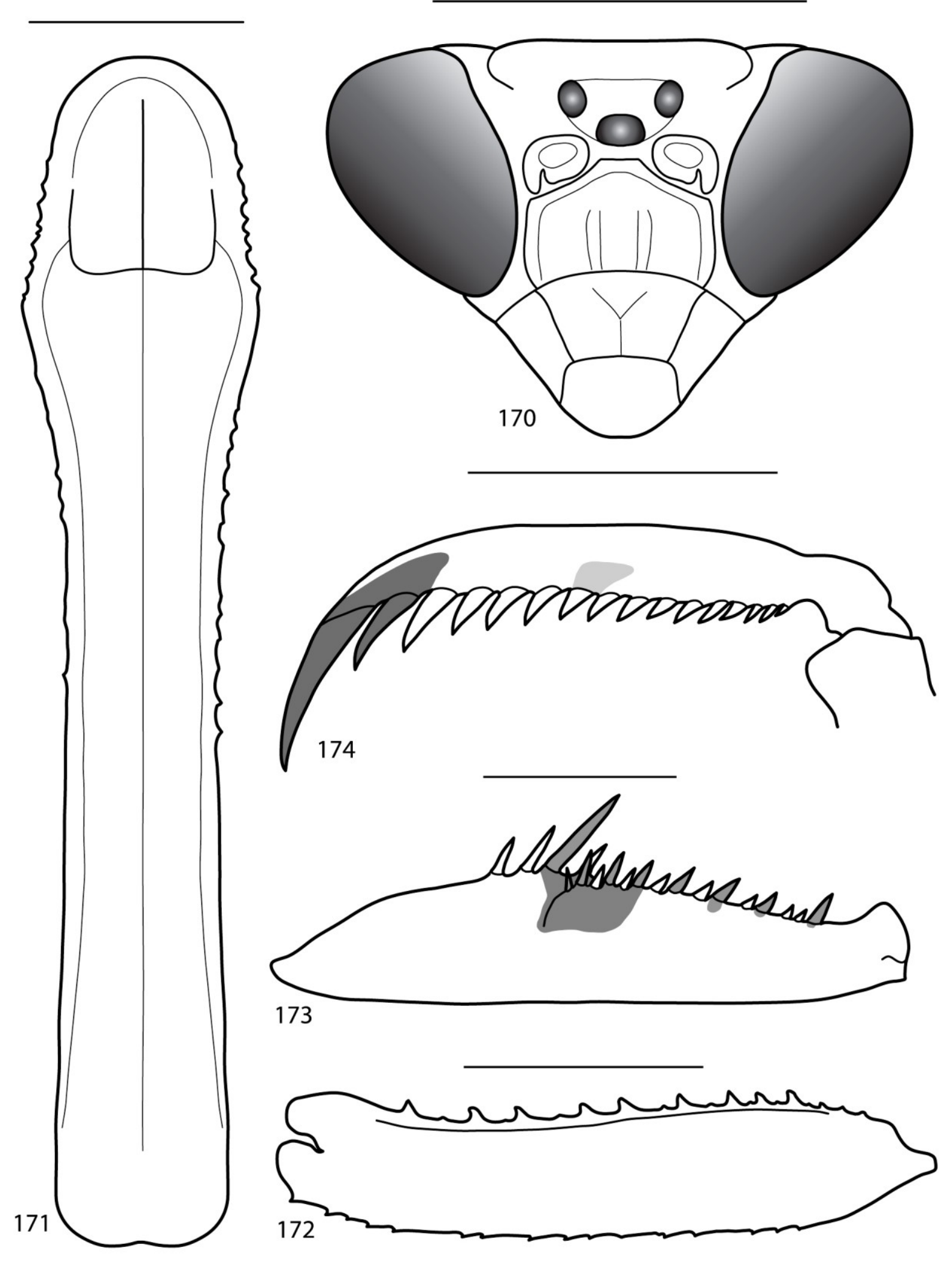

Figuras 170-174. Stagmatoptera septentrionalis macho. 170, cabeça, vista frontal; 171, protorax, vista dorsal; 172, coxa anterior, vista interna; 173, fêmur anterior, vista interna; 174, tíbia anterior, vista interna. Escalas = $5 \mathrm{~mm}$. 

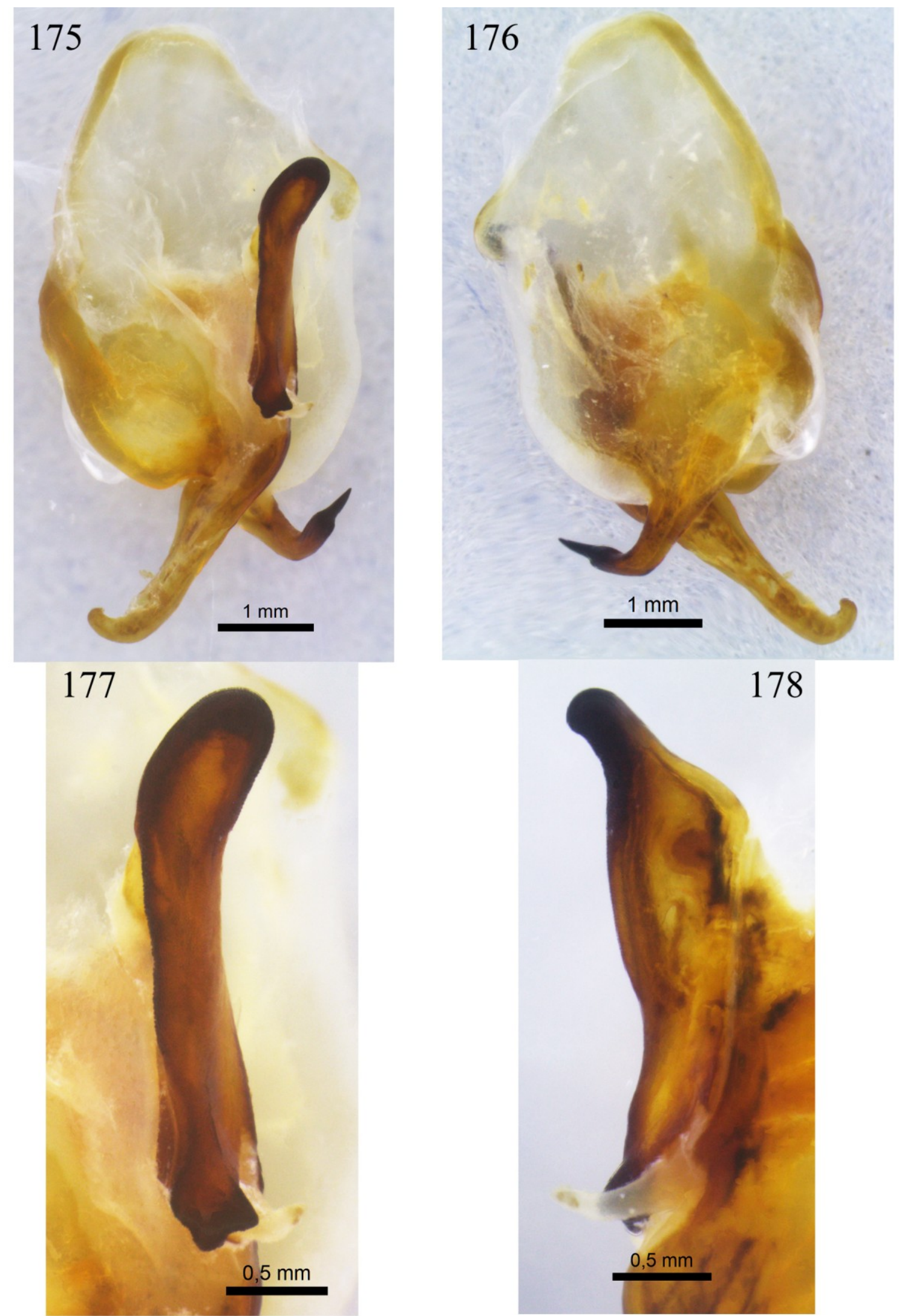

Figuras 175-178. Stagmatoptera septentrionalis macho. 175, falômero esquerdo, vista dorsal; 176, falômero esquerdo, vista ventral; 177, apófise falóide e lobo membranoso, vista dorsal; 178, apófise falóide, vista lateral direita. 


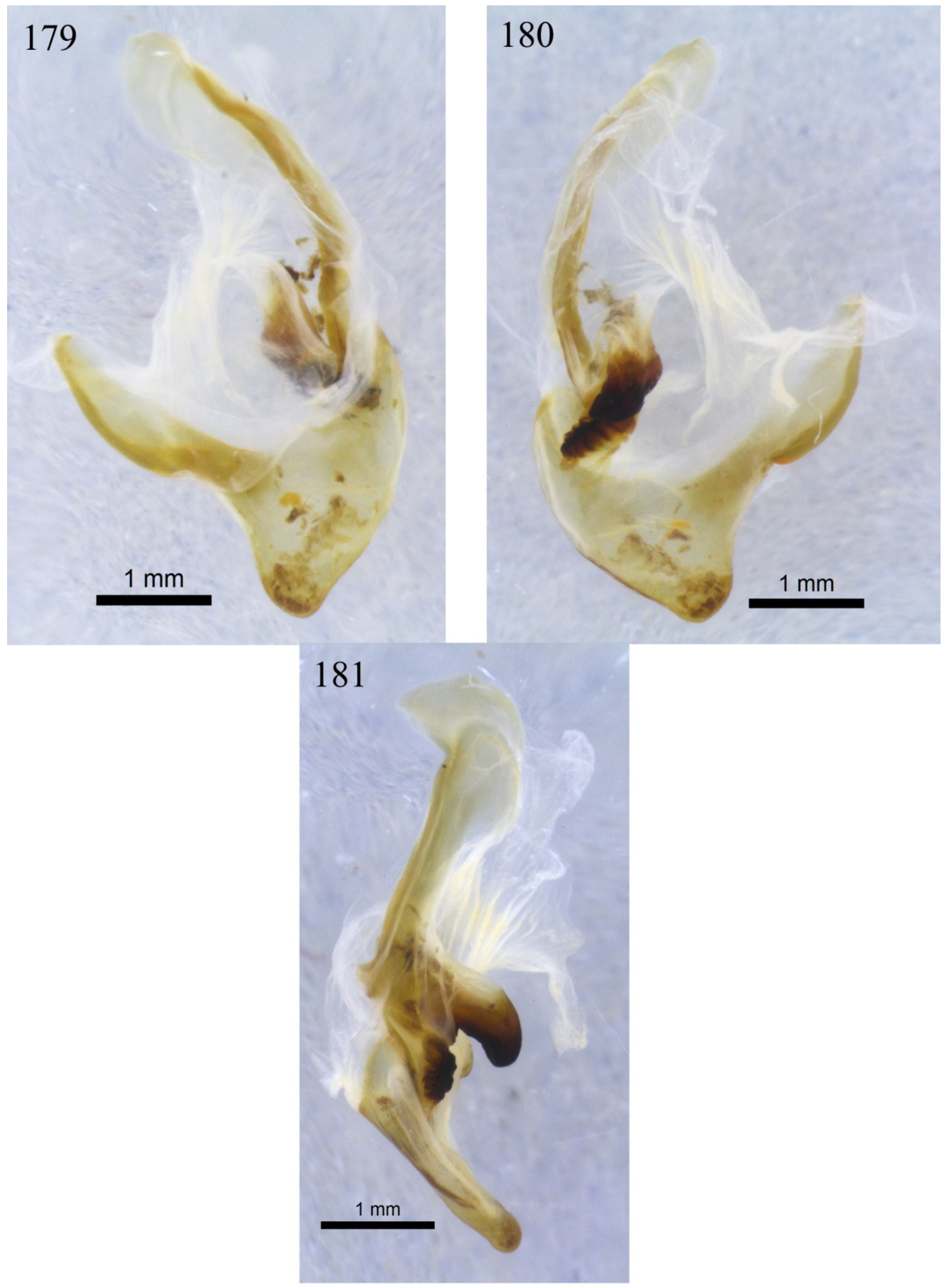

Figuras 179-181. Stagmatoptera septentrionalis macho. 179, falômero direito, vista dorsal; 180, falômero direito, vista ventral; 181, falômero direito, vista lateral direita. 


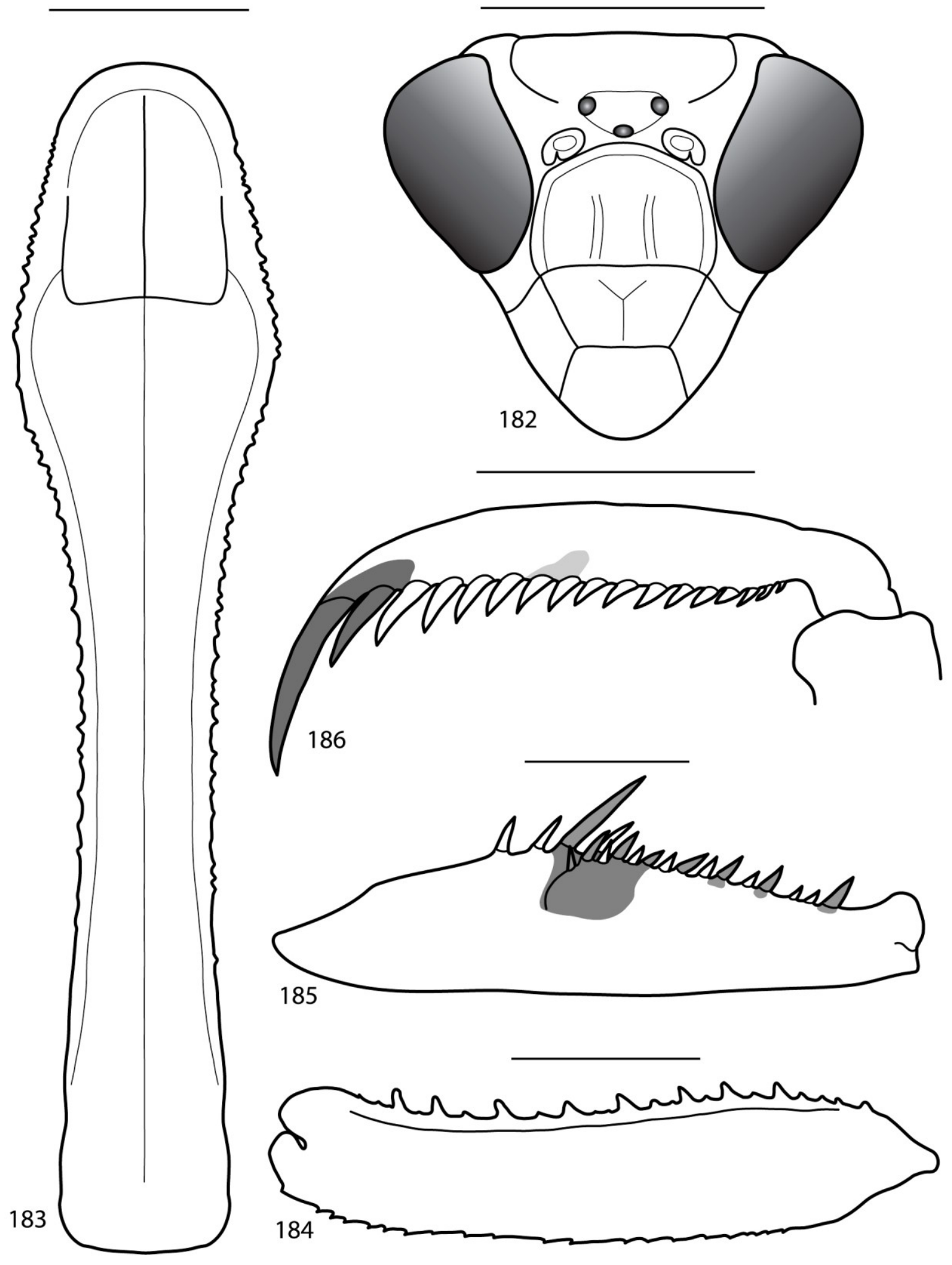

Figuras 182-186. Stagmatoptera septentrionalis fêmea. 182, cabeça, vista frontal; 183, protorax, vista dorsal; 184, coxa anterior, vista interna; 185, fêmur anterior, vista interna; 186, tíbia anterior, vista interna. Escalas = $5 \mathrm{~mm}$. 


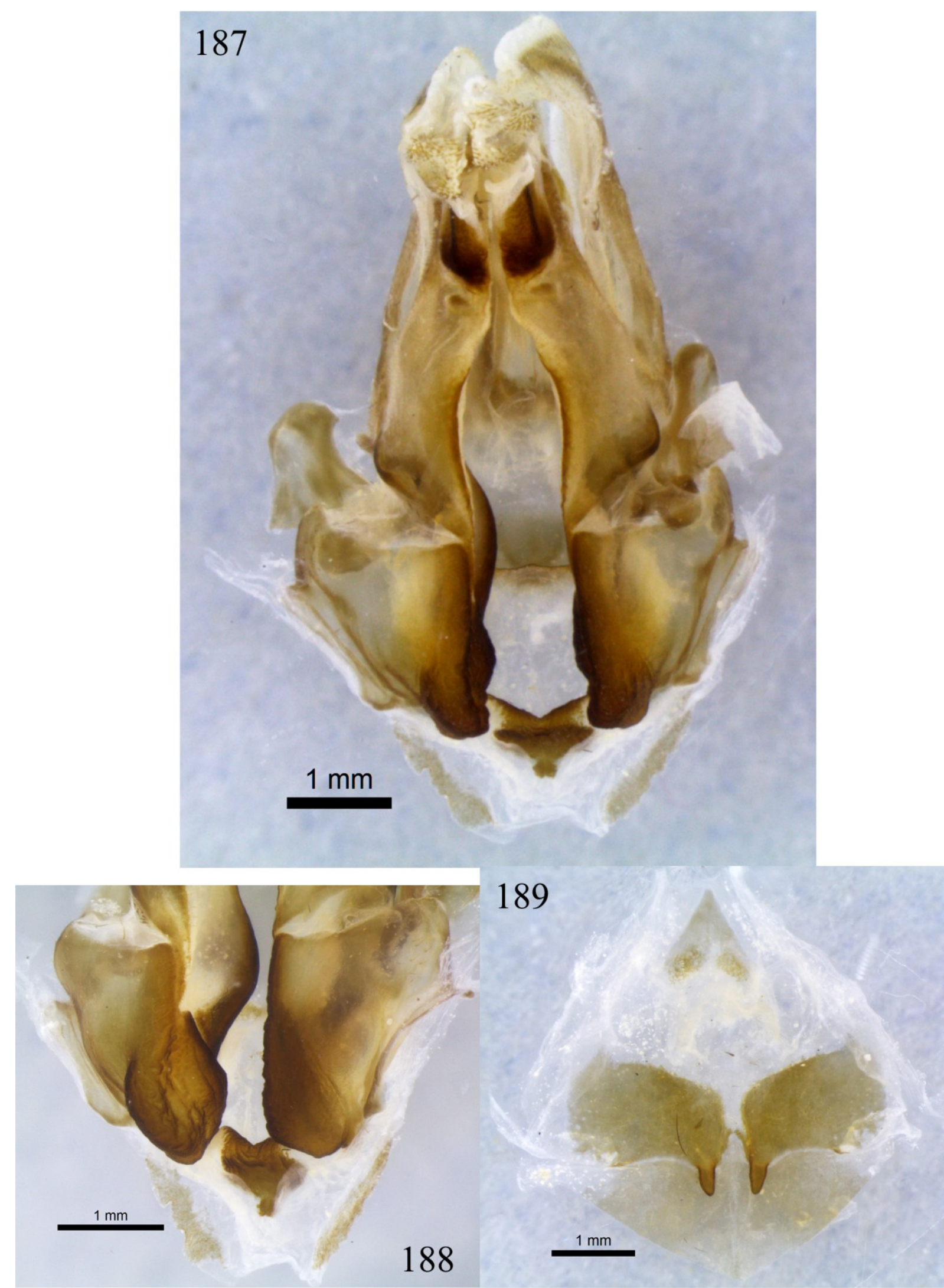

Figuras 187-189. Stagmatoptera septentrionalis fêmea. 187, ovipositor, vista ventral; 188, detalhe das gonocoxas; 189, assoalho da câmara genital, vista dorsal. 


\section{Stagmatoptera sp. n.1}

Descrição: Macho - Figuras 190A, 191- 202.

Antenômeros filiformes. Escudo frontal com duas elevações centrais (Fig. 191).

Protorax curto, grosso, com margens dotadas de crenulação suave na prozona, lisas na metazona. Metazona com uma quilha central pouco desenvolvida (Fig. 192). Coxas anteriores com margem anterior crenulada dotada de 6 a 9 espinhos grandes e 2 a 8 espinhos menores (Fig. 193). Fêmures anteriores alongados e largos, com os três primeiros espinhos discoidais a partir da base, escuros em sua face interna; 14 a 15 espinhos internos, o primeiro espinho interno a partir da base e os grandes espinhos internos são escuros na face interna, podendo apresentar uma pequena mancha de mesma coloração na inserção dos espinhos 8,10 e 12. Mancha femoral interna estendendo-se da canaleta da garra tibial até o $10^{\circ}$ espinho interno a partir da base, com formato retangular e uma coloração preta suave, podendo ser um pouco mais forte na base dos espinhos (Fig. 194). Tíbias anteriores dotadas de 11 a 12 espinhos externos e 15 a 16 espinhos internos; a garra tibial verde na face interna (Fig. 195). Tarsos com manchas pretas apicais na face interna dos tarsômeros I a IV.

Área discoidal das tégminas verde opaca em uma faixa anterior, passando gradualmente para hialina. Estigma oval e grande, com o seguinte padrão: uma mancha branca central triangular, uma mancha preta semicircular proximal, e uma grande mancha marrom posterior e distal. Asas com as áreas discoidal e anal com molduras amarelas ao menos na metade anterior (Fig.190A).

Genitália: Falômero esquerdo mais longo que largo, esclerito L4B mais longo que largo. Processo apical longo, levemente dilatado no lado esquerdo de sua base; inclinado em relação à base, formando um ângulo de aproximadamente $30^{\circ}$, e depois curvado para a esquerda; ápice simples, voltado ventralmente (Fig. 196). Processo distal largo e curto, achatado, curvado bruscamente $90^{\circ}$ para a direita, fortemente comprimido pouco antes do ápice, e comprimido novamente na base do ápice; este bem esclerosado e afilado (Fig. 197). Apófise falóide longa e inclinada em relação à genitália (Fig.198); margem direita rugosa e sinuosa (Fig. 199); ápice posterior simples e indiviso, rugoso e fortemente esclerosado; ápice anterior reto, margens fortemente esclerosadas, e intumescidas, formando uma canaleta (Fig.198). Lobo membranoso curto, curvado para a direita (Fig.198). Membrana adjacente à apófise falóide pilosa (Fig.198). 
Falômero direito com ápice posterior arredondado; braço médio curto, com uma expansão antes da metade, formando uma elevação (Fig. 200); placa ventral curta, fortemente esclerosada (Fig. 201 e 202); processo ventral curto, fortemente esclerosado, ápice formando um ângulo (Fig. 201); apódema anterior longo, passando bruscamente a um ápice arredondado (Fig.202).

Fêmea - Figuras 190B, 203- 210.

Escudo frontal com duas elevações centrais (Fig. 203).

Protorax curto, grosso, com margens dotadas de crenulação suave. Metazona com uma quilha central pouco desenvolvida (Fig. 204). Coxas anteriores com margem anterior crenulada dotada de 7 a 9 espinhos grandes e 5 a 8 espinhos menores (Fig. 205). Fêmures anteriores alongados e largos, com os três primeiros espinhos discoidais a partir da base escuros em sua face interna; 14 a 15 espinhos internos, sendo o mais frequente 15, o primeiro espinho interno a partir da base e os grandes espinhos internos são escuros na face interna. Mancha femoral interna estendendo-se da canaleta da garra tibial até o $10^{\circ}$ espinho interno a partir da base, com formato retangular e uma coloração preta suave (Fig. 206). Tíbias anteriores dotadas de 11 a 12 espinhos externos, e 15 a 17 espinhos internos; a garra tibial verde na face interna (Fig. 207). Tarsos com manchas pretas apicais na face interna dos tarsômeros I a IV.

Estigma oval e grande, com o seguinte padrão: uma mancha branca central triangular, uma mancha preta semicircular proximal, e uma grande mancha marrom posterior e distal. Asas com área costal hialina e as áreas discoidal e anal com molduras amarelas nas veias transversais (Fig. 190B).

Genitália: Base das gonapófises VIII se projetando internamente (Fig.208). Basiválvula com formato aproximadamente triangular (Fig. 208), a superfície interna esculpida (Fig. 209). Interbasiválvula esclerosada e esculpida (Fig. 209). Extensões posterolaterias curtas, fracamente esclerosadas com margens crenuladas (Fig. 209). Esclerito na parede dorsal da papila genital esclerosado, liso (Fig. 210). Plataforma lateroesternal aproximadamente retangular, processos posteriores curtos, cônicos (Fig. 210).

Distribuição: Brasil (Maranhão, Pará).

Diagnose: Mancha no estigma oval, grande, inclinada em relação à tégmina. 
Tabela 10. Medidas e razões de machos e fêmeas de Stagmatoptera sp. n.1.

\begin{tabular}{|c|c|c|}
\hline & Macho $(\mathrm{N}=4)$ & Fêmea $(\mathrm{N}=4)$ \\
\hline Comprimento & 68,4 a $77,7 \mathrm{~mm}$ & 71,8 a $76,2 \mathrm{~mm}$ \\
\hline Largura da cabeça & 7,6 a $8,4 \mathrm{~mm}$ & 9,3 a $9,6 \mathrm{~mm}$ \\
\hline Comprimento da Prozona & 4,4 a $5,3 \mathrm{~mm}$ & 5,9 a $6,6 \mathrm{~mm}$ \\
\hline Comprimento da Metazona & 16,6 a $19,1 \mathrm{~mm}$ & 21 a $22,4 \mathrm{~mm}$ \\
\hline Largura da Dilatação & 4,7 a $6,2 \mathrm{~mm}$ & 7,4 a $7,8 \mathrm{~mm}$ \\
\hline Comprimento da Tégmina & 46,5 a $52,4 \mathrm{~mm}$ & 46,8 a $50,1 \mathrm{~mm}$ \\
\hline Comprimento da Asa & 41,7 a $45,9 \mathrm{~mm}$ & 39,7 a $43,9 \mathrm{~mm}$ \\
\hline Comprimento da Coxa Anterior & 11,8 a $14,5 \mathrm{~mm}$ & 16,7 a $18,2 \mathrm{~mm}$ \\
\hline Comprimento do Fêmur Anterior & 14,3 a $17,3 \mathrm{~mm}$ & 20,4 a $21 \mathrm{~mm}$ \\
\hline Largura do Fêmur Anterior & 3,1 a $3,5 \mathrm{~mm}$ & 4,5 a $4,8 \mathrm{~mm}$ \\
\hline Comprimento da Tíbia Anterior & 7,8 a $9,3 \mathrm{~mm}$ & 10,6 a $11,2 \mathrm{~mm}$ \\
\hline Razão Cabeça/Dilatação & 1,35 a 1,62 & 1,22 a 1,26 \\
\hline Razão Metazona/Prozona & 3,17 a 3,84 & 3,23 a 3,78 \\
\hline Razão Prozona/Dilatação & 0,85 a 0,96 & 0,77 a 0,86 \\
\hline Razão Metazona/Dilatação & 3,05 a 3,6 & 2,76 a 2,9 \\
\hline Razão Metazona/Coxa Anterior & 1,27 a 1,46 & 1,18 a 1,28 \\
\hline Razão Comprimento/Largura & 4,33 a 4,97 & 4,38 a 4,6 \\
\hline Fêmur Anterior & 1,81 a 2,01 & 1,86 a 1,94 \\
\hline Razão Fêmur/Tíbia & & \\
\hline
\end{tabular}

Material examinado: Brasil; $\underline{\text { Maranhão }}$ - Aldeia do Ponto, Jio, 17.ii.1955, $1 \delta^{\Uparrow}$ (MZSP). Caxias, Faz. Gequiri, 13.x.1998, rede entom., col. F.S. Santos, 1 우 (INPA). Caxias, Fumo Verde, 24.x.1999, F. Limeira-de-Oliveira e J.T. Câmara, 19 (INPA). Caxias, zona urbana, 23.ii.2004, coleta insidental [incidental], L. Alves, 1 q (INPA). Caxias, zona urbana/C. Branco, 22.v.2004, coleta incidental, L. Cardoso-da-Silva e outros, $1 ð$ (INPA). São P. Água Branca, Faz. Primavera, 03-10.iii.2002, Armadilha Malaise, F. Limeira-de-Oliveira e J.T.

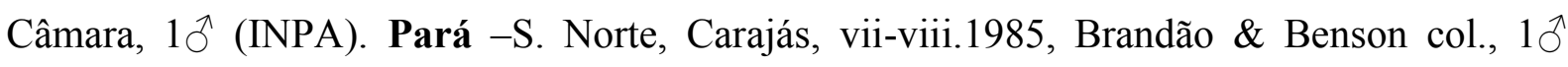
(MZSP). Sem localidade; 1 (NHMW). 

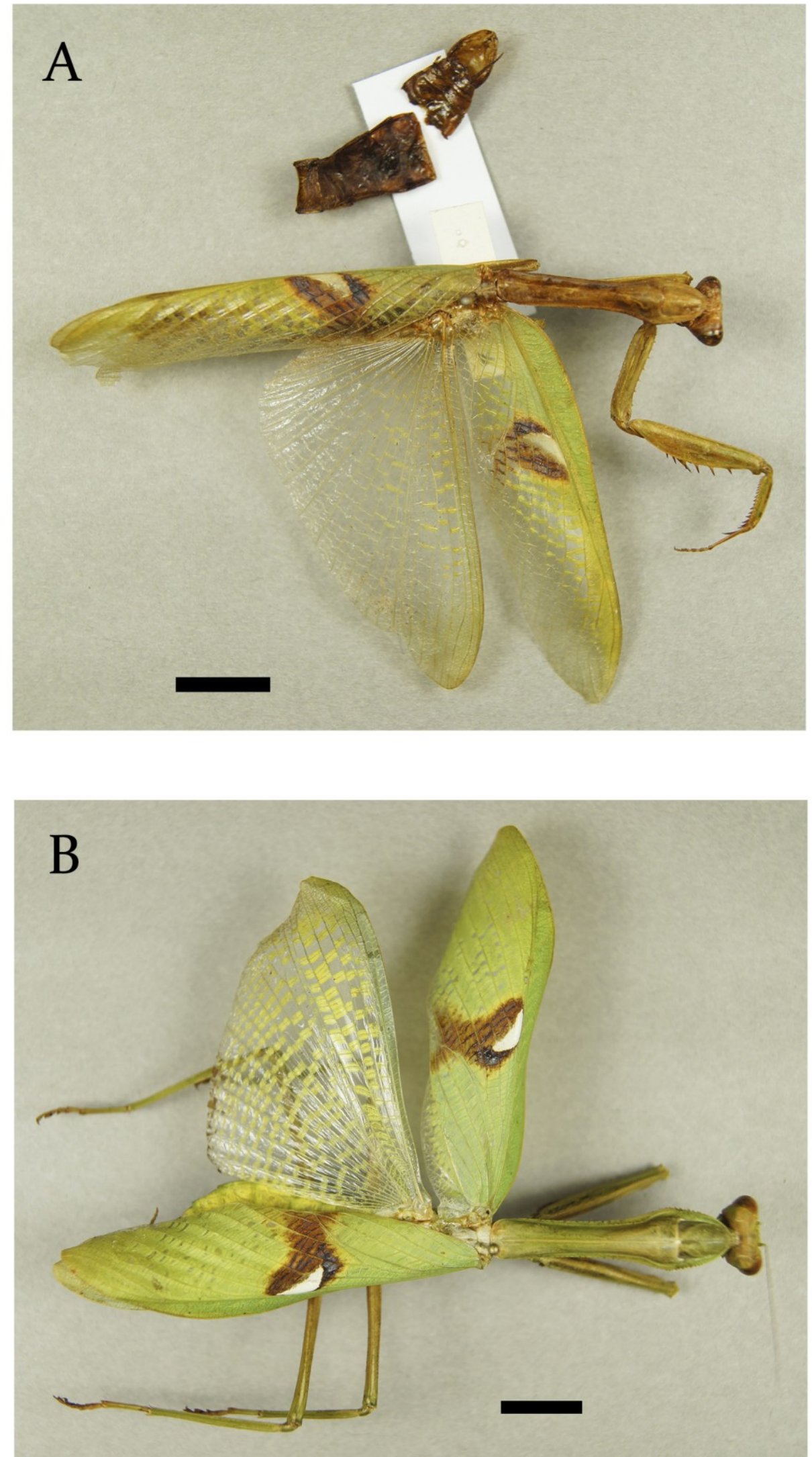

Figura 190. Stagmatoptera sp. n.1, habitus dorsal. A, macho; B, fêmea. Escalas $=1 \mathrm{~cm}$. 


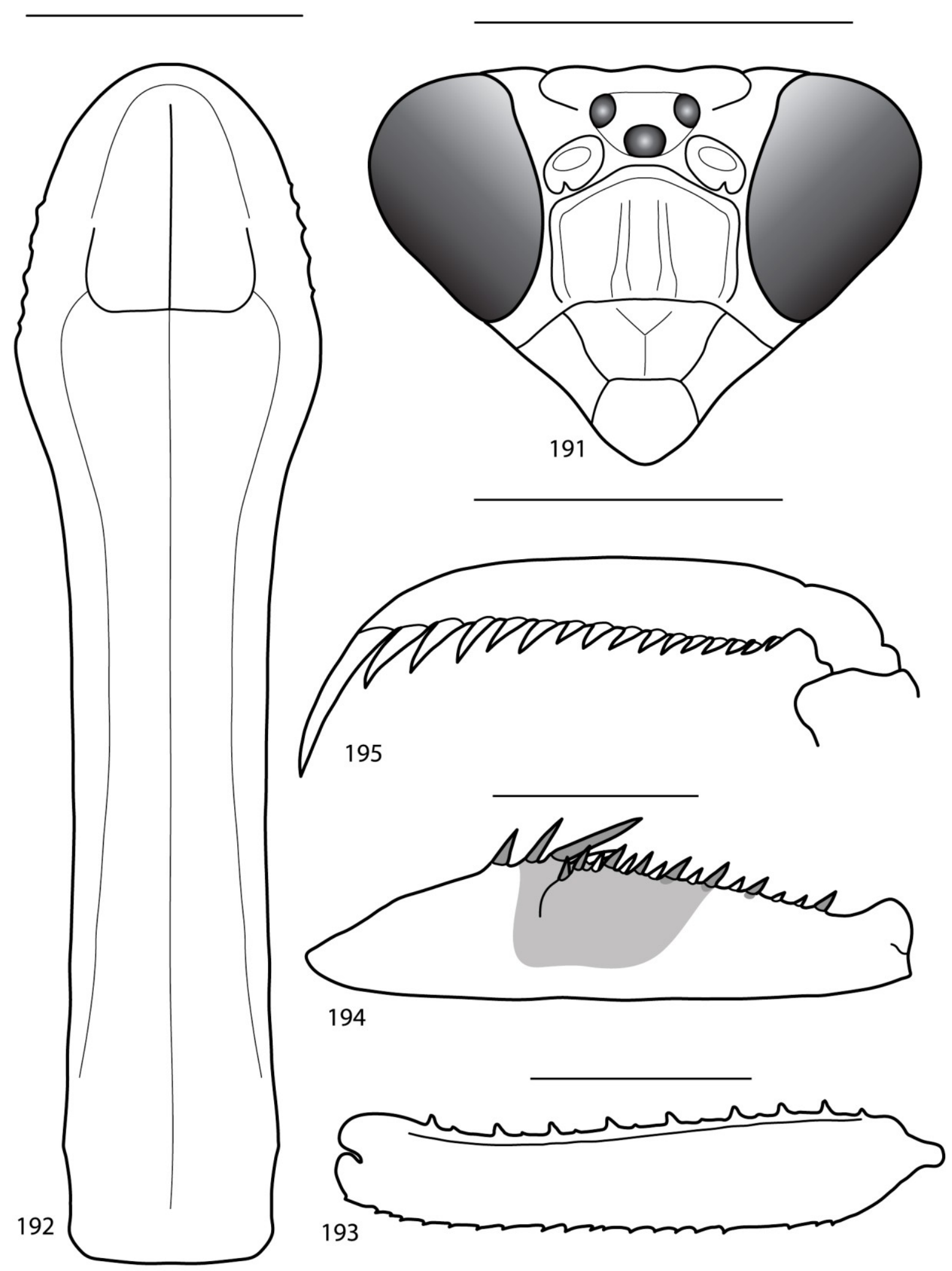

Figuras 191-195. Stagmatoptera sp. n.1 macho. 191, cabeça, vista frontal; 192, protorax, vista dorsal; 193, coxa anterior, vista interna; 194, fêmur anterior, vista interna; 195, tíbia anterior, vista interna. Escalas $=5 \mathrm{~mm}$. 

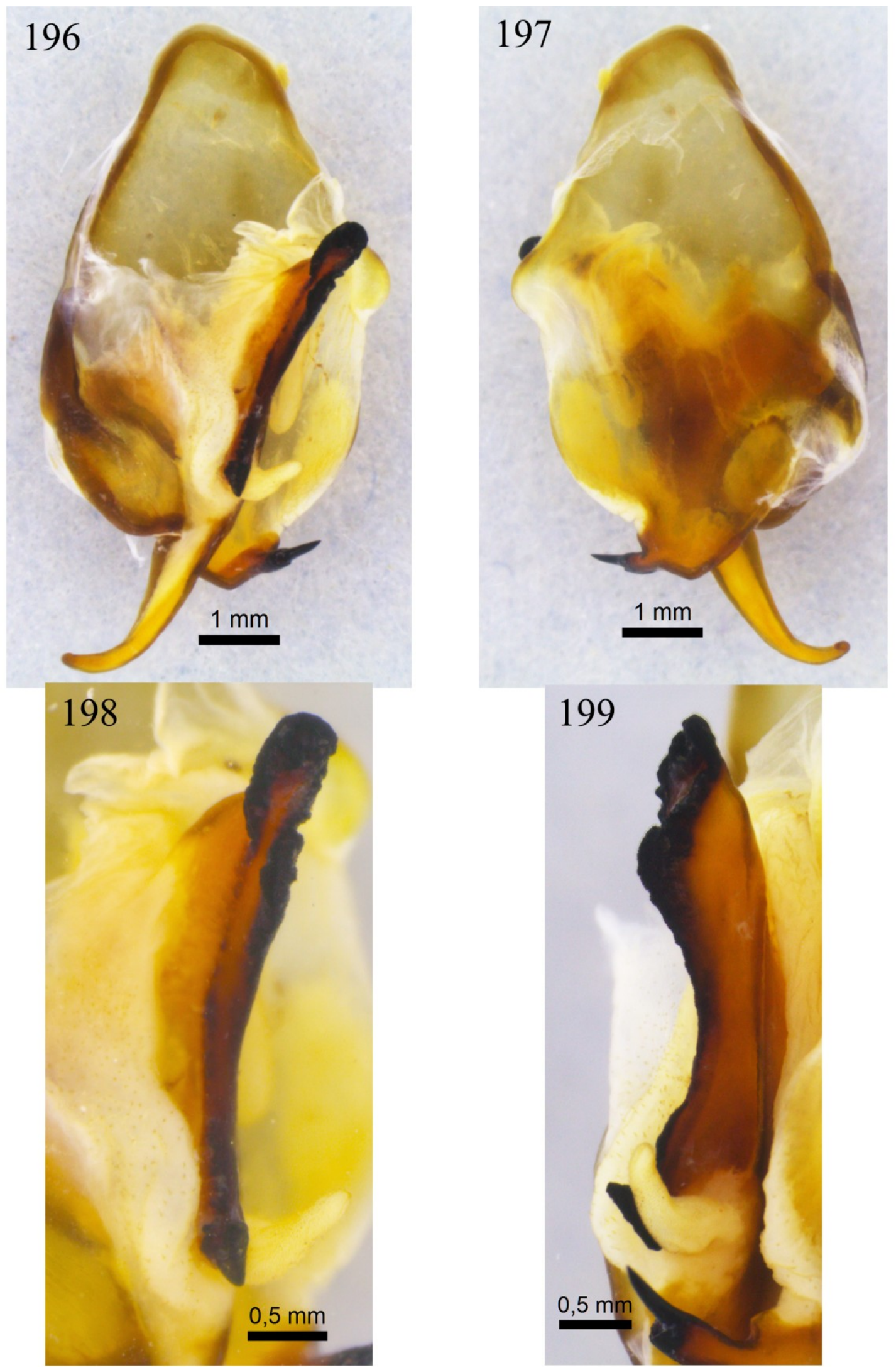

Figuras 196-199. Stagmatoptera sp. n.1 macho. 196, falômero esquerdo, vista dorsal; 197, falômero esquerdo, vista ventral; 198, apófise falóide e lobo membranoso, vista dorsal; 199, apófise falóide, vista lateral direita. 


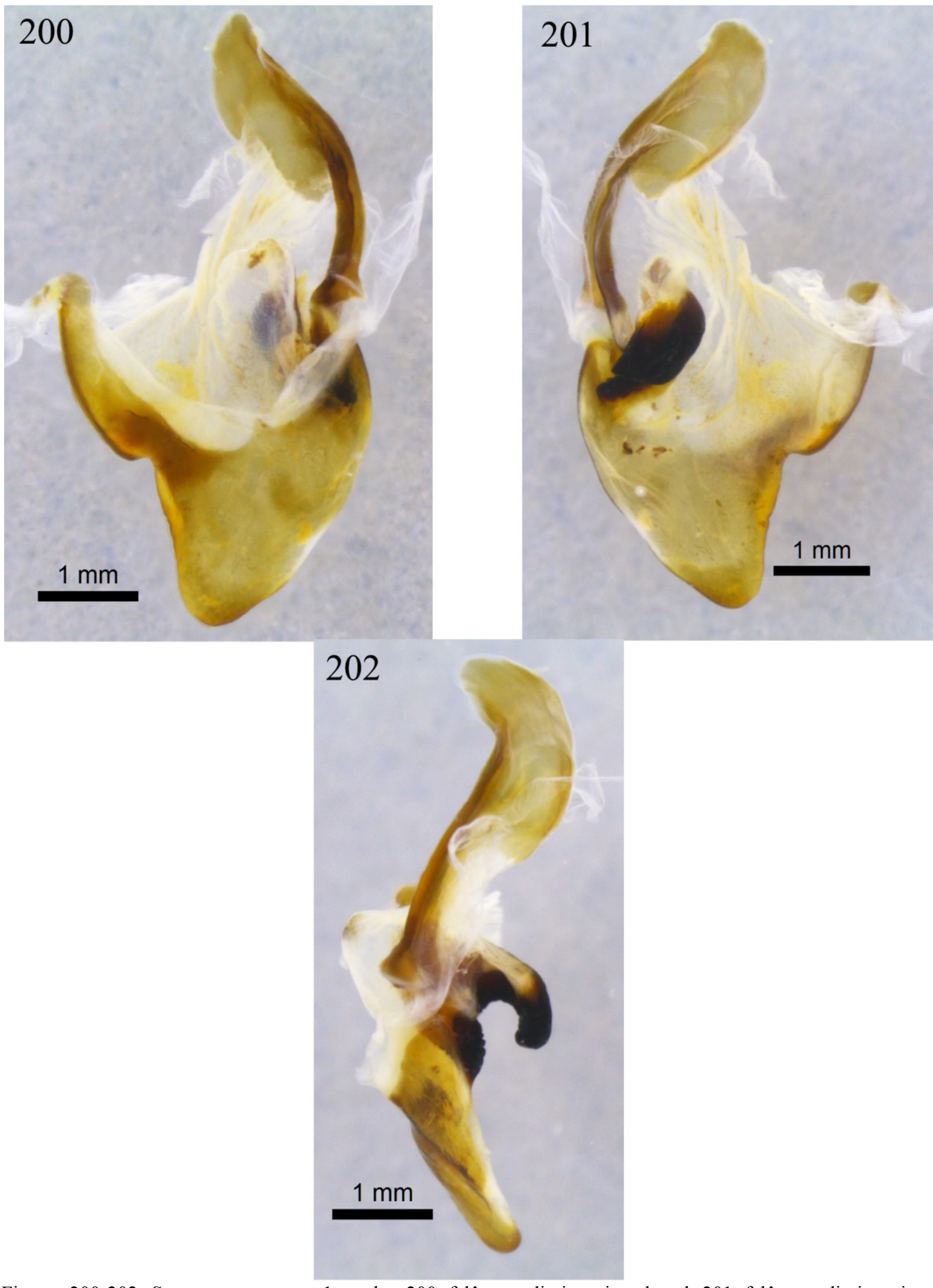

Figuras 200-202. Stagmatoptera sp. n.1 macho. 200, falômero direito, vista dorsal; 201, falômero direito, vista ventral; 202, falômero direito, vista lateral direita. 


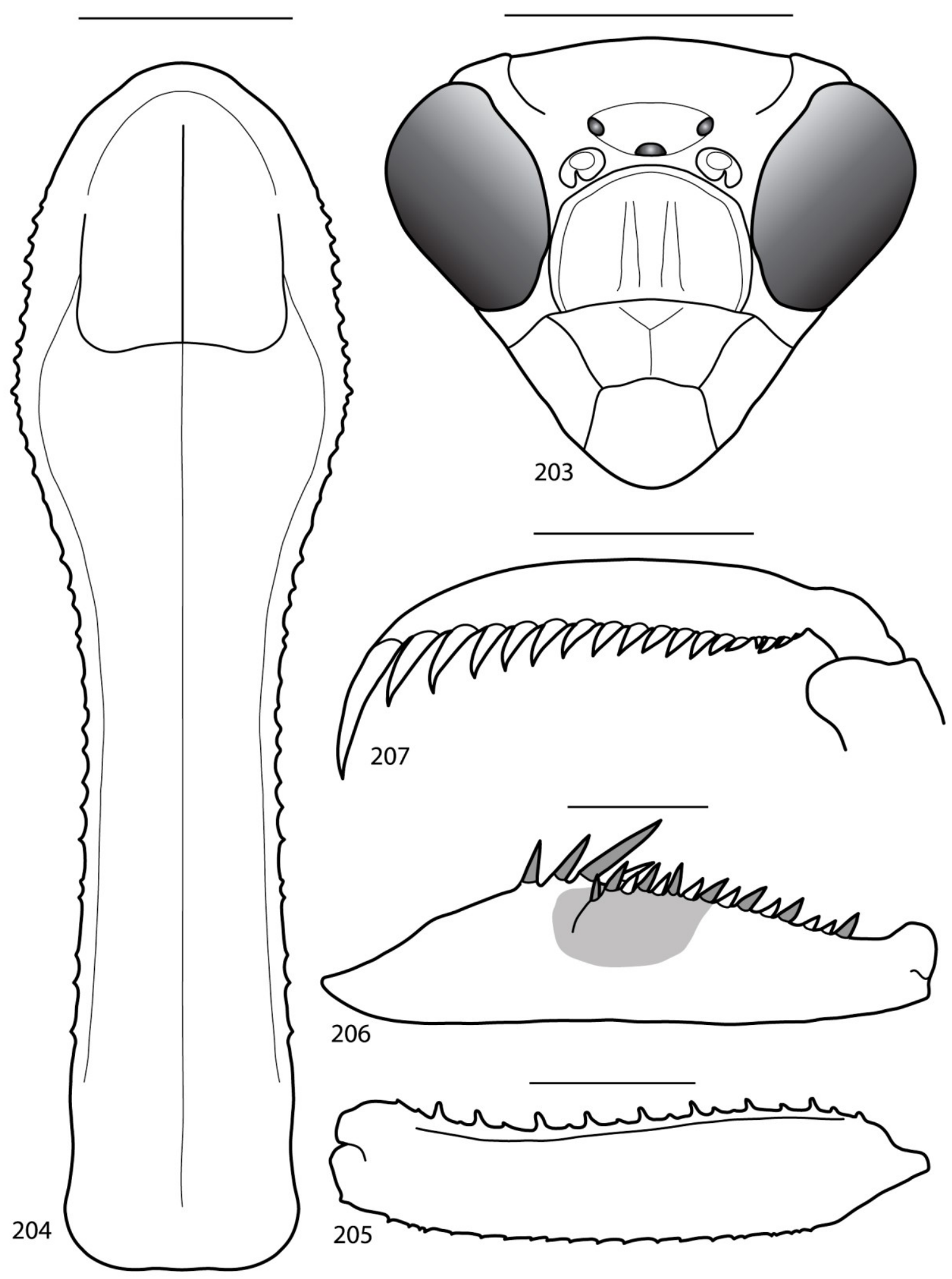

Figuras 203-207. Stagmatoptera sp.n.1 fêmea. 203, cabeça, vista frontal; 204, protorax, vista dorsal; 205, coxa anterior, vista interna; 206, fêmur anterior, vista interna; 207, tíbia anterior, vista interna. Escalas $=5 \mathrm{~mm}$. 


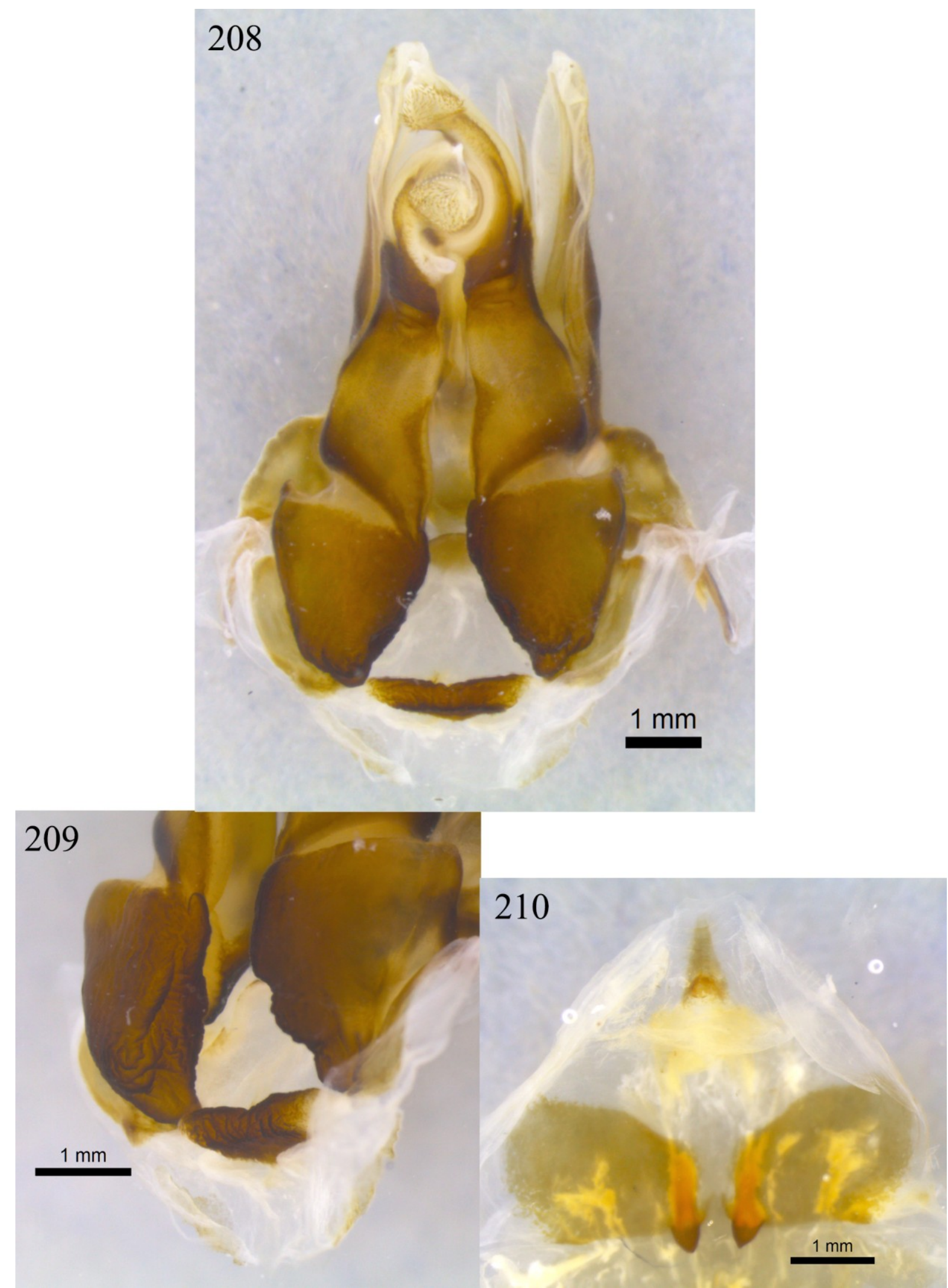

Figuras 208-210. Stagmatoptera sp. n.1 fêmea. 208, ovipositor, vista ventral; 209, detalhe das gonocoxas; 210, assoalho da câmara genital, vista dorsal. 


\section{Stagmatoptera sp. n.2}

\section{Descrição: Macho - Figuras 211-223}

Antenômeros filiformes. Escudo frontal com duas elevações centrais (Fig. 212).

Protorax alongado, delgado, com margens dotadas de crenulação suave na prozona, lisas na metazona. Metazona com uma quilha central pouco desenvolvida (Fig. 213). Coxas anteriores com margem anterior crenulada dotada de 9 a 12 espinhos grandes e 3 a 6 espinhos menores (Fig. 214). Fêmures anteriores alongados e largos, com os três primeiros espinhos discoidais a partir da base, escuros em sua face interna; 15 a 16 espinhos internos, o primeiro espinho interno a partir da base e os grandes espinhos internos são escuros na face interna, podendo apresentar uma pequena mancha de mesma coloração na inserção dos espinhos $10 \mathrm{e}$ 12. Mancha femoral interna estendendo-se da canaleta da garra tibial até o $8^{\circ}$ espinho interno a partir da base, com formato retangular e uma coloração preta fosca (Fig. 215). Tíbias anteriores dotadas de 11 a 12 espinhos externos, e 15 a 17 espinhos internos; a garra tibial escura na face interna, uma mancha preta suave na metade da face interna (Fig. 216). Tarsos com manchas pretas apicais na face interna e externa dos tarsômeros I a IV.

Área discoidal das tégminas verde opaca em uma faixa anterior, passando gradualmente para hialina. Estigma circular de tamanho mediano, porém sem alcançar a metade da área discoidal, com o seguinte padrão: uma mancha branca anterior, uma mancha marrom posterior e no centro, entre as duas, uma pequena mancha semi-hialina. Asas com as áreas discoidal e anal com molduras amarelas nas veias transversais (Fig. 211).

Genitália: Falômero esquerdo mais longo que largo, esclerito L4B tão longo quanto largo. Processo apical longo, levemente dilatado no lado esquerdo de sua base; inclinado $30^{\circ}$ em relação à base, e depois curvando para a esquerda; ápice simples, voltado ventralmente (Fig. 217). Processo distal estreito e curto, achatado, curvado para a direita, ápice bem esclerosado e afilado (Fig. 218). Apófise falóide longa e paralela em relação à genitália (Fig. 219); margem direita lisa e sinuosa (Fig. 220); ápice posterior intumescido com uma projeção voltada para a direita, rugoso e esclerosado; ápice anterior reto, margens esclerosadas, e intumescidas, porém sem formar uma canaleta (Fig. 219). Lobo membranoso curto, curvado para a direita (Fig. 219). Membrana adjacente à apófise falóide glabra (Fig. 219). 
Falômero direito com ápice posterior anguloso; braço médio curto, com uma expansão antes da metade, formando uma grande elevação (Fig. 221); placa ventral curta, fortemente esclerosada (Fig. 222 e 223); processo ventral curto, fortemente esclerosado, ápice arredondado (Fig. 222); apódema anterior longo, passando bruscamente a um ápice arredondado (Fig. 222 e 223).

Distribuição: Trinidad e Tobago, Venezuela.

Diagnose: Mancha femoral interna se estendendo até o $8^{\circ}$ espinho interno, mancha no estigma com formato circular.

Tabela 11. Medidas e razões de machos de Stagmatoptera sp. n.2.

\begin{tabular}{|c|c|c|}
\hline & Macho $(\mathrm{N}=2)$ & Fêmea \\
\hline Comprimento & 85,1 a $91,7 \mathrm{~mm}$ & - \\
\hline Largura da cabeça & 8,4 a $8,5 \mathrm{~mm}$ & - \\
\hline Comprimento da Prozona & 5,5 a $5,6 \mathrm{~mm}$ & - \\
\hline Comprimento da Metazona & 21,7 a $22,4 \mathrm{~mm}$ & - \\
\hline Largura da Dilatação & 6 a $6,3 \mathrm{~mm}$ & - \\
\hline Comprimento da Tégmina & 55,5 a $56,2 \mathrm{~mm}$ & - \\
\hline Comprimento da Asa & 48,9 a $49 \mathrm{~mm}$ & - \\
\hline Comprimento da Coxa Anterior & 14,6 a $15,3 \mathrm{~mm}$ & - \\
\hline Comprimento do Fêmur Anterior & 16,9 a $18,4 \mathrm{~mm}$ & - \\
\hline Largura do Fêmur Anterior & 3,8 a $3,9 \mathrm{~mm}$ & - \\
\hline Comprimento da Tíbia Anterior & 8,8 a 9,2 mm & - \\
\hline Razão Cabeça/Dilatação & 1,33 a 1,42 & - \\
\hline Razão Metazona/Prozona & 3,88 a 4,07 & - \\
\hline Razão Prozona/Dilatação & 0,87 a 0,93 & - \\
\hline Razão Metazona/Dilatação & 3,56 a 3,62 & - \\
\hline Razão Metazona/Coxa Anterior & 1,46 a 1,48 & - \\
\hline Razão Comprimento/Largura & 4,33 a 4,84 & - \\
\hline Fêmur Anterior & 1,92 a 2 & - \\
\hline Razão Fêmur/Tíbia & & \\
\hline
\end{tabular}

Material examinado: Trinidad e Tobago; au sud du barrage de Hillsborough, prés de Green Hill, Tobago, 30.x.2008, F. Langlois \& Y. Bellanger, $2 \circlearrowleft$ (MNHN). 


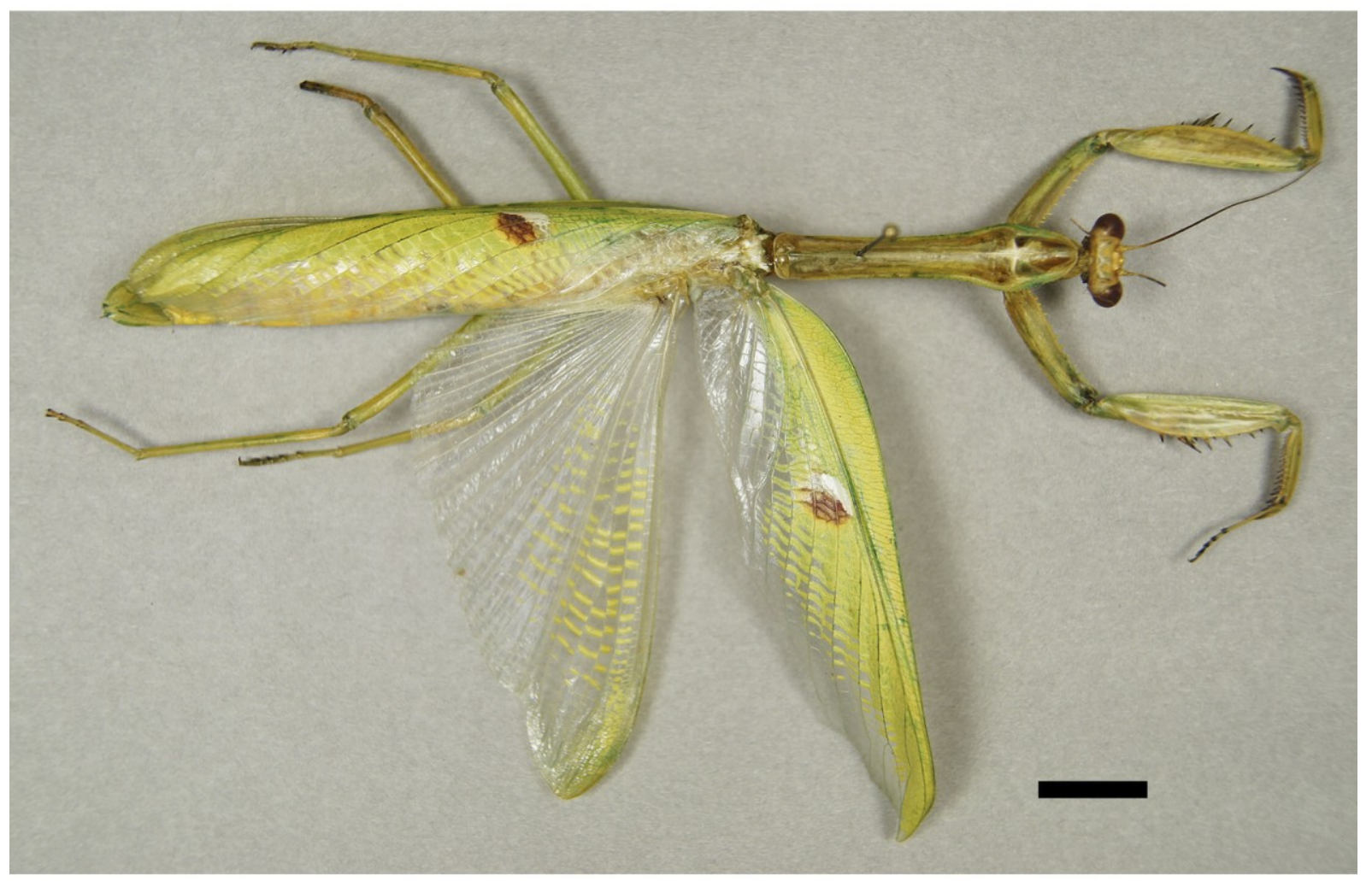

Figura 211. Stagmatoptera sp. n.2, habitus dorsal, macho. Escalas $=1 \mathrm{~cm}$. 


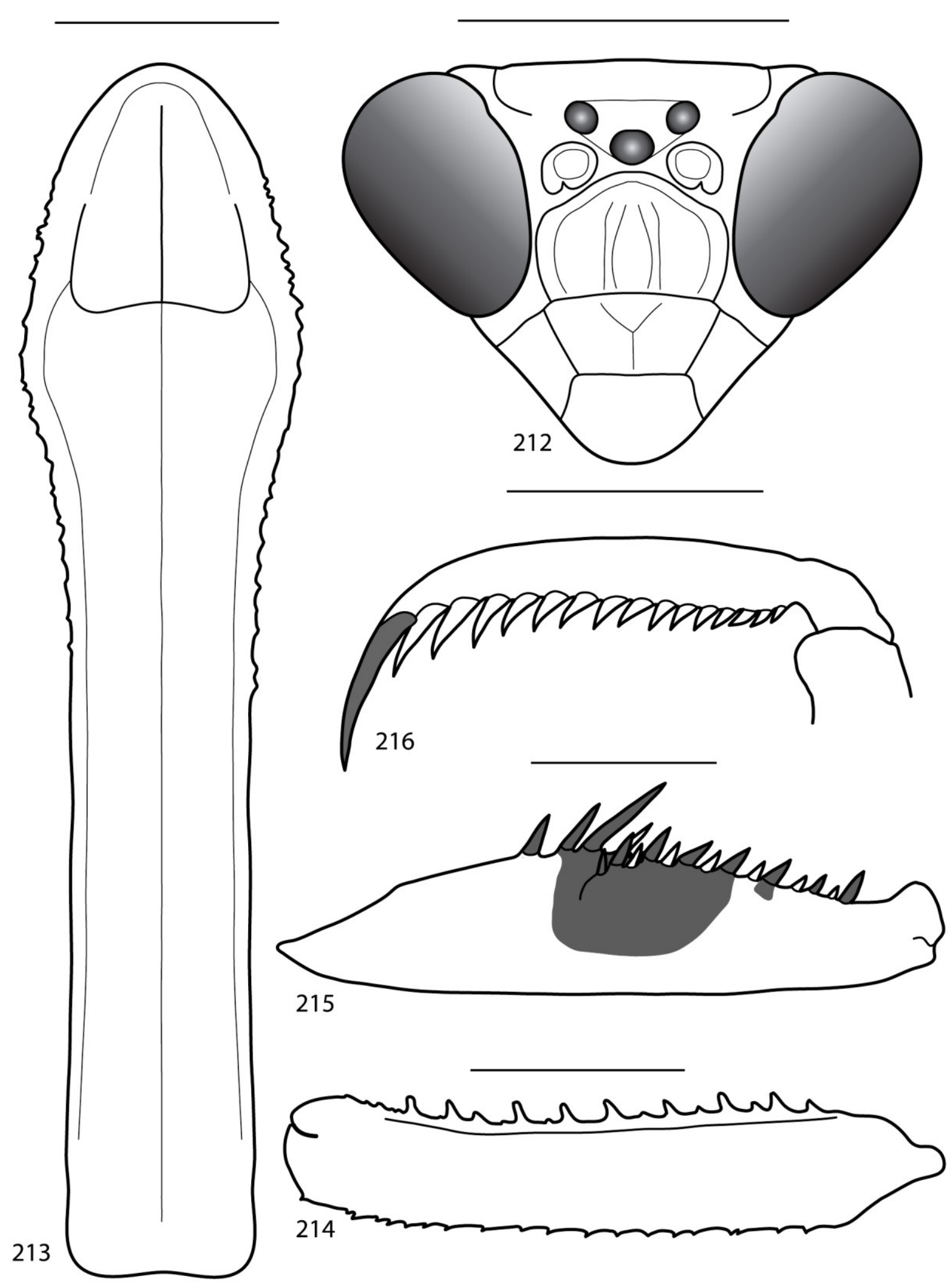

Figuras 212-216. Stagmatoptera sp. n.2 macho. 2, cabeça, vista frontal; 3, protorax, vista dorsal; 4, coxa anterior, vista interna; 5 , fêmur anterior, vista interna; 6, tíbia anterior, vista interna. Escalas $=5 \mathrm{~mm}$. 

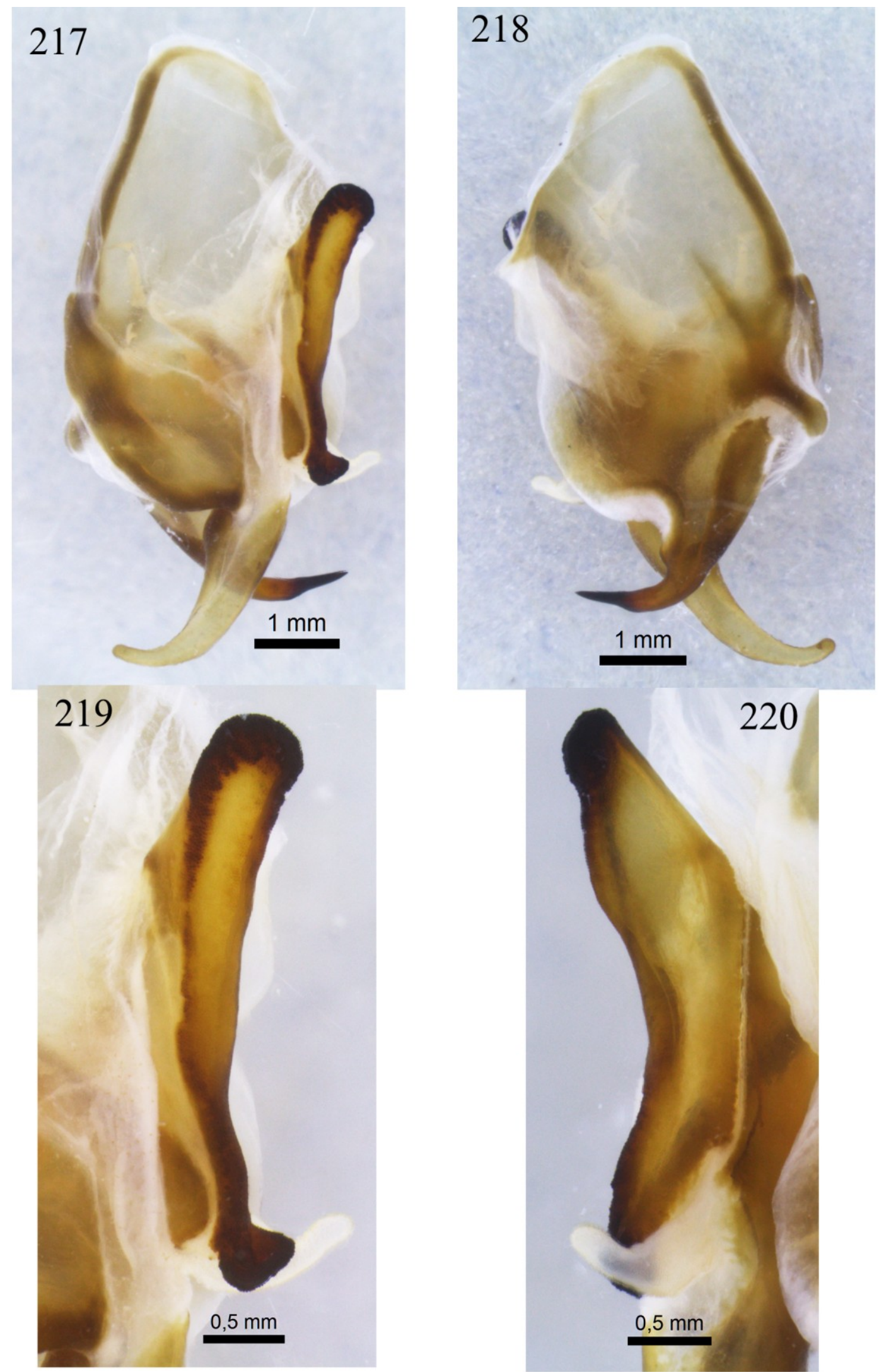

Figuras 217-220. Stagmatoptera sp. n.2 macho. 7, falômero esquerdo, vista dorsal; 8, falômero esquerdo, vista ventral; 9, apófise falóide e lobo membranoso, vista dorsal; 10, apófise falóide, vista lateral direita. 


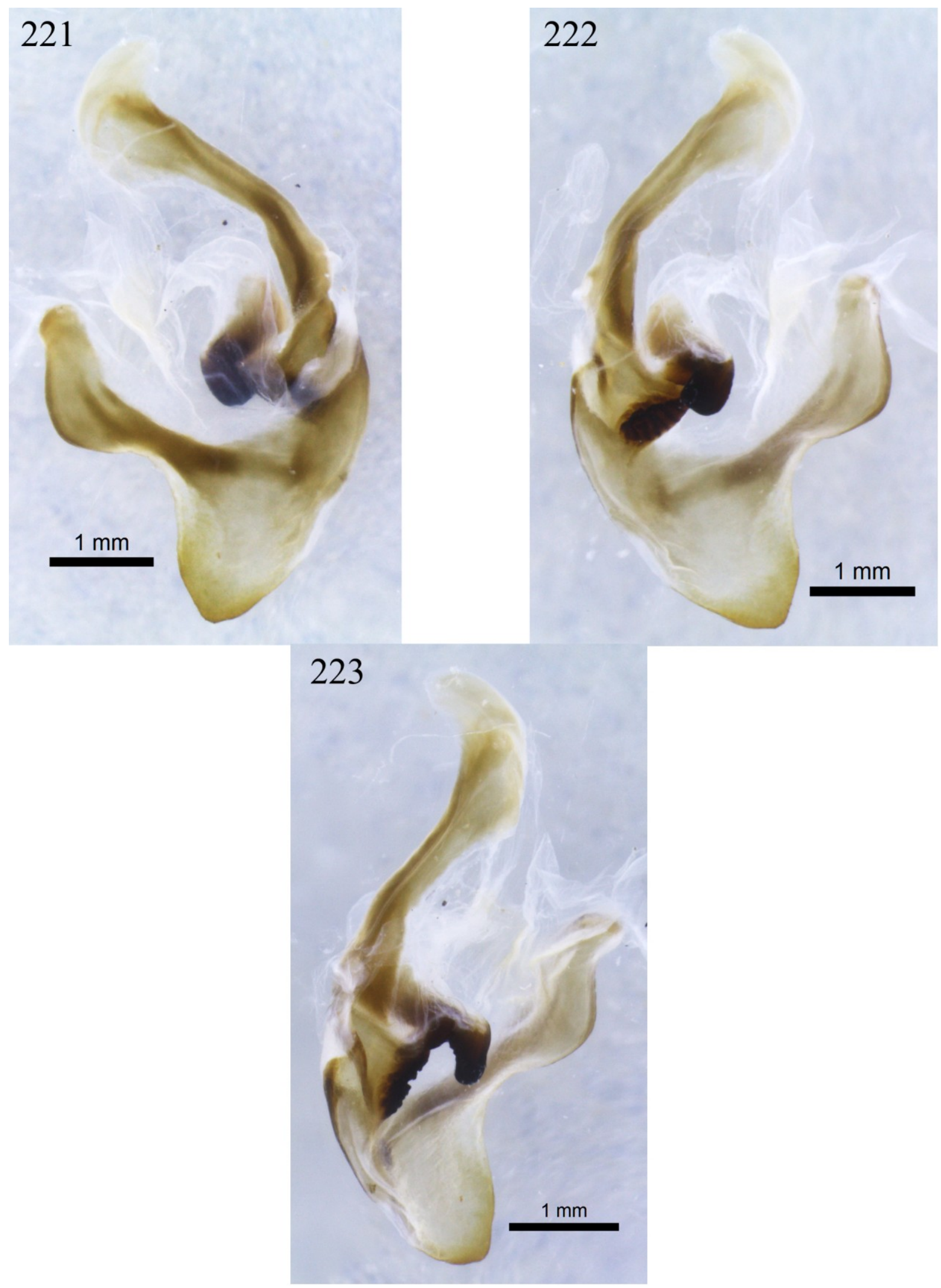

Figuras 221-223. Stagmatoptera sp. n.2 macho. 11, falômero direito, vista dorsal; 12, falômero direito, vista ventral; 13, falômero direito, vista lateral direita. 
Stagmatoptera supplicaria (Burmeister, 1838)

Mantis (Acontistes) supplicaria Burmeister, 1838, p.542 (descr.).

Mantis supplicaria, Charpentier, 1844, p.303 (men.).

Stagmatoptera supplicaria, Saussure, 1871, p.94, t.1, f.11 (redesc.); Stål, 1877, p.72; Westwood, 1889, p.16 (men.); Kirby, 1904, p.299 (men.); Rehn, 1911, p.12, t.5 f.5 (men.); Giglio-Tos, 1914, p.26 (redesc.); Werner, 1925a, p.166 (men.); Giglio-Tos, 1927 , p.595 (redesc.); Terra, 1995, p.65 (men.); Ehrmann, 2002. p.330 (men.); Agudelo et al., 2007, p.126 (men.); Ehrmann \& Koçak, 2009, p.12 (men.).

= Mantis precaria Linnaeus, 1758 de Stoll, 1787, p.51, t.17, f.62 (descr.); Saussure, 1869, p. 67 (men.); Saussure, 1870, p. 232 (men.) - identificação errada.

= Mantis hyalina De Geer, 1773 de Burmeister, 1838, p.532 - identificação errada (redesc.).

= Mantis flavipennis Audinet-Serville, 1839, p.182 (descr.); de Haan, 1942, p.74 (men.).

= Stagmatoptera flavipennis, Giglio-Tos, 1914, p.27 (redesc.); Giglio-Tos, 1927, p.595 (redesc.); Beier, 1930, p.31 (men.); Terra, 1995, p.64 (men.); Ehrmann, 2002, p.328 (men.); Agudelo et al., 2007, p.125 (men.); Ehrmann \& Koçak, 2009, p.12 (men.).

= Stagmatoptera abdominalis (Olivier, 1792) de Werner, 1925a, p.167 (redesc.); Jantsch, 1994, p.160, f.1-7 (redesc.) - identificação errada.

Redescrição: Macho - Figuras 224A, 225-236.

Antenômeros serreados. Escudo frontal com duas elevações centrais (Fig. 225).

Protorax alongado, delgado, com margens dotadas de crenulação suave na prozona, lisas na metazona. Metazona com uma quilha central pouco desenvolvida (Fig. 226). Coxas anteriores com margem anterior crenulada dotada de 5 a 11 espinhos grandes e 0 a 11 espinhos menores (Fig. 227). Fêmures anteriores alongados e finos, com os três primeiros espinhos discoidais a partir da base, pretos em sua face interna; 15 a 16 espinhos internos, sendo o número mais frequente 15 , o primeiro espinho interno a partir da base e os grandes espinhos internos são escuros na face interna, podendo apresentar uma mancha de mesma coloração na inserção dos espinhos 6, 8, 10 e 12 e 15. Mancha femoral interna estendendo-se da canaleta da garra tibial até o $6^{\circ}$ espinho interno a partir da base, com formato retangular, 
começando forte e enfraquecendo-se em direção ao ápice do fêmur (Fig. 228). Tíbias anteriores dotadas de 10 a 13 espinhos externos sendo mais frequente 12, e 13 a 17 espinhos internos, sendo mais frequente 15; garra tibial e o último espinho que a precede pretos na face interna, uma mancha preta na metade da face interna (Fig. 229). Tarsos com manchas pretas apicais nas faces interna e externa dos tarsômeros I a IV e uma mancha basal interna no tarsômero I.

Área discoidal das tégminas hialina. Estigma de tamanho mediano, com o seguinte padrão: uma faixa marrom longa distal e uma pequena mancha marrom proximal. Asas totalmente hialinas (Fig. 224A).

Genitália: Falômero esquerdo mais longo que largo, esclerito L4B mais longo que largo. Processo apical longo, levemente dilatado no lado esquerdo de sua base; inclinado em relação à base, formando um ângulo de aproximadamente $45^{\circ}$, e depois curvando para a esquerda; ápice simples, voltado ventralmente (Fig. 230). Processo distal estreito e curto, curvado para a direita, ápice bem esclerosado e afilado (Fig. 231). Apófise falóide curta e paralela em relação à genitália (Fig. 232); margem direita lisa e levemente sinuosa (Fig. 233); ápice posterior intumescido com duas projeções, uma voltada para a direita e outra posteriormente, rugosa e esclerosada; ápice anterior curvado para a direita, margens esclerosadas, e intumescidas, porém sem formar uma canaleta (Fig. 232). Lobo membranoso curto, curvado para a direita (Fig. 232). Membrana adjacente à apófise falóide glabra (Fig. 232).

Falômero direito com ápice posterior anguloso; braço médio curto, com uma expansão na metade, formando uma suave elevação (Fig. 234); placa ventral curta, fortemente esclerosada (Fig. 235 e 236); processo ventral curto, esclerosado, ápice retangular (Fig. 235); apódema anterior longo, passando suavemente a um ápice arredondado (Fig. 235).

Fêmea - Figuras 224B, 237-244.

Escudo frontal com duas elevações centrais (Fig. 237).

Protorax alongado, delgado, com margens dotadas de crenulação suave. Metazona com uma quilha central pouco desenvolvida (Fig. 238). Coxas anteriores com margem anterior crenulada dotada de 7 a 16 espinhos grandes e 4 a 12 espinhos menores (Fig. 239). Fêmures anteriores alongados e finos, com os três primeiros espinhos discoidais a partir da 
base, pretos em sua face interna; 14 a 17 espinhos internos, sendo o mais frequentes 15 , o primeiro espinho interno a partir da base e os grandes espinhos internos são pretos na face interna, podendo apresentar uma mancha de mesma coloração na inserção dos espinhos 6,8 , 10, 12 e 15. Mancha femoral interna estendendo-se da canaleta da garra tibial até o $6^{\circ}$ espinho interno a partir da base, com formato retangular, começando forte e enfraquecendo-se em direção ao ápice do fêmur (Fig. 240). Tíbias anteriores dotadas de 11 a 12 espinhos externos, e 14 a 17 espinhos internos sendo mais frequente 15; garra tibial e o último espinho que a precede pretos na face interna, uma mancha preta na metade da face interna (Fig. 241). Tarsos com manchas pretas apicais nas faces interna e externa dos tarsômeros I a IV e uma mancha basal interna no tarsômero I.

Estigma oval e grande, quase atingindo a margem posterior da tégmina, com o seguinte padrão: uma mancha branca anterior, uma mancha preta proximal e uma mancha marrom posterior e lateral. Asas com área costal hialina, e as áreas discoidal e anal amarelas com as margens hialinas com molduras amarelas nas veias transversais (Fig. 224B).

Genitália: Base das gonapófises VIII se projetando internamente (Fig, 242). Basiválvula com formato aproximadamente triangular, margem interna dilatada (Fig. 242), a superfície interna esculpida (Fig. 243). Interbasiválvula esclerosada e esculpida (Fig. 243). Extensões posterolaterias longas, esclerosadas com margens lisas (Fig. 243). Esclerito na parede dorsal da papila genital esclerosado, liso (Fig. 244). Plataforma lateroesternal retangular, processos posteriores curtos, cônicos (Fig. 244).

\section{Localidade tipo: -}

Outras localidades: Bolívia, Brasil (Amazonas, Mato Grosso, Para), Colômbia, Equador, Guiana Francesa, Peru, Suriname, Trinidad \& Tobago, Venezuela.

Diagnose: Mancha no estigma dos machos com uma faixa marrom e uma pequena mancha também marrom mais ou menos aparente, nas fêmeas uma grande mancha oval ocupando quase toda a área discoidal. 
Tabela 12. Medidas e razões de machos e fêmeas de Stagmatoptera supplicaria.

\begin{tabular}{|c|c|c|}
\hline & Macho $(\mathrm{N}=34)$ & Fêmea $(\mathrm{N}=17)$ \\
\hline Comprimento & 63,5 a $86,9 \mathrm{~mm}$ & 71,6 a $93,3 \mathrm{~mm}$ \\
\hline Largura da cabeça & 7,1 a $8,5 \mathrm{~mm}$ & 9,3 a $10 \mathrm{~mm}$ \\
\hline Comprimento da Prozona & 4 a $5,1 \mathrm{~mm}$ & 6 a $7,2 \mathrm{~mm}$ \\
\hline Comprimento da Metazona & 17,1 a $24,6 \mathrm{~mm}$ & 25,8 a $32,1 \mathrm{~mm}$ \\
\hline Largura da Dilatação & 4,2 a $6,1 \mathrm{~mm}$ & 6,5 a $8,4 \mathrm{~mm}$ \\
\hline Comprimento da Tégmina & 41,5 a $64,8 \mathrm{~mm}$ & 41,8 a $51,8 \mathrm{~mm}$ \\
\hline Comprimento da Asa & 42,4 a $52,3 \mathrm{~mm}$ & 36,7 a $47,2 \mathrm{~mm}$ \\
\hline Comprimento da Coxa Anterior & 11,8 a $15,1 \mathrm{~mm}$ & 17,3 a $20,2 \mathrm{~mm}$ \\
\hline Comprimento do Fêmur Anterior & 13,7 a $17,5 \mathrm{~mm}$ & 19,8 a $23 \mathrm{~mm}$ \\
\hline Largura do Fêmur Anterior & 2,4 a 3,3 mm & 3,8 a $4,5 \mathrm{~mm}$ \\
\hline Comprimento da Tíbia Anterior & 6,5 a $8,8 \mathrm{~mm}$ & 9,1 a $11,1 \mathrm{~mm}$ \\
\hline Razão Cabeça/Dilatação & 1,3 a 1,77 & 1,19 a 1,45 \\
\hline Razão Metazona/Prozona & 4,17 a 5,5 & 3,84 a 5,02 \\
\hline Razão Prozona/Dilatação & 0,77 a 1,05 & 0,79 a 1,04 \\
\hline Razão Metazona/Dilatação & 3,9 a 5,05 & 3,6 a 4,65 \\
\hline Razão Metazona/Coxa Anterior & 1,41 a 1,69 & 1,41 a 1,65 \\
\hline Razão Comprimento/Largura & 5,24 a 6,33 & 5,07 a 5,85 \\
\hline Fêmur Anterior & & 2,03 a 2,34 \\
\hline Razão Fêmur/Tíbia & 1,87 a 2,24 & \multicolumn{2}{|c}{} \\
\hline
\end{tabular}

Material examinado: Bolívia; Sara, 750m, J. Steinbach S.V., $1 q$ (ZMB). Brasil; Hamburgo/Magdalena[?], 800m, 1 (ZMB). Amazonas - Manaus, 11.vi.1976, J.M. Santos, $1 \delta$ (MCTP) Pará - H. de Saussure, $1 \delta^{\Uparrow}(\mathrm{MHNG})$. Tucurui, Bagagem, 04.viii.1980, eq. Nunes

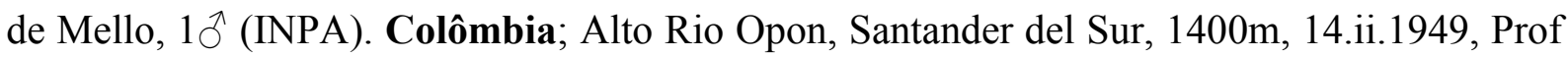
Richter, $1 ठ$ (NHMW). Alto Rio Opon, Santander del Sur, 800-900m, i.1950, Prof Richter, 1 \% (NHMW). Upin, Südamerika, $1 \sigma^{\Uparrow}(\mathrm{ZMB})$. Equador; Stat. rech. Yasuni, cflt. rios Tiputini/Tivacuno, Napo, forêt de plateau/lisiéres, 05-15.ii.1995, S. Poulain rec., $1 ð$ (MNHN). Guiana Francesa; 19 (ZMB). 2 (MHNG). [?] de Géographie, 1913, M. Guitton [?], 1 \% (MNHN). 1900-1901, 1 ( $\mathrm{MNHN}$ ). Charvein, ii.1914, R. Benoist, $1 q$ (MNHN). Maroni, 1903, F. Geay, $1 q(\mathrm{MNHN})$. Nouveau Chantier, 29 (MNHN). [Barrage] Petit Saut, lumière, 10.ii.1994, P.E. Roubrandt, $1 \lesssim(\mathrm{MNHN})$. Route de Kaw, PK33, ii.1985, G. Tavakilian rec., $1 ठ$ (MNHN). Route de Régina, PK79, 15.ii.1994, L. \& A. Sénégaux, 1 đ (MNHN). St-Jeandu-Maroni, iv-v.1914, R. Benoist, $1 q$ (MNHN). St-Jean-du-Maroni, 1914, R. Benoist, $1 q$ $(\mathrm{MNHN})$. St. Laurent du Maroni, 1 ( $(\mathrm{MNHN})$. St-Laurent-du-Maroni, v.1919, $1 \overbrace{}^{\Uparrow}(\mathrm{MNHN})$. 
Station Saut Pararé, Réserve Naturelle des Nouragues, 40 m, Régina, 18.ix.2009, 1ठ (MNHN). Peru; Iquitos, [Loreto], 12-16.viii.1988, Beaudouin leg., 1ð (MNHN). Rio Ampiyacu, Loreto, 19 (MNHN). Suriname; H. de Saussure, 19 (MHNG). Trinidad \& Tobago; Trinidad, $1 \circlearrowleft$ (ZMB). Venezuela; Sawariapo, Alto Orinoco, viii.1946, René Lichy,

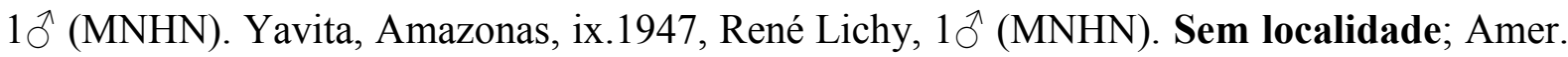
Mer., $1 \circlearrowleft$ (ZMB). $2 \widehat{\jmath}(\mathrm{MNHN})$. 

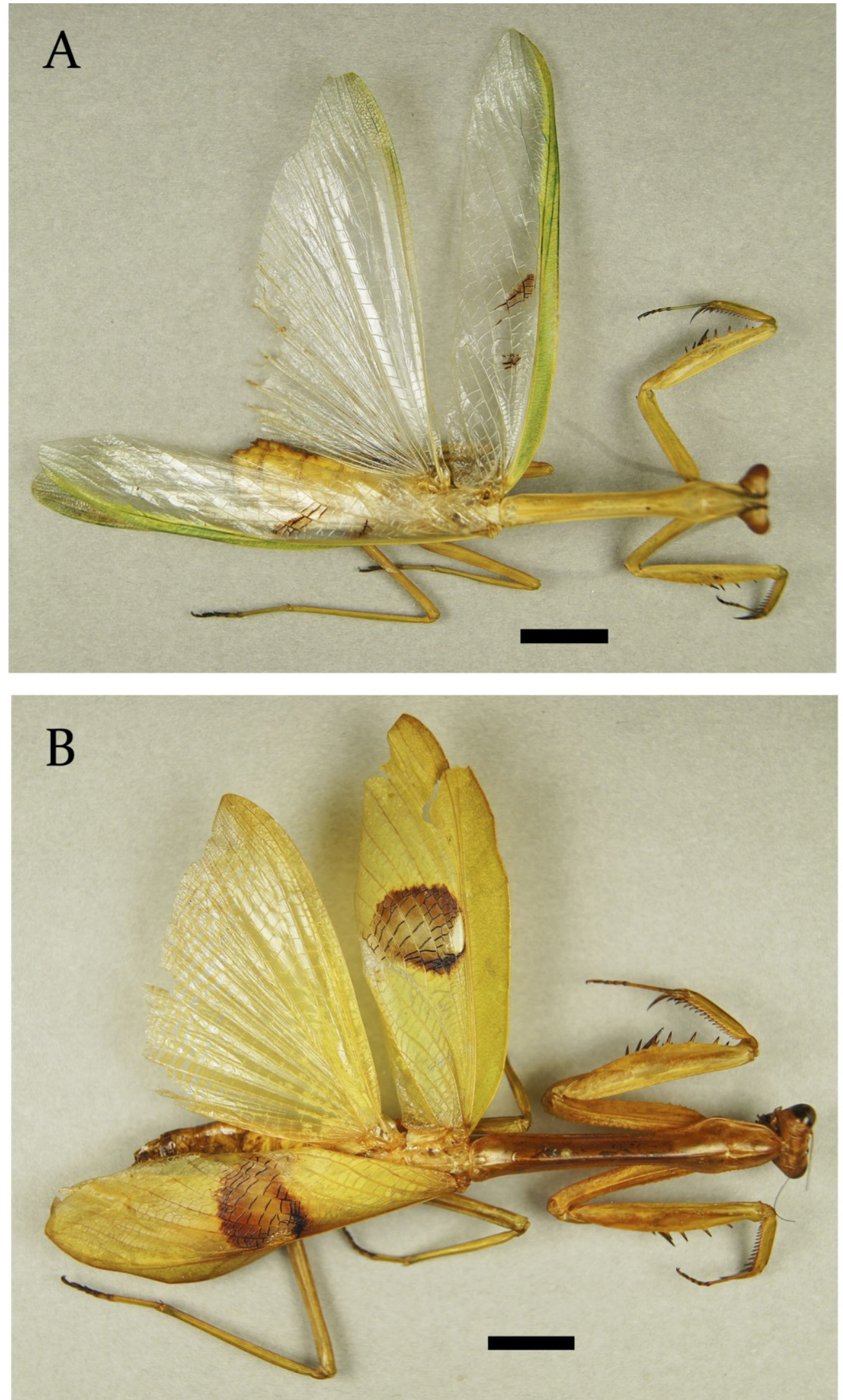

Figura 224. Stagmatoptera supplicaria, habitus dorsal. A, macho; B, fêmea. Escalas $=1 \mathrm{~cm}$. 


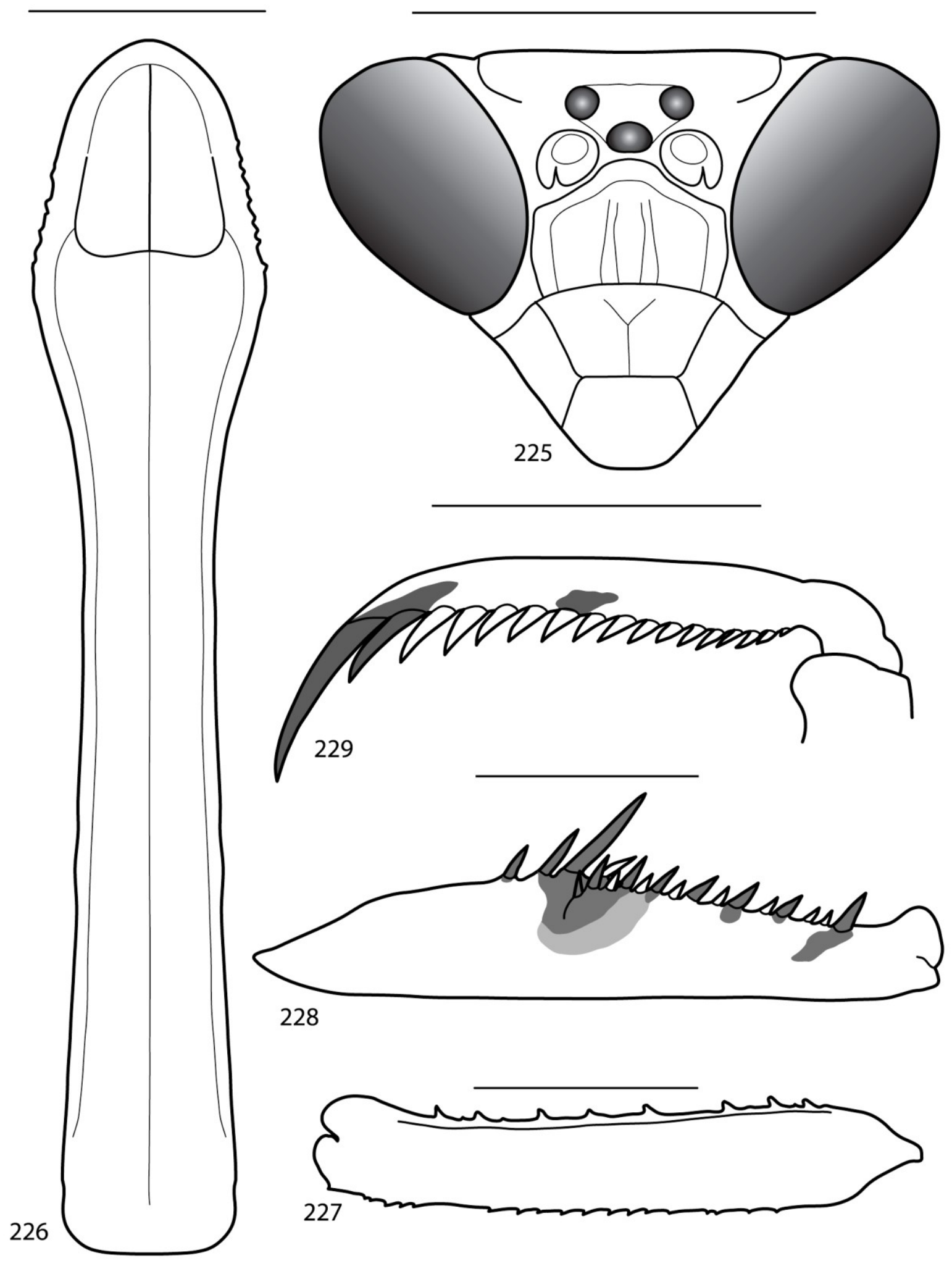

Figuras 225-229. Stagmatoptera supplicaria macho. 225, cabeça, vista frontal; 226, protorax, vista dorsal; 227 , coxa anterior, vista interna; 228, fêmur anterior, vista interna; 229, tíbia anterior, vista interna. Escalas $=5 \mathrm{~mm}$. 


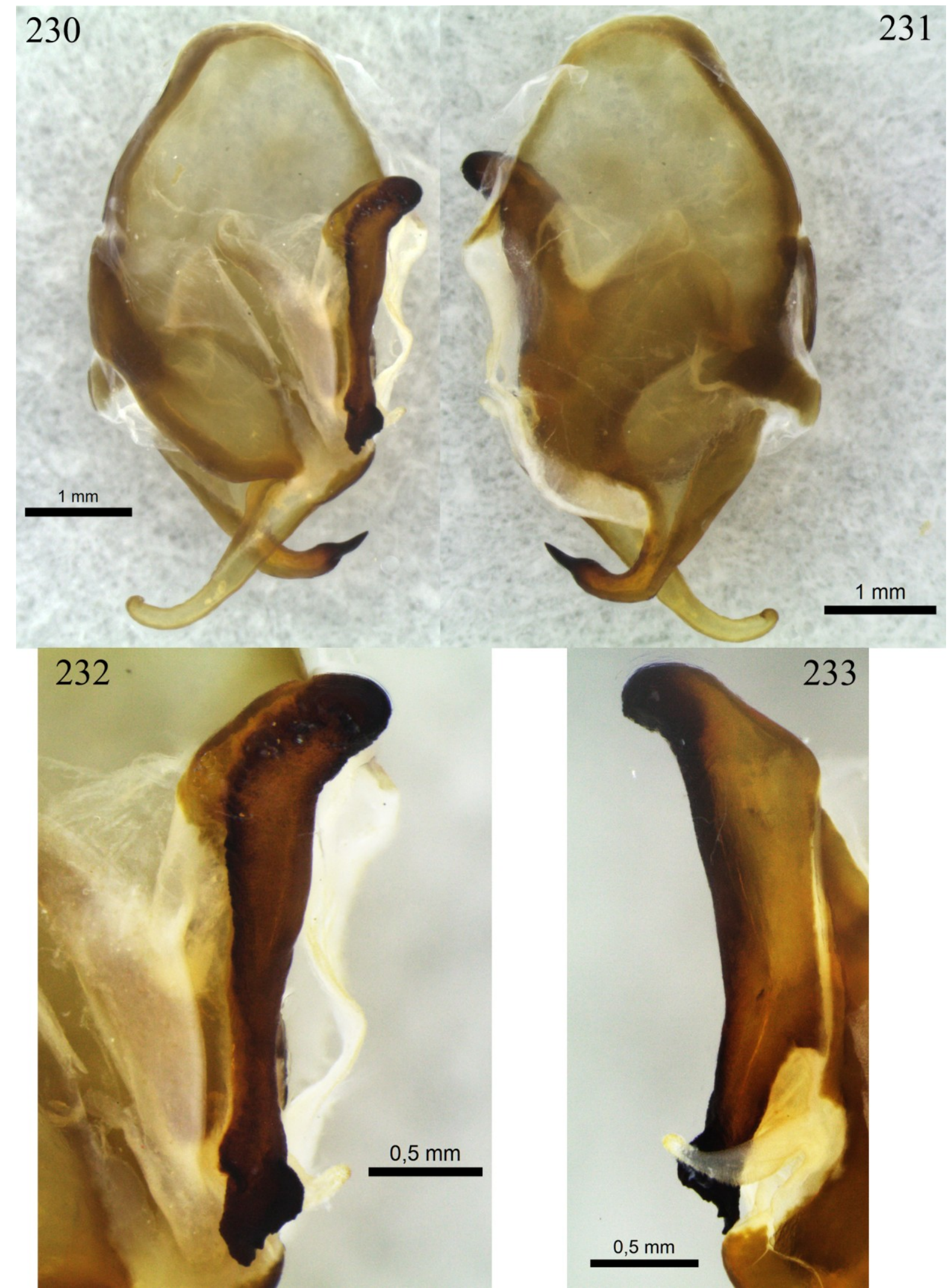

Figuras 230-233. Stagmatoptera supplicaria macho. 230 falômero esquerdo, vista dorsal; 231, falômero esquerdo, vista ventral; 232, apófise falóide e lobo membranoso, vista dorsal; 233, apófise falóide, vista lateral direita. 


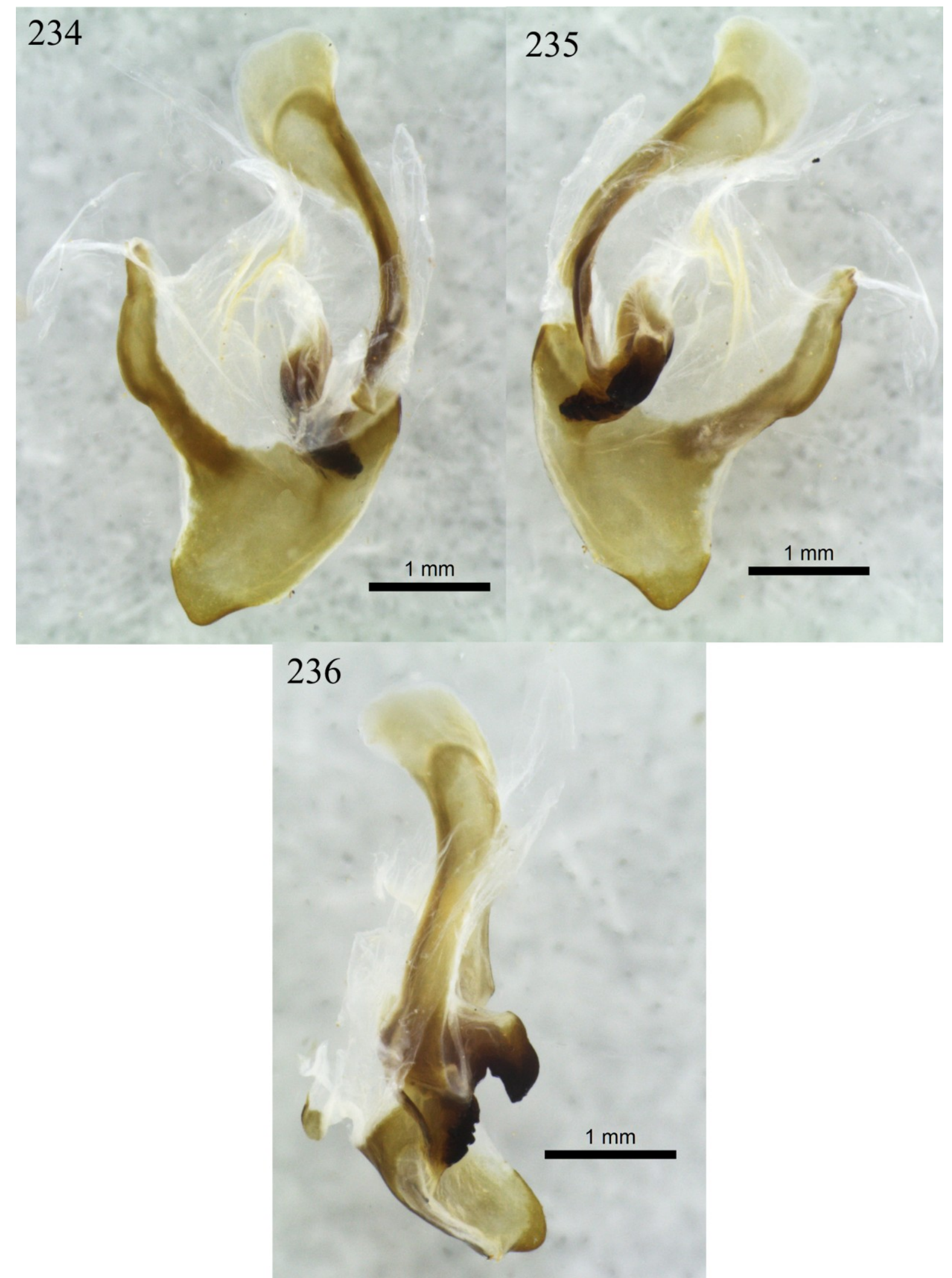

Figuras 234-236. Stagmatoptera supplicaria macho. 234, falômero direito, vista dorsal; 235, falômero direito, vista ventral; 236, falômero direito, vista lateral direita. 


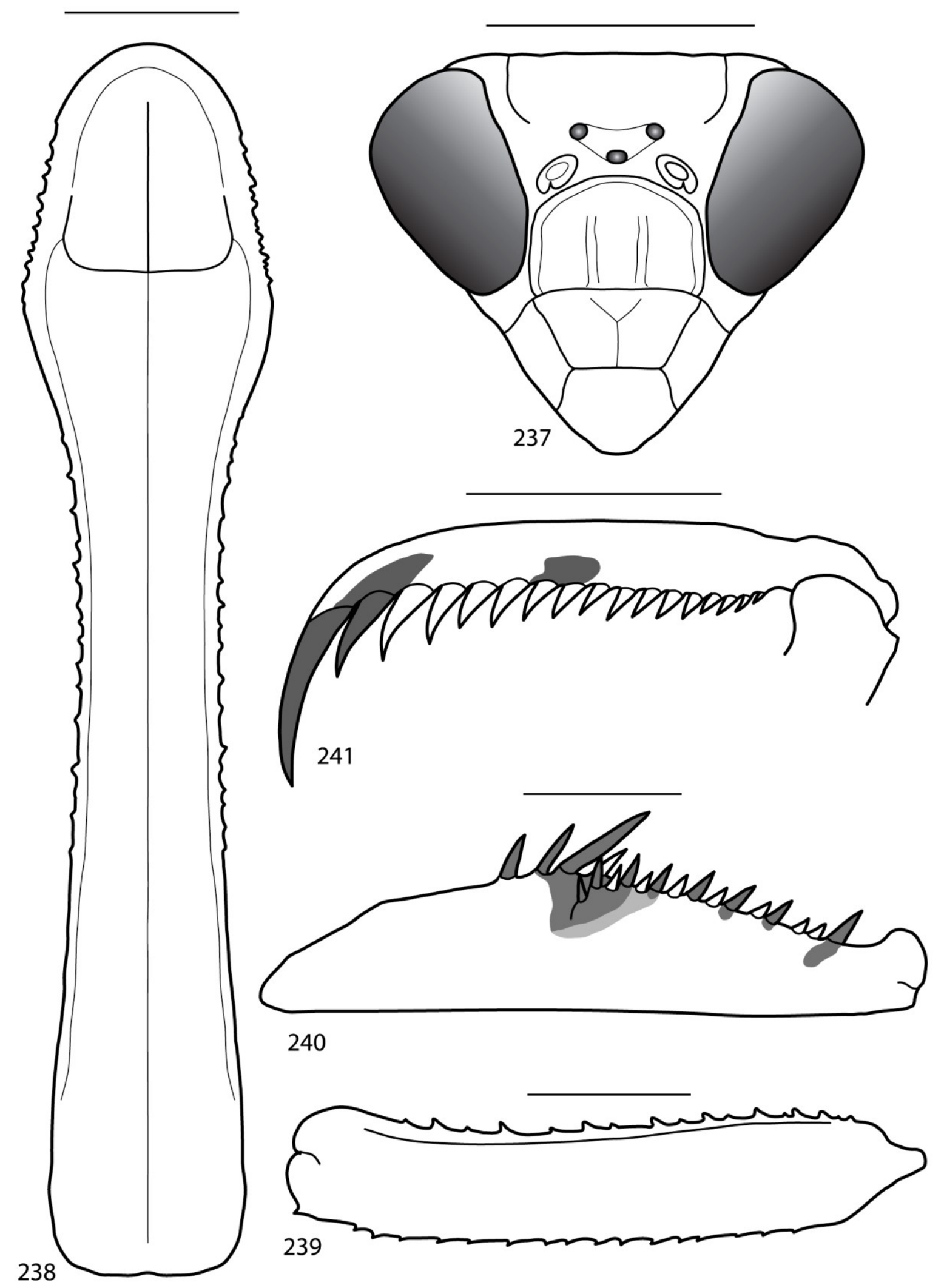

Figuras 237-241. Stagmatoptera supplicaria fêmea. 237, cabeça, vista frontal; 238, protorax, vista dorsal; 239, coxa anterior, vista interna; 240, fêmur anterior, vista interna; 241, tíbia anterior, vista interna. Escalas $=5 \mathrm{~mm}$. 


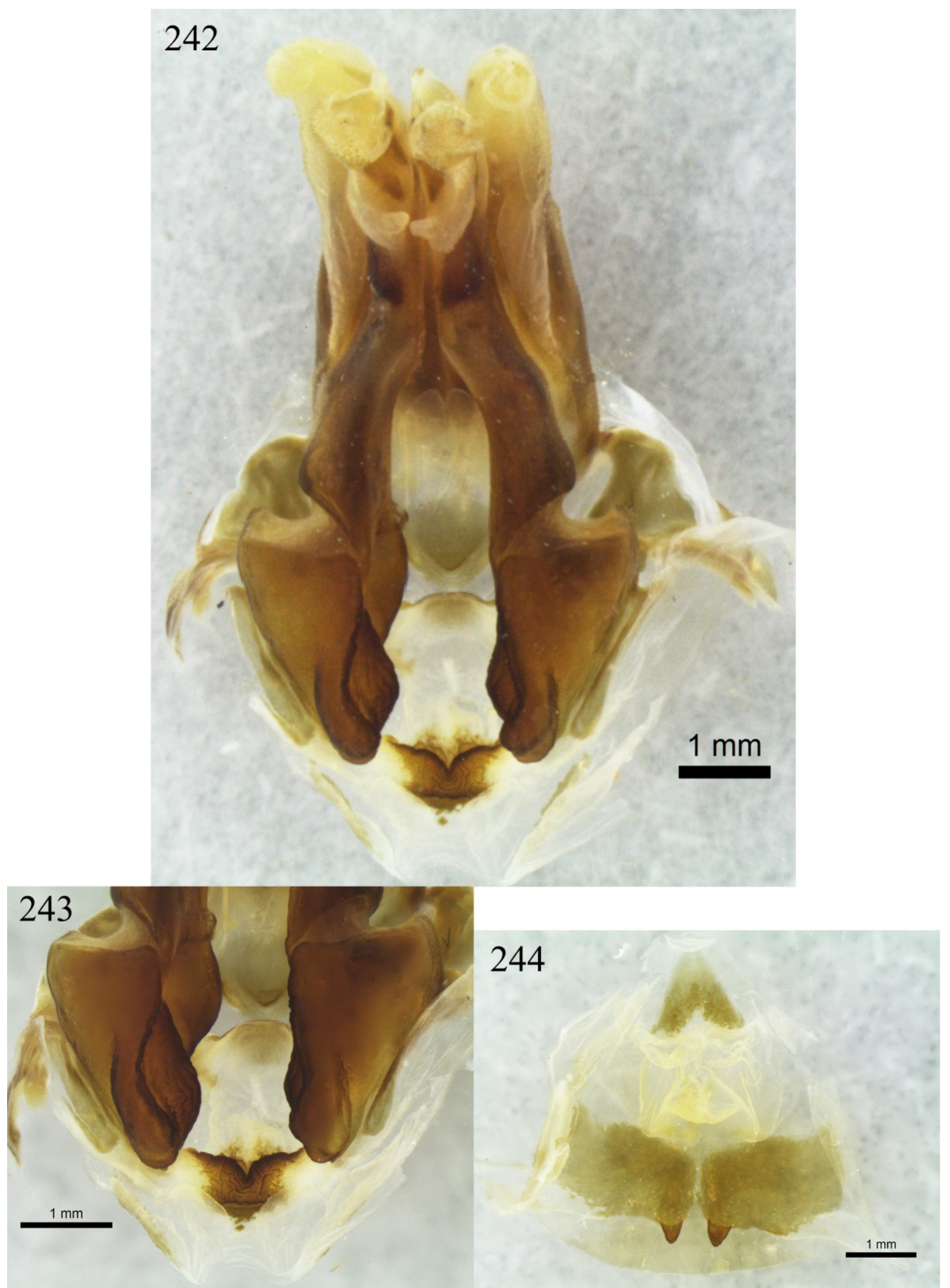

Figuras 242-244. Stagmatoptera supplicaria fêmea. 242, ovipositor, vista ventral; 243, detalhe das gonocoxas; 244, assoalho da câmara genital, vista dorsal. 


\section{Mapas de distribuição}

Com os dados de localidade foi possível fazer mapas de distribuição para quase todas as espécies do gênero Stagmatoptera. Não foi possível fazer mapas de distribuição para $S$. abdominalis e $S$. indicator, pois como dito, nenhum indivíduo dessas duas espécies foi encontrado. Também não há um mapa para S. pumila, pois o único exemplar estudado, isto é, o tipo, não tem dados de local de coleta ou coletor.

Os mapas foram feitos tentando agrupar o menor número possível de espécies que apresentam uma distribuição próxima, para garantir maior clareza. Esses mapas (Fig. 245 249) mostram que algumas espécies apresentam uma distribuição aparentemente mais restrita, como Stagmatoptera precaria (248) e S. biocellata (246), enquanto outras têm uma distribuição mais ampla, como S. hyaloptera (247) e S. supplicaria (249).

Esses mapas, entretanto, não podem ser tomados como uma representação igualmente boa para todas as espécies, uma vez que, em alguns casos foram poucos os exemplares analisados, ou muitos exemplares das mesmas localidades. O esforço de coleta não foi uniforme para todas as espécies, e isso se reflete em uma diferença no número de exemplares que puderam ser estudados. 


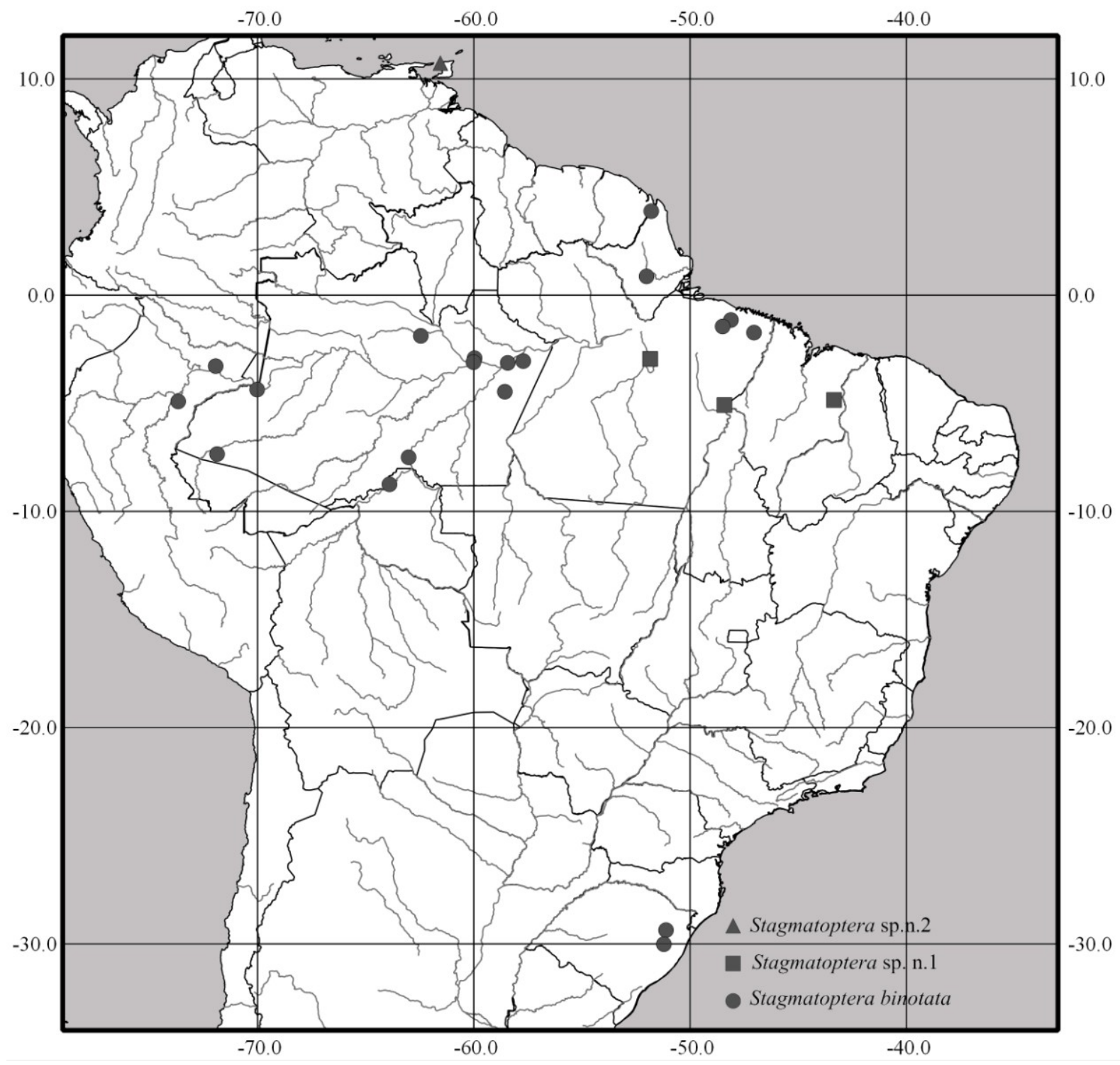

Figura 245. Mapa de distribuição dos exemplares estudados de Stagmatoptera binotata, S. sp. n. 1 e S. sp. n. 2. 


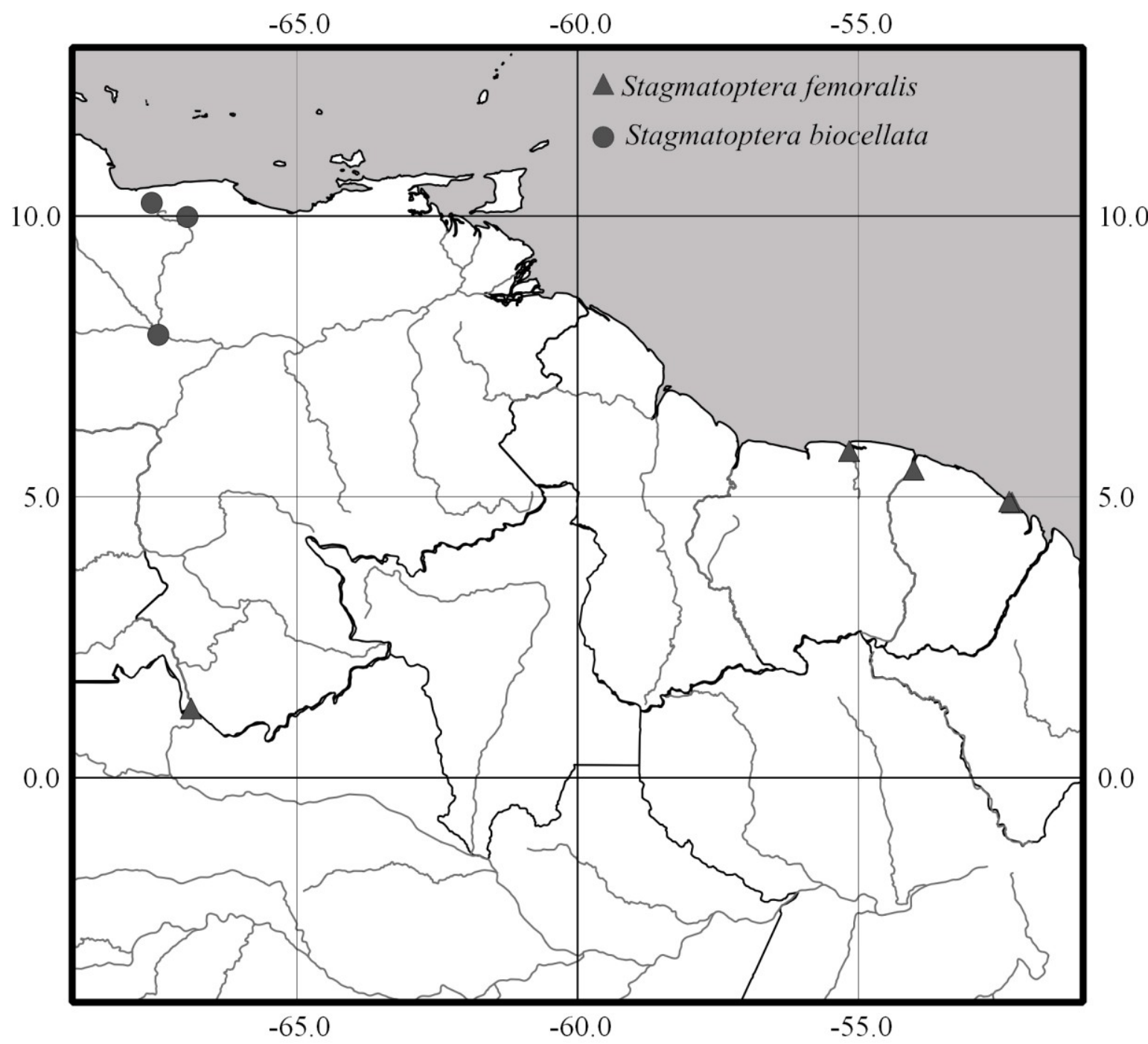

Figura 246. Mapa de distribuição dos exemplares estudados de Stagmatoptera biocellata e S. femoralis. 


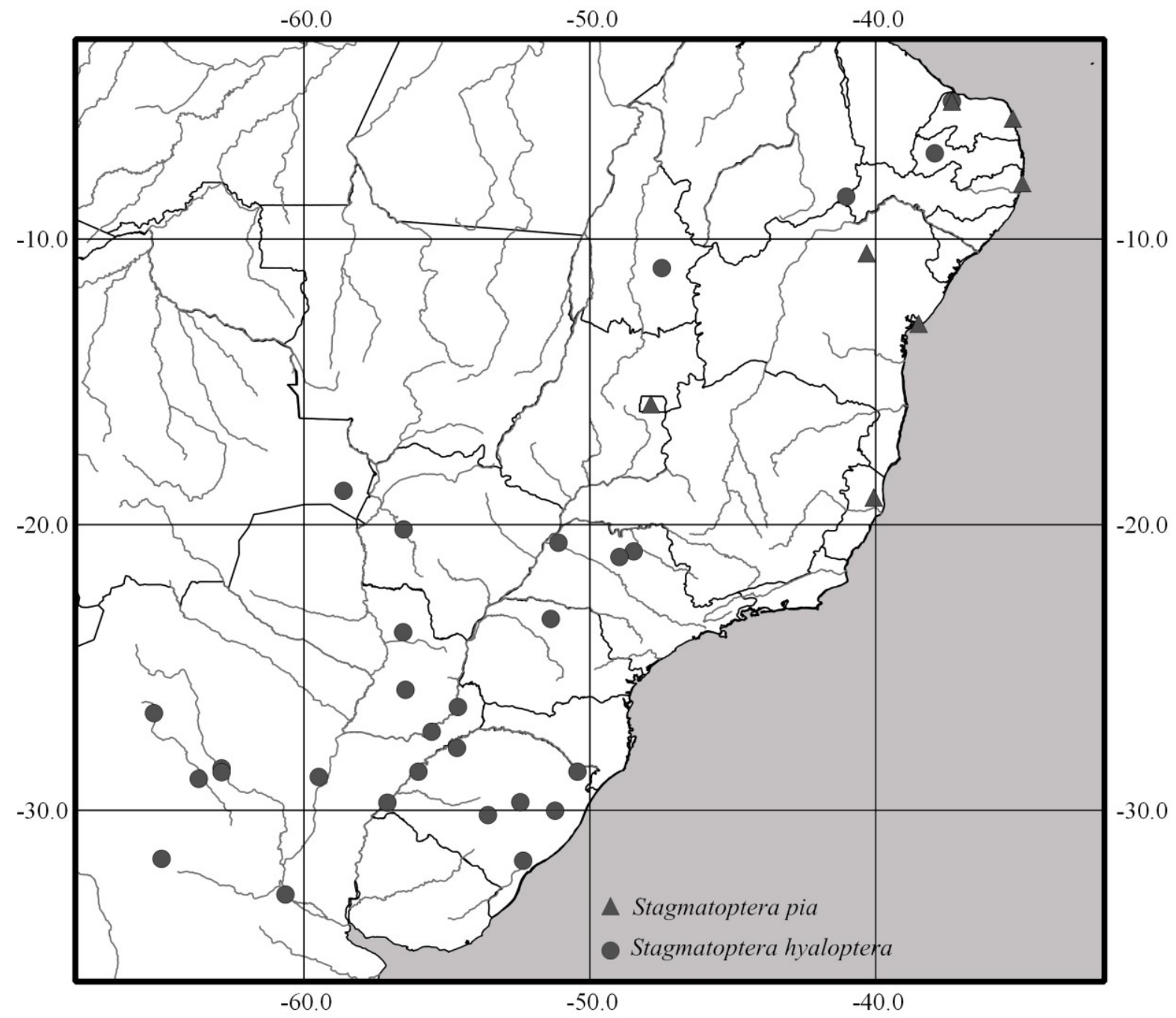

Figura 247. Mapa de distribuição dos exemplares estudados de Stagmatoptera hyaloptera e S. pia. 


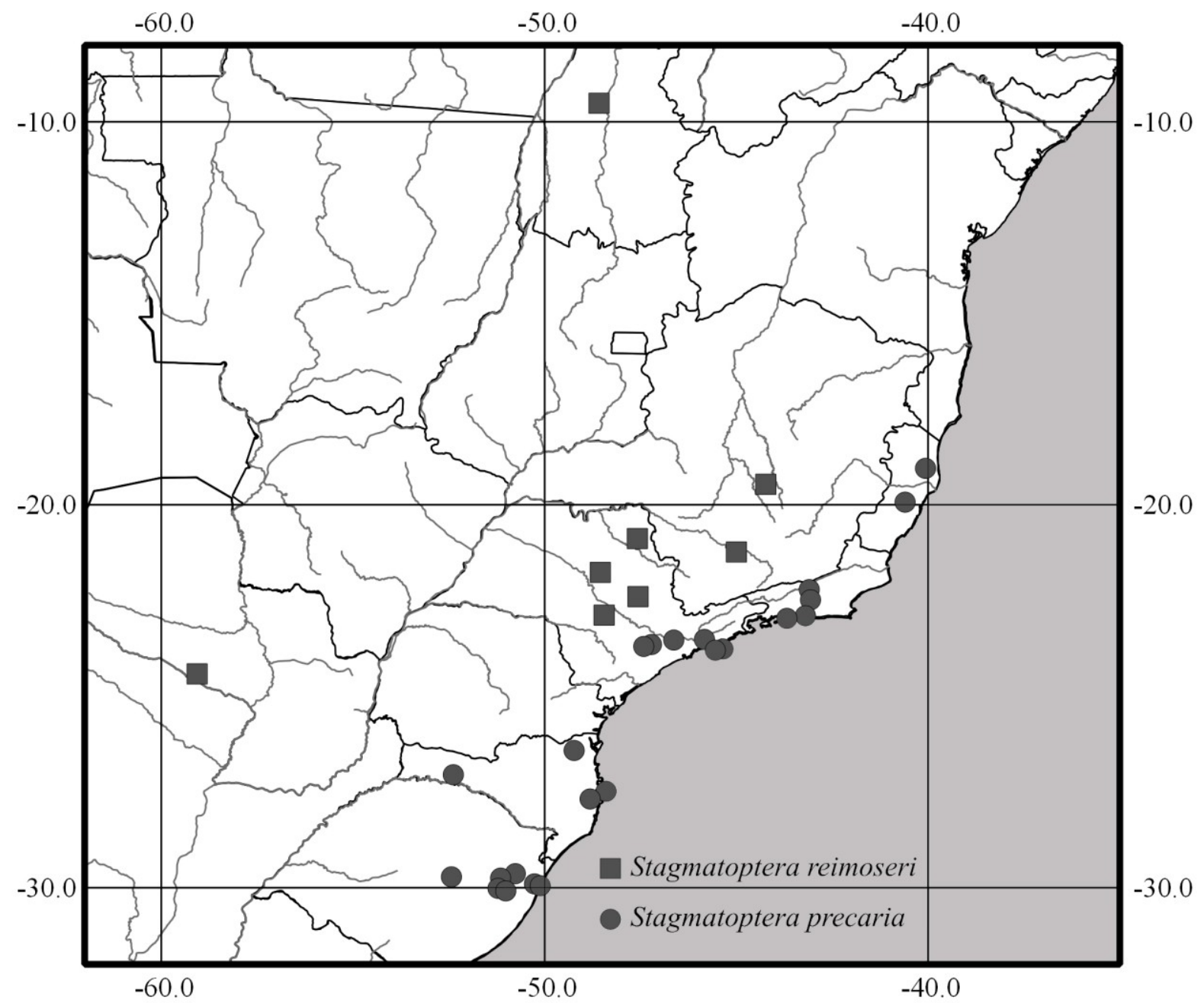

Figura 248. Mapa de distribuição dos exemplares estudados de Stagmatoptera precaria e S. reimoseri. 


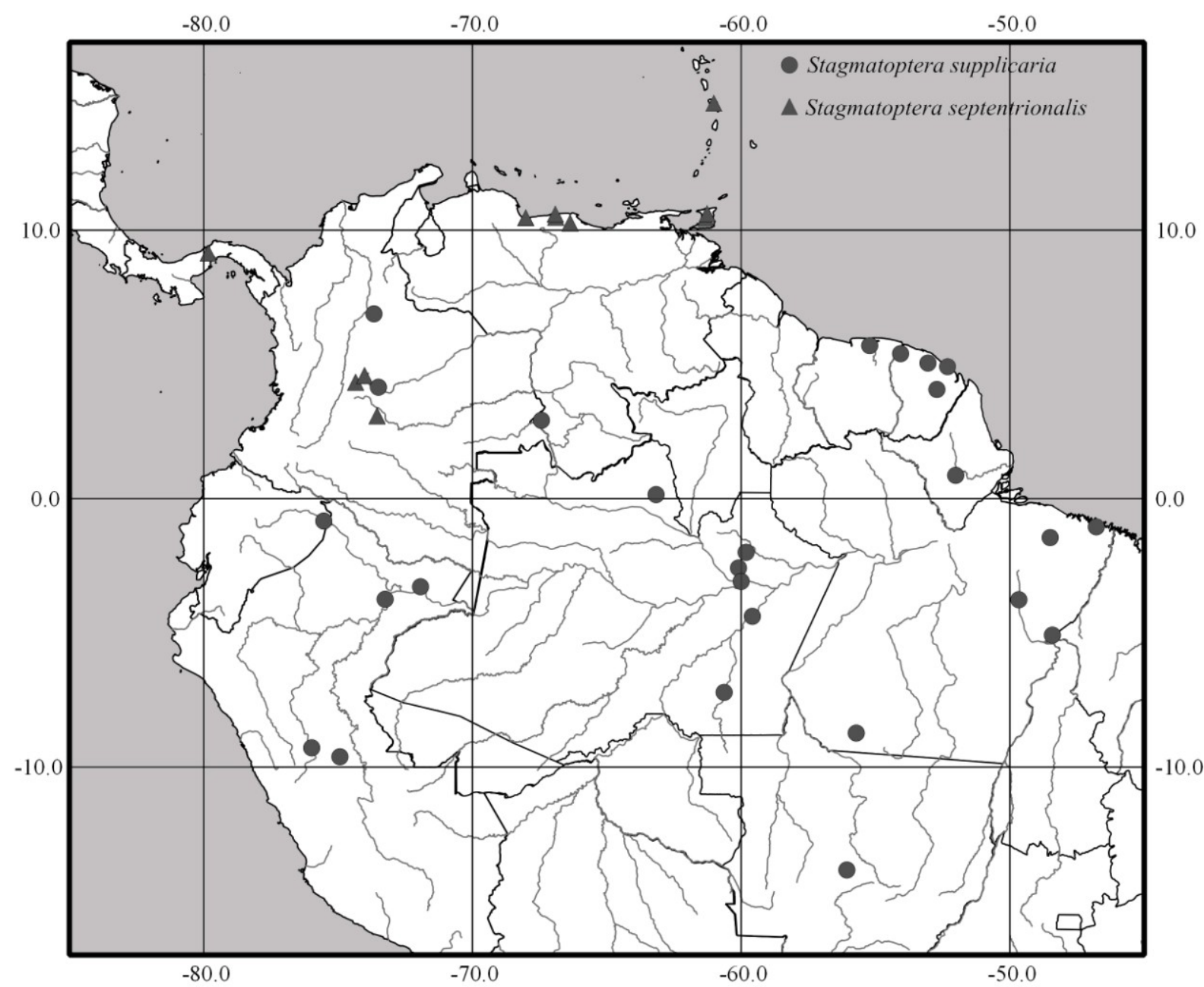

Figura 249. Mapa de distribuição dos exemplares estudados de Stagmatoptera septentrionalis e S. supplicaria. 


\section{Discussão}

O gênero Stagmatoptera foi criado por Burmeister em 1838, como um subgênero, em uma tentativa de organizar o gênero Mantis Linnaeus, 1758. Nesse trabalho ele incluiu espécies que para ele seriam mais próximas entre si devido à mancha na tégmina. No mesmo trabalho, ele tratou de outras espécies, que em trabalhos posteriores foram incluídas em Stagmatoptera, mas que ele não o fez devido a ausência da mancha utilizada como caráter diagnóstico para o gênero.

Devido ao gênero ter sido criado para agrupar as espécies descritas que possuíam uma pequena mancha na região do estigma, ele já abrigou várias espécies que hoje estão em outros gêneros, alguns neotropicais e filogeneticamente próximos de Stagmatoptera, como Parastagmatoptera, outros distantes tanto geográfica- como filogeneticamente, por exemplo Sphodromantis. Esse começo confuso da história do gênero teve uma influência duradoura, de forma que, as últimas espécies que não pertencem de fato ao gênero foram retiradas apenas em 1927.

Outro problema na história do gênero é a confusão que existe em torno do livro escrito e ilustrado por Caspar Stoll. Este autor publicou em 1787 uma versão incompleta de seu livro sobre várias espécies de Mantodea, Phasmatodea, Orthoptera e Blattaria, onde descreveu e ilustrou espécies que pode coletar e estudar. Porém, a versão final desta obra só foi publicada em 1813, graças ao esforço de M. Houttuyn, uma vez que Stoll faleceu em 1795. Possivelmente porque a versão completa do trabalho foi publicada em 1813, é esta a versão citada em todos os trabalhos que mencionam a obra.

Entretanto, isso gera uma confusão com trabalhos publicados após 1787 e antes de 1813 que mencionam as ilustrações feitas por Stoll, pois espécies descritas nestes trabalhos com base nas ilustrações feitas por Stoll tinham dois nomes, sendo o nome atribuído a Stoll considerado sinônimo júnior. Isso ocorre, pois somente na edição completa, publicada em 1813, consta uma lista com epítetos específicos em latim, que podem ser considerados como válidos. Esse problema envolvendo o trabalho de Stoll afeta três espécies: Stagmatoptera abdominalis e $S$. indicator (Olivier, 1792) e S. supplicaria (Burmeister, 1838). Estas espécies, apesar de terem sido descritas por Stoll em 1787, receberam nomes válidos nos trabalhos de outros autores, que mencionam como fonte para a descrição as ilustrações de Stoll. 
As duas espécies descritas por Olivier são as mais divergentes dentro do gênero, e não foi possível encontrar os tipos. Ehrmann (2002) menciona o Museu Nacional de História Natural de Paris como sendo o local onde estão depositados esses tipos, porém nada foi encontrado nessa coleção.

Durante a realização deste trabalho foi possível estudar os tipos de seis das espécies do gênero, depositados em coleções européias, e os tipos de cinco espécies sinônimas juniores. Nas coleções visitadas, ou cujo material foi emprestado, não foi possível encontrar nenhum exemplar, tipo ou não, de Stagmatoptera abdominalis e $S$. indicator.

Stagmatoptera abdominalis foi descrita por Olivier em 1792, com base no trabalho de Stoll (1787), não tendo sido nunca mais encontrado um indivíduo dessa espécie. Os indivíduos que estavam identificados como $S$. abdominalis nas coleções ou em trabalhos posteriores (Jantsch, 1994) eram na realidade machos de S. supplicaria, cuja aparência se assemelha à descrição dada por Giglio-Tos (1927), mas difere pelo fato das faixas nas tégminas de $S$. supplicaria serem a maior distal e a menor proximal, o oposto do que é relatado para $S$. abdominalis. Esta espécie é mantida pois no presente momento não é possível comprovar ou negar sua validade.

Stagmatoptera binotata foi descrita por Scudder em 1869, com base em um exemplar coletado no Peru, e desde então esta espécie foi coletada em vários outros pontos da Floresta Amazônica, podendo esta ser considerada sua área de ocorrência. Entretanto, durante o estudo foram encontrados dois indivíduos na coleção MCTP cujas etiquetas trazem como local de coleta desses indivíduos duas cidades do estado de Rio Grande do Sul, muito longe da área esperada para se encontrar essa espécie. Acredito que essas etiquetas tragam informações equivocadas, embora não possa determinar como possa ter ocorrido erro.

Stagmatoptera biocellata foi descrita por Saussure em 1869. A única coisa que pode se mencionar sobre esta espécie é que Werner em 1925 descreveu alguns exemplares identificados por ele como sendo $S$. biocellata, porém estes exemplares estudados por ele são na realidade $S$. hyaloptera que ele identificou erroneamente. Esse erro foi constatado quando examinei o material citado por ele neste trabalho.

Stagmatoptera femoralis foi descrita por Saussure \& Zehntner em 1994, com base em três fêmeas e dois machos coletados em Cayenne. Em 1914 Giglio-Tos descreveu S. ignota com base em uma fêmea sem indicação de localidade. Pude estudar essa fêmea com base em 
fotos enviadas pelo curador da coleção MRSN onde ela está depositada, e outros exemplares fêmeas em coleções da Europa, e após analisar fêmeas das duas supostas espécies, acredito que ambas são de fato a mesma espécie, e por isso estou propondo sinonimizá-las.

Stagmatoptera hyaloptera foi descrita por Perty em 1832. Serville em 1839 descreveu S. luna citando algumas diferenças de coloração da mancha do estigma como justificativa para a descrição da nova espécie, porém, Westwood, em 1889, sinonimizou as duas espécies. Burmeister, em 1838, descreveu Mantis (Stagmatoptera) pavonina com base em indivíduos cuja localidade era África, e esta espécie foi posteriormente transferida para um gênero africano Chlidonoptera. Foi somente em 1999 que Ehrmann estudou os exemplares utilizados por Burmeister para descrever a espécie, e determinou que eles eram na realidade Stagmatoptera hyaloptera e que as etiquetas de localidade estavam erradas, conclusão esta com a qual concordo após também ter examinado aqueles exemplares.

Stagmatoptera indicator foi descrita por Olivier em 1792, com base no trabalho de Stoll (1787), não tendo sido nunca mais encontrado um indivíduo dessa espécie. Os indivíduos estudados, que estavam identificados como $S$. indicator eram fêmeas inicialmente armazenadas em álcool e depois retiradas do meio líquido e montadas, perdendo desse modo as manchas das tégminas e dos fêmures, sendo, em minha opinião, fêmeas de $S$. femoralis. Essa situação pôde ser comprovada pelo estado de conservação dos exemplares, cujas tégminas e asas estavam amassadas e extremamente frágeis, e as pernas raptoriais estavam com as paredes parcialmente colapsadas.

Stagmatoptera pia foi descrita por Saussure \& Zehntner em 1894, com base em uma exemplar fêmea, cuja etiqueta de localidade tinha como única informação "Brasil". Após examinar este tipo e outras fêmeas identificadas como sendo $S$. pia, estas com rótulo de local de coleta, os dois tipos de $S$. nova, ambos machos, e também outros machos identificados como $S$. nova, acredito que todo este material seja na realidade uma única espécie, cujos machos e fêmeas foram descritos como espécies separadas. Ambas as espécies- $S$. pia e $S$. nova apresentam distribuição congruente, e são muito semelhantes aos indivíduos do sexo correspondente de $S$. femoralis, isto é, $S$. pia se assemelha às fêmeas de $S$. femoralis e $S$. nova se assemelha aos machos de S. femoralis.

Ao estudar as descrições feitas por Giglio-Tos, em seu trabalho de 1927, assim como sua chave de identificação, não foi possível diferenciar Stagmatoptera pia de S. precaria 
(Linnaeus, 1758). A única diferença entre as descrições das duas espécies, não é útil para distingui-las, uma vez que o primeiro espinho interno das tíbias anteriores pode ser preto em ambas as espécies. É possível que Giglio-Tos tenha se confundido em seus estudos, e misturado exemplares das duas espécies ao descrevê-las.

Stagmatoptera precaria foi descrita por Linnaeus em 1758 , e por muito tempo foi a única espécie descrita e a mais conhecida. Acredito que por isso muitos pesquisadores realizaram identificações erradas, atribuindo a essa espécie indivíduos que hoje são reconhecidos como pertencendo às demais espécies do gênero, desse modo ampliando (erroneamente) a área de ocorrência dessa espécie. Agudelo et al. (2007) em seu catálogo de espécies, juntaram os dados da literatura, e colocaram a distribuição dessa espécie como sendo “Argentina, Brasil (Amazonas, Bahia, Espírito Santo, Mato Grosso, Pará, Pernambuco, Rio de Janeiro, Rio Grande do Sul, Santa Catarina, São Paulo), Colômbia, Guiana Francesa, Panamá, Suriname, Trinidad \& Tobago e Venezuela”. Entretanto, após estudar o material depositado em todas as coleções, não pude encontrar nenhum exemplar cuja localidade, quando marcada, não fosse restrita aos estados das regiões Sudeste e Sul brasileiras, isto é, Espírito Santo, Rio de Janeiro, São Paulo, Santa Catarina e Rio Grande do Sul.

Devido a essa distribuição muito mais restrita do que a registrada na literatura, esta utilizada inclusive por Agudelo et al., que afirmo ter havido uma grande confusão de identificação dos indivíduos, inchando a área de distribuição da espécie. Conforme mais espécies foram descritas e as coleções estudadas, creio que as identificações erradas foram corrigidas, mas sem que houvesse uma retificação da área de distribuição de $S$. precaria, refletindo essa correção de identificações. O mesmo problema ocorreu em menor escala, creio eu, com outras espécies do gênero, não chegando a ser tão gritante como uma distribuição por quase toda a América do Sul como em S. precaria.

Stagmatoptera pumila foi descrita por Werner em 1925, só é conhecida por um exemplar macho sem nenhuma identificação de local de coleta, coletor ou data. Este exemplar é diferente das outras espécies do gênero por possuir tanto as tégminas quanto as asas mais curtas que o abdômen, e uma das pernas anteriores mal-formadas. Por causa dessas características não sei se essa espécie é valida, porém não obtive resposta do curador do Naturhistoriska Riksmuseet, responsável por esse espécime, se seria possível retirar a genitália masculina para averiguar a validade dessa espécie aparentemente tão rara. Devido à falta de informações conclusivas a espécie é mantida como válida. 
Stagmatoptera supplicaria foi descrita por Burmeister em 1838, com base no trabalho de Stoll (1787), e em 1839, Serville descreveu S. flavipennis com base no mesmo desenho. Devido a esse fato, S. flavipennis é um sinônimo júnior de $S$. supplicaria, como já havia sido dito por Kirby, em 1904. Porém, Giglio-Tos (1914) não concordou com essa sinonímia, mesmo sendo as duas espécies descritas com base na mesma ilustração de Stoll, e separou novamente as duas espécies, alegando que haveria uma diferença na forma do ápice das tégminas das fêmeas entre as duas espécies, e no fato de que as tégminas dos machos de $S$. flavipennis teriam uma estreita faixa verde opaca após o estigma, e em S. supplicaria as tégminas dos machos seriam totalmente hialinas. Após analisar indivíduos que seriam das duas espécies não acredito que essas diferenças sutis sejam significativas, e juntando a isso as duas descrições baseadas nas mesmas ilustrações, considero que Kirby acertou ao sinonimizar as duas espécies.

\section{Estudo das genitálias}

A genitália masculina trouxa muitas informações úteis na separação das espécies do gênero Stagmatoptera, como já tinha sido relatado por Cerdá (1993), tendo sido possível eliminar as dúvidas que Ehrmann $(1999 ; 2002)$ tinha a respeito da validade de S. reimoseri, uma vez a que a genitália masculina desta é consideravelmente diferente da S. hyaloptera. O uso da genitália masculina também permitiu a conclusão de que os exemplares coletados em Trinidad \& Tobago, depositados na coleção MNHN, são uma espécie nova, tratada neste trabalho como Stagmatoptera sp. n. 2, e não S. femoralis, como estavam previamente identificadas por R. Roy. Esta espécie já tinha sido mencionada por Cerdá, em seu trabalho de 1993, como uma possível nova espécie semelhante a S. biocellata.

A genitália feminina também se mostrou útil na distinção entre as espécies, e acredito que deva ser incluída tanto em estudos taxonômicos quanto em estudos filogenéticos, uma vez que se mostrou rica em informações. A maior dificuldade em seu uso é como descrever essas estruturas tão complexas morfologicamente. Outro problema do uso da genitália feminina é a dificuldade em encontrar fêmeas nas coleções que estejam em um estado de conservação adequado, e cuja genitália resista ao protocolo de dissecção. Algumas genitálias perderam totalmente as membranas que uniam os elementos mais esclerosados, ficando difícil reconhecer estruturas mais membranosas como o esclerito na parede dorsal da papila genital (Fig. 13), e as extensões posterolaterais (Fig. 11 e 12). 
Outro problema encontrado foi preservar a espermateca, para tentar averiguar sua possível importância para estudos taxonômicos. Não foi possível encontrá-la, restando a dúvida se ela se decompõe rapidamente após a morte do animal, ou se ela é destruída no procedimento. Acredito que a primeira explicação seja a mais provável, uma vez que mesmo na genitália ainda não fervida na solução de $\mathrm{KOH}$ não foi possível encontrá-la. 


\section{Conclusão}

O gênero Stagmatoptera foi alvo do primeiro trabalho de revisão taxonômica após anos. Foi possível confirmar a validade da grande maioria das espécies do gênero, seja examinando os tipos de espécies válidas ou de seus sinônimos juniores, seja através do exame de vários indivíduos cuja morfologia era condizente com as descrições feitas pelos autores das espécies. Desse modo, o gênero Stagmatoptera, ao fim deste trabalho, é composto de 14 espécies, duas das quais ainda não foram descritas.

Também foi possível constatar que havia uma sinonímia válida entre duas espécies, que tinha sido refutada erroneamente por Giglio-Tos em seus trabalhos, além de duas novas sinonímias constatadas durante o desenvolvimento deste trabalho: Stagmatoptera nova com $S$. pia e $S$. ignota com S. femoralis.

As espécies Stagmatoptera abdominalis e $S$. indicator tem seu status mantido, embora não tenha sido possível localizar nenhum exemplar pertencente a essas espécies. As descrições existentes na literatura, assim como as ilustrações feitas por Stoll, levam a crer que essas espécies são diferentes das outras espécies do gênero, porém sem material para estudálas, preferi não fazer alterações taxonômicas.

Acredito que algumas espécies sejam mais próximas entre si, do que a outras espécies dentro do gênero. Assim, Stagmatoptera supplicaria e S. septentrionalis, aparentam, em minha opinião, serem mais próximas entre si do que das outras espécies, como $S$. femoralis, $S$. pia e $S$. precaria talvez formem um grupo mais aparentado e ainda outro grupo seria composto por: S. biocellata, S. hyaloptera, S. reimoseri, e Stagmatoptera sp. n.1. Porém, como não realizei uma análise cladística para poder corroborar tais idéias, essas afirmações são meras conjecturas minhas e precisam ser testadas.

As genitálias, tanto masculina quanto a feminina, são úteis no estudo taxonômico, e podem ser uma fonte importante de caracteres morfológicos para futuros estudos cladísticos e taxonômicos.

Realizar uma análise cladística para tentar compreender a história evolutiva do gênero Stagmatoptera, e sua relação com outros gêneros próximos é o próximo passo a ser tomado, visando contribuir com o conhecimento desse grupo de insetos tão fascinantes. 


\section{Referencias bibliográficas}

Agudelo, A.A.; Lombardo, F. \& Jantsch, L.J. 2007. Checklist of the Neotropical mantids (Insecta, Dictyoptera, Mantodea). Biota Colombiana, 8(2): 105-158.

Beckmann, N. \& Hurd, L.E. 2003. Polen feeding and fitness in praying mantids: the vegetarian side of a tritrophic predator. Environmental Entomology, 32(4):881-885.

Beier, M. 1929. Weitere neue Mantiden aus der Sammlung des Naturhistorischen Museums in Wien. Zoologischer Anzeiger, 81(7-10): 245-254.

Beier, M. 1930. Ergebnisse einer zoologischen Sammelreise nach Brasilien, insbesondere in das Amazonasgebiet, ausgeführt von Dr. H. Zerny. Annalen des Naturhistorischen Museums in Wien, 44: 27-32.

Beier, M. 1964. Blattopteroidea - Mantodea. In: Bronn, H.G. H.G. Bronn's Klassen und Ordnung des Tierreich. Leipzig, Akademische Verlagsgesellschaft. v. 5, pt 6, p.850-970.

Burmeister, C.H.C. 1838. Mantodea. In: Handbuch der Entomologie. Berlin. v. 2, pt. 2, p.517-552.

Cerdá, F.J. 1993. Valor taxonomico del complejo falico em mantidos neotropicales (Dictyoptera: Mantodea). Boletim Entomológico Venezolano N.S., 8(1): 33-52.

Charpentier, T. von 1841. VII - Einige Bemerkungen die Orthopteren betreffend, besonders in Bezug auf Burmeister's und Serville's Schriften über diese Insektenabtheilung. In: Germar, E.F. (Ed.). Zeitschrift für die Entomologie. Leipzig, Friedrich Fleischer. v. 3, p. 283-321. 
Charpentier, T. von 1844. V - Bemerkungen zu A. A. H. Lichtensteins Abhandlung über die Mantis-Arten, in den Transactions of the Linnean Society. Vol. VI. Lond. 1802. In: Germar, E.F. (Ed.).Zeitschrift für die Entomologie, Leipzig, Friedrich Fleischer. v.5, pt. 1-2, p. 272311.

Chopard, L. 1949. Sous-ordre des Mantodea. In: Grassé, P.-P. (Org.). Traité de Zoologie, anatomique, sistematique, biologie. Paris, Masson. v. 9, p.386-402.

Ehrmann, R. 1995. Stagmatoptera vischeri Werner, 1933 ist Sphodromantis viridis (Forskål, 1775). Mitteilungen des Internationalen Entomologischen Vereins, 20(3/4): 113-118.

Ehrmann, R. 1999. Stagmatoptera Burmeister 1838, eine interessante Gattung der Ordnung Mantoptera (Insecta: Mantoptera, Familie: Vatidae, Subfamilie: Stagmatopterinae, Tribus: Stagmatopterini). Arthropoda, 7(4): 10-15.

Ehrmann, R. 2002. Mantodea - Gottesanbeterinnen der Welt. Münster, Natur und Tier Verlag. 519p.

Ehrmann, R. \& Koçak, A.O. 2009. The Neotropical mantids (Insecta: Dictyoptera: Mantodea) (Ehrmann - 30.v.2009). CESA News, 49: 1-18.

Fabricius, J.C. 1775. Systema entomologicae, sistens insectorum classes, ordines, genera, species, adiectis, synonymis, locis, ... Flensburgi. $30+832 p$.

Giglio-Tos, E. 1914. Mantidi Esotici. VII - Vatinae. Bolletino dei Musei di Zoologia ed Anatomia comparata della R. Universita di Torino, 29(684): 1-87.

Giglio-Tos, E. 1927. Orthoptera - Mantidae. Das Tierreich, 50: 1-747. 
Goeze, J.A.E. 1778. Entomologische Beyträge zu des Ritter Linné zwölften Ausgabe des Natursystems. Leipzig, Weidmanns Erben und Reich. 352p.

Griffini, A. 1896. Ortotteri raccolti nel Darien dal dott.. E. Festa. II - Blattidi, Mantidi e Fasmidi. Bolletino dei musei di zoologia ed anatomia comparata della R. Università di Torino, 11(236): 1-12.

Grimaldi, D. 2003. A revision of Cretaceous Mantises and their relationships, including new taxa (Insecta: Dictyoptera: Mantodea). American Museum Novitates, 3412: 1-47.

Hebard, M. 1919. Studies in the Dermaptera and Orthoptera of Colombia. First Paper Dermaptera and orthopterous families Blattidae, Mantidae and Phasmidae. Transactions of the American Entomological Society, 45(2): 89-179.

Hebard, M. 1921. Studies in the Dermaptera and Orthoptera of Colombia. Second Paper Dermaptera and orthopterous families Blattidae, Mantidae and Phasmidae. Transactions of the American Entomological Society, 47(2): 107-169.

Hebard, M. 1923. Studies in the Mantidae and Phasmidae of Panama (Orthoptera). Transactions of the American Entomological Society, 48(4): 327-362.

Howell, G.I.; Barry, K.L. \& Herberstein, M.E. 2007. Mate location, antennal morphology, and ecology in two praying mantids (Insecta:Mantodea). Biological Journal of the Linnean Society, 91:307-313.

Jantsch, L.J. 1994. Estudos morfológicos em macho de Stagmatoptera abdominalis (Mantodea, Mantidae, Vatinae). Biociências, 2(1):159-162. 
Jantsch, L.J. \& Corseuil, E. 1988. Espécies de louva-a-deus (Insecta, Mantodea) do Rio Grande do Sul, Brasil. Revista Brasileira de Zoologia, 5(2): 221-243.

Kirby, W.F. 1904. A sinonimic catalogue of Orthoptera. Euplexoptera, Cursoria et Goessinia (Forficulidae, Hemimeridae, Blattidae, Mantidae, Phasmidae). London, British Museum. 501p.

Klass, K.-D. 1997. The external male genitalia and the phylogeny of Blattaria and Mantodea. Bonner Zoologische Monographien, 42: 1-341.

Klass, K.-D. 1998a. The ovipositor of Dictyoptera (Insecta): homology and ground-plan of the main elements. Zoologischer Anzeiger, 236 (2-3): 69-101.

Klass, K.-D. 1998b. The proventriculus of the Dicondylia, with comments on evolution and phylogeny in Dictyoptera and Odonata (Insecta). Zoologischer Anzeiger, 237: 15-42.

Klass, K.-D.; Eulitz, U.; Schmidt, C. \& Barton, A. 2009. The tibiotarsal articulation and intertibiotarsal leg sclerite in Dictyoptera (Insecta). Insect Systematics and Evolution, 40(4): 361-387.

Klass, K.-D. \& Meier, R. 2006. A phylogenetic analysis of Dictyoptera (Insecta) based on morphological characters. Entomologische Abhandlungen, 63(1-2): 3-50.

Krishna, K.; Grimaldi, D.A.; Krishna, V. \& Engel, M.S. 2013. Treatise on the Isoptera of the World. Bulletin of the American Museum of Natural History 377(1): 1-200.

La Greca, M. 1953-1954. Sulla struttura morfologica dell'apparato copulatore dei Mantoidei. Annali dell'Istituto Superiore di Scienze e Lettere "S. Chiara" di Napoli, 4:1-28 
Leverault, P. 1936. The Morphology of the carolina mantis. The University of Kansas Science Bulletin, 24(13): 205-259.

Lichtenstein, A.A.H. 1802. A dissertation on two natural genera confounded under the name of Mantis. Transactions of the Linnean Society, 6: 1-39.

Linnaeus, C. 1758. Systema Naturae per regna tria naturae secundum classes, ordines, genera species, cum characteribus differentiis... Holmiae, Laurentii Salvii. 1384p.

Maekawa, K.; Kitade, O. \& Matsumoto, T. 1999. Molecular phylogeny of orthopteroid insects based on the mitochondrial Cytochrome Oxydase II gene. Zoological Science, 16(1): $175-184$

Perty, M. 1832. Delectus animalium articulatorum, quae in itinere per brasiliam annis 1817-1820 jussu et auspiciis Maximiliani Josephi I bavariae regis augustissimi. Monachii, Impensis Editoris.

Rehn, J.A.G. 1904a. Studies in American mantids or soothsayers. Proceedings of the United States National Museum, 27: 561-574.

Rehn, J.A.G. 1904b. A new mantis of the genus Stagmatoptera from Nicaragua. Canadian Entomologist, 36: 107-108.

Rehn, J.A.G. 1911. Mantodea. Subfamilie: Vatinae. In: Wytsman, P.A.G. Genera Insectorum. Bruxelles. v.119, p. 1-28.

Roy, R. 1999. Morphology and taxonomy. In: Prete, F.R.; Wells, P.H. \& Hurd, L.E. (Eds). The Praying Mantids. Baltimore, The John Hopkins University Press. cap. 2, p.19-42. 
Saussure, H. 1869. Essai d'un système des Mantides. Mitteilungen der Schweizerischen Gesellschaft, 3(2): 49-73.

Saussure, H. 1870. Additions au système des Mantides. Mitteilungen der Schweizerischen Gesellschaft, 3(5): 221-244.

Saussure, H. 1871a. Mélanges orthoptérologiques (troisième fascicule). Mémoires de la Société de Physyque et d'Histoire Naturelle de Genève, 21: 1-215.

Saussure, H. 1871b. Synopsis des Mantides Americains. Genève et Bale, H. Georg LibraireEditor. 186 p. (Mémoires pour servir à l'histoire naturelle du Mexique, des Antilles et des États-Unis, v. 4).

Saussure, H. 1872. Mission Scientifique au Mexique et dans l'Amérique Centrale. Recherches zoologiques, pour servirà l'histoire de La faune de l'Amerique Central et du Mexico. Paris. v.6, pt. 2, p. 202-295, 2 pls.

Saussure, H. \& Zehntner, L. 1894. Familie Mantidae. In: Biologia Centrali-Americana. Insecta, Orthoptera, Mantidae. London. v.1, p. 123-197.

Scudder, S.H. 1869. Notes on Orthoptera collected by professor James Orton on either side of the Andes of equatorial South America. Proceedings of the Boston Society of Natural History, 12: 330-345.

Serville, J.G.A. 1831. Revue méthodique des Insectes de l'ordre des Orthoptères. Annales des sciences naturelles, 22: 28-65. 
Serville, J.G.A. 1839. Histoire Naturelle des Insectes - Orthoptères. Paris, Librarie Encyclopedique de Roret. 776p.

Snodgrass, R.E. 1935. Morphology of the insect abdomen II: The genital ducts and the ovipositor. Smithsonian Miscellaneous Collections, 89(8); 1-148.

Snodgrass, R.E. 1937. The male genitalia of orthopteroid insects. Smithsonian Miscellaneous Collections, 96(5): 1-107.

Ståll, C. 1877. Systema Mantodeorum. Essai d'une systematization nouvelle des Mantodées. Bihang till Kongl. Svenska vetenskaps-akademiens handlingar, 4(10): 1-91.

Stoll, C. 1787. Natuurlyke en naar't leeven naauwkeurig gekleurde afbeeldingenen en beschryvingen der spooken, wandelende bladen, zabelspringhaanen, krekels, treksprinkhaanen en kakkerlakken. In alle vier deelen der waereld Europa, Asia, Afrika, en America huishoudende by een verzamelt en beschreeven door Caspar Stoll. Amsterdam, J.C. Sepp. 79p.

Stoll, C. 1813. Natuurlyke en naar't leeven naauwkeurig gekleurde afbeeldingenen en beschryvingen der spooken, wandelende bladen, zabelspringhaanen, krekels, treksprinkhaanen en kakkerlakken. In alle vier deelen der waereld Europa, Asia, Afrika, en America huishoudende by een verzamelt en beschreeven door Caspar Stoll. Amsterdam, J.C. Sepp. 110p.

Svenson, G.J. \& Whiting, M.F. 2004. Phylogeny of Mantodea based on molecular data: evolution of a charismatic predator. Systematic Entomology, 29(3): 359-370. 
Svenson, G.J. \& Whiting, M.F. 2009. Reconstructing the origins of praying mantises (Dictyoptera, Mantodea): the roles of Gondwanan vicariance and morphological convergence. Cladistics, 25(5): 468-514.

Terra, P.S. 1995. Revisão sistemática dos gêneros de louva-a-deus da região Neotropical (Mantodea). Revista Brasileira de Entomologia, 39(1): 13-94.

Ware, J.L.; Litmann, J.; Klass, K.-D. \& Spearman, L.A. 2008. Relationships among the major lineages of Dictyoptera: the effect of outgroup selection on dictyopteran tree topology. Systematic Entomology, 33(3): 429-450.

Wattenwyl, B. de 1893. Révision du système des orthoptères et description des espèces raportées par M. Leonardo Fea de Birmanie. Annali del Museo Civico di Storia Naturale di Genova, 13(33): 1-230.

Werner, F. 1925a. Zur Kenntnis amerikanischer Mantodeen (Orthoptera Oothecaria). Konowia, 4(3-4): 160-168.

Werner, F. 1925b. Zur Kenntnis amerikanischer Mantodeen (Orthoptera Oothecaria). Konowia, 4(6): 382-391.

Werner, F. 1933. Neue Orthoptera im Naturhistorischen Museum Basel. Über einige von Herrn H. Hediger auf Neuguinea gesammelten Mantodeen. Verhandlungen der Naturforschenden Gesellschaft in Basel, 43:1-3.

Westwood, J.O. 1889. Revisio insectorum - Familiae Mantidarum, speciebus novis aut minus cognitis descriptis et delineatis. London, Gurney and Jackson. 53p. 
Yager, D.D. 1999. Hearing. In: Prete, F.R.; Wells, P.H. \& Hurd, L.E. (Eds). The Praying Mantids. Baltimore, The John Hopkins University Press. cap.6, p.93-113.

Yager, D.D. \& Svenson, G.J. 2008. Patterns of praying mantis auditory system evolution based on morphological, molecular, neurophysiological, and behavioural data. Biological Journal of the Linnean Society, 94(3): 541-568. 